\title{
(1)
}

UNIVERSIDAD PERUANA DE CIENCIAS APLICADAS

FACULTAD DE INGENIERÍA

PROGRAMA ACADÉMICO DE INGENIERIA CIVIL

\section{“ADOBE ESTABILIZADO CON MUCÍLAGO DE PENCA DE TUNA, RESISTENTES AL CONTACTO \\ CON EL AGUA PARA LA CONSTRUCCIÓN DE VIVIENDAS POPULARES EMPLEADOS EN LA SIERRA DEL PERÚ"}

\section{TESIS}

Para optar el título profesional de Ingeniero Civil

\section{AUTOR (ES)}

Nieto Palomino, Lucero Antuhane (0000-0003-1422-8914)

Tello Perez, Edna Florencia (0000-0001-8049-3156)

\section{ASESOR}

Eyzaguirre Acosta, Carlos Augusto (0000-0001-9769-2135)

Lima, 15 de Noviembre del 2019 


\section{DEDICATORIA}

Lucero Nieto:

Dios

Por darme, salud y por darme la fuerza para lograr cumplir con todos mis objetivos.

A mi familia

Por su apoyo leal y por darme consejos en momentos

difíciles, y por el apoyo económico para terminar exitosamente mi carrera universitaria y sobre todo por depositar su en esta investigación.

Edna Tello:

Dios

Por darme salud, por guiarme por el camino correcto, y por darme las fuerzas para lograr cumplir con todas mis metas.

A mis padres Clara y Jackson

Por su apoyo incondicional en momentos difíciles, el cual me impulsaron a terminar exitosamente mis estudios universitarios y sobre todo por depositar su confianza en la culminación de esta tesis.

A mis hermanos José, Jonathan y Manuel

Por darme esos ánimos y consejos para seguir adelante a pesar de los diferentes obstáculos, y por creer en mí.

A mi familia

Que estuvo pendiente de mi salud y me brindaron los recursos necesarios para culminar esta investigación. Gracias a todos. 


\section{AGRADECIMIENTOS}

Al ingeniero Carlos Augusto Eyzaguirre Acosta por su asesoramiento, por su dedicación mediante consejos, conocimientos y experiencia en el desarrollo de esta investigación.

Al técnico de laboratorio de materiales y suelos Guillermo Casinos Vega, por su tiempo y supervisión en los diferentes ensayos realizados para esta tesis.

A los profesores de la Universidad Peruana de Ciencias Aplicadas, quienes con sus conocimientos y constantes apoyo se pudo culminar la presente tesis. 


\section{RESUMEN}

La presente investigación aborda la estabilización del adobe a través de la utilización de mucílago de penca de tuna con el fin de mejorar sus propiedades físicas como material de construcción. En la actualidad, el adobe es unos de los materiales más usados en la elaboración de viviendas en la Sierra del Perú por ser económico y de fácil adquisición; no obstante, este material al entrar en contacto con el agua pierde resistencia y durabilidad. Por tal motivo, esta tesis tiene como objetivo diseñar una unidad de albañilería de adobe estabilizado con mucílago de penca de tuna con el fin de prolongar la vida útil de las viviendas populares. Para validar esta investigación se realizaron diversos ensayos, para el suelo ensayos preliminares, de campo y laboratorio, para el mucilago ensayos de densidad y viscosidad; las unidades de adobes estabilizados y convencionales se analizaron través de ensayos mecánicos y físicos con la finalidad de comparar sus resultados. Los resultados obtenidos reflejaron que la unidad estabilizada presenta mejores resultados que el adobe convencional, se identificó que las dos mejores dosificaciones D: $20.5 \%$ y D: $18.0 \%$ obtuvieron en compresión $23.3 \mathrm{~kg} / \mathrm{cm} 2$ y 25.2 $\mathrm{kg} / \mathrm{cm} 2$, en flexión $17.62 \mathrm{~kg} / \mathrm{cm} 2$ y $17.61 \mathrm{~kg} / \mathrm{cm} 2$, en absorción $10.99 \%$ y $11.43 \%$, en inmersión se clasificó con daños leves y en la prueba de chorro de agua con $4.89 \mathrm{~mm}$ y $5.31 \mathrm{~mm}$ de profundidad de penetración respectivamente.

\section{Palabras claves:}

Mucílago de penca de tuna, viscosidad, dosificación, adobe estabilizado, adobe convencional 


\begin{abstract}
This investigation presents the stabilization of the adobe thanks to the use of prickly pear mucilage to improve its physical properties as a building material. Nowadays, adobe is one of the most used materials in the elaboration of houses in the mountains of Perú because it is economical and easy to acquire; however, when this material comes into contact with water, it loses strength and durability. For this reason, this thesis aims to design a stabilized of adobe masonry stabilized with mucilage of prickly in order to prolong the life of popular homes. In order to validate this investigation, several tests were carried out, for the soil preliminary, field trials and laboratory tests, and for the mucilage of prickly pear leaves with density and viscosity tests; for the stabilized and conventional adobe units, they were analyzed through mechanical and physical tests in order to compare their results. The results obtained in each trial reflected that the unit incorporated with mucilage of prickly has better results than conventional adobe, it was possible to identify that the two best dosages D: $20.5 \%$ and D: $18.0 \%$ obtained in the compression $23.3 \mathrm{~kg} / \mathrm{cm} 2$ and $25.2 \mathrm{~kg} / \mathrm{cm} 2$, in flexion $17.62 \mathrm{~kg} / \mathrm{cm} 2$ and $17.61 \mathrm{~kg} /$ $\mathrm{cm} 2$, in absorption $10.99 \%$ and $11.43 \%$, in immersion it was classified with slight damages and in the water jet test with $4.89 \mathrm{~mm}$ and $5.31 \mathrm{~mm}$ of depth of penetration respectively.
\end{abstract}

\title{
Keywords:
}

Mucilage of prickly pear leaves, viscosity, dosage, stabilized adobe, conventional adobe 
DEDICATORIA .............................................................................................................................. 3

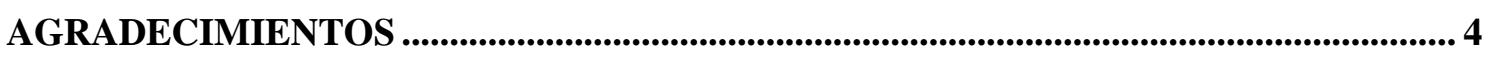

RESUMEN

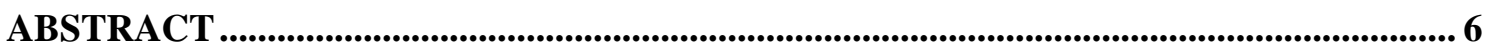

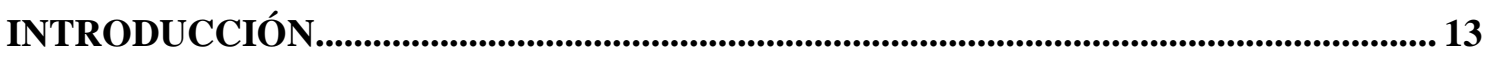

ESTADO DE ARTE ............................................................................................................................. 14

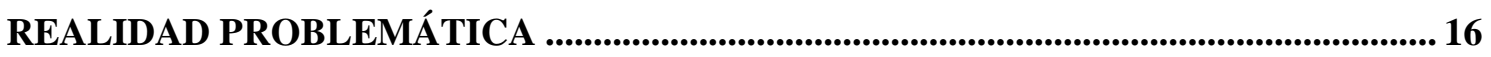

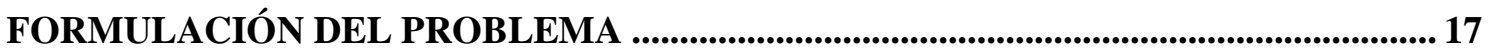

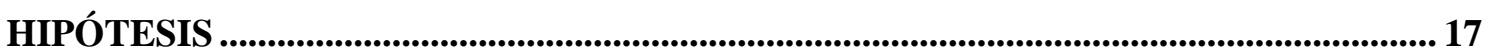

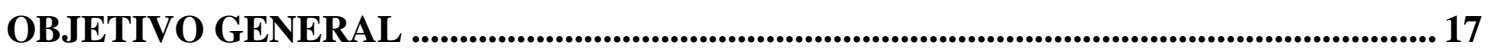

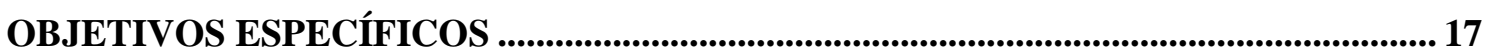

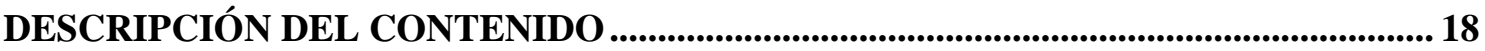

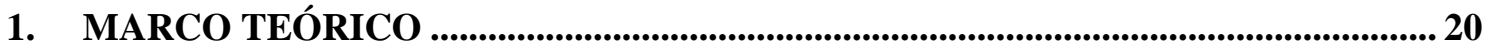

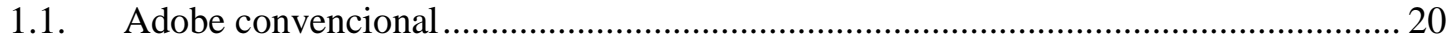

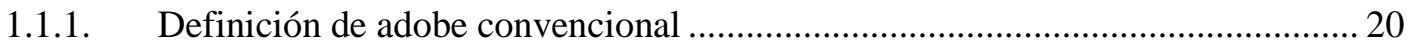

1.1.2. Componentes del adobe convencional ............................................................. 21

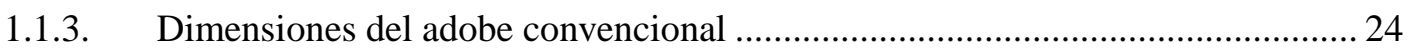

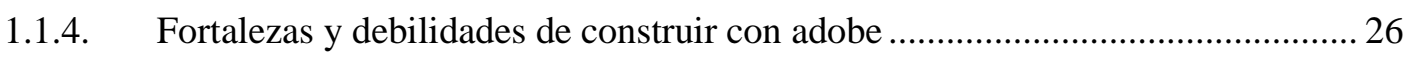

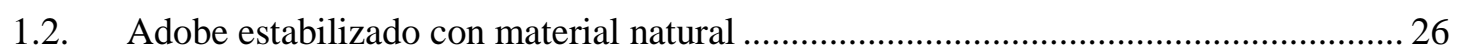

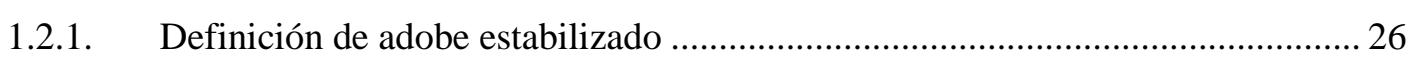

1.2.2. Definición de los materiales para estabilizar el adobe ....................................... 27

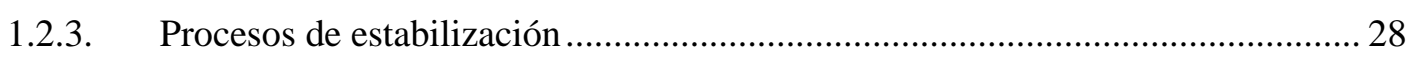

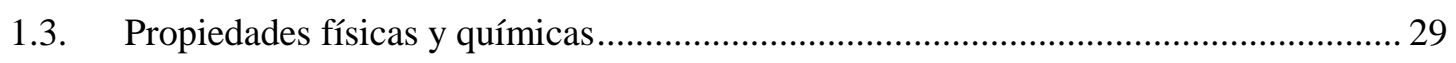

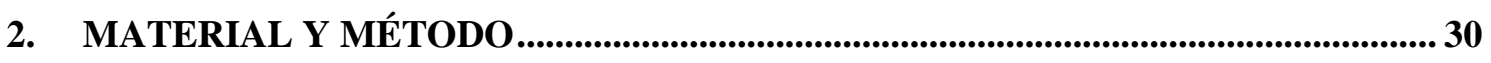

2.1. Material.......................................................................................................................................... 30

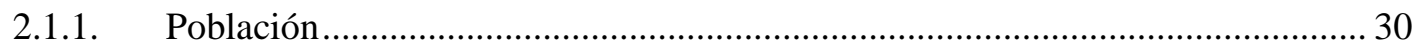

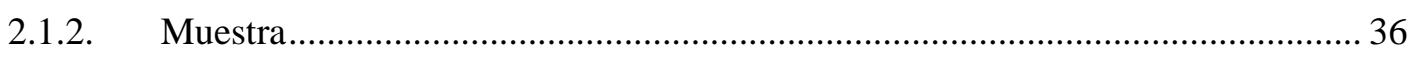

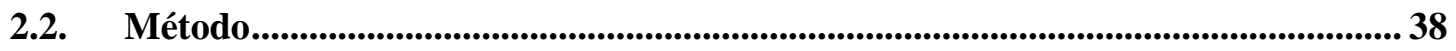

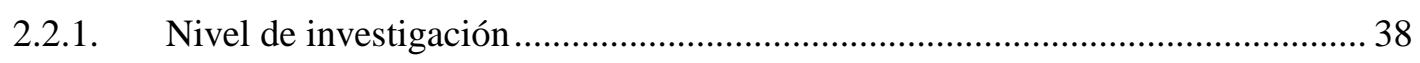

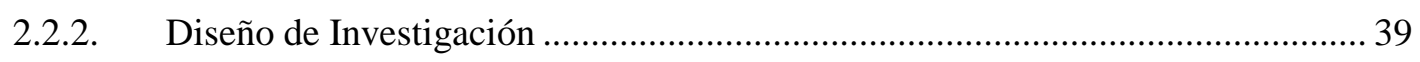

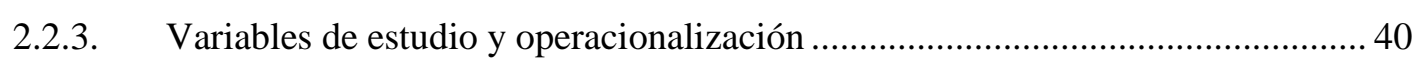

2.2.4. Técnicas e Instrumentos de recolección de datos ............................................... 41

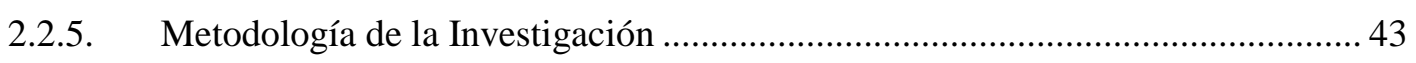


3.1. OBJETIVO 1: Analizar los materiales más adecuados para la elaboración de la mezcla a través de ensayos preliminares (prueba de color, prueba olfativa y prueba de brillo) y ensayos físicos (ensayo de cinta de barro, resistencia seca, granulometría, peso específico y límites de Atterberg) para el suelo y, ensayos de densidad y viscosidad para el mucílago de

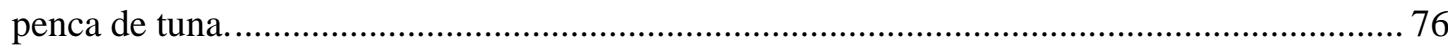

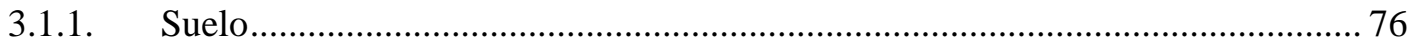

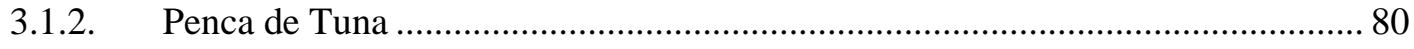

3.2. OBJETIVO 2: Seleccionar la dosificación ideal de la mezcla para obtener los mejores resultados de resistencia a la compresión, flexión y absorción en la unidad de adobe estabilizado.

3.2.1. Ensayo por unidad de adobe

3.3. OBJETIVO 3: Comparar los resultados de resistencia mecánica (compresión y flexión) y resistencia física (absorción) de las unidades y pilas de adobes convencionales de

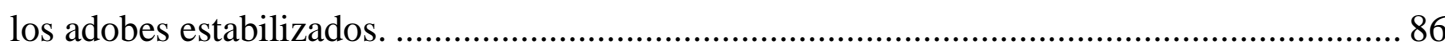

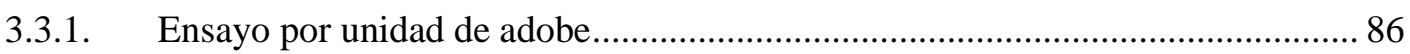

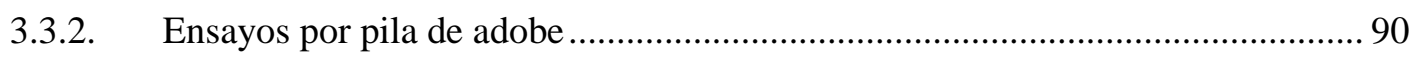

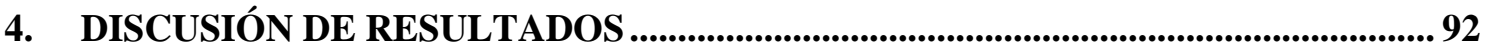

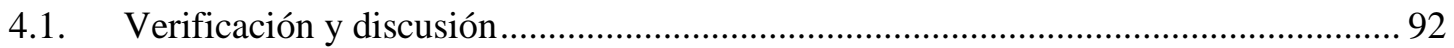

4.1.1. OBJETIVO 1: Analizar los materiales más adecuados para la elaboración de la mezcla a través de ensayos preliminares (prueba de color, prueba olfativa y prueba de brillo) y ensayos físicos (ensayo de cinta de barro, resistencia seca, granulometría, peso específico y límites de Atterberg) para el suelo y, ensayos de densidad y viscosidad para el mucílago de penca de tuna.

4.1.2. OBJETIVO 2: Seleccionar la dosificación ideal de la mezcla para obtener los mejores resultados de resistencia a la compresión, flexión y absorción en la unidad de adobe estabilizado.

4.1.3. OBJETIVO 3: Comparar los resultados de resistencia mecánica (compresión y flexión) y resistencia física (absorción) de las unidades y pilas de adobes convencionales de los adobes estabilizados.

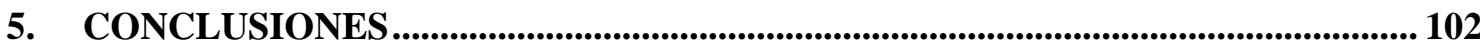

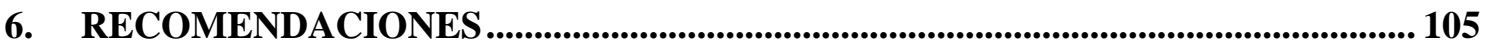

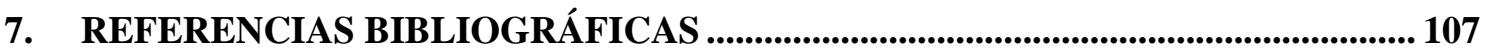

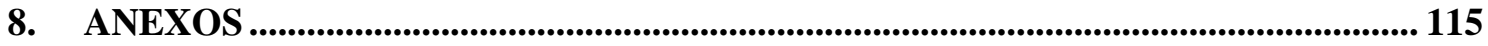




\section{ÍNDICE DE FIGURAS}

Figura 1. 1 Dimensiones del adobe completo y medio adobe que se requiere para la elaboración de muros. Fuente: Marcial Blondet y Julio Vargas, 2015 ...................................................... 25 Figura 1. 2. Planta de tuna con sus respectivas pencas. Fuente: La Gerencia Regional de

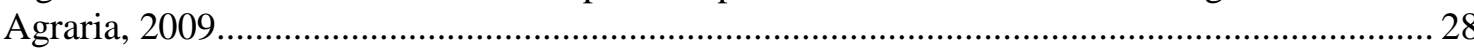

Figura 2. .1. Mapa Climático del Perú. Fuente: SENAMHI, 2017 ............................................ 30

Figura 2. 2. Mapa de las 3 regiones naturales del Perú. Fuente: sinia, 2006............................ 35

Figura 2. 3. Mapa de los 24 departamentos del Perú. Fuente: sinia, 2006 ................................... 35

Figura 2. 4. Lugar de extracción de la primera muestra (Distrito de Huarochirí- Zona Trabanda).

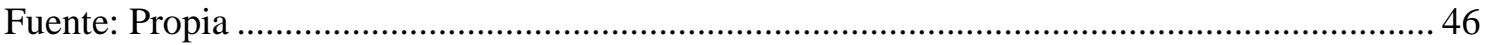

Figura 2. 5. Lugar de extracción de la primera muestra (Distrito de Huarochirí- Zona Trabanda).

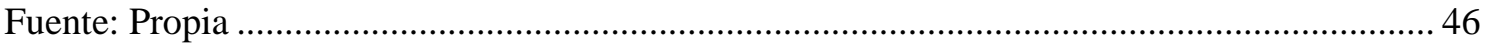

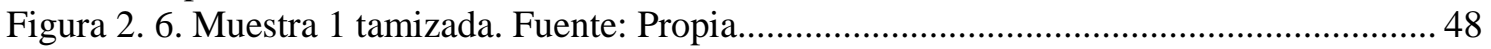

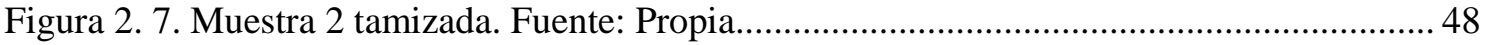

Figura 2. 8. Muestra 1 humedecida y amasada. Fuente: Propia ................................................... 48

Figura 2. 9. Muestra 2 humedecida y amasada. Fuente: Propia .................................................. 48

Figura 2. 10. Cinta de barro de la primera muestra. Fuente: Propia........................................... 48

Figura 2. 11. Cinta de barro de la segunda muestra. Fuente: Propia ........................................... 48

Figura 2.12. Muestra 2 parcialmente humedecida y amasada. Fuente: Propia ........................... 49

Figura 2.13. Muestra 2 parcialmente humedecida y amasada. Fuente: Propia ........................... 49

Figura 2. 14. Bolitas de barro de la primera muestra. Fuente: Propia .......................................... 49

Figura 2.15. Bolitas de barro de la segunda muestra. Fuente: Propia ....................................... 49

Figura 2. 16. Bolita de la primera muestra siendo sometida a una presión entre el dedo pulgar y

dedo índice. Fuente: Propia...................................................................................................... 49

Figura 2.17. Bolita de la segunda muestra siendo sometida a una presión entre el dedo pulgar y

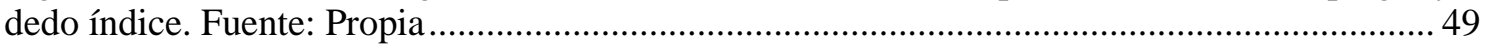

Figura 2. 18. Obtención del peso de la muestra para el ensayo. Fuente: Propia ........................... 50

Figura 2. 19. Ordenamiento de los tamices de mayor a menor abertura. Fuente: Propia............. 51

Figura 2. 20. Colocación del material en la columna de tamices. Fuente: Propia......................... 51

Figura 2. 21. Obtención de los pesos retenidos en cada tamiz. Fuente: Propia............................. 51

Figura 2. 22. Obtención del peso seco de la muestra 1. Fuente: Propia ..................................... 52

Figura 2. 23. Obtención del peso seco de la muestra 2. Fuente: Propia ....................................... 52

Figura 2. 24. Coloca la muestra en el picnómetro. Fuente: Propia .......................................... 52

Figura 2. 25. Peso de la muestra $\mathrm{N}^{\circ} 1$ más el picnómetro. Fuente: Propia .....................................52

Figura 2. 26. Peso de la muestra $\mathrm{N}^{\circ} 2$ más el picnómetro. Fuente: Propia....................................53

Figura 2. 27. Picnómetro con la muestra 1, 2 y agua destilada. Fuente: Propia............................ 53

Figura 2. 28. Temperatura de la muestra 1. Fuente: Propia .......................................................... 53

Figura 2. 29. Temperatura de la muestra 2. Fuente: Propia ........................................................ 53

Figura 2. 30. Peso de la muesral luego del tiempo de reposo. Fuente: Propia ............................. 53

Figura 2. 31. Peso de la muestra 2 luego del tiempo de reposo. Fuente: Propia ........................... 53

Figura 2. 32. Se pesa la muestra para el ensayo. Fuente: Propia.................................................. 54

Figura 2. 33. Utensilios para el ensayo- agua destilada, espátula y muestra. Fuente: Propia ..... 54

Figura 2. 34. Mezcla de tierra y agua destilada. Fuente: Propia ................................................... 55

Figura 2. 35. Hallando consistencia con Casagrande. Fuente: Propia......................................... 55

Figura 2. 36. Muestra de tierra obtenida de la herramienta Casagrande. Fuente: Propia............. 55

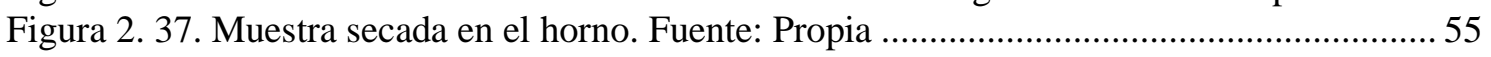

Figura 2. 38. Muestra pesada que pasa por el tamiz $\mathrm{N}^{\circ} 40$. Fuente: Propia..................................56

Figura 2. 39. Agua destilada y tierra a ensayar. Fuente: Propia ................................................. 56

Figura 2. 40. Esfera aplastada de tierra seleccionada para realizar el ensayo. Fuente: Propia.... 56

Figura 2. 41. 1,5 gr - 2,0 gr de tierra de la esfera, para formar los cilindros. Fuente: Propia..... 56

Figura 2. 42. Cilindros de tierra de $3.2 \mathrm{~mm}$ con algunas fisuras. Fuente: Propia.......................... 56 
Figura 2. 43. Muestra total de cilindros con un peso aproximado de 6g. Fuente: Propia ............56

Figura 2. 44. Extracción de las pencas de tuna en Huarochirí- Sincocaya, Fuente: Propia) ....... 57

Figura 2. 45. Proceso para extraer el mucílago de la penca de tuna, Fuente: Propia .................... 58

Figura 2. 46. Modelo de picnómetro utilizado para el ensayo, Fuente: Propia............................. 59

Figura 2. 47. Ensayo de viscosidad en el mucílago de penca de tuna, Fuente: Propia..................60 60

Figura 2. 48. Personal cortando trozos pequeños de la penca de tuna. Fuente: Propia ................. 61

Figura 2. 49. Trozos de pencas remojados en agua. Fuente: Propia .......................................... 61

Figura 2. 50. Tierra zarandeada para retener piedras de diámetro mayor a $1.5 \mathrm{~cm}$. Fuente: Propia

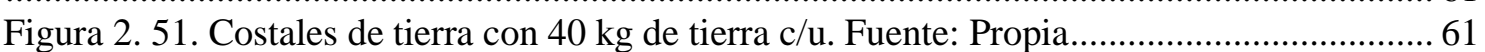

Figura 2. 52. Costal de paja de trigo con un peso de 5 kilos. Fuente: Propia............................... 62

Figura 2. 53. Gabera con medidas internas por cada espacio de 40x20x13 cm. Fuente: Propia, 62

Figura 2. 54. Personal vaciando los sacos (Izquierda) y removiendo la tierra (Derecha). Fuente:

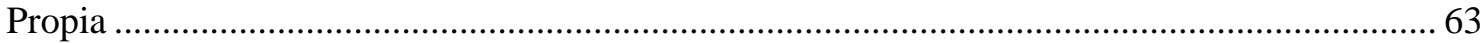

Figura 2. 55. Comparación entre la cantidad de líquido que hay en mezcla final (Izquierda) con

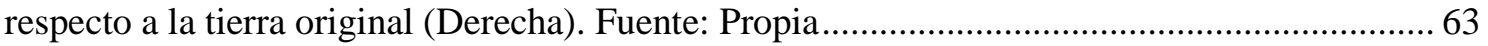

Figura 2. 56. Viscosidad de la tuna siendo incorporada en la mezcla. Fuente: Propia ................. 63

Figura 2. 57. Incorporación de la paja en la mezcla para elaboración del adobe .Fuente: Propia64

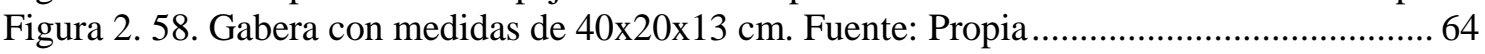

Figura 2. 59. Colocación de la mezcla en la gabera (Derecha). Fuente: Propia............................ 64

Figura 2. 60. Tierra aplastada con la mano y el pie para la elaboración del adobe. Fuente: Propia

Figura 2. 61. Levantamiento de la gabera para la obtención del adobe. Fuente: Propia .............. 65

Figura 2. 62. Adobe colocado de costado para un secado uniforme. Fuente: Propia....................65 65

Figura 2. 63. Ensayo de compresión del adobe en la Maquina Universal. Fuente: Propia .......... 66

Figura 2. 64. Ensayo de resistencia la flexión en adobe. Fuente: Propia ........................................... 67

Figura 2. 65. Obtención del peso del adobe a través de una balanza. Fuente: Propia ................... 69

Figura 2. 66. Adobes secados superficialmente. Fuente: Propia ..................................................6 69

Figura 2. 67. Adobes sumergidos en tinas de agua por alrededor de 24 horas. Fuente: Propia .. 70

Figura 2. 68. Evaluación del deterioro de los adobes después de ser sumergido. Fuente: Propia

Figura 2. 69. Ensayo de chorro de agua en adobe. Fuente: Propia............................................... 71

Figura 2. 70. Representación gráfica de las velocidades y áreas usadas para el cálculo del ensayo de chorro de agua. Fuente: Chen, 2009 ....................................................................................... 71

Figura 2. 71. Herramientas para calcular el caudal del agua que sale del caño. Fuente: Propia 72

Figura 2. 72. Dimensiones de la pila de adobes. Fuente: M.V.C.S. Norma E.080, 2017 ........... 73

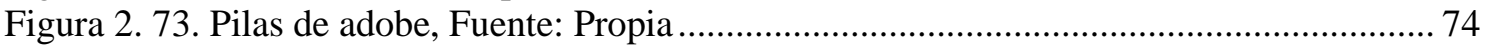

Figura 2. 74. Mortero para la pila de adobe, Fuente: Propia ...................................................... 74

Figura 2. 75. Ensayo de compresión de la pila de adobe en la Maquina Universal. Fuente: Propia 


\section{ÍNDICE DE TABLAS}

Tabla 1. 1. Pruebas de campo para identificar si un suelo es apto para fabricar adobes. Fuente: Buena Tierra, 2001

Tabla 1. 2.a. Dimensiones de adobe con uso Modular. Fuente ICG, 2010 ................................ 25

Tabla 1. 2.b. Dimensiones de adobe con uso en Tabiques. Fuente ICG, 2010 ............................25

Tabla 1. 3. Ventajas y desventajas de emplear adobe. Fuente: Olarte \& A.1, 2003 .................... 26

Tabla 2. 1.a. Temperatura promedia máxima para la región Sierra del 2017. Fuente: Senamhi, 2017.

Tabla 2. 1.b. Temperatura promedia minima para la región Sierra del 2017. Fuente: Senamhi, 2017.

Tabla 2. 2. Humedad Relativa de la región Perú. Fuente: MINAMI, 2015 ................................. 32

Tabla 2. 3. Precipitación semanal de los distintos departamentos del Perú. Fuente: Senamhi, 2016-2017

Tabla 2. 4. Cantidad de viviendas particulares según tipo de material predominante en la región natural Sierra en el Perú.

Tabla 2. 5. Viviendas particulares con ocupantes presentes, por material de predominante en las paredes exteriores de la vivienda en el distrito de Huarochirí, Fuente: INEI, 2007 .................... 37 Tabla 2. 6. Variables Independientes y Dependientes para cada objetivo específico. Fuente:

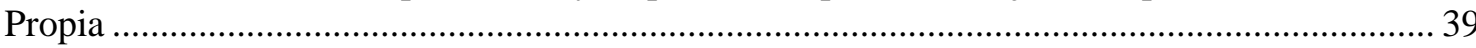
Tabla 2. 7. Variables de estudio y operacionalización del Primer Objetivo Específico. Fuente:

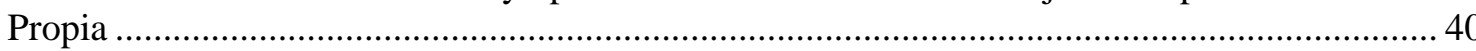
Tabla 2. 8. Variables de estudio y operacionalización del Segundo Objetivo Específico. Fuente: Propia .

Tabla 2. 9. Variables de estudio y operacionalización del Tercer Objetivo Específico. Fuente:

Propia .....

Tabla 2. 10. Instrumentos de recolección para cada objetivo específico. Fuente: Propia............. 43

Tabla 2. 11. Cantidad de muestra necesaria de acuerdo con la capacidad del picnómetro.

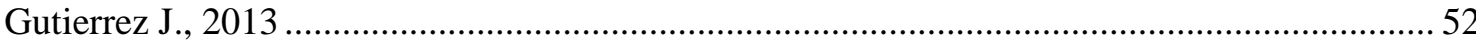

Tabla 2. 12. Coeficiente de balasto para la clasificación de suelos. Fuente: Norma SUCS ........ 57

Tabla 2. 13. Cantidad de agua y penca de tuna por dosis. Fuente: Propia ...................................6 60

Tabla 2. 14. Cantidad de materiales utilizados para la elaboración de adobe según el número de

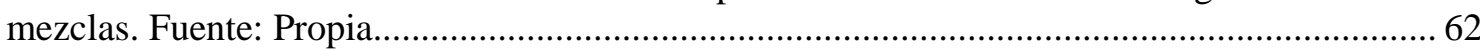

Tabla 2. 15. Calificaciones de los resultados de la prueba de inmersión en los adobes Fuente:

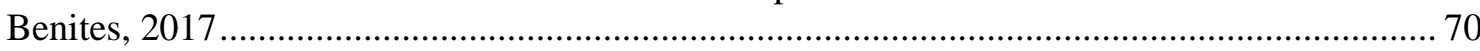

Tabla 3.1. Resultados de Pruebas Previas. Fuente: Propia............................................................. 76

Tabla 3.2. Presencia de fisuras en las dos muestras. Fuente: Propia ............................................... 77

Tabla 3.3. Resultado de peso específico relativo para la muestra 1. Fuente: Propia.................... 78

Tabla 3.4. Resultado de peso específico para la muestra 2. Fuente: Propia ................................... 78

Tabla 3.5. Resultado del contenido de humedad de la muestra 1. Fuente: Propia ....................... 79

Tabla 3.6. Resultado del contenido de humedad de la muestra 2. Fuente: Propia ....................... 79

Tabla 3.7. Densidad del mucílago de penca de tuna extraída a una temperatura de $24.2^{\circ} \mathrm{C}$.

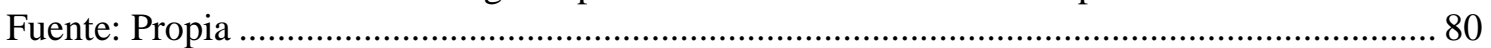

Tabla 3.8. Viscosidad del mucílago de penca de tuna. Fuente: Propia ....................................... 81

Tabla 3.9. Ensayos a compresión en adobes de $20 \mathrm{~cm}$ x $20 \mathrm{~cm}$ x $13 \mathrm{~cm}$. Fuente: Propia............ 82

Tabla 3.10. Máxima carga aplicada en las 6 muestras distintas. Fuente: Propia ......................... 82

Tabla 3.11. Modulo de rotura de las 6 muestras distintas. Fuente: Propia................................... 83

Tabla 3.12. Ensayo de absorción de los adobes al ser sumergidos por 24 horas. Fuente: Propia 83 Tabla 3.13. Clasificación de los adobes después de la inmersión por dos días. Fuente: Propia . 84 
Tabla 3.14. Cálculo de presión para el ensayo de chorro de agua. Fuente: Propia.

Tabla 3.15. Longitud de penetración de las 6 muestras distintas. Fuente: Propia........................ 86

Tabla 3.16. Ensayos a compresión en pilas de adobes de $20 \mathrm{~cm} \mathrm{x} 40 \mathrm{~cm}$ x $42 \mathrm{~cm}$. Fuente: Propia

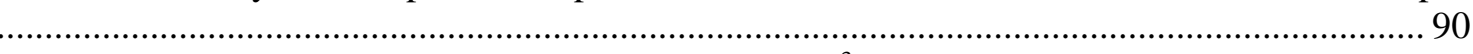

Tabla 4.1. Tabla de Pesos Específicos promedio (ton $/ \mathrm{m}^{3}$ ), Fuente: Gutierrez, 2013 ................. 94

Tabla 4.2. Porcentaje de variación de las máximas fuerzas aplicadas según dosificación. Fuente:

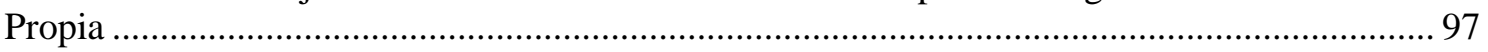

\title{
INDICE DE GRÁFICAS
}

Gráfica 2. 1 Cantidad de viviendas particulares en la región natural de Sierra del Perú. Fuente:

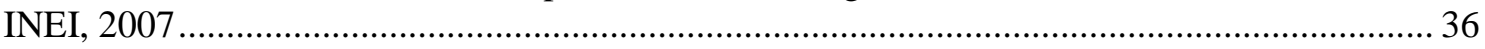

Gráfica 2. 2. Precipitación en el distrito de Huarochirí en los años de 2015 a 2017. Fuente:

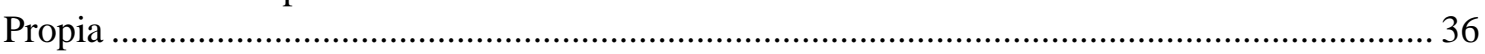

Gráfica 2. 3. Precipitación promedio de los años 2015 a 2017 en el distrito de Huarochirí.

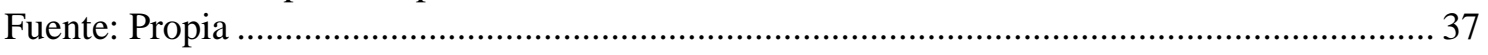

Gráfica 3.1. Promedio de los 3 valores de esfuerzo máximo de compresión por cada muestra.

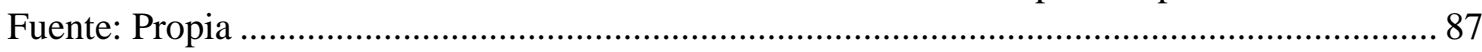

Gráfica 3.2. Módulo de Rotura para cada muestra. Fuente: Propia ........................................... 87

Gráfica 3.3. Promedio de los 2 valores de absorción por cada muestra. Fuente: Propia.............. 88

Gráfica 3.4. Clasificación final de las dosificaciones según su deterioro. Fuente: Propia........... 89

Gráfica 3.5. Profundidad de penetración de las dosificaciones. Fuente: Propia ........................... 89

Gráfica 3.6. Ensayos a compresión en pilas de adobes de $20 \mathrm{~cm} \mathrm{x} 40 \mathrm{~cm}$ x $42 \mathrm{~cm}$. Fuente:

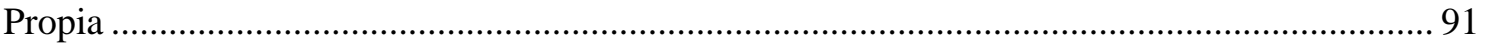

\begin{abstract}
ANEXOS
Anexo A: Granulometría de la primera muestra 115

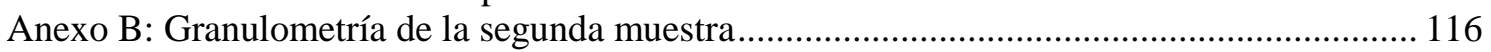

Anexo C: Gravedad específica de los suelos (Picnómetro) para la primera muestra.................. 116

Anexo D: Gravedad específica de los suelos (Picnómetro) para la segunda muestra................ 116

Anexo E: Formato de límite de consistencia de la primera muestra ........................................... 116

Anexo F: Formato de Límite de consistencia de la segunda muestra ....................................... 116

Anexo G: Sistema de clasificación de suelos unificados (SUCS) para la tierra de la primera

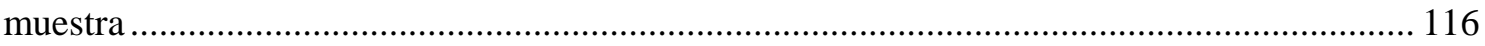

Anexo H: Sistema de clasificación de suelos unificados (SUCS) para la tierra de la segunda

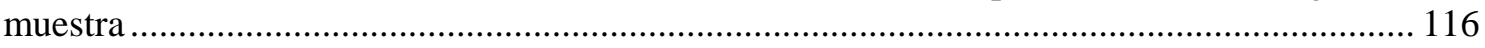

Anexo I: Costo unitario de elaboración de adobes, muros y reparación de muros estabilizados

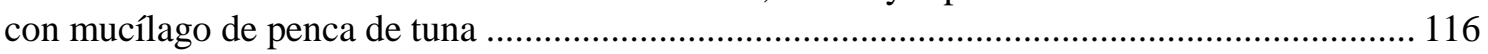

Anexo J: Costo unitario de elaboración de adobes, muros y reparación de muros convencionales

Anexo k: Manual de elaboración de adobe resistente al agua................................................. 125
\end{abstract}




\section{INTRODUCCIÓN}

La construcción con adobes ha sido utilizada por siglos en diferentes lugares del mundo para edificar viviendas, muestras de éstas, se puede corroborar en las ruinas de ciudades en Egipto, Irán, China y Mesoamérica, incluso se puede apreciar restos arqueológicos de adobe en el Perú como es la ciudad de Caral, La ciudadela de Chan Chan, entre otros. Esta elección de material se debe mayormente a que el adobe tiene un buen desempeño como aislante acústico, buenas condiciones como aislante térmico, además de que sus componentes para su elaboración se encuentran en grandes cantidades, generalmente su composición está conformada por tierra, arcilla, fibra vegetal (paja) y agua, en distintas proporciones.

Sin embargo, debido a la intervención de agentes externos como la lluvia, vientos y sismos, este elemento ha demostrado tener una limitada durabilidad, esencialmente con las precipitaciones, pues este al estar en contacto con el agua y humedad, sus propiedades de rigidez y resistencia se reducen, el cual conlleva a su desintegración. Este defecto se evidencia más en nuestro país, debido a que tiene una gran diversidad climatológica, el cual genera lluvias periódicas en las distintas regiones, este fenómeno natural afecta en mayor proporción a las zonas rurales de escasos recursos económicos, pues son las que tienen mayor cantidad de viviendas elaboradas con ladrillo de adobe por ser un elemento económico, ecológico, que no requiere conocimientos difíciles para su elaboración; es decir, se puede emplear la autoconstrucción de viviendas.

Por tal motivo, se debe mejorar las propiedades del adobe con la finalidad de que pueda resistir las intervenciones de agentes externos, y de esta manera beneficiar aquellas personas que viven en condiciones precarias por tener escasos recursos para vivir en unas viviendas en buenas condiciones. Una propuesta de solución ante este defecto es elaborar un adobe impermeabilizado con mucílago de penca de tuna en su composición, ya que es un material natural que se encuentra en grandes proporciones en la Sierra del Perú, evita que el exceso de agua ingrese a la unidad por capilaridad; es decir, permitirá que el adobe tenga mayor resistencia al entrar en contacto con el agua y de esta manera perdure en el tiempo. 


\section{Estado de Arte}

Debido a que el adobe es un material que presenta baja resistencia a la lluvia y zonas húmedas, diversos países a través de sus investigaciones buscan alternativas para estabilizar el adobe ya sea con cemento, asfalto, yeso y cal o con polímeros naturales, como es el caso del mucílago de penca de tuna. La investigación realizada por Suárez E. y Aranda Y. (2013) en la revista Nova Scientia en la Universidad De La Salle Bajío en México busca determinar el "Efecto de la impermeabilidad del Mucílago de Nopal en bloques de tierra comprimidos", con el propósito de crear un bloque de tierra compactado resistente a la humedad. La investigación tuvo como objetivo ver el efecto del mucílago de nopal (mucílago de penca de tuna) en bajas concentraciones en bloques de tierra comprimidos y describir algunas relaciones posibles entre los resultados obtenidos. La muestra estaba conformada por 5 lotes constituidos por 10 BTC para la concentración de 0.48, 0.96, 1.44, 1.92 y 2.4\%. Para elaborar los BTC se utilizó arcilla, medrano, cemento y solución de mucílago de penca de tuna en agua a diversas concentraciones. Una vez obtenida el BTC se procede a realizaron las pruebas físicas de compresión seca y húmeda, abrasión o durabilidad, absorción de agua, porosidad, y permeabilidad. Como se puede observar en el trabajo de Aranda y Suarez los resultados experimentales muestran que los bloques de tierra comprimida incrementan la resistencia a la compresión seca y húmeda hasta un $61.5 \% \pm 4.6 \%$, la porosidad disminuye conforme se incrementa la concentración de mucílago. El mucílago de penca de tuna no permite la interacción entre el agua y el sólido dificultando el acceso del líquido por capilaridad.

Además, la investigación realizada por Vargas J., Heredia E., Bariola J. \& Povindar K. (1986) titulada "Preservación de las construcciones de adobe en áreas lluviosas", busca comparar los resultados experimentales de utilizar diferentes estabilizadores (penca de tuna, variedad de cactus, tallo de plátano, fruto de algarrobina y asfalto) para fabricar unidades de albañilería. Con el objetivo de mejorar la durabilidad de las construcciones de adobe frente a la humedad. Para el presente estudio primero seleccionan y determinan las características del suelo, luego se utilizan distintos estabilizantes para incrementar la resistencia del enlucido frente a la acción erosiva de la lluvia. Se fabrican los especímenes de $40 \mathrm{~cm} \times 40 \mathrm{~cm} \times 20 \mathrm{~cm}$ con $28 \%$ de estabilizante de tuna respecto al peso seco del suelo, $2 \%$ y $4 \%$ de asfalto respecto al peso seco del suelo, $10 \%$ de extracto de algarrobina respecto al peso del agua, y hojas de plátano cortadas en trozos de $50 \mathrm{~mm}$ las cuales se 
hirvieron para obtener un líquido, finalmente se realizan los ensayos de lluvia simulada. Concluyen que las unidades de adobe estabilizadas con penca de tuna y asfalto presentaron daños leves, mientras que las unidades estabilizadas con hojas de plátano y frutos de algarrobina presentaron daños moderados. Además, profundizan el estudio analizando los días óptimos de remojo para la penca de tuna de modo que se aprovechen todos los beneficios que aporta este estabilizante.

Por otro lado, la investigación realizada por Quintana D. \& Vera M. (2017) Titulada "Evaluación de la erosión y la resistencia a compresión de adobes con sustitución parcial $\mathrm{y}$ total de agua en peso por mucílago de tuna en porcentajes de $0 \%, 25 \%, 50 \%, 75 \%$ y $100 \%$ ”, busca evaluar la erosión y la resistencia a la compresión de adobes con sustancias parciales y totales de mucílago de tuna, mediante la elaboración de bloques de adobe de $25 \times 13 \times 10 \mathrm{~cm}$ con adición de paja de $10 \mathrm{~cm}$ y distintas dosis de mucílago. Se realizaron diversos ensayos de laboratorio (absorción, succión y resistencia la compresión) para concluir que cuanto mayor es el portaje de mucílago de tuna en los adobes los resultados son mejores, es el caso que para el ensayo de absorción las únicas muestras que se pudieron evaluar fueron las que contenían $75 \%$ y $100 \%$ de mucílago de tuna ya que las otras muestras se desmoronaron y en el ensayo de compresión la unidad que contenía $100 \%$ de mucílago de tuna presento mayor resistencia.

En el Perú entidades como El Ministerio de Vivienda, Construcción y Saneamiento, Servicio Nacional de Capacitación para la Industria de la Construcción (SENCICO), el Instituto Nacional de Defensa Civil y el Centro de Estudios y Prevención de Desastres (PREDES), elaboraron diversos manuales donde recomiendan la utilización del mucílago de tuna para fabricar unidades de adobe más resistentes, pero en ninguna de estas publicaciones se puede apreciar, un método más factible y eficiente para extraer este mucílago o un porcentaje optimo que se debe de emplear en la mezcla para garantizar la impermeabilización de la unidad.

Estos estudios son opciones y recomendaciones que se tomarán en cuenta para la presente investigación, ya que brindan alternativas de solución a la problemática. 


\section{Realidad problemática}

El Perú, es un país que posee un variado y complejo sistema climatológico, el cual es influenciado, en su mayoría, por La Cordillera de los Andes, el Anticiclón del Pacifico Sur, la corriente Oceánica de Humboldt y la Corriente del Niño, esto ha dado como resultado que nuestro país sea afectado por lluvias periódicas en el año (Romero, I. y Pereyra, J., 2012).

Este fenómeno, que para muchos es favorable, para otros es perjudicial, como es el caso del adobe, material más predominante en la construcción de viviendas en las zonas de la región Sierra del Perú. El Censo Nacional realizado por el Instituto Nacional de Estadística e Informática (INEI), llevado a cabo el 2017 revela que de un total de 10millones 102 mil 849 viviendas particulares el 27.9\% (2 millones 148 mil 494 viviendas) son viviendas de adobe. Esta unidad de albañilería tiene gran demanda en esas zonas de escasos recursos por ser un material biodegradable, de bajo costo y de fácil adquisición. Sin embargo, las poblaciones que emplean esta unidad no toman en cuenta la vulnerabilidad del material frente al contacto con el agua, pues este le provoca pérdida de rigidez y resistencia; por consiguiente, acelera su desintegración natural. Además, si se añade la humedad natural de la zona, la posibilidad de colapso de la vivienda se incrementa, inclusive el riesgo de vidas de las personas que habitan en ella.

Esta problemática se puede evidenciar en los registros de Instituto Nacional de Defensa Civil (INDECI), el cual indica que, durante los años del 2011, en el Perú, hubo alrededor de 5963 casas destruidas por lluvias intensas y 40179 viviendas afectadas por el mismo fenómeno. Asimismo, el número de daños humanos ascendió a 261231 afectados y 30 517 damnificados. Además, basándonos en los datos expuestos por el Instituto Nacional De Estadística e informática (INEI) en el año 2013, se muestra la tabla 1 donde se evidencia que existe gran cantidad de viviendas particulares hechas con adobe o tapial. 
Tabla 1.0. Diferentes materiales utilizados para la elaboración de viviendas en áreas residenciales. Fuente: INEI, 2013

\begin{tabular}{|l|c|c|c|}
\hline $\begin{array}{l}\text { MATERIAL PREDOMINANTE EN } \\
\text { LAS PAREDES EXTERIORES / ÁREA } \\
\text { DE RESIDENCIA }\end{array}$ & $\begin{array}{c}\text { URBANO (CANT. } \\
\text { VIVIENDAS) }\end{array}$ & $\begin{array}{c}\text { RURAL (CANT. } \\
\text { VIVIENDAS) }\end{array}$ & $\begin{array}{c}\text { TOTAL (CANT. } \\
\text { VIVIENDAS) }\end{array}$ \\
\hline Ladrillo o bloque de cemento & $3,952,328.56$ & $135,208.07$ & $4,087,481.70$ \\
\hline Piedra o sillar con cal o cemento & $44,748.79$ & $7,889.77$ & $52,638.24$ \\
\hline Adobe o tapia & $1,223,349.37$ & $1,409,754.00$ & $2,633,150.22$ \\
\hline Quincha (caña con barro) & $106,087.06$ & $34,767.24$ & $140,854.28$ \\
\hline Piedra con barro & $4,490.94$ & $63,212.29$ & $67,706.11$ \\
\hline Madera & $370,437.29$ & $222,015.02$ & $592,456.94$ \\
\hline Estera & $26,362.94$ & $8,617.84$ & $34,980.77$ \\
\hline Otro material & $149,684.05$ & $69,617.77$ & $219,302.75$ \\
\hline TOTAL & $5,877,489.00$ & $1,951,082.00$ & $7,828,571.00$ \\
\hline
\end{tabular}

En la tabla 1 se aprecia que, el 33.6\% (2 633150 viviendas) de las viviendas particulares en el Perú son hechas con adobe o tapial y que en las zonas rurales este porcentaje se incrementa en un $72.3 \%$ (1 409754 viviendas); por lo tanto, el riesgo de damnificados y posibles muertes sigue siendo muy alto, debido a que la mayoría de las viviendas construidas con este material se encuentran en zonas de constantes lluvias.

\section{Formulación del problema}

¿Emplear adobes estabilizados en la construcción de muros portantes en la Región Sierra del Perú, garantizará la vida útil de las viviendas cuando estas entran al contacto con el agua debido a las precipitaciones estacionales de la zona?

\section{Hipótesis}

El adobe estabilizado con mucílago de penca de tuna tendrá mejor resistencia a la compresión, flexión y absorción en comparación a los adobes convencionales, utilizados en la construcción de viviendas populares en la región Sierra del Perú.

\section{Objetivo general}

Diseñar una unidad de albañilería de abobe estabilizado con mucílago de penca de tuna con el fin de prolongar la vida útil de las viviendas populares.

\section{Objetivos específicos}

- Analizar los materiales más adecuados para la elaboración de la mezcla a través de ensayos preliminares (prueba de color, prueba olfativa y prueba de brillo) y ensayos físicos (ensayo de cinta de barro, resistencia seca, granulometría, peso específico y límites de Atterberg) para el suelo, y ensayos de densidad y viscosidad para el mucílago de penca de tuna. 
- Seleccionar la dosificación ideal de la mezcla para obtener los mejores resultados de resistencia a la compresión, flexión y absorción en la unidad de adobe estabilizado.

- Comparar los resultados de resistencia mecánica (compresión y flexión) y resistencia física (absorción) de las unidades y pilas de adobes convencionales de los adobes estabilizados.

\section{Descripción del Contenido}

En primer lugar, se presenta la justificación de la investigación, el cual comienza con la explicación de investigaciones anteriores, que tratan de solucionar a través de diversos ensayos la vulnerabilidad del adobe, también se argumenta y delimita el problema del elemento frente al contacto del agua. Asimismo, se formula una hipótesis del trabajo, estableciendo las variables e indicadores y, por último, se presenta los objetivos: general y específicos.

En el capítulo I: Se explica los fundamentos teóricos, necesarios para la investigación: como las características de los materiales que se utilizan, generalmente, en la elaboración del adobe, así como los tipos y procesos de estabilización natural que se le puede atribuir al adobe para mejorar sus propiedades mecánicas, físicas y químicas. Además, se expone las técnicas y ensayos más importantes que están relacionados con la solución del problema.

En el capítulo II: Se divide en materiales y métodos de investigación. En el primer punto, se define la población y la muestra involucrada en la investigación, donde se explican los parámetros de la región Sierra del Perú, las características climáticas, temperatura máxima y mínima, humedad, precipitación máxima, material predominante en la construcción de las viviendas en esta región y en qué lugares de toda la Sierra se elaboran adobe con mayor frecuencia. En el segundo punto, se presenta el nivel de investigación, diseño de investigación, métodos, técnicas e instrumentos de recolección de datos para seleccionar el suelo y técnicas de extracción del mucílago de penca de tuna que cumplan con las recomendaciones de otros autores y los requisitos propuestos por las normas. Se concluye el capítulo con las técnicas de procesamiento y análisis de datos, en la cual se realizan ensayos mecánicos y físicos en las unidades y pilas de adobe convencional y adobe estabilizado con distintos porcentajes de mucílago de penca de tuna.

En el capítulo III: Se muestran los resultados conforme a los objetivos planteados al inicio de la investigación. 
En el capítulo IV: Se verifican y discuten los resultados de los ensayos y comparación de resultados.

En el capítulo V: Se presenta las conclusiones de la tesis según los objetivos planteados. En el capítulo VI: Se evidencian las recomendaciones para futuras investigaciones que tienen la misma línea temática propuesta por esta investigación.

En el capítulo VII: Se presenta la bibliografía de la tesis, distinguiéndose entre los diferentes tipos de publicaciones utilizadas. 


\section{MARCO TEÓRICO}

En este capítulo, se explicará todo lo referente al adobe convencional desde su definición, componentes que lo conforman, dimensiones; asimismo, definirá el adobe estabilizado con material natural y describirá los diferentes procesos de estabilización.

\subsection{Adobe convencional}

A continuación, se describirán la definición del adobe, componentes, dimensiones y fortalezas y debilidades que ocurren al elaborar adobes para construcción de viviendas populares en la Sierra del Perú.

\subsubsection{Definición de adobe convencional}

Según la Norma E.080 (2000) “Adobe” se define adobe como bloque macizo de tierra sin cocer, el cual puede contener paja u otro material que mejore su estabilidad frente agentes externos. La norma presenta ciertos requisitos: para el tipo de tierra a usarse en la fabricación de adobes considerar que la gradación del suelo debe contener aproximadamente arcilla 10-20\%, limo 15-25\% y arena 55-70\%, no debe utilizarse suelos orgánicos, puesto de que incrementar el porcentaje de arcilla se generaran grietas internas por contracción de secado, de incrementar la arena se perderá la cohesión y de utilizar suelos orgánicos se perdería resistencia a la compresión y a la a humedad. Además, la norma solo permite perforaciones perpendiculares a su cara de asiento (cara mayor) y que estas no representen más del $12 \%$ del área bruta.

A continuación, se muestran algunas definiciones, todas validas, pero difieren desde el punto de vista del autor:

- Vélez G. (2010) por su parte define al adobe como un ladrillo hecho con barro, que posee un peso promedio de unos 14 kilos.

- Gendrop P. (2001) por el contrario, define el adobe de varias maneras, entre las más comunes: "masa de barro moldeada en forma de ladrillo y secada al sol" o "ladrillo formado por una masa de tierra arcillosa, agua y algún aditivo, secada al sol y al aire". Además, indica que los términos tierra, masa de barro y tierra arcillosa resulta ambiguos e imprecisos para la ciencia del suelo.

- Saroza B. et al. (2008) llama adobe a aquel material de construcción fabricado en forma de ladrillo y elaborado en base al suelo, constituido éste por unas adecuadas proporciones de arena, limo, arcilla, fibra orgánica y agua. 
Para efectos de la investigación, se utiliza la definición de la M.V.C.S (2000) de la norma E.0.80: Adobe, ya que esta es más detallada.

\subsubsection{Componentes del adobe convencional}

Los componentes principales para la elaboración del adobe son el suelo, paja, arcilla y agua como se describe a continuación:

\subsubsection{Suelo}

Sánchez K. (2010), indica que el suelo es la materia prima para la elaboración del bloque de adobe y mortero de barro. Se caracteriza por estar compuesto por la mezcla de arcilla, limo y arena; la primera tiene como función aglutinar la mezcla, pues al mojarse se inserta entre la arena y la grava; la última es un material inerte que le da estructura y resistencia a la combinación. Sin embargo, no todos los suelos sirven para elaborar adobe, ya que algunos de éstos no presentan la calidad ni las proporciones relativas de los componentes recomendables para la elaboración de la mezcla, incluso pueden no presentar cohesión ni plasticidad adecuada o pueden tener presencia de sustancias orgánicas.

Según M.V.C.S. (2000) en E.0.80: Adobe, indica cuales podrían ser los posibles porcentajes para cada componente, el porcentaje de arcilla debe estar entre 10 a $20 \%$, limo alrededor de 15 a $25 \%$ y la arena entre 55 a $70 \%$. Asimismo, existe otras maneras de elegir el suelo apto para fabricar adobes, estos en su mayoría son ensayos en campo mencionados por Tejada U. (2001) en su libro "Buena Tierra- Apuntes para el diseño y construcción con Adobe" como se muestra en la tabla 1.1. 
Tabla 1. 1. Pruebas de campo para identificar si un suelo es apto para fabricar adobes. Fuente: Buena Tierra, 2001

\begin{tabular}{|c|c|c|c|}
\hline TIPO & PROCEDIMIENTO & INDICADORES PRINCIPALES & RESULTADOS \\
\hline $\begin{array}{l}\text { Prueba de } \\
\text { color }\end{array}$ & $\begin{array}{l}\text { Observaciones del color del } \\
\text { suelo }\end{array}$ & $\begin{array}{l}\text {-Negro: Suelos orgánicos } \\
\text {-Claro y brillante: inorgánicos } \\
\text {-Gris claro: limoso, con carbonato cálcico, suelo } \\
\text { poco cohesivo }\end{array}$ & $\begin{array}{l}\text { Claros y brillantes } \\
\text { (aprobados) }\end{array}$ \\
\hline $\begin{array}{l}\text { Prueba } \\
\text { dental }\end{array}$ & $\begin{array}{l}\text { Se muele ligeramente una } \\
\text { pizca de suelo entre los } \\
\text { dientes }\end{array}$ & $\begin{array}{l}\text {-Arenosos: Partículas duras, rechinan entre los } \\
\text { dientes, sensación desagradable. } \\
\text {-Limoso: partículas más pequeñas, rechinan sólo } \\
\text { ligeramente, más suaves que los arenosos. } \\
\text {-Arcilloso: no rechinan, suaves y quebradizos. }\end{array}$ & $\begin{array}{l}\text { Limosos } \\
\text { (aprobados) }\end{array}$ \\
\hline $\begin{array}{l}\text { Prueba } \\
\text { Olfativa }\end{array}$ & Se aprecia el olor del suelo & Olor rancio: Suelos orgánicos & $\begin{array}{l}\begin{array}{l}\text { Sin olor rancio } \\
\text { (aprobado) }\end{array} \\
\end{array}$ \\
\hline $\begin{array}{l}\text { Prueba de } \\
\text { brillo }\end{array}$ & $\begin{array}{l}\text { Se corta una muestra de } \\
\text { suelo al estado de masilla }\end{array}$ & $\begin{array}{l}\text {-Opacos: Suelos arenosos } \\
\text { - Mates: Limosos con poca arcilla } \\
\text {-Brillantes: arcillosos }\end{array}$ & Mates (aprobado) \\
\hline $\begin{array}{l}\text { Prueba de } \\
\text { enrollado }\end{array}$ & $\begin{array}{l}\text { Se corta una muestra de } \\
\text { suelo al estado de masilla } \\
\text { Se forma un rollo de suelo } \\
\text { hidratado de } 5 \text { a } 10 \mathrm{~cm} \text { y se } \\
\text { lo desplaza entre el índice y } \\
\text { el pulgar. }\end{array}$ & $\begin{array}{l}\text { Si muestra se rompe entre } 5 \text { a } 10 \mathrm{~cm} \text {. el contenido } \\
\text { de arena será el adecuado. Si soporto una longitud } \\
\text { mayor, el contenido de arcilla será muy alto; si se } \\
\text { rompe antes de } 5 \mathrm{~cm} \text {. Se tratará de un suelo arenoso }\end{array}$ & $\begin{array}{l}\text { La muestra se } \\
\text { rompió a } 8 \mathrm{~cm} . \\
\text { (aprobado) }\end{array}$ \\
\hline $\begin{array}{l}\text { Prueba de } \\
\text { resistencia } \\
\text { seca de } \\
\text { bolita }\end{array}$ & $\begin{array}{l}\text { Se preparan tres o más } \\
\text { bolitas de } 2 \mathrm{~cm} \text { de diámetro y } \\
\text { se deja secar } 24 \text { horas. } \\
\text { Luego se presionan entre el } \\
\text { pulgar y el índice. }\end{array}$ & $\begin{array}{l}\text { Si las bolitas no se rompen, significará que el } \\
\text { contenido de arcilla conferirá adecuada resistencia } \\
\text { a los adobes. Si se rompe el suelo será de baja } \\
\text { resistencia. }\end{array}$ & $\begin{array}{l}\text { Las bolitas no se } \\
\text { llegaron a romper } \\
\text { de ningún modo } \\
\text { usando solo los } \\
\text { dedos (aprobado) }\end{array}$ \\
\hline $\begin{array}{l}\text { Prueba de la } \\
\text { botella }\end{array}$ & $\begin{array}{l}\text { Se utiliza una botella o tubo } \\
\text { de ensayo de } 1 / 2 \text { litro de } \\
\text { capacidad. Llenar } 1 / 4 \text { de la } \\
\text { parte con suelo y } 3 / 4 \text { partes } \\
\text { con agua. Se agita la } \\
\text { suspensión y se deja reposar } \\
\text { por } 5 \text { horas }\end{array}$ & $\begin{array}{l}\text { Permite establecer los porcentajes de finos y } \\
\text { arenas. Las arenas reposan inmediatamente. Los } \\
\text { limos reposan a los pocos minutos. Las arcillas } \\
\text { requieren para reposar } 5 \text { horas. Luego de ese } \\
\text { tiempo puede establecer los porcentajes } \\
\text { aproximados de los componentes. Los rangos } \\
\text { deben estar dentro de los indicados en la } \\
\text { NORMA. }\end{array}$ & $\begin{array}{l}60 \% \text { de arena } 20 \% \\
\text { de limos } 20 \% \text { de } \\
\text { arcilla (aprobado) }\end{array}$ \\
\hline $\begin{array}{l}\text { Prueba de } \\
\text { agua para el } \\
\text { barro }\end{array}$ & $\begin{array}{l}\text { Se separa una pequeña } \\
\text { porción de la masa de barro } \\
\text { para la fabricación de los } \\
\text { adobes. Se la tira de golpe } \\
\text { contra el piso. Se la trata de } \\
\text { levantar con el uso de una } \\
\text { sola mano }\end{array}$ & $\begin{array}{l}\text { Permite establecer si la cantidad de agua es } \\
\text { aceptable para la fabricación de los adobes. } \\
\text {-Si la más no se conserva su figura y solides, } \\
\text { teniendo finalmente dificultades de levantarse, } \\
\text { tiene demasiada agua. } \\
\text {-Si la masa conserva su figura y material al } \\
\text { levantarlo, cantidad de agua aceptable. } \\
\text {-Si la masa se esparce al momento de la colisión } \\
\text { con el piso o si llega a dejar materia pegada al piso } \\
\text { al momento de levantar el material, entonces } \\
\text { indica escasa cantidad de agua. }\end{array}$ & $\begin{array}{l}\text { Conserva su figura } \\
\text { y material al } \\
\text { levantar la masa } \\
\text { 8aprobado) }\end{array}$ \\
\hline $\begin{array}{l}\text { Adobes de } \\
\text { Prueba }\end{array}$ & $\begin{array}{l}\text { Antes de la fabricación en } \\
\text { cantidad, se producen unos } \\
\text { adobes previos aparte. }\end{array}$ & $\begin{array}{l}\text { Proporciona más seguridad para la fabricación de } \\
\text { los bloques. } \\
\text {-Si los adobes se rajan al secarse, entonces el suelo } \\
\text { contiene arcilla. } \\
\text {-Si los adobes no se rajan, entonces el suelo es } \\
\text { aceptable. }\end{array}$ & $\begin{array}{l}\text { No se observa } \\
\text { rajaduras } \\
\text { (aprobado) }\end{array}$ \\
\hline
\end{tabular}

Según Instituto de la Construcción y Gerencia (ICG) (2010) se recomienda.

- Tener la cantidad suficiente de suelo tanto para fabricar los adobes como morteros.

- Escoger un material de calidad que contenga poca cantidad de piedras, no tenga materia orgánica y residuos, con la finalidad de que el tamizado sea sencillo. 
- El sitio de extracción del suelo debe estas ubicado lo más cerca posible del lugar de construcción para facilitar la extracción y traslado del material.

\subsubsection{Paja}

La paja es una fibra vegetal, que es utilizada como material para la elaboración de las estructuras de tierra. Este elemento incrementa la calidad de la mezcla, modifica la textura de los componentes haciéndolos más ásperos (mayor adherencia entre elementos) y proporciona mayor liviandad. (Sánchez K, 2010)

Las fibras conforman una especie de red a la que se adhieren las partículas del suelo, controla su desplazamiento, dilatación y retracción durante el fraguado; asimismo, funcionan como articulaciones en los edificios, el cual flexibilizan las estructuras ante posibles fallas por sobrecargas o movimientos símicos. Pruebas realizadas por Bouhicha M, et al., 2005, Galán C, et al., 2010 y Babu G y Vasudevan A, 2008 como se citó en Benites V, 2017 indican:

"La adición de fibras disminuye la contracción de adobes, mejora la resistencia al corte debido a que aumenta la cohesión entre las partículas del suelo, incrementa la resistencia a la compresión y fuerzas de cizallamiento, hace más dúctil la falla, y se obtiene una mejor resistencia a la flexión, ya que la interacción de las fibras entre sí y la flexibilidad de las fibras hace que se comporten como una malla estructural que mantiene al suelo unido". (p. 25-26)

En la Norma E.080 (2017) titulada Diseño y Construcción con tierra reforzada en el artículo 12 item 4 recomienda que en suelos arcillosos se utilice paja de una longitud aproximada de $50 \mathrm{~mm}$ y una proporción de volumen de 1 de paja por 5 de tierra, esta proporción debe ser verificada al inicio de la obra. Además, en el Artículo 19 item 3 indica que la proporción entre paja cortada y tierra puede variar entre 1:1 y 1:2 y en el ítem 4 del mismo artículo recomienda que si la paja es escasa se puede utilizar agregado grueso y la proporción adecuada se determina mediante las pruebas de Control de Fisuras o Dosificación Suelo Arena Gruesa.

\subsubsection{Arcilla}

La arcilla es el componente más importante del suelo, ya que le provee de resistencia seca y causa su contracción por secado. Asimismo, actúa como un aglomerante en el suelo mientras que el resto de las partículas actúa como relleno (Sánchez K, 2010). Existen muchos métodos que permiten verificar la capacidad de la arcilla en el suelo, como indica 
en la norma E.080 (Diseño y construcción con tierra reforzada) con prueba "cinta de barro" y prueba "presencia de arcilla" o "resistencia seca".

Según Juárez y Rico (2005, citado por Benites V, 2017) no todas las arcillas presentan comportamientos similares, esto se debe a la separación de sus micelas y a los elementos químicos que lo conforman, que pueden influir en su grado de actividad. Su clasificación se basa mayormente en su grado de estabilidad frente al agua. El primer tipo son arcillas conocidas como expansivas que pertenecen al grupo de esmectitas (Montmorillonitas, nontronitas y saponitas) estas tienen la propiedad de permitir la entrada del agua entre sus láminas de estructura, el cual genera que el elemento (arcilla) se hinche, provocando efectos nocivos para la construcción. El segundo tipo son las caolinitas, que tienen un comportamiento estable al entrar en contacto con el agua, ya que no permiten el ingreso de 11 moléculas de agua en su composición, esta característica es conocida como adsorción. Por último, están las ilitas que se expanden al estar en contacto con el agua, pero a menor intensidad que las esmectitas.

Para el caso del adobe no es recomendable emplear un suelo que contenga excesiva cantidad de arcilla, pues en su elaboración se emplea una cantidad considerable de agua, lo cual produciría fisuras a causa de la retracción que se da durante el secado como lo menciona Guerrero L. (2001, citado por Benites V, 2017).

\subsubsection{Agua}

Según Klees, D. y Natalini, M. (2014), el agua o dihidruro de oxígeno es un líquido incoloro, inodoro e insaboro necesario para la construcción de viviendas hechas con adobe. Este material debe estar limpio, libre de material particulado, partículas en suspensión o disolución como cloruros o sulfatos. El control de calidad y cantidad de este material es muy importante, ya que este actúa como lubricante de las partículas de la mezcla de barro, pues si es muy húmeda o muy seca, esto se reflejará en el producto final. Asimismo, si la mezcla es muy plástica dificultará la realización del ensayo a compresión, afectará la resistencia y durabilidad del material. Los autores consideran que la cantidad total de agua generalmente esta entre 8 y $16 \%$ de la mezcla.

\subsubsection{Dimensiones del adobe convencional}

Para su fabricación se puede utilizar distintos moldes de diferentes formas con diferentes materiales, comúnmente son hechos de madera o acero, esto depende mayormente del lugar de fabricación, los hay cónicos, cilíndricos, trapezoidales, etc. (Ramírez M., 2011). 
Para facilidades constructivas y comportamiento mecánico, se recomienda utilizar adobes de forma rectangular y cuadrada; además que el largo no puede superar al doble del ancho y la altura con respecto al largo sea aproximadamente de $1 \mathrm{a} 4$, con el fin de que al momento de traslapar garantice su estabilidad en la dirección vertical y horizontal. (Benites V., 2017). Asimismo, según recomendaciones de varios autores las dimensiones en el ladrillo de adobe pueden ser los siguientes:

- Vélez G. (2010), menciona que tradicionalmente los adobes son rectangulares con medidas de $25 \mathrm{~cm} \times 35 \mathrm{~cm} \times 10 \mathrm{~cm}$.

- Lopez, J. y Bernilla, P. (2012), comenta que las dimensiones del adobe deben permitir una adecuada manipulación de la unidad para el albañil y el operador, esas medidas en general serian de $40 \mathrm{~cm} \times 40 \mathrm{~cm}$, pero hay variaciones que dependen de las características de la zona.

- ICG (2010), recomiendan posibles dimensiones de adobe según su uso como se muestra en la tabla 1.2.a y 1.2.b

Tabla 1. 2.a. Dimensiones de adobe con uso Modular. Fuente ICG, 2010

\begin{tabular}{|c|c|c|c|c|}
\hline $\begin{array}{c}\text { ESPESOR } \\
\text { NOMINAL }\end{array}$ & DENOMINACIÓN & LARGO (cm) & ANCHO (cm) & ALTO (cm) \\
\hline \multirow{2}{*}{40} & Adobe entero & 40.0 & 40.0 & 10.0 \\
\cline { 2 - 5 } & Medio adobe & 40.0 & 20.0 & 10.0 \\
\hline \multirow{2}{*}{30} & Adobe entero & 30.0 & 30.0 & 10.0 \\
\cline { 2 - 5 } & Medio adobe & 30.0 & 15.0 & 10.0 \\
\hline
\end{tabular}

Tabla 1.2.b. Dimensiones de adobe con uso en Tabiques. Fuente ICG, 2010

\begin{tabular}{|c|c|c|c|c|}
\hline $\begin{array}{c}\text { ESPESOR } \\
\text { NOMINAL }\end{array}$ & DENOMINACIÓN & LARGO (cm) & ANCHO (cm) & ALTO (cm) \\
\hline \multirow{2}{*}{40} & Adobe entero & 36.0 & 38.0 & 8.0 \\
\cline { 2 - 5 } & Medio adobe & 36.0 & 18.0 & 8.0 \\
\hline \multirow{2}{*}{30} & Adobe entero & 26.0 & 28.0 & 8.0 \\
\cline { 2 - 5 } & Medio adobe & 26.0 & 13.0 & 8.0 \\
\hline
\end{tabular}

- Blondet M. y Vargas J. (2015), comentan que para la elaboración de los muros se necesita dos tipos de adobe, uno cuadrado y otro rectangular. En la figura 1.1 se muestran las dimensiones de cada tipo de adobe.

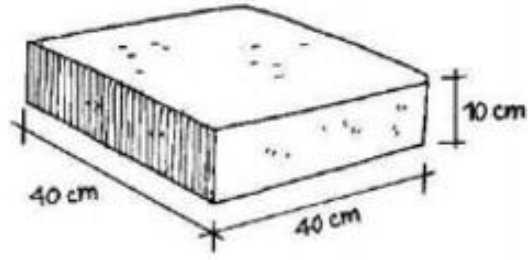

Adobe cuadrado

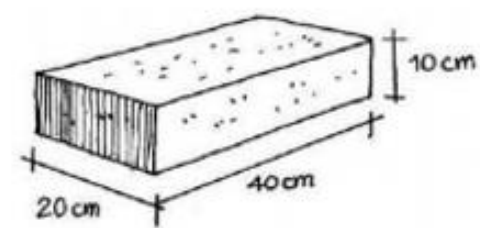

Medio adobe

Figura 1. 1 Dimensiones del adobe completo y medio adobe que se requiere para la elaboración de muros. Fuente: Marcial Blondet y Julio Vargas, 2015 
Esto se debe a que el medio adobe completará las partes del muro, el cual no entrará el adobe completo.

- El Ministerio de Vivienda, Construcción y Saneamiento (2010) en el manual de construcción: Edificaciones de adobe, presenta ciertos criterios que las dimensiones en un adobe deben cumplir:

- Para un adobe rectangular, el largo debe ser aproximadamente el doble del ancho.

- La relación del largo y alto debe ser de 4 a 1 aproximadamente.

○ La altura debe ser mayor a $8 \mathrm{~cm}$

Sin embargo, los mejores adobes, según su recomendación son de 40 cm x 40 cm x 8 cm.

\subsubsection{Fortalezas y debilidades de construir con adobe}

Como menciona De Olarte J., Linares Z., Rodríguez J. y Jiménez F. (2003) en la base de datos de Sistemas constructivos para edificaciones menciona algunas ventajas y desventajas de emplear el adobe en la construcción de viviendas (tabla 1.3).

Tabla 1. 3. Ventajas y desventajas de emplear adobe. Fuente: Olarte \& A.1, 2003

\begin{tabular}{|l|l|}
\hline \multicolumn{1}{|c|}{ FORTALEZAS } & \multicolumn{1}{c|}{ DEBILIDADES } \\
\hline $\begin{array}{l}\text { El adobe presenta un bajo costo de producción } \\
\text { y edificación en comparación a otros materiales } \\
\text { de construcción. }\end{array}$ & $\begin{array}{l}\text { Toda edificación construida con adobe presenta poca resistencia a } \\
\text { cargas laterales por sismo. }\end{array}$ \\
\hline $\begin{array}{l}\text { Para su manufactura no se requiere de ningún } \\
\text { tipo de energía, ya que es un material que se } \\
\text { deja secar a temperatura ambiente, sin generar } \\
\text { un impacto negativo al medio ambiente. }\end{array}$ & $\begin{array}{l}\text { Ll proceso constructivo presenta un ritmo lento, debido a que los } \\
\text { ladrillos de adobe son muy pesados y difíciles de manipular } \\
\text { requiere más mano de obra y más tiempo para construir una } \\
\text { vivienda. }\end{array}$ \\
\hline $\begin{array}{l}\text { Presenta gran capacidad de aislamiento } \\
\text { térmico y acústico. }\end{array}$ & $\begin{array}{l}\text { Al estar compuesto por material natural requiere de mantenimiento } \\
\text { constante para que los muros no se degraden por efectos de } \\
\text { interperismo. }\end{array}$ \\
\hline
\end{tabular}

\subsection{Adobe estabilizado con material natural}

A continuación, se explicará definición de adobe estabilizado, definición de los materiales para estabilizar y los procesos de estabilización.

\subsubsection{Definición de adobe estabilizado}

Para aumentar la resistencia de los muros ante los efectos de la intemperie, se recomienda estabilizar no solo a los recubrimientos, sino también a los adobes.

En la Norma E.080 (2017) titulada Diseño y Construcción con tierra reforzada, se define al adobe estabilizado como "un adobe en el que se ha incorporado otros materiales 
(asfalto, cemento, cal, etc.) con el fin de mejorar sus condiciones de resistencia a la compresión y estabilidad ante la presencia de humedad". La misma norma específica que, para el caso de la fabricación de adobes estabilizados, la gradación del suelo puede variar con relación a la especificada para la fabricación de adobes comunes.

\subsubsection{Definición de los materiales para estabilizar el adobe}

Existen distintos elementos para mejorar las propiedades físicas y mecánicas del adobe, que pueden ser desde polímeros naturales (Cabuya, penca de tuna, fibras de coco, etc.) hasta materiales procesados (cemento, asfalto, etc.).

Para esta investigación se tomó en cuenta las características de un material natural, el mucílago de la penca de tuna para incrementar la resistencia del adobe al contacto con el agua.

\subsubsection{Mucílago de penca de tuna}

Según Gerencia Regional Agraria en su publicación Cultivo de Tuna (2009), la penca de tuna (figura 1.2) es un vegetal arborescente de 3 a $5 \mathrm{~m}$ de alto, su tronco es leñoso y mide de entre 20 a $50 \mathrm{~cm}$ de diámetro. En el Perú las variedades más usuales desarrollan portes de aproximadamente 1,5 a 2,0 m de altura. Asimismo, se indica que la planta de la tuna se puede desarrollar en zonas que cumplan con las siguientes características:

- En zonas con climas áridos y muy áridos con lluvias de verano (la precipitación anual es alrededor de 125 milímetros a más. Sin embargo, los excesos de humedad pueden provocar daños por insectos o enfermedades fungosas.

- Se adapta a suelos con diversas composiciones, pero tiene un mejor desarrollo en suelos arenosos, sueltos, de media profundidad y un con un $\mathrm{PH}$ preferentemente alcalino.

- La altitud en el que se desarrollan está entre los 800 y 2800 msnm, aunque también se pueden encontrar en altitudes menores cerca a la costa.

Como se observa en la figura 1.2 la penca de tuna o cladodios que forman el tallo y dan origen a los frutos, este tallo contiene una sustancia viscosa también conocido como mucílago de penca de tuna, la cual tiene la capacidad de formar redes moleculares y retener fuertemente grandes cantidades de agua, así como de modificar propiedades como 
viscosidad, elasticidad, textura, retención de agua, además de que es un buen gelificante, espesante, y emulsificante. (Gerencia Regional Agraria, 2009).

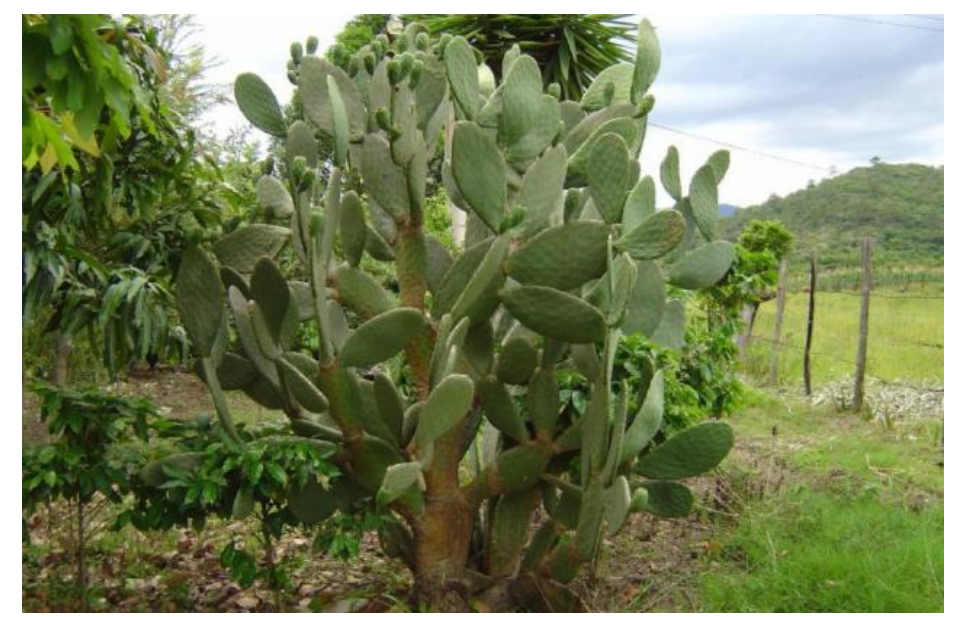

Figura 1. 2. Planta de tuna con sus respectivas pencas. Fuente: La Gerencia Regional de Agraria, 2009.

\subsubsection{Procesos de estabilización}

Según los autores Arteaga K., Humberto O. y Gutiérrez O. (2011) existen dos formas de estabilizar el adobe, estás se muestran a continuación:

\subsubsection{Homogénea}

El proceso de estabilización homogénea consiste en agregar material faltante a la mezcla; es decir, si la tierra es poco cohesiva, se agrega un poco de arcilla, en cambio si la tierra es muy cohesiva, el material agregado es arena. Se toma en cuenta que los materiales se incorporan en seco y deben ser parecidos al material a estabilizar.

\subsubsection{Heterogénea}

En este tipo de proceso, se incorpora otro tipo de material que ayudará a mejorar las propiedades de la mezcla. Este proceso divide los estabilizantes en tres categorías: consolidantes, fibras e impermeabilizantes.

- Consolidantes: Estos estabilizantes se enlazan con los limos y las arenas para mantenerlos unidos, generando que el elemento aumente su resistencia a los esfuerzos de compresión y cortante; asimismo, disminuye la absorción del agua. Entre estos elementos tenemos a la cal, la cual es considerada como uno de los mejores consolidantes, ya que no produce porosidad, la tierra no pierde su estado de adherencia. En cuanto a sustancias orgánicas, algunas cumplen la función de 
aglutinantes, presentes en vegetales como las cactáceas y las suculentas, en coloides orgánicos, en la leche y huevos.

- Fibras: Con los estabilizantes por fibra, se controla el comportamiento de dilatación y retracción durante el fraguado; es decir, evita la aparición de fisuras cuando este empieza a secarse. Estas fibras pueden ser de origen vegetal, como paja, diferentes gramíneas, virutas de madera, acículas de pináceas, cáscaras de coco, tallos del maíz y fibras de pita o fique, o de origen animal, como lana, crines de caballo, pelo de llama. El material agregado debe estar seco, para evitar que se descomponga.

- Impermeabilizantes: Su función es evitar que el exceso de agua ingrese al material, a través de la capilaridad y por las lluvias. Este estabilizante actúa como una capa sobre las arcillas para evitar que se expandan al entrar al contacto con el agua. Las grasas, de tipo vegetal, animal o fósil, son parte de los materiales usados como impermeabilizantes. La cantidad debe ser la apropiada para que no interfieran con el comportamiento de las arcillas.

\subsection{Propiedades físicas y químicas}

Las propiedades de las sustancias se clasifican en propiedades físicas y químicas. Las propiedades físicas son aquellas que se pueden medir sin que se afecte su composición mientras que las propiedades químicas son aquellas sustancias que sufre una transformación de su estructura interna, convirtiéndose en otras sustancias nuevas.

Viscosidad: En Vargas I. (2004, citado en ALAIS, 1985) nos define como la resistencia de un líquido a fluir, a mayor viscosidad el líquido fluirá más lentamente. La viscosidad tiene que ver con la facilidad con que las moléculas del líquido puedan moverse con respecto a otras; por lo tanto, depende de las fuerzas de atracción entre las moléculas y de la estructura que tengan dichas moléculas.

Durabilidad: Según Bañon L. (2010) es una propiedad que consiste en la capacidad de soportar, durante su vida útil, las condiciones físicas y químicas a las que va a estar expuesta un elemento, conservando sus condiciones de funcionalidad y aspecto por un determinado periodo de tiempo. 


\section{MATERIAL Y MÉTODO}

En este capítulo se definirá la población y la muestra involucrada en la investigación, se presentará el nivel de investigación, diseño de investigación, métodos, técnicas e instrumentos de recolección de datos para seleccionar los materiales y de esta manera elaborar adobes. Asimismo, se explicará las técnicas de procesamiento y análisis de datos, en la cual se realizan ensayos mecánicos y físicos en las unidades y pilas de adobes.

\subsection{Material}

En esta investigación se ha seleccionado la población y muestra correspondiente que más se ajusta a la problemática planteada anteriormente. A continuación, se explicará cada una de ellas:

\subsubsection{Población}

Para esta investigación se tomó como población a todos los habitantes de la zona Sierra del Perú, debido a que en estos lugares no solo existen gran cantidad de viviendas de adobe, sino la tradición de construir, ampliar y mejorar sus hogares con este material a pesar de las fuertes lluvias periódicas en la región. A continuación, se explicará los parámetros que se tomaron en cuenta para demostrar el nivel de precipitación y los elementos climatológicos que afectan a esta región.

\subsubsection{Clima}

Según Servicio Nacional de Meteorología e Hidrología del Perú (Senamhi) las características climáticas del Perú son peculiares debido a la extensión y el relieve topográfico, como se muestra en la figura 2.1 cada color indica un tipo de clima.

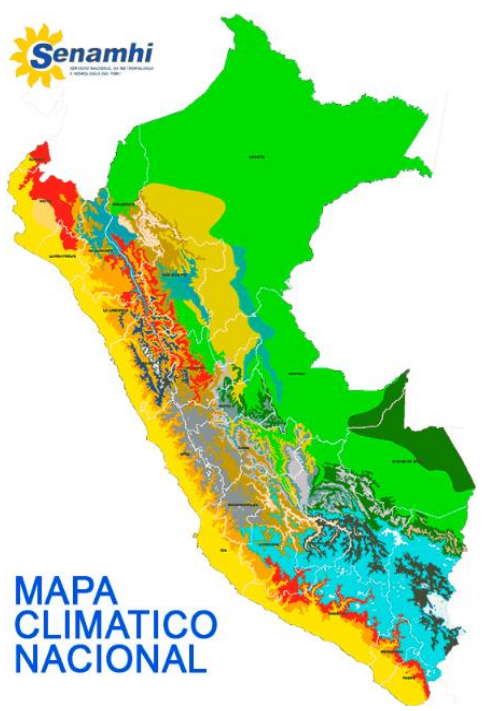

Figura 2.1. Mapa Climático del Perú. Fuente: SENAMHI, 2017 
Algunos de estos climas son:

- Clima lluvioso frio: Este clima se extiende entre los 3 mil y 4 mil msnm. Se caracteriza por sus precipitaciones anuales de $700 \mathrm{~mm}$ en promedio y una temperatura media anual de $12^{\circ} \mathrm{C}$.

- Clima Lluvioso SemiFrigido (de Tundra): Este clima se extiende de 3500 y 6000 msnm. Se caracteriza por presentar precipitaciones anuales de $700 \mathrm{~mm}$ y presenta una temperatura media anual de $7^{\circ} \mathrm{C}$.

- Clima Semiseco Frio: Es propio de la región de la Sierra, corresponde a los valles interandinos bajos e intermedios, ubicado entre 1000 y $3000 \mathrm{msnm}$. Las temperaturas sobre pasan los $20^{\circ} \mathrm{C}$ y las precipitaciones anuales promedio son $500 \mathrm{~mm}$, aunque en zonas más elevadas pueden llegar hasta los $1200 \mathrm{~mm}$.

\subsubsection{Temperatura}

Para determinar la temperatura promedio de la región Sierra se consultó las publicaciones semanales del Senamhi sobre las temperaturas máximas y mínimos en la Costa, Sierra y la Selva del Perú. A continuación, en la tabla 2.1.a. y 2.1.b. se observa que la región Sierra está dividida en 3 sectores; Sierra norte, Sierra central y Sierra sur, y cada una de ellas presenta una temperatura máxima de $33.6{ }^{\circ} \mathrm{C}, 30.3{ }^{\circ} \mathrm{C}$ y $32.8{ }^{\circ} \mathrm{C}$, y temperatura mínima de $-3.1^{\circ} \mathrm{C},-10.8^{\circ} \mathrm{C}$ y $-22.0^{\circ} \mathrm{C}$ respectivamente.

Tabla 2. 1.a. Temperatura promedia máxima para la región Sierra del 2017. Fuente: Senamhi, 2017

\begin{tabular}{|c|c|c|c|c|}
\hline \multicolumn{2}{|c|}{ FECHA } & $\begin{array}{c}\text { SIERRA NORTE } \\
\text { T máx. }\left({ }^{\circ} \mathbf{C}\right)\end{array}$ & $\begin{array}{c}\text { SIERRA CENTRO } \\
\text { T máx. }\left({ }^{\circ} \mathbf{C}\right)\end{array}$ & $\begin{array}{c}\text { SIERRA SUR } \\
\text { T máx. }\left({ }^{\circ} \mathbf{C}\right)\end{array}$ \\
\hline 24-abr & 30-abr & 30,6 & 20,2 & 18,2 \\
\hline 01-may & 07-may & 30,6 & 30,3 & 31,2 \\
\hline 08-may & 14-may & 31,2 & 30,1 & 31,4 \\
\hline 15-may & 21 -may & 29,6 & 30,2 & 30,2 \\
\hline 22-may & 28-may & 30,0 & 29,1 & 30,6 \\
\hline 19-jun & 25-jun & 17,5 & 17,0 & 14,2 \\
\hline 26-jun & 02-jul & 16,0 & 16,5 & 14,4 \\
\hline 03-jul & 09-jul & 30,0 & 27,8 & 30,0 \\
\hline 10-jul & 16-jul & 29,8 & 28,7 & 31,0 \\
\hline 17-jul & 23 -jul & 29,6 & 29,4 & 32,8 \\
\hline 24-jul & 30 -jul & 33,6 & 29,6 & 31,2 \\
\hline 31-jul & 06-ago & 16,5 & 16,5 & 14,2 \\
\hline 07-ago & 13-ago & 31,0 & 29,0 & 29,8 \\
\hline 14-ago & 20-ago & 31,6 & 29,9 & 30,4 \\
\hline 21-ago & 27-ago & 30,2 & 29,0 & 32,2 \\
\hline 28-ago & 03-sep & 30,7 & 29,5 & 31,6 \\
\hline
\end{tabular}




\begin{tabular}{|c|c|c|c|c|}
\hline \multicolumn{2}{|c|}{ FECHA } & $\begin{array}{l}\text { SIERRA NORTE } \\
\text { T mín. }\left({ }^{\circ} \mathrm{C}\right)\end{array}$ & $\begin{array}{c}\text { SIERRA CENTRO } \\
\text { T mín. }\left({ }^{\circ} \mathrm{C}\right)\end{array}$ & $\begin{array}{l}\text { SIERRA SUR } \\
\text { T mín. }\left({ }^{\circ} \mathrm{C}\right)\end{array}$ \\
\hline 24-abr & $30-a b r$ & 7,0 & 1,0 & $-12,5$ \\
\hline 01-may & 07-may & 3,2 & $-1,6$ & $-13,0$ \\
\hline 08-may & 14-may & 4,0 & $-4,2$ & $-16,4$ \\
\hline 15-may & 21-may & 3,7 & $-3,2$ & $-15,0$ \\
\hline 22-may & 28-may & 3,7 & $-0,3$ & $-8,6$ \\
\hline 19-jun & 25 -jun & 13,2 & 10,4 & 10,0 \\
\hline 26-jun & 02-jul & 15,4 & 11,6 & 8,8 \\
\hline 03-jul & 09-jul & 0,3 & $-4,2$ & $-21,0$ \\
\hline 10-jul & 16-jul & $-1,9$ & $-5,8$ & $-19,0$ \\
\hline 17-jul & 23-jul & $-2,1$ & $-10,8$ & $-18,8$ \\
\hline 24-jul & 30-jul & $-1,0$ & $-9,6$ & $-18,8$ \\
\hline 31-jul & 06-ago & 15,5 & 12,0 & 11,8 \\
\hline 07-ago & 13-ago & $-3,1$ & $-9,0$ & $-17,8$ \\
\hline 14-ago & 20 -ago & 1,7 & $-5,3$ & $-22,0$ \\
\hline 21-ago & 27 -ago & 1,8 & $-9,2$ & $-21,0$ \\
\hline 28-ago & 03-sep & 1,3 & $-3,0$ & $-14,0$ \\
\hline
\end{tabular}

El estudio de SENAMHI de la Provincia de Huarochirí está ubicado en la Sierra centro del Perú posee una humedad de $-2,4{ }^{\circ} \mathrm{C}$.

\subsubsection{Humedad}

El Ministerio del Ambiente y el Instituto Nacional de Estadística e Información (INEI) realizaron un estudio estadístico. A continuación, en la tabla 2.2 se detalla los porcentajes de humedad relativa promedio anual de los departamentos del Perú para el año 2015.

Tabla 2. 2. Humedad Relativa de la región Perú. Fuente: MINAMI, 2015

\begin{tabular}{|c|c|c|c|c|}
\hline $\begin{array}{c}\text { HUMEDA } \\
\text { RELATIVA (\%) }\end{array}$ & \multicolumn{4}{|c|}{ REGIONES } \\
\hline $92-93$ & - & - & - & - \\
\hline $80-88$ & La Libertad & Apurimac & Huancavelica & Pasco \\
\hline $73-79$ & Ayacucho & - & - & - \\
\hline $63-69$ & Cajamarca & Huánuco & Cusco & Puno \\
\hline $48-59$ & Junín & - & - & - \\
\hline
\end{tabular}

\subsubsection{Estudio de Precipitaciones}

Existen medianas e intensas precipitaciones en cada departamento del país, esto se puede evidenciar en la tabla 2.3 el cual contiene los datos expuestos semanalmente por Senamhi (solo se mostrarán las localidades en la sierra con mayor acumulado semanal de lluvias). 
Tabla 2. 3. Precipitación semanal de los distintos departamentos del Perú. Fuente: Senamhi, 2016-2017

$12 / 09 / 16-18 / 09 / 16$

\begin{tabular}{|c|c|c|}
\hline LOCALIDAD & DEPARTAMENTO & $\begin{array}{c}\text { mm DE } \\
\text { LLUVIAS }\end{array}$ \\
\hline Santiago de Paucaray & Ayacucho & 34.7 \\
\hline El Carmen de la Frontera & Piura & 33.6 \\
\hline Cutervo & Cajamarca & 32.0 \\
\hline Chugur & Cajamarca & 25.1 \\
\hline Namora & Cajamarca & 23.8 \\
\hline Encañada & Cajamarca & 23.3 \\
\hline Frias & Piura & 22.5 \\
\hline Celendin & Cajamarca & 19.8 \\
\hline Huarmaca & Piura & 19.4 \\
\hline Cajamarca & Cajamarca & 19.2 \\
\hline
\end{tabular}

\begin{tabular}{|c|c|c|}
\hline \multicolumn{2}{|c|}{$\mathbf{2 6 / 0 9 / 1 6 - 2 / 1 0 / 1 6}$} \\
\hline LOCALIDAD & DEPARTAMENTO & $\begin{array}{c}\text { mm DE } \\
\text { LLUVIAS }\end{array}$ \\
\hline Pomabamba & Ancash & 45.1 \\
\hline Colcamabma & Huancavelica & 43.9 \\
\hline Jauja & Junin & 35.8 \\
\hline Chavin de Huantar & Cusco & 35.7 \\
\hline Machu Picchu & Ancash & 35.6 \\
\hline Curahuasi & Apurimac & 35.1 \\
\hline Celendin & Cajamarca & 34.3 \\
\hline Cashapampa & Ancash & 34.2 \\
\hline Quiruvilca & La Libertad & 33.7 \\
\hline Recuay & Ancash & 33.5 \\
\hline
\end{tabular}

\begin{tabular}{|c|c|c|}
\hline \multicolumn{3}{|c|}{$\mathbf{1 0 / 1 0 / 1 6 - 1 6 / 1 0 / 1 6}$} \\
\hline \multirow{2}{*}{ LOCALIDAD } & DEPARTAMENTO & $\begin{array}{c}\text { mm DE } \\
\text { LLUVIAS }\end{array}$ \\
\hline Chungur & Cajamarca & 45.1 \\
\hline Cajamarca & Cajamarca & 43.9 \\
\hline Celendin & Cajamarca & 35.8 \\
\hline Pomabamba & Ancash & 35.7 \\
\hline Santa Rosa & Puno & 35.6 \\
\hline Cachicadan & La Libertad & 35.1 \\
\hline Chaupimarca & Pasco & 34.3 \\
\hline Huanchac & Junin & 34.2 \\
\hline Paucarbamba & Huancavelica & 33.7 \\
\hline Llalli & Puno & 33.5 \\
\hline
\end{tabular}

\section{\begin{tabular}{|l|l|}
\hline \multicolumn{2}{|c|}{$24 / 10 / 16-30 / 10 / 16$} \\
\hline
\end{tabular}}

\begin{tabular}{|c|c|c|}
\hline LOCALIDAD & DEPARTAMENTO & $\begin{array}{c}\text { Mm DE } \\
\text { LLUVIAS }\end{array}$ \\
\hline Cusco & Cusco & 54.6 \\
\hline Mañazo & Puno & 48.2 \\
\hline Los Uros & Puno & 35.3 \\
\hline Huaraya Moho & Puno & 34.8 \\
\hline Runatullo & Junin & 32.3 \\
\hline Capachica & Puno & 31.7 \\
\hline Jacas Chico & Huanuco & 31.0 \\
\hline Cabanilla & Puno & 30.8 \\
\hline Ollachea & Puno & 29.4 \\
\hline Puno & Puno & 29.1 \\
\hline
\end{tabular}

14/11/16- 20/11/16

\begin{tabular}{|c|c|c|}
\hline LOCALIDAD & DEPARTAMENTO & $\begin{array}{c}\text { mm DE } \\
\text { LLUVIAS }\end{array}$ \\
\hline Zurite & Cusco & 41.7 \\
\hline Urubamba & Cusco & 26.2 \\
\hline Tambobamba & Apurimac & 22.9 \\
\hline Curpahuasi & Apurimac & 21.6 \\
\hline Sicuani & Cusco & 19.8 \\
\hline Llusco & Cusco & 17.4 \\
\hline Paruro & Cusco & 15.6 \\
\hline Tamburco & Apurimac & 15.2 \\
\hline El Tambo & Junin & 15.0 \\
\hline Pachas & Huanuco & 14.9 \\
\hline
\end{tabular}

$19 / 09 / 16-25 / 09 / 16$

\begin{tabular}{|c|c|c|}
\hline LOCALIDAD & DEPARTAMENTO & $\begin{array}{c}\text { mm DE } \\
\text { LLUVIAS }\end{array}$ \\
\hline Quiruvilca & La Libertad & 70.2 \\
\hline El Carmen de la Frontera & Puno & 48.5 \\
\hline Cutervo & Junin & 44.1 \\
\hline Chugur & La Libertad & 43.7 \\
\hline Namora & La Libertad & 36.1 \\
\hline Encañada & Lima & 33.2 \\
\hline Frias & Lima & 33.1 \\
\hline Celendin & Lima & 32.4 \\
\hline Huarmaca & Junin & 31.3 \\
\hline Cajamarca & Pasco & 31.1 \\
\hline \multicolumn{2}{|c|}{$\mathbf{3 / 1 0 / 1 6 - 9 / 1 0 / 1 6}$} \\
\hline
\end{tabular}

\begin{tabular}{|c|c|c|}
\hline \multirow{3}{|c|}{ 3/10/16-9/10/16 } \\
\hline LOCALIDAD & DEPARTAMENTO & $\begin{array}{c}\text { mm DE } \\
\text { LLUVIAS }\end{array}$ \\
\hline Salpo & La Libertad & 38.3 \\
\hline Comas & Junin & 32.4 \\
\hline Richan & Junin & 28.6 \\
\hline Machu Picchu & Cusco & 28.6 \\
\hline Quinua & Ayacucho & 27.2 \\
\hline Ollanchea & Puno & 27.1 \\
\hline Yanacocha & Junin & 26.7 \\
\hline Celendin & Cajamarca & 25.7 \\
\hline Huanza & Lima & 24.9 \\
\hline Chumpimarca & Pasco & 21.3 \\
\hline \multicolumn{2}{|c|}{}
\end{tabular}

\begin{tabular}{|c|c|c|}
\hline \multirow{2}{*}{ LOCALIDAD } & DEPARTAMENTO & $\begin{array}{c}\text { mm DE } \\
\text { LLUVIAS }\end{array}$ \\
\hline Chungur & Cajamarca & 59.1 \\
\hline Cusco & Cusco & 54.6 \\
\hline Cajamarca & Cajamarca & 54.5 \\
\hline Tambobamba & Apurimac & 41.6 \\
\hline Mañani & Puno & 40.0 \\
\hline Machu Picchu & Cusco & 34.5 \\
\hline Zurite & Cusco & 33.1 \\
\hline Pachas & Huanuco & 31.1 \\
\hline Cashapampa & Ancash & 30.0 \\
\hline Santa Rosa de Ocopa & Junin & 29.7 \\
\hline
\end{tabular}

7/11/16- 13/11/16

\begin{tabular}{|c|c|c|}
\hline \multirow{2}{*}{ LOCALIDAD } & DEPARTAMENTO & $\begin{array}{c}\text { mm DE } \\
\text { LLUVIAS }\end{array}$ \\
\hline Huancane & Puno & 40.1 \\
\hline Tambobamba & Apurimac & 35.5 \\
\hline Azangaro & Puno & 33.4 \\
\hline Sicuani & Cusco & 31.8 \\
\hline Cajamarca & Cajamarca & 31.2 \\
\hline Curahuasi & Apurimac & 24.7 \\
\hline Machu Picchu & Cusco & 21.1 \\
\hline Jacas Chico & Huanuco & 21.0 \\
\hline Tamburco & Apurimac & 19.8 \\
\hline Taraco & Puno & 19.8 \\
\hline
\end{tabular}

\begin{tabular}{|c|c|c|}
\hline \multicolumn{3}{|c|}{$\mathbf{2 1 / 1 1 / 1 6 - ~ 2 7 / 1 1 / 1 6}$} \\
\hline \multirow{2}{*}{ LOCALIDAD } & DEPARTAMENTO & $\begin{array}{c}\text { mm DE } \\
\text { LLUVIAS }\end{array}$ \\
\hline Jacas Chico & Huanuco & 37.0 \\
\hline Pachas & Huanuco & 25.2 \\
\hline Puno & Puno & 24.6 \\
\hline Acobamba & Huancavelica & 23.8 \\
\hline Viques & Junin & 21.8 \\
\hline Huancayo & Junin & 21.5 \\
\hline Pilchaca & Huancavelica & 20.7 \\
\hline Andahuaylas & Apurimac & 19.9 \\
\hline Yanahuanca & Pasco & 19.2 \\
\hline Junin & Junin & 19.2 \\
\hline
\end{tabular}


28/11/16- $4 / 12 / 16$

\begin{tabular}{|c|c|c|}
\hline LOCALIDAD & DEPARTAMENTO & $\begin{array}{c}\text { mm DE } \\
\text { LLUVIAS }\end{array}$ \\
\hline Jacas Chico & Huanuco & 76.3 \\
\hline Cutervo & Cajamarca & 74.1 \\
\hline Runatullo & Junin & 72.1 \\
\hline Pomabamba & Ancash & 62.9 \\
\hline Jauja & Junin & 59.9 \\
\hline Isla Taquile & Puno & 56.1 \\
\hline Cusco & Cusco & 55.0 \\
\hline Chaglla & Huanuco & 54.6 \\
\hline Huambros & Cajamarca & 54.5 \\
\hline Huancane & Puno & 53.3 \\
\hline
\end{tabular}

\begin{tabular}{|c|c|c|}
\hline \multirow{2}{*}{ 5/12/16- 11/12/16 } \\
\hline Acostambo & HePARTAMENTO & $\begin{array}{c}\text { mm DE } \\
\text { LLUVIAS }\end{array}$ \\
\hline Chaglla & Huanuco & 84.2 \\
\hline Cajabamba & Cajamarca & 68.2 \\
\hline San Rafael & Huanuco & 57.2 \\
\hline Comas & Junin & 54.0 \\
\hline Machu Picchu & Cusco & 53.9 \\
\hline Namora & Cajamarca & 52.1 \\
\hline Cajamarca & Cajamarca & 48.7 \\
\hline Salcabamba & Huancavelica & 47.6 \\
\hline Ricran & Junin & 47.0 \\
\hline
\end{tabular}

\begin{tabular}{|c|c|c|}
\hline LOCALIDAD & DEPARTAMENTO & $\begin{array}{c}\text { Mm DE } \\
\text { LLUVIAS }\end{array}$ \\
\hline Challabamba & Cusco & 35.2 \\
\hline Dos de Mayo & Huanuco & 30.6 \\
\hline Cerro de Pasco & Pasco & 29.9 \\
\hline Runatullo & Junin & 27.7 \\
\hline Pizacoma & Puno & 27.6 \\
\hline Junin & Junin & 26.8 \\
\hline Jacas Chico & Huanuco & 26.2 \\
\hline Azangaro & Puno & 24.9 \\
\hline Los Uros & Puno & 22.9 \\
\hline Chaglla & Huanuco & 22.6 \\
\hline
\end{tabular}

\begin{tabular}{|c|c|c|}
\hline LOCALIDAD & DEPARTAMENTO & mm DE \\
LLUVIAS
\end{tabular}

\begin{tabular}{|c|c|c|}
\hline LOCALIDAD & DEPARTAMENTO & $\begin{array}{c}\text { mm DE } \\
\text { LLUVIAS } \\
\end{array}$ \\
\hline Ayabaca & Piura & 101.1 \\
\hline Pomabamba & Ancash & 87.9 \\
\hline Runatullo & Junin & 83.4 \\
\hline Santiago de Chuco & La Libertad & 75.5 \\
\hline Machu Picchu & Cusco & 60.1 \\
\hline Cutervo Sihuas & Cajamarca & 75.2 \\
\hline Santiago de Chuco & Ancash & 72.5 \\
\hline Yanahuanca & La Libertad & 70.9 \\
\hline La Encañada & Pasco & 67.0 \\
\hline Chaglla & Cajamarca & 64.2 \\
\hline
\end{tabular}

Se puede apreciar que en el mes de setiembre, octubre, noviembre y diciembre las precipitaciones máximas fueron La Libertad (Quiruvilca) con $70.2 \mathrm{~mm}$, Cajamarca (Chugur) con $89.9 \mathrm{~mm}$, Cusco (Zurite) con $41.7 \mathrm{~mm}$ y Piura (Ayabaca) con $101.1 \mathrm{~mm}$ respectivamente.

\subsubsection{Tipos de vivienda según el material predominante}

El tipo de material que normalmente se usa para la construcción de viviendas en el Perú, depende principalmente de las posibilidades económicas de la población, así como de los recursos disponibles en la región. Entre estos tipos de materiales se tiene a los ladrillos, adobes, tapial, madera, quincha, estera, entre otras.

A continuación, en la figura 2.2 se muestran las tres regiones del Perú (Costa, Sierra, Selva) y en la figura 2.3 se muestran los 24 departamentos del Perú con la finalidad de identificar cada una de ellos en su respectiva región natural. 


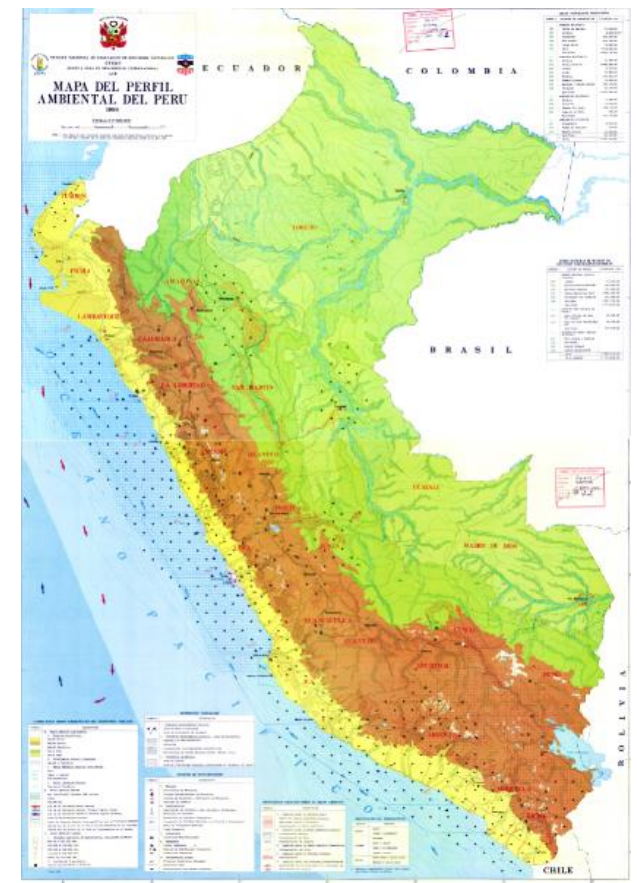

Figura 2. 2. Mapa de las 3 regiones naturales del Perú. Fuente: Sinia, 2006

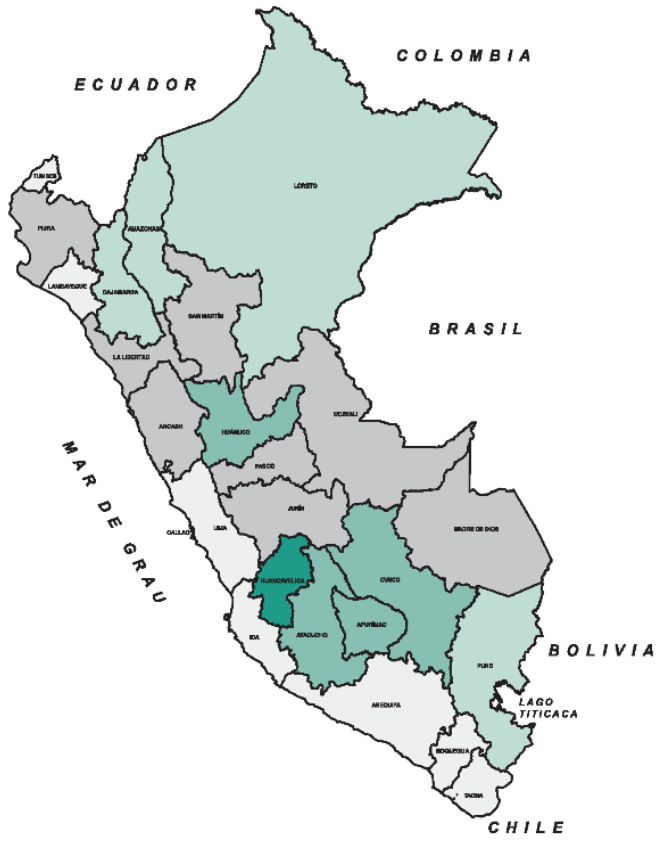

Figura 2. 3. Mapa de los 24 departamentos del Perú. Fuente: Sinia, 2006

Asimismo, esta investigación se centrará en la región natural Sierra debido a que en esta región existe una gran cantidad de la población que aun utiliza el adobe como material esencial en la construcción de sus casas. Esto se puede evidenciar en la tabla 2.4 la cual contiene los datos expuestos por el INEI (2007), donde el material más utilizado después del ladrillo o bloque de cemento es el adobe o tapial en más de $98 \%$.

Tabla 2. 4. Cantidad de viviendas particulares según tipo de material predominante en la región natural Sierra en el Perú.

Fuente: INEI, 2007

\begin{tabular}{|c|c|c|c|c|c|c|c|c|c|}
\hline REGIONES & TOTAL & $\begin{array}{c}\text { LADRILLO } \\
\text { O BLOQUE } \\
\text { DE } \\
\text { CEMENTO }\end{array}$ & $\begin{array}{c}\text { ADOBE } \\
\text { O TAPIA }\end{array}$ & $\begin{array}{c}\text { MADERA } \\
\text { (PONA, } \\
\text { TORNILLO, } \\
\text { ETC.) }\end{array}$ & $\begin{array}{c}\text { QUINCHA } \\
\text { (CAÑA } \\
\text { CON } \\
\text { BARRO) }\end{array}$ & ESTERA & $\begin{array}{c}\text { PIEDRA } \\
\text { CON } \\
\text { BARRO }\end{array}$ & $\begin{array}{c}\text { PIEDRA O } \\
\text { SILLAR } \\
\text { CON CAL } \\
\text { O } \\
\text { CEMENTO }\end{array}$ & $\begin{array}{c}\text { OTRO } \\
\text { MATERIAL }\end{array}$ \\
\hline Apurimac & $104,787.00$ & $8,636.00$ & $91,707.00$ & 385.00 & 326.00 & 159.00 & $3,085.00$ & 59.00 & 430.00 \\
\hline Arequipa & $286,291.00$ & $200,397.00$ & $22,497.00$ & $2,885.00$ & $7,057.00$ & $12,843.00$ & $10,280.00$ & $25,609.00$ & $4,723.00$ \\
\hline Ancash & $248,398.00$ & $81,643.00$ & $142,584.00$ & $3,150.00$ & $2,613.00$ & $15,150.00$ & $1,587.00$ & 201.00 & $1,470.00$ \\
\hline Ayacucho & $158,261.00$ & $24,675.00$ & $108,648.00$ & $8,216.00$ & $1,406.00$ & $1,579.00$ & $11,697.00$ & 399.00 & $1,641.00$ \\
\hline Cajamarca & $325,399.00$ & $46,810.00$ & $249,578.00$ & $5,114.00$ & $12,278.00$ & 438.00 & $10,247.00$ & 157.00 & 777.00 \\
\hline Cusco & $293,584.00$ & $38,161.00$ & $223,575.00$ & $14,024.00$ & 986.00 & 517.00 & $12,818.00$ & $1,247.00$ & $2,256.00$ \\
\hline Huancavelica & $111,275.00$ & $5,845.00$ & $96,258.00$ & 346.00 & 311.00 & 208.00 & $7,631.00$ & 163.00 & 513.00 \\
\hline Huánuco & $175,534.00$ & $35,917.00$ & $107,753.00$ & $25,638.00$ & $1,556.00$ & 356.00 & $2,561.00$ & 130.00 & $1,623.00$ \\
\hline Junín & $287,035.00$ & $103,721.00$ & $125,529.00$ & $40,631.00$ & $9,163.00$ & 442.00 & $2,179.00$ & 311.00 & $5,059.00$ \\
\hline La libertad & $364,226.00$ & $127,913.00$ & $224,802.00$ & $1,439.00$ & $1,879.00$ & $4,452.00$ & $2,128.00$ & 389.00 & $1,224.00$ \\
\hline Lima & $1,921,949.00$ & $1,505,535.00$ & $171,766.00$ & $153,375.00$ & $14,671.00$ & $41,765.00$ & $3,393.00$ & $2,751.00$ & $28,693.00$ \\
\hline Pasco & $64,782.00$ & $18,310.00$ & $28,923.00$ & $13,772.00$ & 773.00 & 136.00 & $1,250.00$ & 186.00 & $1,432.00$ \\
\hline Puno & $353,838.00$ & $79,390.00$ & $229,548.00$ & $4,076.00$ & 343.00 & 549.00 & $32,641.00$ & 408.00 & $6,883.00$ \\
\hline
\end{tabular}


En la gráfica 2.1, se realizó un comparativo entre la cantidad de viviendas totales de cada departamento con respecto a las viviendas hechas con adobe y tapial y se obtuvo que del total de las viviendas particulares en cada región, alrededor de 50\% de estás están hechas de adobe o tapial.

Gráfica 2. 1 Cantidad de viviendas particulares en la región natural de Sierra del Perú. Fuente: INEI, 2007

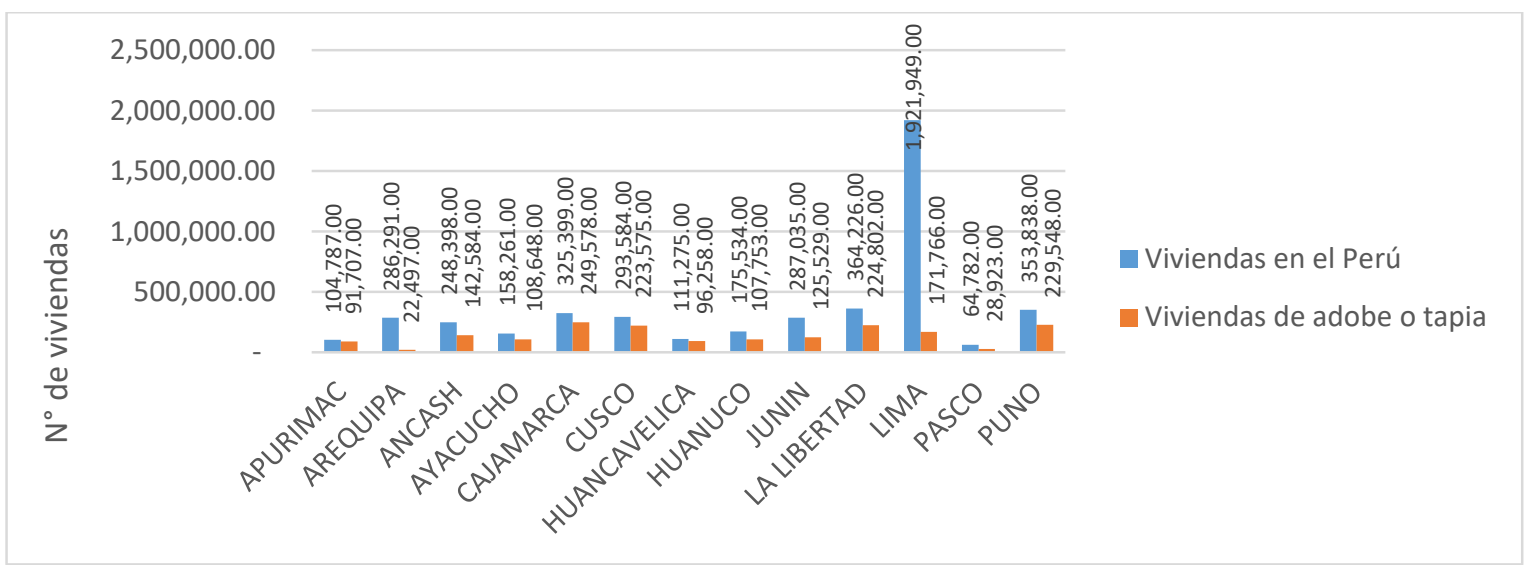

\subsubsection{Muestra}

La investigación tomará como distrito de muestra el distrito de Huarochirí de la provincia de Huarochirí en la región Lima, debido a tres factores fundamentales.

- El primero, porque presenta intensas precipitaciones en varios meses, según los datos Senamhi como se muestra en la gráfica 2.2.

Gráfica 2. 2. Precipitación en el distrito de Huarochirí en los años de 2015 a 2017. Fuente: Propia

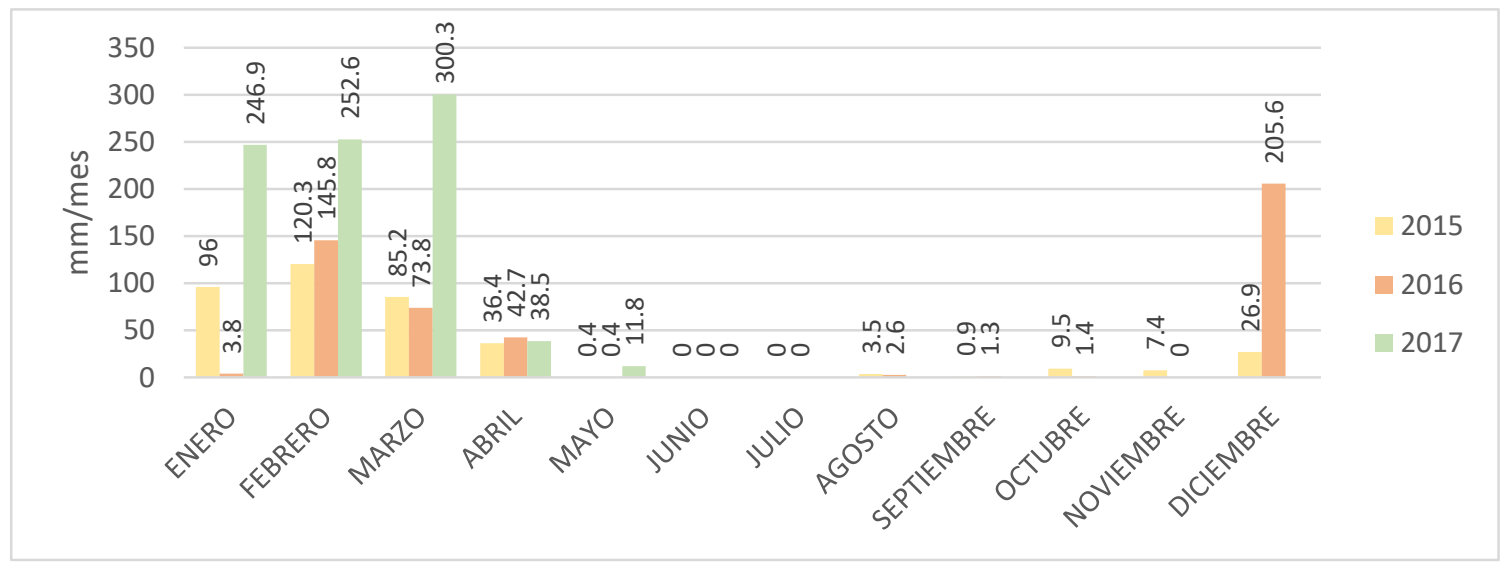

En la gráfica 2.3, se muestra las precipitaciones promedias en los meses de diciembre, enero, febrero, marzo y abril de los años de 2015, 2016 y 2017, que son $116.3 \mathrm{~mm}, 115.6 \mathrm{~mm}, 172.9 \mathrm{~mm}, 153.1 \mathrm{~mm}$ y $39.2 \mathrm{~mm}$ respectivamente, el cual evidencian, la existencia de intensas precipitaciones en la zona. 
Gráfica 2. 3. Precipitación promedio de los años 2015 a 2017 en el distrito de Huarochirí. Fuente: Propia

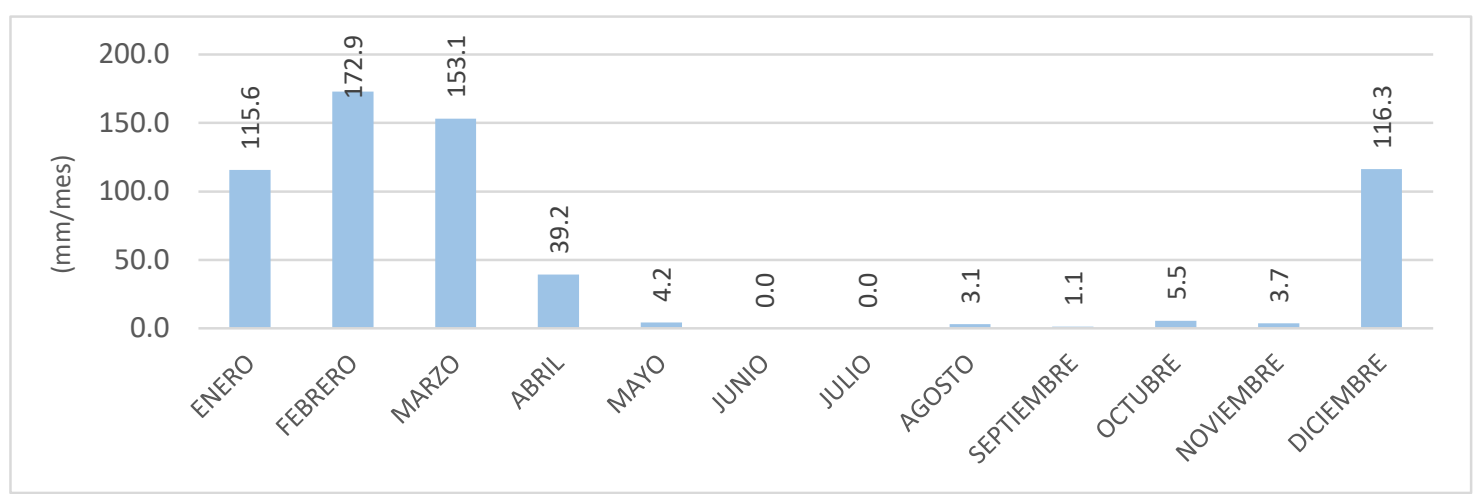

- El segundo, por la cantidad de viviendas de adobe que existen en el distrito según los datos de INEI- Censo 2007, en la tabla 2.5 se observa que el $92.06 \%$ de viviendas en el distrito de Huarochirí son hechas de adobe o tapial y solo el $2.11 \%$ son de ladrillo o bloque de cemento. Es por tal motivo, y respaldado por cifras, que es necesario realizar esta investigación con la finalidad de que nuestra propuesta de nuevos ladrillos de adobe impermeabilizado con mucílago de penca de tuna para la elaboración de muros portantes, puedan dar soluciones viables y económicas contra este fenómeno natural; además, pueda mejorar la resistencia del material frente al contacto con el agua e incrementar su resistencia mecánica.

- Tabla 2. 5. Viviendas particulares con ocupantes presentes, por material de predominante en las paredes exteriores de la vivienda en el distrito de Huarochirí, Fuente: INEI, 2007

\begin{tabular}{|c|c|c|c|c|c|c|c|c|}
\hline $\begin{array}{c}\text { TIPO DE VIVIENDA Y } \\
\text { TOTAL DE } \\
\text { OCUPANTES } \\
\text { PRESENTES }\end{array}$ & $\begin{array}{c}\text { LADRILLO } \\
\text { O BLOQUE } \\
\text { DE } \\
\text { CEMENTO }\end{array}$ & $\begin{array}{c}\text { ADOBE } \\
\text { O } \\
\text { TAPIAL }\end{array}$ & $\begin{array}{l}\text { MADERA } \\
\text { (PONA, } \\
\text { TORNILLO, } \\
\text { ETC.) }\end{array}$ & $\begin{array}{l}\text { QUINCHA } \\
\text { (CAÑA } \\
\text { CON } \\
\text { BARRO) }\end{array}$ & ESTERA & $\begin{array}{c}\text { PIEDRA } \\
\text { CON } \\
\text { BARRO }\end{array}$ & $\begin{array}{c}\text { PIEDRA O } \\
\text { SILLAR } \\
\text { CON CAL } \\
\text { Y } \\
\text { CEMENTO }\end{array}$ & $\begin{array}{c}\text { OTRO } \\
\text { MATERIAL }\end{array}$ \\
\hline Viviendas particulares (001) & 12 & 511 & & & & 28 & & 3 \\
\hline Ocupantes presentes (002) & 33 & 1449 & & & & 80 & & 13 \\
\hline \multicolumn{9}{|l|}{ Casa independiente } \\
\hline Viviendas particulares (004) & 10 & 496 & & & & 8 & & 3 \\
\hline Ocupantes presentes (005) & 31 & 1422 & & & & 17 & & 13 \\
\hline \multicolumn{9}{|l|}{ Departamento en edificio } \\
\hline \multicolumn{9}{|l|}{ Vivienda en quinta } \\
\hline Viviendas particulares $(010)$ & 1 & 2 & & & & & & \\
\hline Ocupantes presentes $(011)$ & 1 & 7 & & & & & & \\
\hline \multicolumn{9}{|l|}{$\begin{array}{l}\text { Vivienda en la casa de una } \\
\text { vecindad }\end{array}$} \\
\hline Viviendas particulares (013) & & 10 & & & & & & \\
\hline Ocupantes presentes (014) & & 17 & & & & & & \\
\hline \multicolumn{9}{|l|}{ Choza o cabaña } \\
\hline Viviendas particulares (016) & & 2 & & & & 20 & & \\
\hline Ocupantes presentes $(017)$ & & 2 & & & & 63 & & \\
\hline \multicolumn{9}{|l|}{ Vivienda improvisada } \\
\hline \multicolumn{9}{|l|}{$\begin{array}{l}\text { Local no dest. para hab. } \\
\text { humanas }\end{array}$} \\
\hline Viviendas particulares (022) & 1 & 1 & & & & & & \\
\hline Ocupantes presentes $(023)$ & 1 & 1 & & & & & & \\
\hline \multicolumn{9}{|l|}{ Otro tipo } \\
\hline TOTAL & 90 & 3920 & 0 & 0 & 0 & 216 & 0 & 32 \\
\hline PORCENTAJE (\%) & 2.11 & 92.06 & 0.00 & 0.00 & 0.00 & 5.07 & 0.00 & 0.75 \\
\hline
\end{tabular}


- El tercero, es debido que esta provincia se encuentra ubicada a una altitud de 2380 msnm, altitud que se encuentra entre los intervalos de 800 a 2800 msnm recomendadas por Gerencia Regional Agraria en su publicación Cultivo de Tuna (2009) para encontrar pencas de tuna. Asimismo, los adobes estabilizados que serán empleados en la elaboración de viviendas populares en Huarochirí pueden ser utilizados en otras provincias con altitudes que estén dentro de los límites recomendados y que tengan una altitud similar a la muestra estudiada como lo indica los registros del Compendio Estadístico Perú (2014), entre éstas tenemos a Sihuas con 2784 msnm (Ancash), Chincheros con 2795 msnm (Apurímac), Arequipa con 2337 msnm (Arequipa), La Unión con 2675 msnm (Arequipa), Huamanga con 2760 msnm (Ayacucho), Huanta con 2642 msnm ( Ayacucho), Chota con 2388 msnm (Cajamarca), San Pablo 2365 msnm (Cajamarca), Huaytará con 2712 msnm (Huancavelica), Huánuco con 1898 msnm (Huánuco), Ambo con 2076 msnm (Huánuco), Sandia con 2249 msnm (Puno), entre otras.

\subsection{Método}

La finalidad de desarrollar el método es precisar, a través de un lenguaje claro y sencillo, el nivel y diseño de investigación, variables, técnicas e instrumentos, etc. Para de esta manera alcanzar los objetivos planteados anteriormente. Este método será sustentado por normas, criterios de investigadores, entre otros.

\subsubsection{Nivel de investigación}

El primer objetivo específico “Analizar los materiales más adecuados para la elaboración de la mezcla a través de ensayos preliminares (prueba de color, prueba olfativa y prueba de brillo) y ensayos físicos (ensayo de cinta de barro, resistencia seca, granulometría, peso específico y límites de Atterberg) para el suelo, y ensayos de densidad y viscosidad para el mucílago de penca de tuna”, una vez obtenido sus resultados se verifican si cumplen las normas American Society of Testing Materials (ASTM), La Norma Técnica Peruana (NTP), la Norma E.080 Diseño y Construcción con Tierra Reforzada (2017), ICG (2010) para la elaboración de adobe.

El segundo objetivo específico "Seleccionar la dosificación ideal de la mezcla para obtener los mejores resultados de resistencia a la compresión, flexión y absorción en la unidad de adobe estabilizado", reúne las características de un estudio explorativo, debido 
a que se elaboran adobes con $8.5 \mathrm{~kg} / \mathrm{L} \%, 11.3 \mathrm{~kg} / \mathrm{L} \%, 13 \mathrm{~kg} / \mathrm{L} \%, 18 \mathrm{~kg} / \mathrm{L} \%$ y $20.5 \mathrm{~kg} / \mathrm{L} \%$ de mucílago de penca de tuna (esta solución está en relación a la cantidad de trozos de penca de tuna remojados en litros de agua) con el fin de obtener las dos dosificaciones óptimas a través de ensayos de compresión y flexión (mecánicos) y ensayos de permeabilidad (físicos). Una vez obtenida las dos dosificaciones se elaborarán las pilas de adobe estabilizadas las cuales serán ensayadas a compresión. Además, se redactará un manual de elaboración del adobe para evitar errores en la fabricación.

El tercer objetivo "Comparar los resultados de resistencia mecánica (compresión y flexión) y resistencia física (absorción) de las unidades y pilas de adobes convencionales de los adobes estabilizados" reúne las características de un estudio explorativo, ya que se realizarán ensayos de compresión, tracción y permeabilidad en los unidades de adobes.

\subsubsection{Diseño de Investigación}

Se considera que el diseño de la investigación es "experimental”, debido a que sometemos a un elemento a varios estímulos para posteriormente observar y evaluar los efectos que se producen en él. Para esta investigación se ha decidido determinar las variables dependientes e independientes para cada objetivo específico mencionado en la tabla 2.6.

Tabla 2. 6. Variables Independientes y Dependientes para cada objetivo específico. Fuente: Propia

\begin{tabular}{|c|c|c|c|}
\hline \multicolumn{2}{|r|}{ OBJETIVOS } & $\begin{array}{c}\text { VARIABLES } \\
\text { DEPENDIENTES }\end{array}$ & $\begin{array}{c}\text { VARIABLES } \\
\text { INDEPENDIENTES }\end{array}$ \\
\hline & $\begin{array}{l}\text { Analizar los materiales más adecuados para la } \\
\text { elaboración de la mezcla a través de ensayos } \\
\text { preliminares (prueba de color, prueba olfativa y prueba } \\
\text { de brillo) y ensayos físicos (ensayo de cinta de barro, } \\
\text { resistencia seca, granulometría, peso específico y } \\
\text { límites de Atterberg) para el suelo, y ensayos de } \\
\text { densidad y viscosidad para el mucílago de penca de } \\
\text { tuna. }\end{array}$ & Material Adecuado & Método \\
\hline & $\begin{array}{l}\text { Seleccionar la dosificación ideal de la mezcla para } \\
\text { obtener los mejores resultados de resistencia a la } \\
\text { compresión, flexión y absorción en la unidad de adobe } \\
\text { estabilizado. }\end{array}$ & $\begin{array}{l}\text { Los resultados de } \\
\text { resistencia mecánica } \\
\text { y física }\end{array}$ & $\begin{array}{l}\text { Dosificación ideal de } \\
\text { mucílago de penca de } \\
\text { tuna en la mezcla }\end{array}$ \\
\hline 3) & $\begin{array}{l}\text { Comparar los resultados de resistencia mecánica } \\
\text { (compresión y flexión) y resistencia física (absorción) } \\
\text { de las unidades y pilas de adobes convencionales de los } \\
\text { adobes estabilizados. }\end{array}$ & $\begin{array}{l}\text { Comparación del } \\
\text { adobe convencional } \\
\text { con adobe } \\
\text { estabilizado }\end{array}$ & $\begin{array}{l}\text { Ensayos físicos y } \\
\text { mecánicos }\end{array}$ \\
\hline
\end{tabular}

- En el primer objetivo específico se tiene una variable dependiente: Material Adecuado, el cual involucra a la "tierra" y "viscosidad del mucílago de la penca de tuna". Asimismo, el primero dependerá de la cantidad de arcilla en el adobe, puesto que si la cantidad sobrepasa el porcentaje recomendado (15\% a $25 \%)$ producirá que 
los adobes al momento de ser secados se rajen y/o fisuren; este será calculado a través de ensayos en campo (presencia de arcillas) y ensayos de laboratorio (Granulometría), y el segundo material dependerá de la cantidad de trozos de penca de tuna que se remojen en el agua y del tiempo de remojo de este, pues a mayor cantidad de trozos y tiempo de remojo la sustancia tendrá mayor viscosidad; para medir su consistencia se realizó ensayos de viscosidad.

- En el segundo objetivo específico se consideró solo una variable dependiente: los resultados de resistencia mecánica y física, el cual dependerá de la dosificación ideal de la viscosidad de penca de tuna, puesto que la cantidad del resto de los materiales serán agregadas según lo acostumbrado en el lugar de muestra.

- En el tercer objetivo específico, la variable dependiente es la Comparación de adobe convencional con adobe estabilizado, con la finalidad de mostrar los distintos valores obtenidos de los diferentes ensayos físicos y mecánicos mencionados con anterioridad como es la absorción (determinará qué cantidad de agua ingresa en los espacios vacíos del adobe por capilaridad), inmersión (simula cómo reacciona el adobe ante una posible inundación), compresión y flexión ( se observa su comportamiento ante una fuerza externa)

\subsubsection{Variables de estudio y operacionalización}

Una vez identificadas las variables dependientes e independientes para cada objetivo específico se procederán a describir como es medida cada variable, la cual incluye elecciones de los procedimientos e instrumentos necesarios.

En la tabla 2.7, 2.8 y 2.9 se detallan las variables de estudio y operacionalización del primer, segundo y tercer objetivo específico respectivamente.

Tabla 2. 7. Variables de estudio y operacionalización del Primer Objetivo Específico. Fuente: Propia

\begin{tabular}{|l|c|c|c|c|}
\hline \multicolumn{1}{|c|}{ VARIABLE } & DIMENSIONES & INDICADORES & $\begin{array}{c}\text { UNIDAD DE } \\
\text { MEDIDA }\end{array}$ & $\begin{array}{c}\text { INSTRUMENTO DE } \\
\text { INVESTIGACION }\end{array}$ \\
\hline $\begin{array}{l}\text { Independiente(VI): } \\
\text { X: Método }\end{array}$ & Satisfacción & Grado de satisfacción & Grado & Observación \\
\hline & Suelo arcilloso & Porcentaje de arcilla & Porcentaje & Ensayos \\
\cline { 2 - 5 } & $\begin{array}{c}\text { Viscosidad de } \\
\text { Ducílago de } \\
\text { Y: Material adecuado }\end{array}$ & $\begin{array}{c}\text { Unidades de trozos de } \\
\text { penca }\end{array}$ & Unidad & Observable \\
\cline { 3 - 5 } & penca de tuna & Tiempo de remojo & Días & Observable \\
\hline
\end{tabular}


Tabla 2. 8. Variables de estudio y operacionalización del Segundo Objetivo Específico. Fuente: Propia

\begin{tabular}{|c|c|c|c|c|}
\hline VARIABLE & DIMENSIONES & INDICADORES & $\begin{array}{l}\text { UNIDAD DE } \\
\text { MEDIDA }\end{array}$ & $\begin{array}{l}\text { INSTRUMENTO DE } \\
\text { INVESTIGACIÓN }\end{array}$ \\
\hline \multirow{5}{*}{$\begin{array}{l}\text { Independiente(VI): } \\
\text { X: Dosificación ideal de } \\
\text { mucílago de penca de tuna } \\
\text { en la mezcla }\end{array}$} & $\begin{array}{c}\text { Dosificación de } \\
20.5 \%\end{array}$ & Proporción & $\mathrm{Kg} / \mathrm{L}$ & Observable \\
\hline & $\begin{array}{c}\text { Dosificación de } \\
18.0 \%\end{array}$ & Proporción & $\mathrm{Kg} / \mathrm{L}$ & Observable \\
\hline & $\begin{array}{c}\text { Dosificación de } \\
13.0 \%\end{array}$ & Proporción & $\mathrm{Kg} / \mathrm{L}$ & Observable \\
\hline & $\begin{array}{c}\text { Dosificación de } \\
11.3 \% \\
\end{array}$ & Proporción & $\mathrm{Kg} / \mathrm{L}$ & Observable \\
\hline & $\begin{array}{l}\text { Dosificación de } \\
8.5 \%\end{array}$ & Proporción & $\mathrm{Kg} / \mathrm{L}$ & Observable \\
\hline \multirow{5}{*}{$\begin{array}{l}\text { Dependiente (VD): } \\
\text { Y: Los resultados de } \\
\text { resistencia mecánica y } \\
\text { física }\end{array}$} & Compresión & $\begin{array}{l}\text { Incremento de } \\
\text { resistencia }\end{array}$ & $\mathrm{Kg} / \mathrm{cm}^{2}$ & Ensayo \\
\hline & Flexión & $\begin{array}{l}\text { Incremento de } \\
\text { resistencia }\end{array}$ & $\mathrm{Kg} / \mathrm{cm}^{2}$ & Ensayo \\
\hline & Chorro de agua & $\begin{array}{l}\text { Incremento de } \\
\text { resistencia }\end{array}$ & Penetración & Observable \\
\hline & Inmersión & $\begin{array}{l}\text { Incremento de } \\
\text { resistencia }\end{array}$ & Días & Observable \\
\hline & Absorción & $\begin{array}{l}\text { Incremento de } \\
\text { resistencia }\end{array}$ & $\%$ & Ensayo \\
\hline
\end{tabular}

Tabla 2. 9. Variables de estudio y operacionalización del Tercer Objetivo Específico. Fuente: Propia

\begin{tabular}{|l|c|c|c|c|}
\hline \multicolumn{1}{|c|}{ VARIABLE } & DIMENSIONES & INDICADORES & $\begin{array}{c}\text { UNIDAD DE } \\
\text { MEDIDA }\end{array}$ & $\begin{array}{c}\text { INSTRUMENTO DE } \\
\text { INVESTIGACIÓN }\end{array}$ \\
\hline & Compresión & Incremento de resistencia & $\mathrm{Kg} / \mathrm{cm}^{2}$ & Ensayo \\
\cline { 2 - 5 } & Flexión & Incremento de resistencia & $\mathrm{Kg} / \mathrm{cm}^{2}$ & Ensayo \\
\cline { 2 - 5 } \begin{tabular}{l} 
Independiente(VI): $\begin{array}{l}\text { X: Ensayos físicos y } \\
\text { mecánicos }\end{array}$ \\
\cline { 2 - 5 }
\end{tabular} & Chorro de agua & Incremento de resistencia & Penetración & Observable \\
\cline { 2 - 5 } & Absorción & Incremento de resistencia & Días & Observable \\
\hline $\begin{array}{l}\text { Dependiente (VD): } \\
\text { Y: Comparación del } \\
\text { adobe convencional con } \\
\text { el adobe } \\
\text { impermeabilizado }\end{array}$ & Técnica superior & Viable técnicamente & Si o no & Observable \\
\hline
\end{tabular}

\subsubsection{Técnicas e Instrumentos de recolección de datos}

Para lograr reunir los datos correspondientes que conduzcan a comprobar el grado de validez de la hipótesis, se requiere elaborar un plan detallado de procedimientos. Se toma en cuenta que los datos recolectados son extraídos de la muestra seleccionada, el cual contiene, en su mayoría, las características de la población de interés (Sabino C., 2015). Esto se logrará través de la identificación de las técnicas e instrumentos de recolección por cada objetivo específico, como se explicará a continuación: 


\subsubsection{Técnicas}

La técnica aplicada para el primer, segundo y tercer objetivo fue la "observación" tipo participante - estructurada, puesto que el observador se involucra en los eventos de estudio a través de la ejecución de varios ensayos, el cual están predeterminados a través de una guía que rige las observaciones (Lupicinio I., 2008), esto permitirá seleccionar los recursos apropiados para la elaboración del adobe. Así como registrar la información obtenida por los diferentes ensayos realizados en la investigación, el cual nos permitirá ordenar y llevar un mejor control de los datos.

\subsubsection{Instrumentos de Recolección}

En esta investigación, la información obtenida fue anotada en una libreta de apuntes, en los formatos obtenidos en los laboratorios y fotografías para posteriormente ser redactados con mayor detalle en el informe correspondiente. A continuación, se describirá cómo y en que ensayos fueron utilizados estos instrumentos:

- La libreta de apuntes fue utilizada mayormente cuando se obtenía información de los ensayos preliminares (olor, color y brillo), de los ensayos en campo (presencia de arcilla y cinta de barro) de la tierra, extracción del mucílago de penca de tuna y ensayos físicos en la unidad de adobe (Inmersión y chorro de agua), el cual no requerían de maquinaria o herramientas supervisadas por una persona especializada.

- Formatos de laboratorio, estos fueron obtenidos a través de las guías de laboratorios asignadas por la misma universidad, el cual facilitaron la colocación de los datos obtenidos en los laboratorios de materiales y suelos, puesto que permitían colocarlos de forma ordenada y resumida.

- Fotografías, este instrumento fue utilizado como evidencia de los procesos y procedimientos de los ensayos realizados en la investigación.

Para un mejor entendimiento en la tabla 2.10 se indicarán de forma resumida las técnicas e instrumentos utilizados para la elección de cada recurso y los ensayos realizados para cada objetivo específico. 
Tabla 2. 10. Instrumentos de recolección para cada objetivo específico. Fuente: Propia

\begin{tabular}{|c|c|c|c|c|}
\hline & TÉCNICAS & $\begin{array}{l}\text { MATERIALES } \\
\text { ELEMENTOS }\end{array}$ & ENSAYOS & INSTRUMENTOS \\
\hline \multirow{6}{*}{$\begin{array}{c}\text { Primer } \\
\text { Objetivo } \\
\text { especifico }\end{array}$} & \multirow{3}{*}{$\begin{array}{l}\text { Observación: } \\
\text { participante } \\
\text { - } \\
\text { estructurada }\end{array}$} & \multirow{3}{*}{ Tierra } & $\begin{array}{l}\text { Ensayos preliminares (olor, } \\
\text { color y brillo) }\end{array}$ & $\begin{array}{l}\text { Libreta de apuntes, } \\
\text { fotografías }\end{array}$ \\
\hline & & & $\begin{array}{l}\text { Ensayos en campo } \\
\text { (presencia de arcilla y cinta } \\
\text { de barro) }\end{array}$ & $\begin{array}{l}\text { Libreta de apuntes, } \\
\text { fotografías }\end{array}$ \\
\hline & & & $\begin{array}{lr}\text { Ensayos en laboratorio } \\
\text { (granulometría, peso } \\
\text { específico, humedad) }\end{array}$ & $\begin{array}{l}\text { Formatos establecidos por } \\
\text { cada laboratorio, fotografías }\end{array}$ \\
\hline & \multirow{3}{*}{$\begin{array}{l}\text { Observación: } \\
\text { participante } \\
\text { - } \\
\text { estructurada }\end{array}$} & \multirow{3}{*}{ Pencas de tuna } & $\begin{array}{l}\text { Extracción del mucílago de } \\
\text { la penca de tuna }\end{array}$ & $\begin{array}{l}\text { Libreta de } \\
\text { fotografías }\end{array}$ \\
\hline & & & Ensayo de densidad & $\begin{array}{l}\text { Formatos establecidos por } \\
\text { cada laboratorio, fotografías }\end{array}$ \\
\hline & & & Ensayo de viscosidad & $\begin{array}{l}\text { Formatos establecidos por } \\
\text { cada laboratorio, fotografías }\end{array}$ \\
\hline $\begin{array}{l}\text { Segundo } \\
\text { Objetivo } \\
\text { especifico }\end{array}$ & $\begin{array}{l}\text { Observación: } \\
\text { participante } \\
\text { - } \\
\text { estructurada }\end{array}$ & Dosificación Ideal & Proporciones & $\begin{array}{l}\text { Libreta de apuntes, } \\
\text { fotografías }\end{array}$ \\
\hline \multirow{3}{*}{$\begin{array}{c}\text { Tercer } \\
\text { Objetivo } \\
\text { especifico }\end{array}$} & \multirow{2}{*}{$\begin{array}{l}\text { Observación: } \\
\text { participante } \\
\text { - } \\
\text { estructurada }\end{array}$} & \multirow[t]{2}{*}{ Unidad de adobe } & $\begin{array}{l}\text { Ensayos físicos (chorro de } \\
\text { agua, inmersión } \\
\text { absorción) }\end{array}$ & $\begin{array}{l}\text { Libreta de apuntes, } \\
\text { fotografías }\end{array}$ \\
\hline & & & $\begin{array}{l}\text { Ensayos mecánicos (flexión, } \\
\text { compresión) }\end{array}$ & $\begin{array}{l}\text { Formatos establecidos por } \\
\text { cada laboratorio, fotografías }\end{array}$ \\
\hline & $\begin{array}{l}\text { Observación: } \\
\text { participante } \\
\text { - } \\
\text { estructurada }\end{array}$ & Pila de adobe & Ensayos de compresión & $\begin{array}{c}\text { Formatos establecidos por } \\
\text { cada laboratorio, } \\
\text { fotografías }\end{array}$ \\
\hline
\end{tabular}

\subsubsection{Metodología de la Investigación}

A continuación, se explicarán las técnicas y ensayos que se utilizarán para obtener datos que servirán para el desarrollo del presente estudio.

OBJETIVO 1: Analizar los materiales más adecuados para la elaboración de la mezcla a través de ensayos preliminares (prueba de color, prueba olfativa y prueba de brillo) y ensayos físicos (ensayo de cinta de barro, resistencia seca, granulometría, peso específico y límites de Atterberg) para el suelo y, ensayos de densidad y viscosidad para el mucílago de penca de tuna.

En primer lugar, se buscó determinar las propiedades que deben tener los materiales de tal forma que cumplan los requisitos de la norma y recomendaciones de otros autores, para la elaboración de los dos tipos de adobe: convencional y estabilizado. Para esto se decidió viajar hacia el lugar de estudio, el distrito de Huarochirí, en donde: 
- Se obtienen dos muestras de tierra de lugares distintos, las cuales se seleccionan a través de pruebas preliminares y ensayos de campo, los resultados nos permitirán realizar una selección preliminar del material, posteriormente estos resultados serán corroborados con ensayos mecánicos en laboratorio.

- Se recogió paja de trigo de la zona de Trabanda- pueblo de Huarochirí, la cual formará parte de la mezcla, esta proporción dependerá del tipo de suelo que se va a utilizar.

- Se recolectó pencas de tuna de la zona de Sincocaya - pueblo de Huarochirí con la finalidad de extraer su mucílago (sustancia viscosa), el cual será utilizado como estabilizador para impermeabilizar la nueva unidad.

En segundo lugar, se realizarán distintos tipos de ensayo para obtener algunas características de los materiales a utilizar para la mezcla.

- Se acudirá al laboratorio de mecánica de suelos con la finalidad de realizar los ensayos de granulometría, peso específico y los límites de Atterberg, el cual nos permitirá saber la composición de la tierra.

- Se realizará la extracción del mucílago de penca de tuna, para posteriormente realizar ensayos de viscosidad y densidad y de esa forma identificar sus propiedades.

OBJETIVO 2: Seleccionar la dosificación ideal de la mezcla para obtener los mejores resultados de resistencia a la compresión, flexión y absorción en la unidad de adobe estabilizado.

Se realizarán distintas mezclas con diferentes dosificaciones del mucílago de penca de tuna para la elaboración del nuevo adobe estabilizado con la finalidad de escoger la opción que muestre mejores resultados de permeabilidad, al compararlo con las características del adobe convencional.

- Se estableció que las dimensiones para este nuevo adobe estabilizado serían las mismas del lugar de estudio (Huarochirí), las cuales son $40 \mathrm{~cm}$ x $20 \mathrm{~cm}$ x $13 \mathrm{~cm}$, ya que estas dimensiones cumplen con lo establecido en la Norma E.080 (2017) titulada Diseño y Construcción con tierra reforzada. 
- Se elaborará cinco tipos de adobes $8.5 \mathrm{~kg} / \mathrm{L} \%, 11.3 \mathrm{~kg} / \mathrm{L} \%, 13 \mathrm{~kg} / \mathrm{L} \%, 18 \mathrm{~kg} / \mathrm{L} \%$ y $20.5 \mathrm{~kg} / \mathrm{L} \%$ de solución de mucílago de penca de tuna en agua respectivamente.

- Los ensayos que se realizarán en las unidades de albañilería son las siguientes: mecánicos y físicos; los primeros para obtener su resistencia ante diferentes esfuerzos (Ensayo de compresión y flexión) y los segundos para observar su comportamiento ante fuertes lluvias (Ensayo de chorro de agua) y posibles inundaciones (Ensayo de inmersión y absorción).

Se selecciona dos diseños los cuales deberán tener la mejor resistencia mecánica y al agua para luego elaborar las pilas de adobe estabilizado.

OBJETIVO 3: Comparar los resultados de resistencia mecánica (compresión y flexión) y resistencia física (absorción) de las unidades y pilas de adobes convencionales de los adobes estabilizados.

Una vez identificadas las mejores dosificaciones para el adobe estabilizado se procederá a comparar con el adobe convencional, de igual forma se evaluará las pilas de adobe para determinar su comportamiento en conjunto, con el fin de comparar sus resultados y sacar las respectivas conclusiones.

- Para el ensayo de compresión en pila de Adobe, se elaborará tres pilas de ladrillos por cada tipo y la altura será 3 veces la longitud mínima del ladrillo como lo establece en la Norma E.080 (2017) titulada Diseño y Construcción con tierra reforzada. Una vez obtenido los resultados de los ensayos se compararán entre ellos, para luego determinar cuál es el adobe con mejor dosificación de mucílago de penca de tuna.

\subsubsection{Técnicas de procesamiento y Análisis de datos}

Se definirán las técnicas que permitirán descifrar los datos recolectados. En este caso, los resultados serán presentados mediante fotografías, gráficos y tablas, con la finalidad de resumir y describir la información.

A continuación, se explicará las operaciones realizadas con mayor detalle.

OBJETIVO 1: Analizar los materiales más adecuados para la elaboración de la mezcla a través de ensayos preliminares (prueba de color, prueba olfativa y prueba de brillo) y 
ensayos físicos (ensayo de cinta de barro, resistencia seca, granulometría, peso específico y límites de Atterberg) para el suelo y, ensayos de densidad y viscosidad para el mucílago de penca de tuna.

\subsection{Suelo}

Para esta investigación se tomó 2 muestras de suelos de distintos lugares del distrito de Huarochirí.

- El lugar de extracción para la primera muestra fue de Trabanda, el cual tiene un suelo color mate y de menor cantidad de piedras como se observa en la figura 2.4.

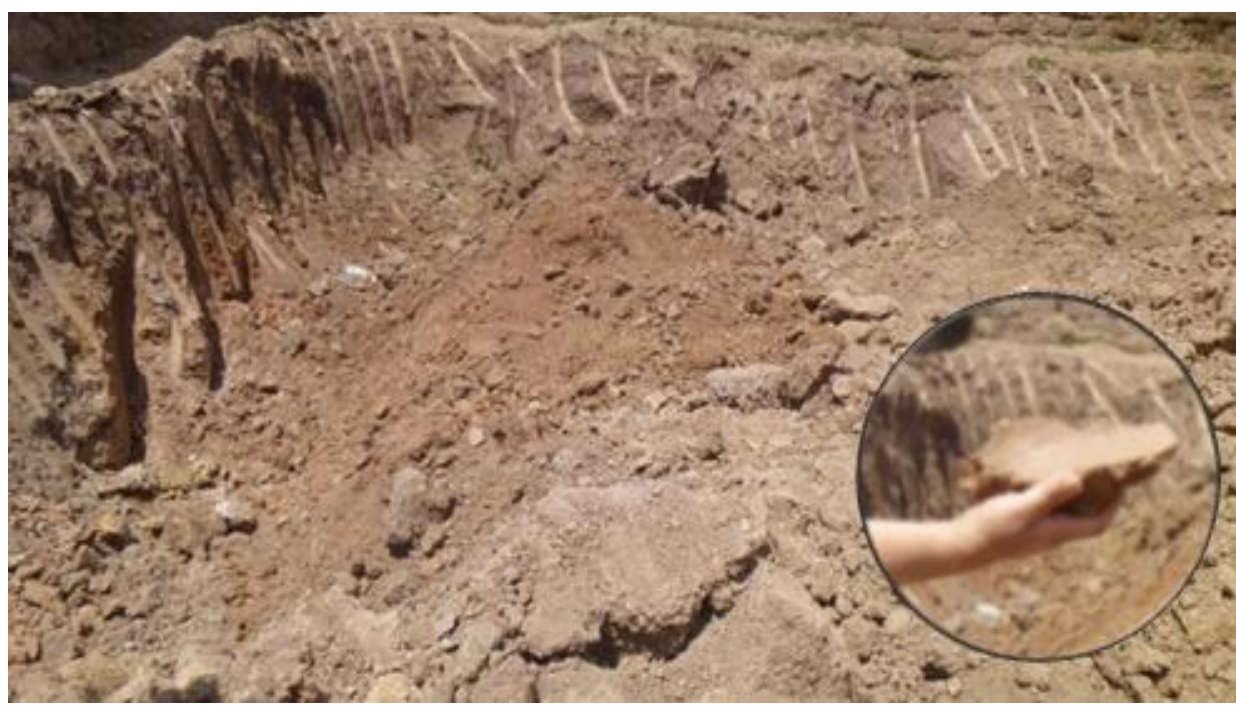

Figura 2. 4. Lugar de extracción de la primera muestra (Distrito de Huarochirí- Zona Trabanda). Fuente: Propia

- El lugar de extracción para la segunda muestra se llama Carachuco, este lugar tiene un suelo color rojizo y con mediana cantidad de piedras como se observa en la figura 2.5 .

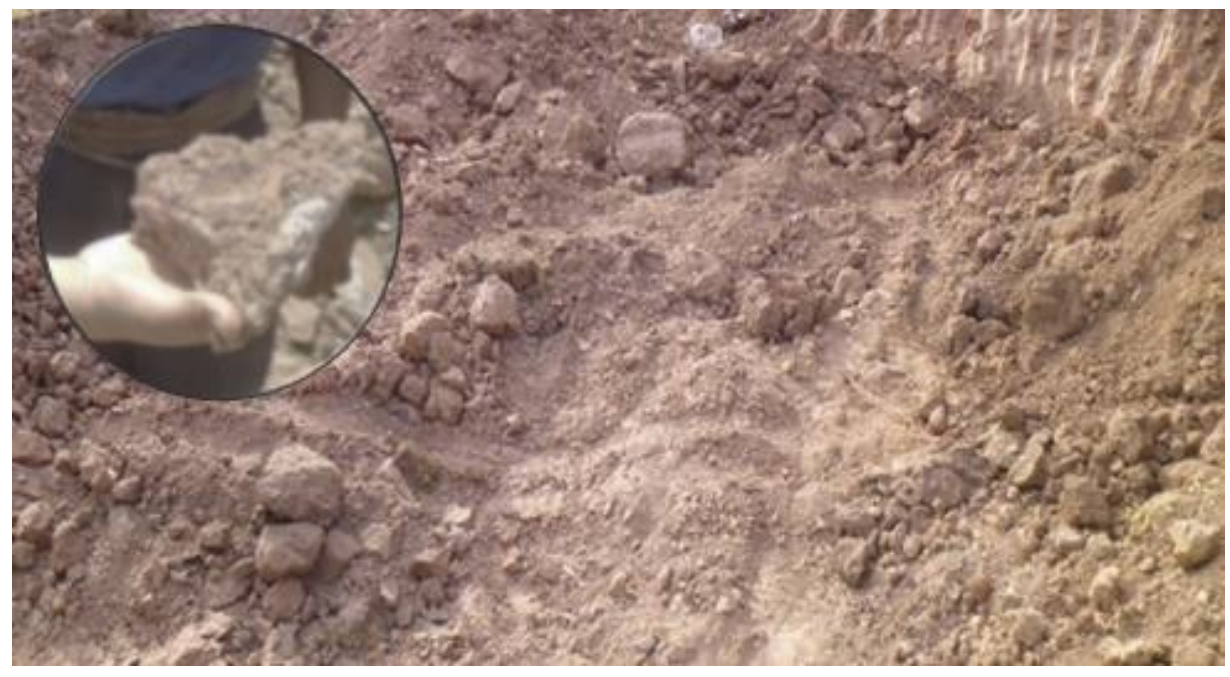

Figura 2. 5. Lugar de extracción de la primera muestra (Distrito de Huarochirí- Zona Trabanda). Fuente: Propia 


\subsection{Ensayos preliminares}

Estos en su mayoría son ensayos en campo mencionados por Tejada U. (2001) en su libro

"Buena Tierra- Apuntes para el diseño y construcción con Adobe":

- Prueba de color: Observar el color del suelo. Si son negros: suelos orgánicos, claros y brillantes: inorgánicos y si es gris claro: limosos con carbonato de calcio o suelos poco cohesivos.

- Prueba olfativa: Se aprecia el olor del suelo. Olor rancio: suelos orgánicos, no recomendados para la construcción de los elementos

- Prueba de brillo: Se corta una muestra de suelo en estado masilla. Opacos: suelos arenosos, mates: limosos con poca arcilla y brillantes: arcillosos.

\subsection{Ensayo físico en el campo}

Uno de los aspectos más importantes que se debe conocer antes de iniciar una edificación con tierra, es la calidad del material. Por tal motivo, es recomendable realizar una serie de ensayos de campo que permitan obtener las cualidades de la tierra a utilizar y descartar aquellos que son inadecuados (ICG, 2014).

\section{- Ensayo de Cinta de Barro}

También conocida como prueba de cohesión. El objetivo es verificar si en la muestra de suelo, el porcentaje de arcilla es el adecuado. A continuación, se indicará el procedimiento para este ensayo, teniendo en cuenta la información expuesto En la Norma E.080 (2017) y construcción con tierra reforzada e ICG (2014):

En primer lugar, se tamiza la muestra con una malla de $5 \mathrm{~mm}$ de abertura, con la finalidad de extraer las piedras de gran tamaño u otros elementos como se observa en la figura 2.6 y figura 2.7. En segundo lugar, se toma con una mano parte de la tierra tamizada, se remueve, se le añade agua hasta lograr una consistencia plástica y se amasa con los dedos durante 15 min como se indica en la figura 2.8 y figura 2.9. En tercer lugar, se toma esa muestra humedecida y se comienza a aplanar poco a poco con los dedos hasta conseguir un cilindro de $4 \mathrm{~mm}$, esto se puede apreciar en la figura 2.10 y figura 2.11. Si la cinta está entre $20 \mathrm{~cm}$ a $25 \mathrm{~cm}$ de longitud, el suelo es muy arcilloso, si se corta a los $10 \mathrm{~cm}$ o menos, el suelo es arenoso, pero si la cinta está entre los $15 \mathrm{~cm}$, el suelo tiene una proporción adecuada de arcilla. 


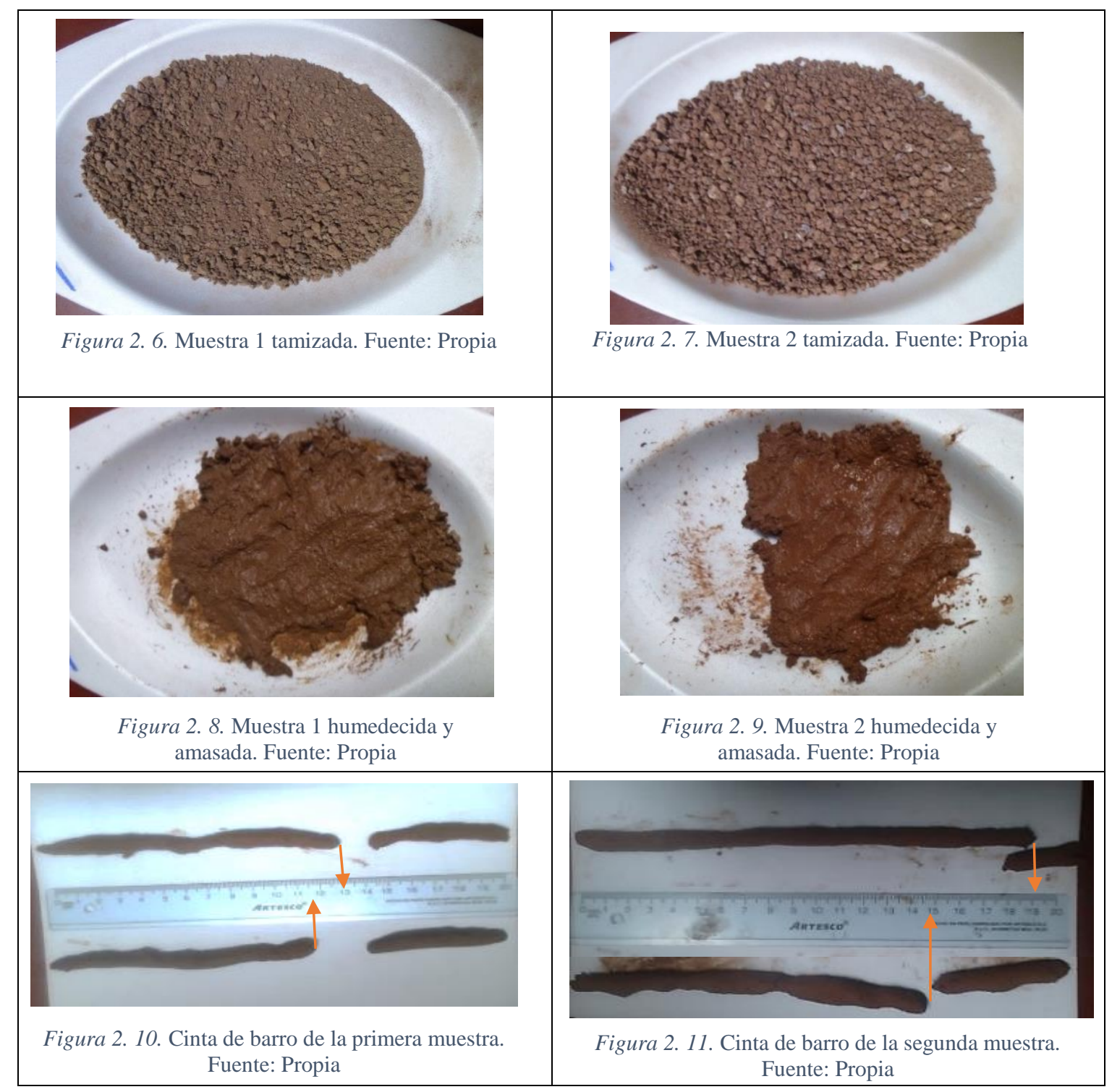

- Presencia de Arcilla o Resistencia Seca

El objetivo de esta prueba es comprobar la resistencia de rotura de la tierra al ser sometida a la fuerza de una o dos manos. Se toma en cuenta que la resistencia será influenciada por varios factores como es el tipo de arcilla y su capacidad de cohesión, del grado de porosidad y de la proporción entre los componentes del suelo como es la arena, limo y arcilla (ICG, 2014).

El M.V.C.S. (2017) en la Norma E.080 Diseño y construcción con tierra reforzada indica cuales son los pasos que seguir para la realización de este ensayo, como se muestra a continuación:

○ En primer lugar, se tamiza la muestra con una malla de $5 \mathrm{~mm}$ de abertura, con la finalidad de solo quedarse con piedras de pequeño tamaño como se indica en la figura 2.7 y figura 2.8. En segundo lugar, se le agrega la cantidad mínima de agua 
en una porción de la muestra tamizada y se amasa como se muestra en la figura 2.12 y figura 2.13. En tercer lugar, con esa mezcla se forma 4 bolitas del mismo tamaño sobre las palmas de la mano, sin que estas se deformen a simple vista al secarse., esto se observa en la figura 2.14 y figura 2.15. En cuarto lugar, se deja secar las bolitas de tierra alrededor de 48 horas (se debe evitar que los materiales se humedezcan o se mojen por lluvias o derrames de agua). Finalmente, se debe presionar fuertemente cada una de las bolitas con el dedo pulgar y dedo índice con se muestra en la figura 2.16 y figura 2.17 , en caso de que alguna de ellas se agriete, quiebre o rompe se debe volver hacer una vez más el ensayo, si se vuelve a romper no se recomienda usar ese suelo, en caso contrario la tierra puede ser utilizada como material de construcción.

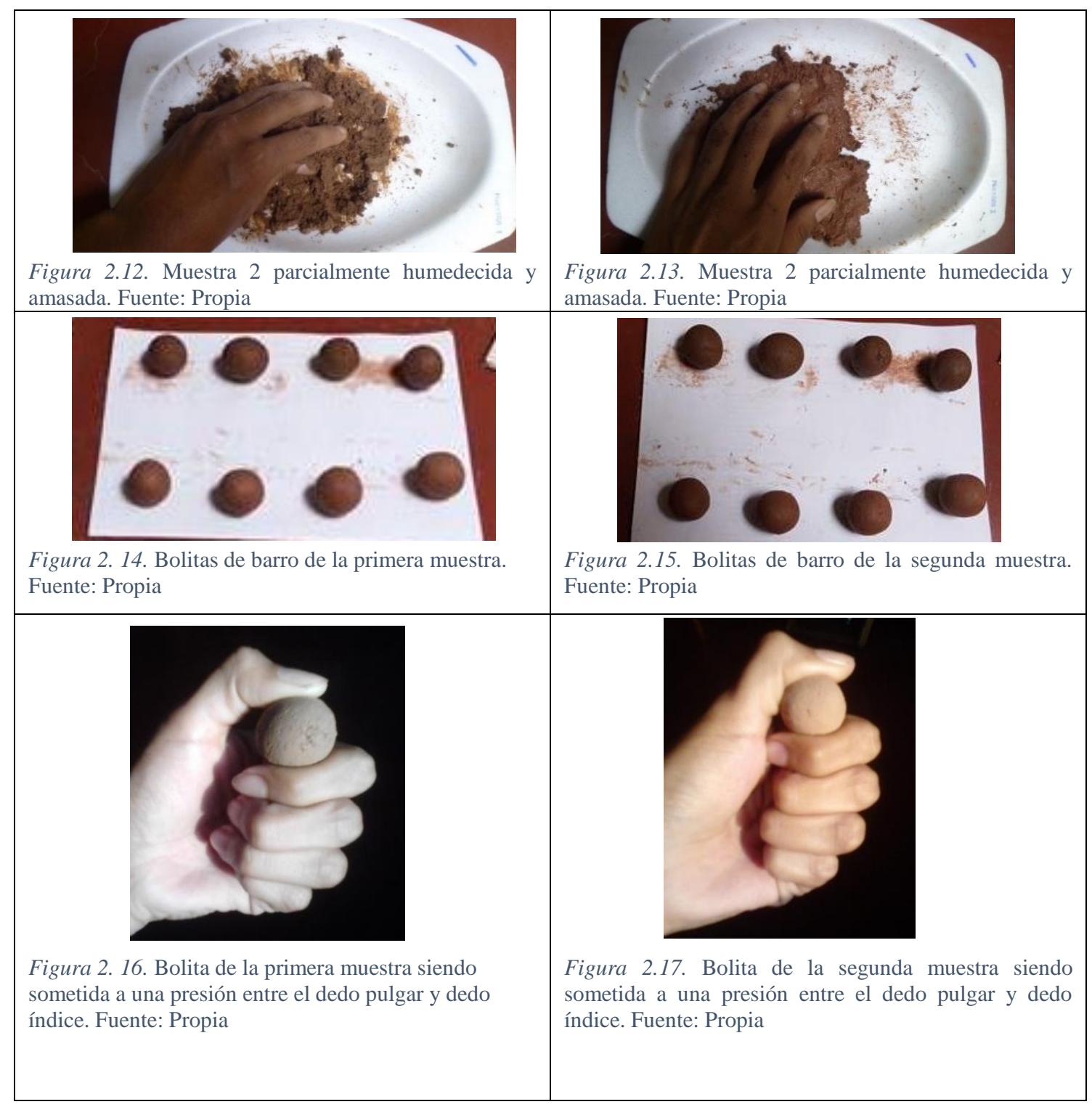




\subsection{Ensayo Físico en laboratorio}

Los ensayos de laboratorio nos permitirán establecer las propiedades mecánicas de un material con un mínimo porcentaje de error. En esta investigación, se realizarán ensayos físicos en el laboratorio para el material tierra como se muestra a continuación:

\section{- Granulometría de suelos por tamizado}

En Gutierrez J. (2013, citado en la norma ASTM D-2216-08 y NTP 339.127)) indica que el objetivo y procedimiento para este ensayo son los siguientes:

- Objetivo: Determinar los porcentajes de suelo de una muestra que pasan por los distintos tamices de la serie empleada en el ensayo (3", 2", 1 11/2, 1", 3/4", 1/2", 3/8", $1 / 4 ", \mathrm{~N}^{\circ} 4, \mathrm{~N}^{\circ} 10, \mathrm{~N}^{\circ} 20, \mathrm{~N}^{\circ} 60, \mathrm{~N}^{\circ} 140, \mathrm{~N}^{\circ} 200$ y fondo), hasta el de $74 \mathrm{~mm}\left(\mathrm{~N}^{\circ} 200\right)$

- Procedimiento:

Primero, se pesa la muestra que se utilizará para este ensayo como se observa en la figura 2.18. Segundo, se ordenan los tamices de mayor a menor según la abertura, para nuestro caso se requerirá los tamices $\mathrm{N}^{\circ} 20, \mathrm{~N}^{\circ} 40, \mathrm{~N}^{\circ} 60, \mathrm{~N}^{\circ} 140$, $\mathrm{N}^{\circ} 200$ y fondo como indica la figura 2.19. Tercero se agrega el material dentro de la columna de tamices, se tapa y se agita bien alrededor de 10 minutos para después destaparlo con cuidado con la finalidad de no derramar la muestra, como se aprecia en la figura 2.20. Cuarto, se pesa la tierra retenida en cada tamiz en una balanza con una sensibilidad de 0.1 gr como indica en la figura 2.21. Finalmente se anota los datos en el formato de prueba con la finalidad de poder graficar la curva granulométrica.

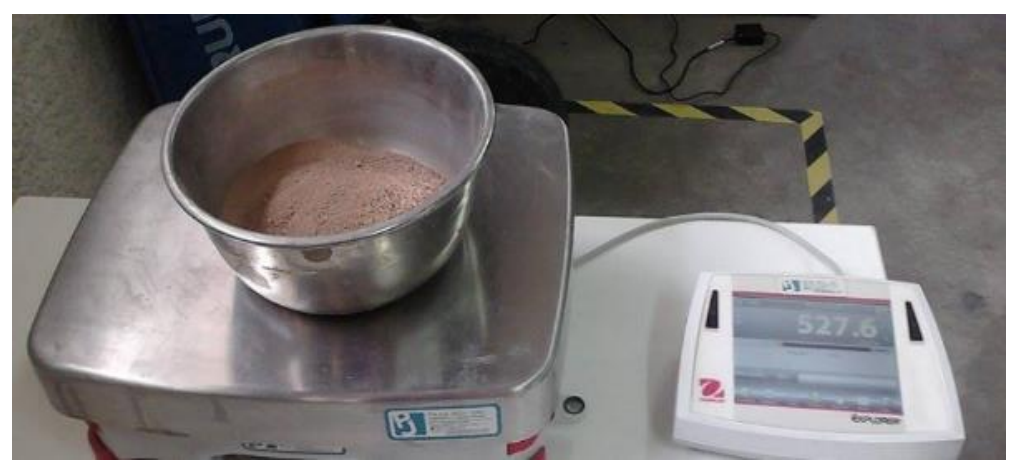

Figura 2. 18. Obtención del peso de la muestra para el ensayo. Fuente: Propia 


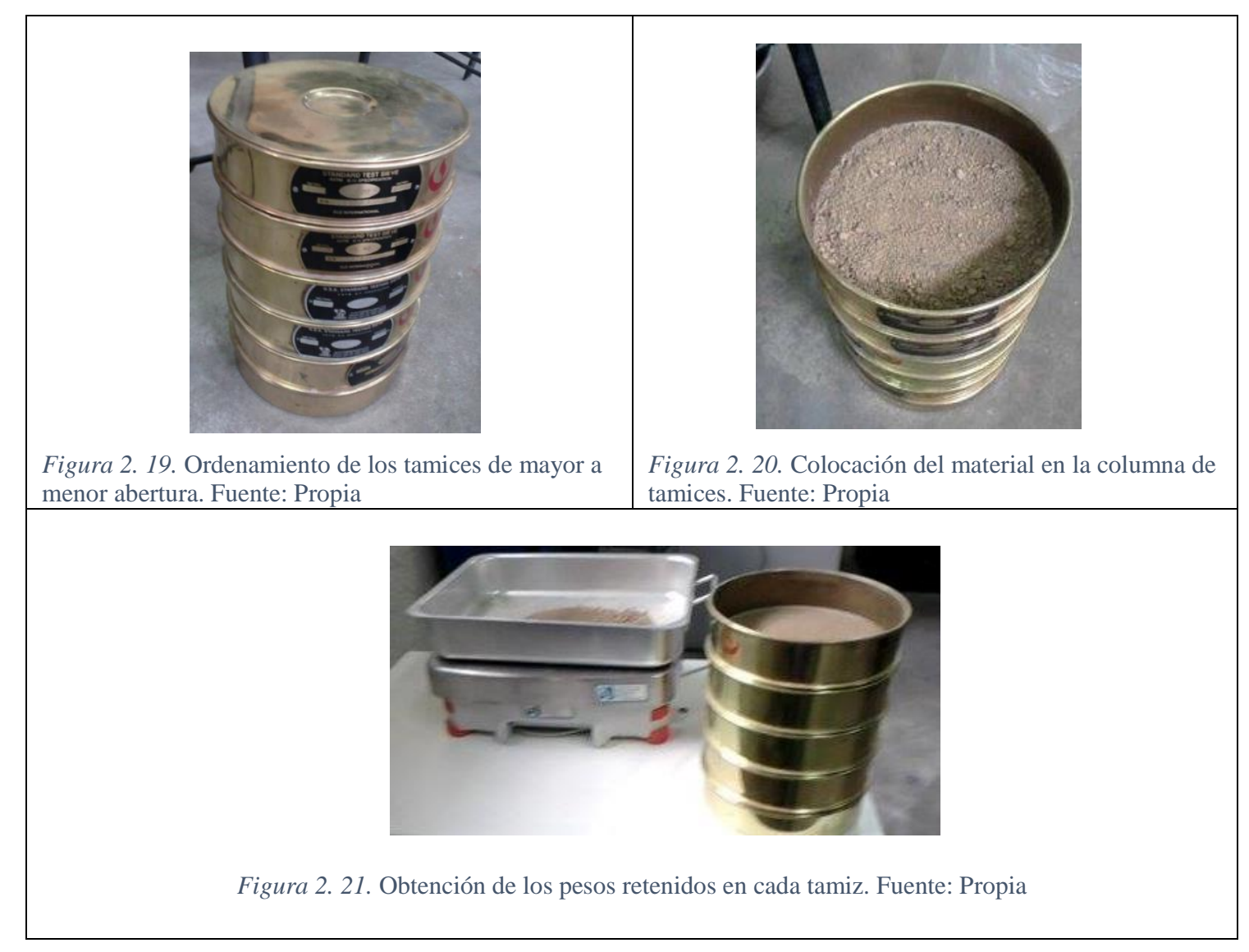

\section{- Peso especifico}

En Gutierrez J. (2013, como se citó en la norma ASTM D-854) indica que el objetivo y procedimiento para este ensayo son los siguientes:

○ Objetivo: Determinar el peso específico del suelo por medio de un picnómetro.

- Espécimen de ensayo: La muestra puede ser ensayada a su humedad natural, si la muestra contiene partículas de diámetros mayores y menores que la abertura del tamiz $\mathrm{N}^{\circ} 8$, debe ser separada por dicho tamiz y determinar el peso específico de la fracción fina y la facción gruesa. Se recomienda utilizar kerosene como reemplazo del agua destilada, ya que es un mejor agente humedecedor.

○ Procedimiento:

Primero se determina la cantidad de muestra que se utilizará para el ensayo, este valor dependerá de la capacidad del picnómetro a utilizar, para esta investigación se utilizará entre 120-130 g de muestra ya que nuestro picnómetro tiene una capacidad de $500 \mathrm{~cm}^{3}$, como se muestra en la tabla 2.11 . 
Tabla 2. 11. Cantidad de muestra necesaria de acuerdo con la capacidad del picnómetro. Gutierrez J., 2013

\begin{tabular}{|c|c|}
\hline $\begin{array}{c}\text { CAPACIDAD DE } \\
\text { PICNÓMETRO }\left(\mathbf{c m}^{\mathbf{3}}\right)\end{array}$ & $\begin{array}{c}\text { CANTIDAD REQUERIDA } \\
\text { APROXIMADAMENTE (gr) }\end{array}$ \\
\hline 100 & $25-35$ \\
\hline 250 & $55-65$ \\
\hline 500 & $120-130$ \\
\hline
\end{tabular}

En segundo lugar, se pesó la muestra calculada (120-130g) como se evidencia en la figura 2.22 y figura 2.23. Luego se colocó esta muestra en el picnómetro (figura 2.24) para posteriormente pesarlo como se observa en la figura 2.25 y figura 2.26. A continuación se agrega en otro picnómetro agua destilada y la muestra con ayuda de una espátula. Para remover el aire atrapado se debe tomar el picnómetro horizontalmente y agitarlo con una mano la base del picnómetro de forma circular. Posteriormente se llena el picnómetro con agua destilada hasta el fondo del menisco coincida con la marca de calibración en el cuello del picnómetro como se muestra en figura 2.27. Se mide la temperatura como indican en la figura 2.28 y figura 2.29. Para finalizar el ensayo se pesa la muestra luego de haber reposado aproximadamente 30 minutos como se observa en la figura 2.30 y figura 2.31.

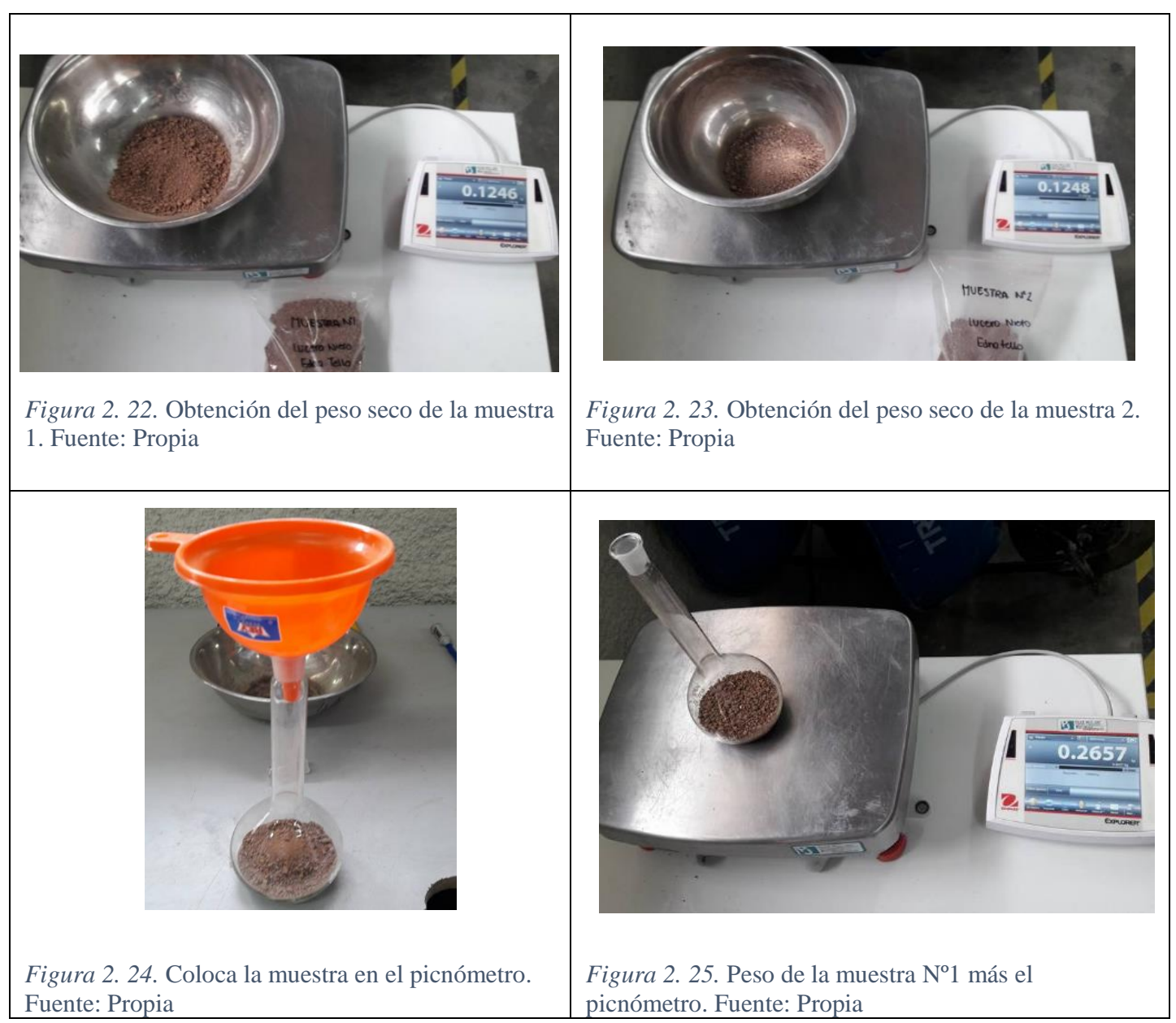




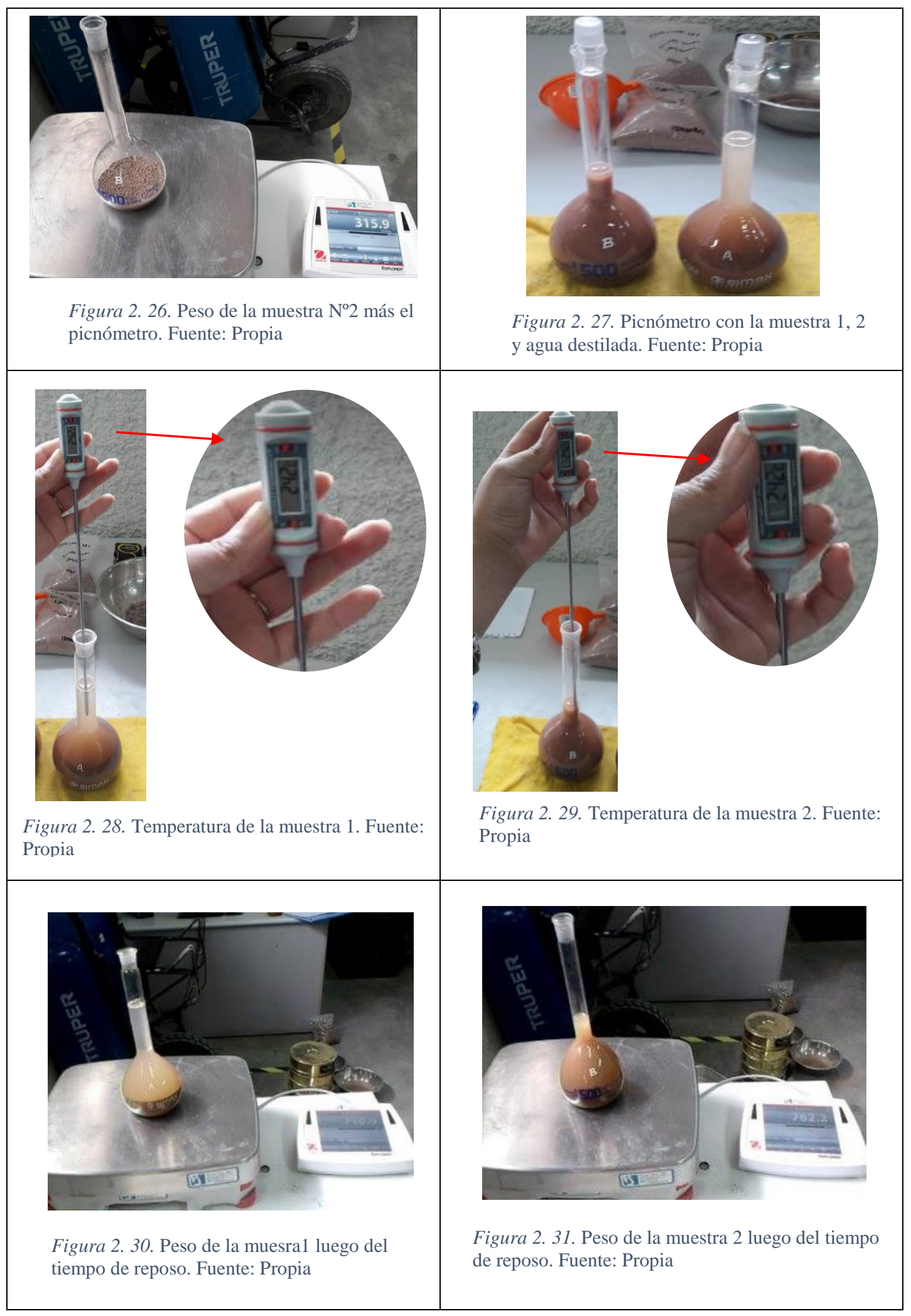

\section{- Límites de Atterberg (consistencia)}

\section{Limite líquido:}

"El líquido de un suelo es el contenido de humedad expresado en porcentaje del suelo 
en el horno, cuando este se halla en el límite entre el estado plástico y estado líquido" (Gutierrez, J., 2013, citado de la norma ASTM D-2216-08 y NTP 339.127)

El procedimiento según Gutierrez, J. (2013) es el siguiente:

Primero, se pesa una porción de la muestra que pasó por el tamiz $\mathrm{N}^{\circ} 40$ y los envases en que éstas reposarán como indica la figura 2.32 y figura 2.33, después se seca la muestra en el horno o estufa, luego se mezcla bien el suelo con 15 a $20 \mathrm{ml}$ de agua destilada en una vasija de porcelana con ayuda de una espátula (esta mezcla debe de ser en forma alternada), después se incrementa de 1 a $3 \mathrm{ml}$ de agua y se mezcla bien, hasta tener una pasta homogénea como se observa en la figura 2.34. Segundo, se coloca parte de la mezcla en la cazuela sobre el sitio en que reposa en la base, se expande con ayuda de la espátula tratando de realizar la menor cantidad de pasadas y evitando la inclusión de burbujas dentro de la masa. Tercero, nivelar el suelo con la espátula y al mismo tiempo emparejarlo para conseguir una profundidad de $1 \mathrm{~cm}$, regresar el exceso a la vasija de porcelana. Cuarto, dividir el suelo en la taza de bronce con pasadas firmes, máximo 6 pasadas, de modo que se forme una ranura limpia y de dimensiones apropiadas como se muestra en la figura 2.35. Quinto, girando la manija a una velocidad de 1,9 a 2,1 golpes por segundo hasta que las dos mitades de la pasta de suelo se pongan en contacto con el fondo de la ranura, después sacar una tajada de suelo aproximadamente de ancho de la espátula tomando de uno y otro lado de forma recta (se debe incluir la porción que se hizo contacto) y colocase en otro recipiente como se observa en la figura 2.36. Sexto, repetir la operación anterior por lo menos dos veces más hasta que el número de golpes de cada prueba este entre intervalos de 25-35, 20-30 y 15-25 golpes. Séptimo, se colocan los recipientes con las muestras en el horno durante un día como indica en la figura 2.37, finalmente se pesan y se hacen los respectivos cálculos.

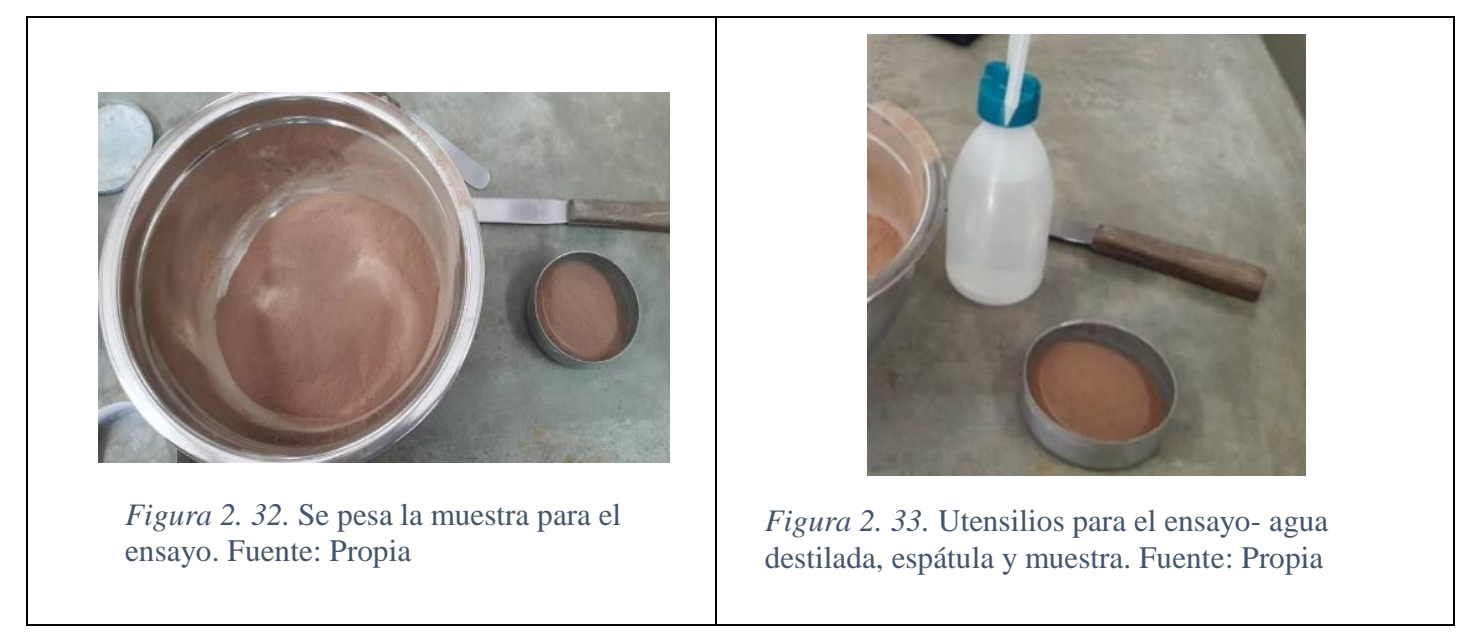




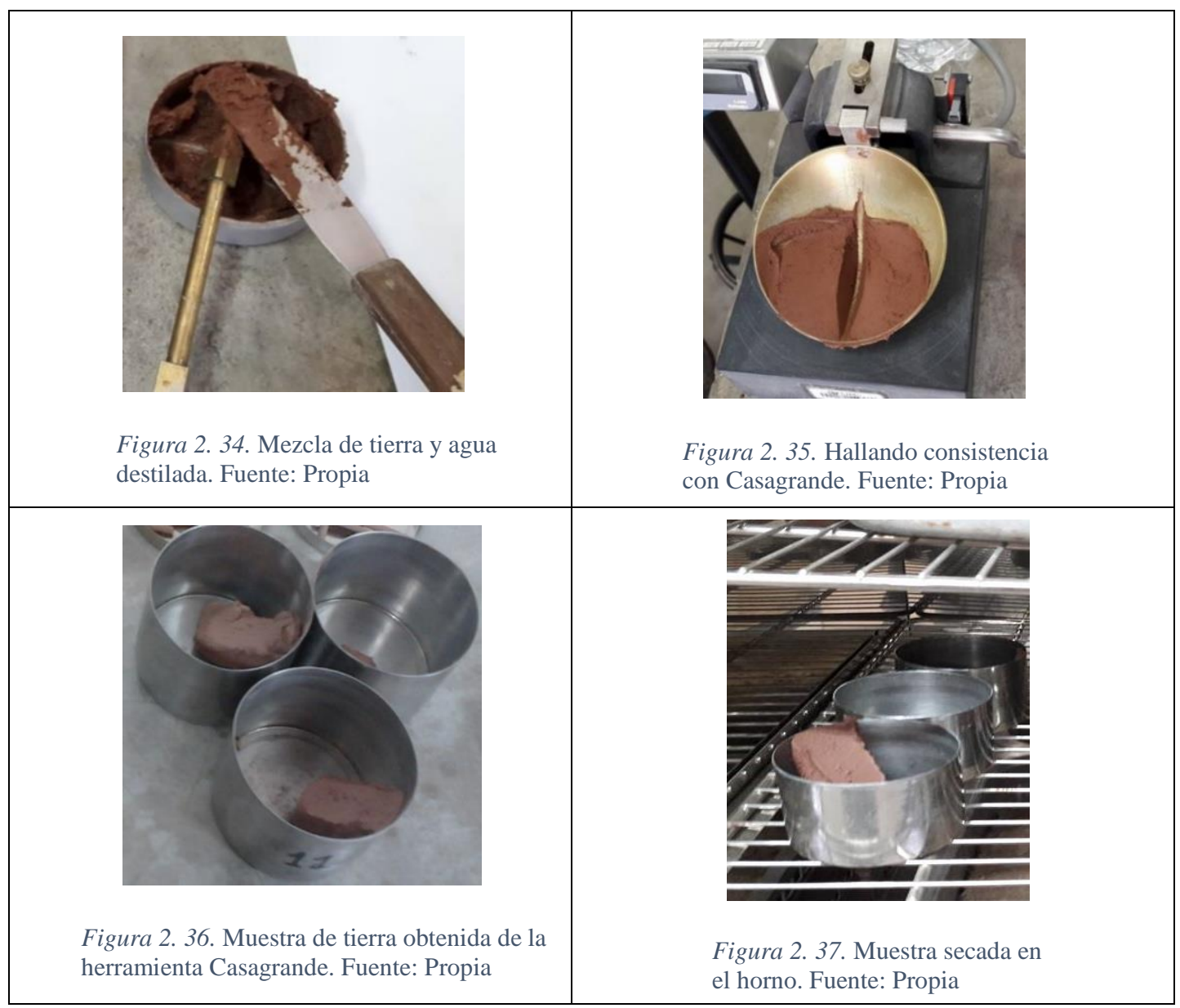

\section{Limite plástico}

"Se denomina limite plástico a la humedad más baja con la que pueden formarse barritas de suelo de unos $3.2 \mathrm{~mm}$ de diámetro, rodando dicho suelo entre la palma de la mano y una superficie lisa (vidrio esmerilado) sin que dichas barritas se desmoronen.”(Gutierrez, J., 2013,)

Primero, se pesan los recipientes en la que se colocarán las muestras, a continuación, se toma una pequeña muestra de la tierra que pasa por el tamiz $\mathrm{N}^{\circ} 40$ como se observa en la figura 2.38 y figura 2.39 , y se le pone a secar en el horno o estufa. Segundo, se agrega un poco de agua destilada hasta que se pueda formar con facilidad una esfera de tierra sin que esta se pegue mucho a los dedos al momento de aplastarla como se indica en la figura 2.40. Tercero, se toma una porción de $1.5 \mathrm{gr}$ a $2.0 \mathrm{gr}$ de esta esfera como se observa en la figura 2.41, a esta se le rueda con los dedos de la mano sobre una superficie lisa hasta formar cilindros de un diámetro de $3.2 \mathrm{~mm}$ como indica la figura 2.42, si se ha desmoronado o formado pequeñas fisuras, el proceso termina en caso contrario se repite cuantas veces sea necesario hasta conseguir que esta se muestre fisuras como se muestra en la figura 2.41. Quinta, las porciones 
desmoronadas se colocan en recipientes hasta que su contenido pese al menos 6 gr como se indica en la figura 2.43. Finalmente, se coloca al horno el recipiente con muestra durante un día, después se pesa y se hace los respectivos cálculos.

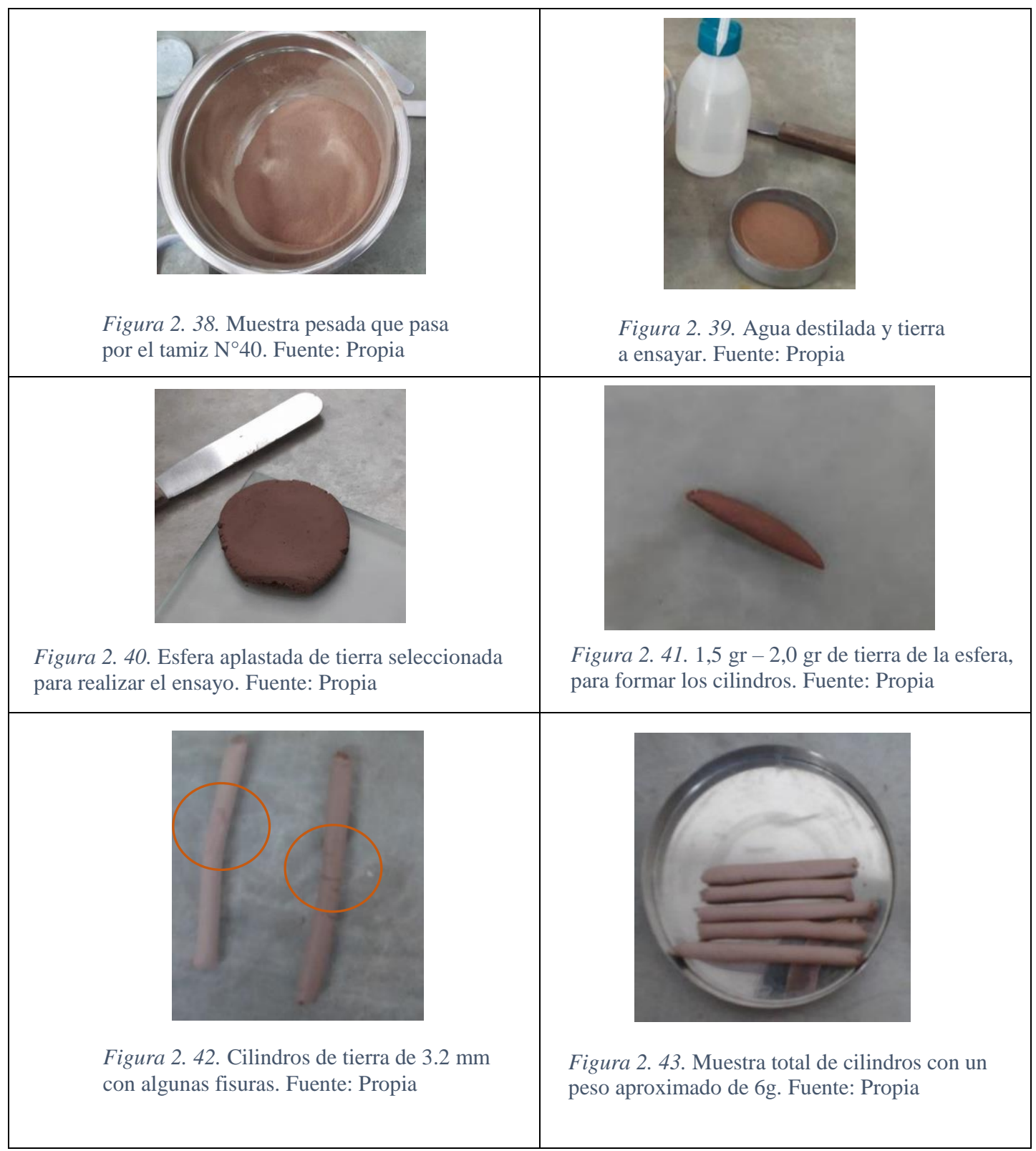

\section{- Clasificación de suelos SUCS}

Es una clasificación que permite describir la textura y tamaño de las partículas del suelo. Para esta clasificación es necesario realizar previamente la granulometría, tamizado y ensayos para tener el límite líquido, límite plástico e índice de plasticidad (Benites V., 2017). Este sistema representa a los suelos a través de letras como se muestra en la tabla 2.12 . 
Tabla 2. 12. Coeficiente de balasto para la clasificación de suelos. Fuente: Norma SUCS

\begin{tabular}{|cc|c|c|}
\hline COEFICIENTE BALASTO VERTICAL KV & Kv & PROMEDIO \\
\hline GW $\left./ \mathbf{c m}^{\mathbf{3}}\right)$ & Gravas bien graduadas & $14-20$ & 17 \\
\hline GC & Gravas Arcillosas & $11-19$ & 15 \\
\hline GP & Gravas mal graduadas & $8-14$ & 11 \\
\hline GM & Gravas Limosas & $6-14$ & 10 \\
\hline SW & Arenas bien graduadas & $6-16$ & 11 \\
\hline SC & Arenas arcillosas & $6-16$ & 11 \\
\hline SP & Arenas mal graduadas & $5-9$ & 7 \\
\hline SM & Arenas limosas & $5-9$ & 7 \\
\hline ML & Limos orgánicos & $4-8$ & 6 \\
\hline CL & Arcillas con gravas o con arena & $4-6$ & 5 \\
\hline OL & Limos Orgánicos y arcillas limosa & $3-5$ & 4 \\
\hline MH & Limos inorgánicos & $1-5$ & 3 \\
\hline CH & Arcillas inorgánicas & $1-5$ & 3 \\
\hline OH & Arcillas orgánicas & $1-4$ & 2 \\
\hline
\end{tabular}

Primero se debe de determinar si son suelos de Granos finos o Granos gruesos, esto dependerá de la cantidad de suelo retenido en el tamiz $\mathrm{N}^{\circ} 200$ (suelos retenido $>50 \%$ de la muestra ensayada).

Segundo, si la muestra es:

- Granos finos se debe de identificar en que grupo de limos y arcillas pertenecen, si son inferiores o superiores para esto se debe recomienda revisar el anexo $\mathrm{E}$ o $\mathrm{F}$.

- Granos gruesos se debe de diferenciar si son Arenas o Gravas, si más del 50\% de la fracción gruesa es retenido en el tamiz $\mathrm{N}^{\circ} 4$ entonces es Gravas, en caso contrario son arenas.

Si son Arenas, se debe de identificar si son arenas con finos o arenas limpias para esto se debe revisar el anexo E o F.

Si son Gravas, se debe determinar si son gravas con finos o gravas limpias para esto se debe revisar el anexo $\mathrm{E}$ o $\mathrm{F}$.

\subsection{Penca de Tuna}

La penca de Tuna fue extraída del distrito de Huarochirí de la zona de Sincocaya como se muestra en la figura 2.44 .

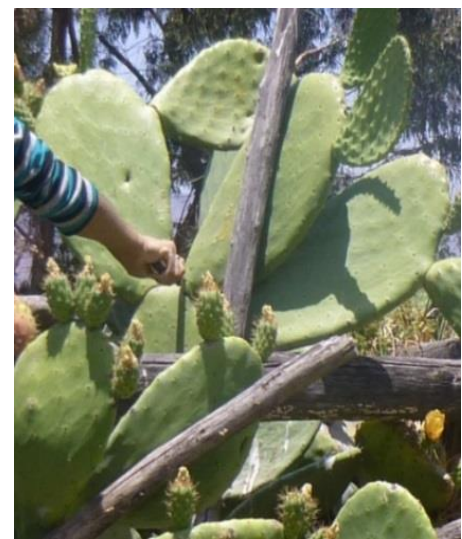

Figura 2. 44. Extracción de las pencas de tuna en Huarochirí- Sincocaya, Fuente: Propia) 


\subsection{Extracción del mucílago de penca de tuna}

Existen diversas técnicas, algunos optan por chancar, licuar, hervir la Penca de Tuna; mientras que autores como Vargas J., Heredia E., Bariola J. \& Povindar K. (1986) y León R. (2012) realizaron comparaciones entre los métodos y concluyen que el método óptimo y económicamente factible es la del remojo. Para lo cual, primero se debe de limpiar muy bien la penca de tuna para eliminar posibles espinas que quedaron de la extracción como se muestra en la figura 2.45.a, luego cortar la penca de tuna en rebanadas de aproximadamente $30 \mathrm{~mm}$, como indica figura 2.45.b y finalmente se deja remojando en un recipiente como se observa en la figura 2.45.c. Se toma en cuenta que los días de remojo variarán de acuerdo a la estación, León R. indica que, durante el invierno (15$20^{\circ} \mathrm{C}, 82-92 \%$ H.R) el tiempo de remojo oscila entre 15 y 25 días y en el verano $\left(20-25^{\circ} \mathrm{C}\right.$, 76-88\% H.R) el tiempo de remojo disminuye entre los 7 y 15 días, mientras que Vargas J., Heredia E., Bariola J. \& Povindar K. indica que las mejores condiciones de remojo son 18 días ( $20^{\circ} \mathrm{C}, 82-92 \%$ H.R) o entre 7 y 14 días $\left(20-25^{\circ} \mathrm{C}\right.$, H.R $77-88 \%$ ). Eso quiere decir que épocas con mayor temperatura el tiempo de remojo es de 7 a 15 días y épocas con menor temperatura el tiempo de remojo debe de ser mayor a 15 días con la finalidad de obtener una sustancia gomosa como indica la figura 2.45.d.

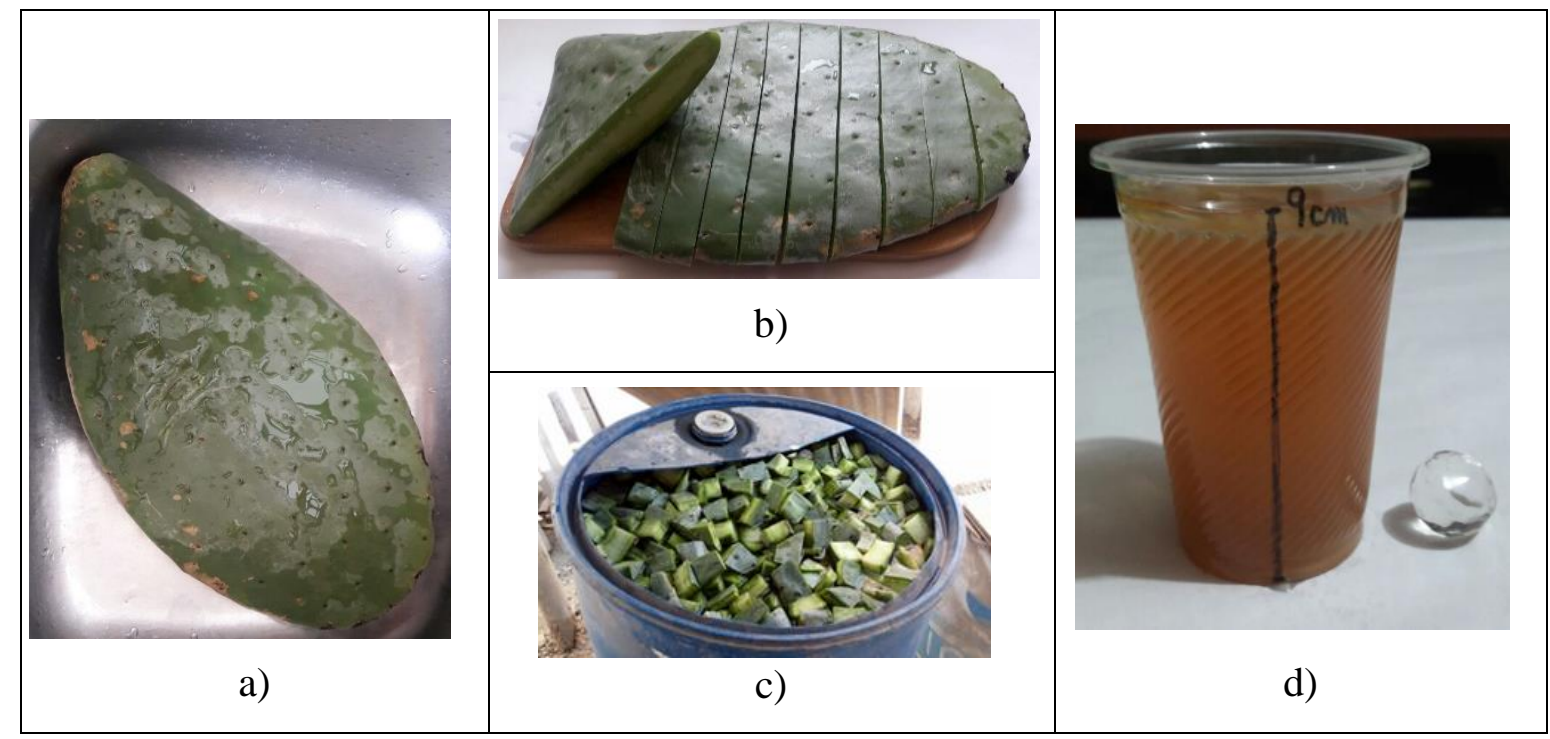

Figura 2. 45. Proceso para extraer el mucílago de la penca de tuna, Fuente: Propia

Para el desarrollo de esta investigación, se remojaron 3.4, 4.5, 5.2, 7.2 y 8.2 kilos de trozos de penca de tuna en 40 litros de agua, cada concentración por un periodo de 15 días, para poder elaborar adobes estabilizados de distintas concentraciones 


\subsection{Ensayos en el mucílago de penca de tuna}

\section{- Densidad}

Según Mispireta, C. (2012) la densidad es una característica básica de todo líquido y se define como la relación entre masa por unidad de volumen. Existen diversos métodos para determinar esta propiedad entre las cuales el método que ofrece mayor sencillez es el método del picnómetro como se describe a continuación:

Antes de comenzar con el ensayo se verifica que el picnómetro esté limpio, seco y en buen estado como indica la figura 2.46, con la finalidad de evitar errores en la obtención de los datos. Primero, pesamos el picnómetro vacío y anotamos su masa. Segundo, enrasamos el picnómetro con agua, lo cerramos y esperamos que el agua suba por el capilar hasta que rebose, después lo secamos para luego pesarlo (enrasar significa llenar el recipiente completamente de agua sin que, en este, se origine de burbujas). Tercero, enrasamos el picnómetro con la muestra de mucílago de penca de tuna, se espera que rebose y se pesa. Se toma en cuenta que la densidad del líquido dependerá de su temperatura.

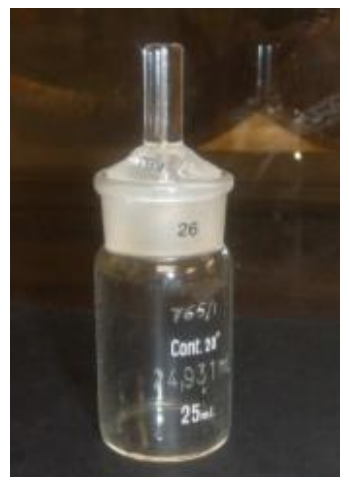

Figura 2. 46. Modelo de picnómetro utilizado para el ensayo, Fuente: Propia.

- Viscosidad

Existen diversos métodos para determinar la viscosidad de un fluido, uno de ellos es medir la velocidad de caída de un sólido esférico a través de un líquido obedeciendo la Ley de Stokes como se indica en la figura 2. 47. Para determinar la viscosidad de un flujo se necesita conocer dos parámetros, las densidades tanto de la esfera como de los fluidos y la velocidad de la canica en las distintas soluciones. 


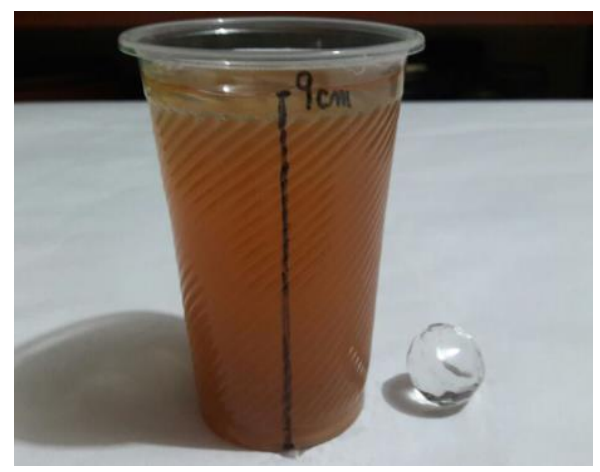

Figura 2. 47. Ensayo de viscosidad en el mucílago de penca de tuna, Fuente: Propia

Como se mencionó en el ítem 2.2.5.2.2.1 se elaborarán adobes para 5 concentraciones distintas, por lo que es necesario determinar la viscosidad para cada una de ellas.

OBJETIVO 2: Seleccionar la dosificación ideal de la mezcla para obtener los mejores resultados de resistencia a la compresión, flexión y absorción en la unidad de adobe estabilizado.

\subsection{Unidad de adobe}

\subsection{Elaboración de los adobes}

Para la elaboración del adobe se decidió seguir el procedimiento indicado en el Manual de construcción: Edificaciones de adobe (2010). Asimismo, se presentarán ordenadamente a continuación:

Para la elaboración de 200 adobes como se evidencia en la figura 2.50, se zarandeó 2000 $\mathrm{kg}$ de tierra con el fin de retirar aquellas piedras con un diámetro mayor a $1.5 \mathrm{~cm}$. Asimismo, para un mayor control y manejo, la tierra fue colocado en costales de 40 kilos como se muestra en la figura 2.51 .

Se cortó en pequeños pedazos grandes cantidades de pencas de tuna como se muestra en la figura 2.48, que posteriormente serian maceradas en recipientes de agua a diferentes proporciones de trozos de tuna como se evidencia en la tabla 2.13.

Tabla 2. 13. Cantidad de agua y penca de tuna por dosis. Fuente: Propia

\begin{tabular}{|c|c|c|c|}
\hline $\mathbf{N}^{\circ}$ & DOSIS (kg/L) \% & AGUA (L) & TUNA (kg) \\
\hline 1 & 20.5 & 40 & 8.2 \\
\hline 2 & 18.0 & 40 & 7.2 \\
\hline 3 & 13.0 & 40 & 5.2 \\
\hline 4 & 11.3 & 40 & 4.5 \\
\hline 5 & 8.5 & 40 & 3.4 \\
\hline
\end{tabular}


Posteriormente, se colocó los trozos de penca de tuna en un recipiente con agua por 15 días como se muestra en la figura 2.49, periodo en el cual las pulpas de penca de tuna se disolvieron casi en su totalidad, después se retiró las cáscaras del fluido por medio de un tamiz hasta que solo quedó la sustancia viscosa.

Para evitar la aparición de posibles fisuras, se utilizó como fibra alrededor de 5 kilos de paja de trigo seca recolectada de la zona de Huarochirí como se indica en la figura 2.52. Además, para moldear los adobes se utilizó una gabera que proporcionaba dos adobes a la vez, cada uno de estos espacios tenían medidas internas de $25 \mathrm{~cm}$ x $40 \mathrm{~cm}$ x $13 \mathrm{~cm}$ como se muestra en la figura 2.53 .

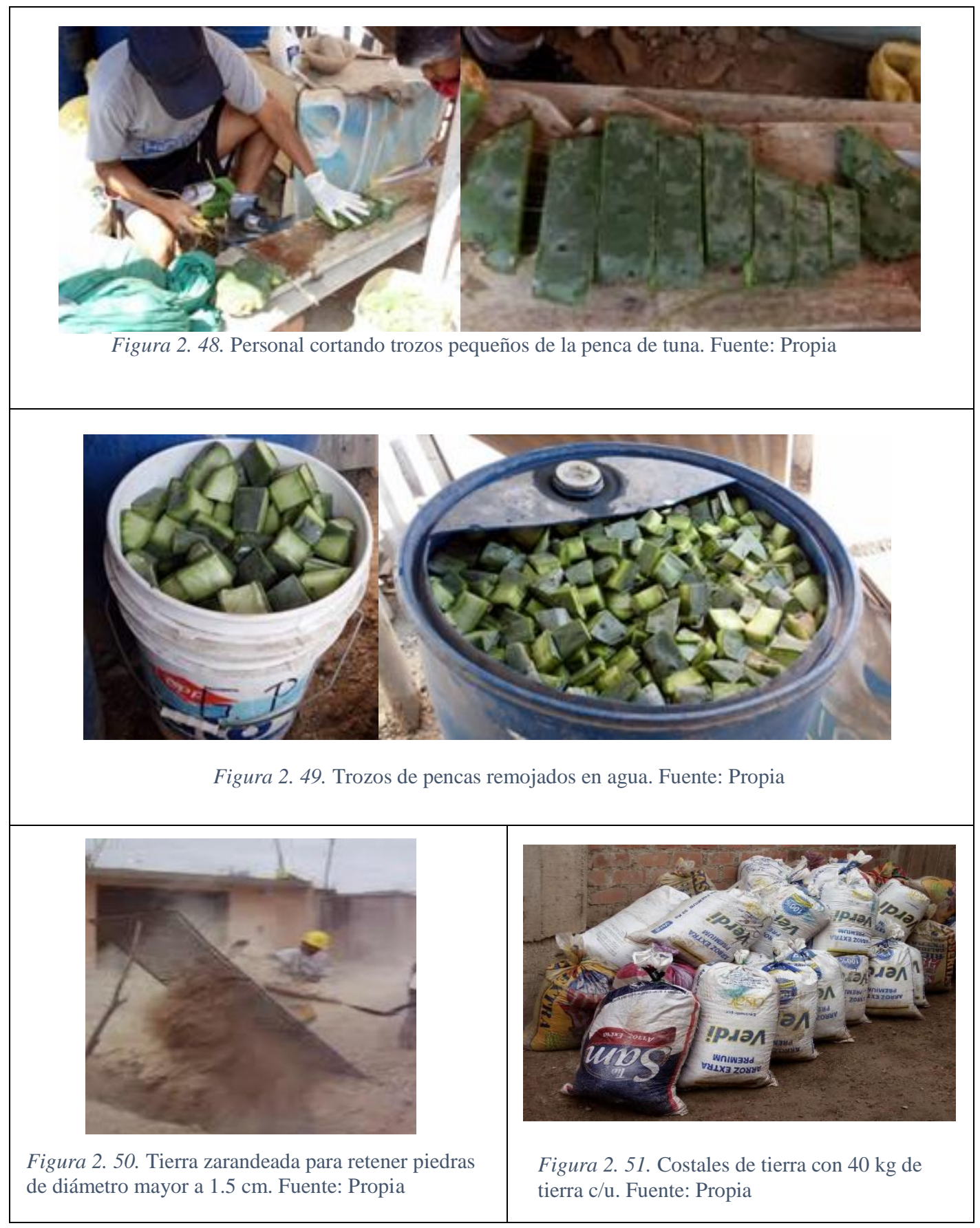




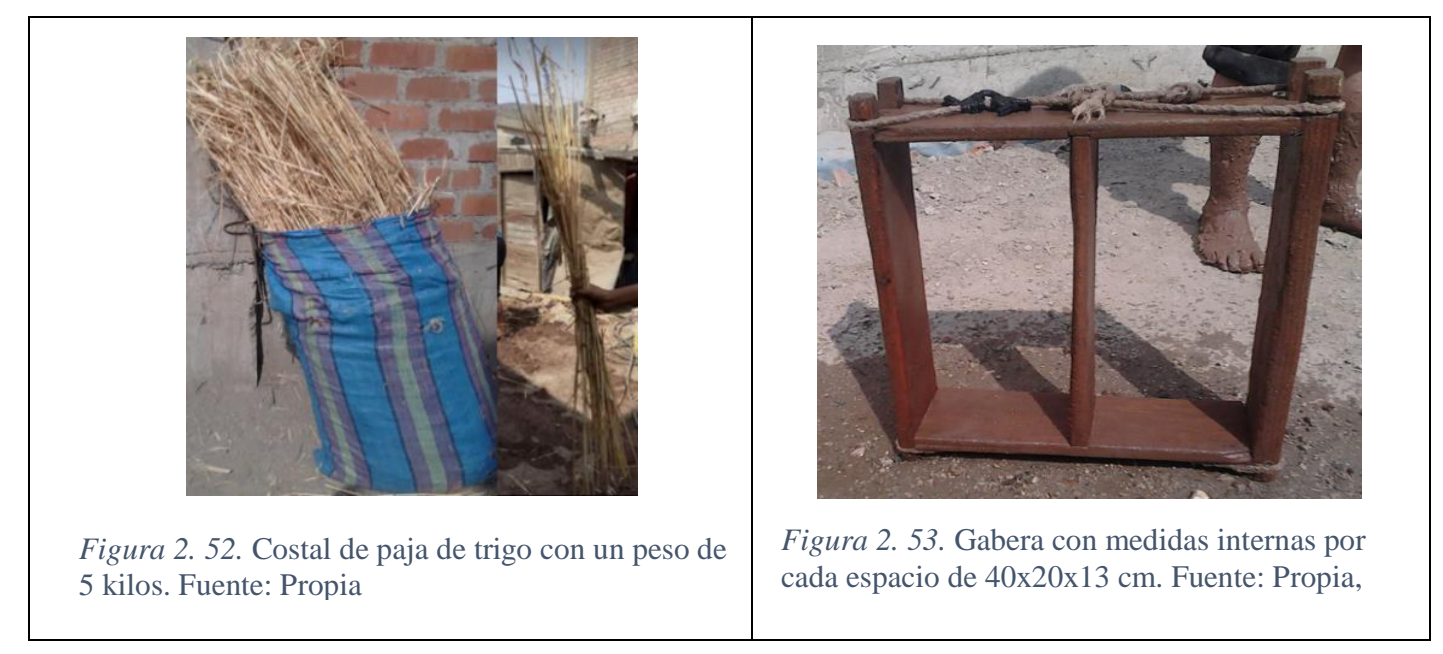

Después, se realizó 6 grupos de adobe que contenían distintas dosificaciones de mucílago de pencas de tuna (Dosificación 8.5\%, 11.3\%, 13\%, 18\%, 20\%: relación entre el peso de trozos de penca de tuna con respecto a la cantidad de litros de agua para una determinada muestra- $\mathrm{kg} / \mathrm{L}$ ). El primer grupo fueron considerados elementos patrón, ya que no contenían mucílago mientras que los cincos grupos restantes tenían la misma cantidad de litros de mucílago de penca de tuna a diferentes concentraciones como se muestra en la tabla 2.14.

Tabla 2. 14. Cantidad de materiales utilizados para la elaboración de adobe según el número de mezclas. Fuente: Propia

\begin{tabular}{|c|c|c|c|c|c|c|c|}
\hline \multirow{2}{*}{$\mathbf{N}^{\circ}$} & \multirow{2}{*}{$\begin{array}{l}\text { DOSIFICACIÓN } \\
\text { (KG/L) \% }\end{array}$} & \multirow{2}{*}{$\begin{array}{l}\text { CANTIDAD } \\
\text { DE ADOBES }\end{array}$} & \multirow{2}{*}{ AGUA (L) } & \multirow{2}{*}{$\begin{array}{c}\text { VISCOSIDAD } \\
(\mathrm{L})\end{array}$} & \multirow{2}{*}{$\begin{array}{c}\text { PAJA } \\
\text { (gr) }\end{array}$} & \multicolumn{2}{|c|}{ TIERRA } \\
\hline & & & & & & $\operatorname{SACOS}(40 \mathrm{~g})$ & kg \\
\hline 0 & - & 40.0 & 80.0 & - & 700.0 & 10.0 & 400.0 \\
\hline 1 & 20.5 & 40.0 & 40.0 & 40.0 & 700.0 & 10.0 & 400.0 \\
\hline 2 & 18.0 & 28.0 & 30.0 & 30.0 & 500.0 & 7.0 & 280.0 \\
\hline 3 & 13.0 & 28.0 & 30.0 & 30.0 & 500.0 & 7.0 & 280.0 \\
\hline 4 & 11.3 & 28.0 & 30.0 & 30.0 & 500.0 & 7.0 & 280.0 \\
\hline 5 & 8.5 & 28.0 & 30.0 & 30.0 & 500.0 & 7.0 & 280.0 \\
\hline
\end{tabular}

Se vació los costales con tierra en un espacio abierto y plano como se muestra en la figura 2.54. A continuación, se humedeció la pala, herramienta que nos ayudará a mezclar los materiales. Después se humedece la tierra con un porcentaje de agua del diseño de mezcla, se remueve bien y se deja reposar por una hora como se observa en la imagen 2.55. Luego se agregó el mucílago de penca de tuna de acuerdo al diseño como se observa en la figura 2.56 y se removió bien. Posteriormente, se agregó la paja con una longitud aproximada de $10 \mathrm{~cm}$ como se muestra en la figura 2.57. A continuación, con ayuda de una pala se vació la mezcla hacia la gabera, que previamente fue humedecido con la finalidad de que no absorba agua de la mezcla y no se pegue en la herramienta como se observa en la figura 2.58. La mezcla en la gabera se removió y se le aplastó bien con ayuda de las manos 
y pies para luego alisar la superficie como se muestra en la figura 2.59. Finalmente, como se observa en la figura 2.60 se levanta la gabera con el fin de que los adobes caigan o se deslicen de ella por su propio peso; este proceso se repitió varias veces.

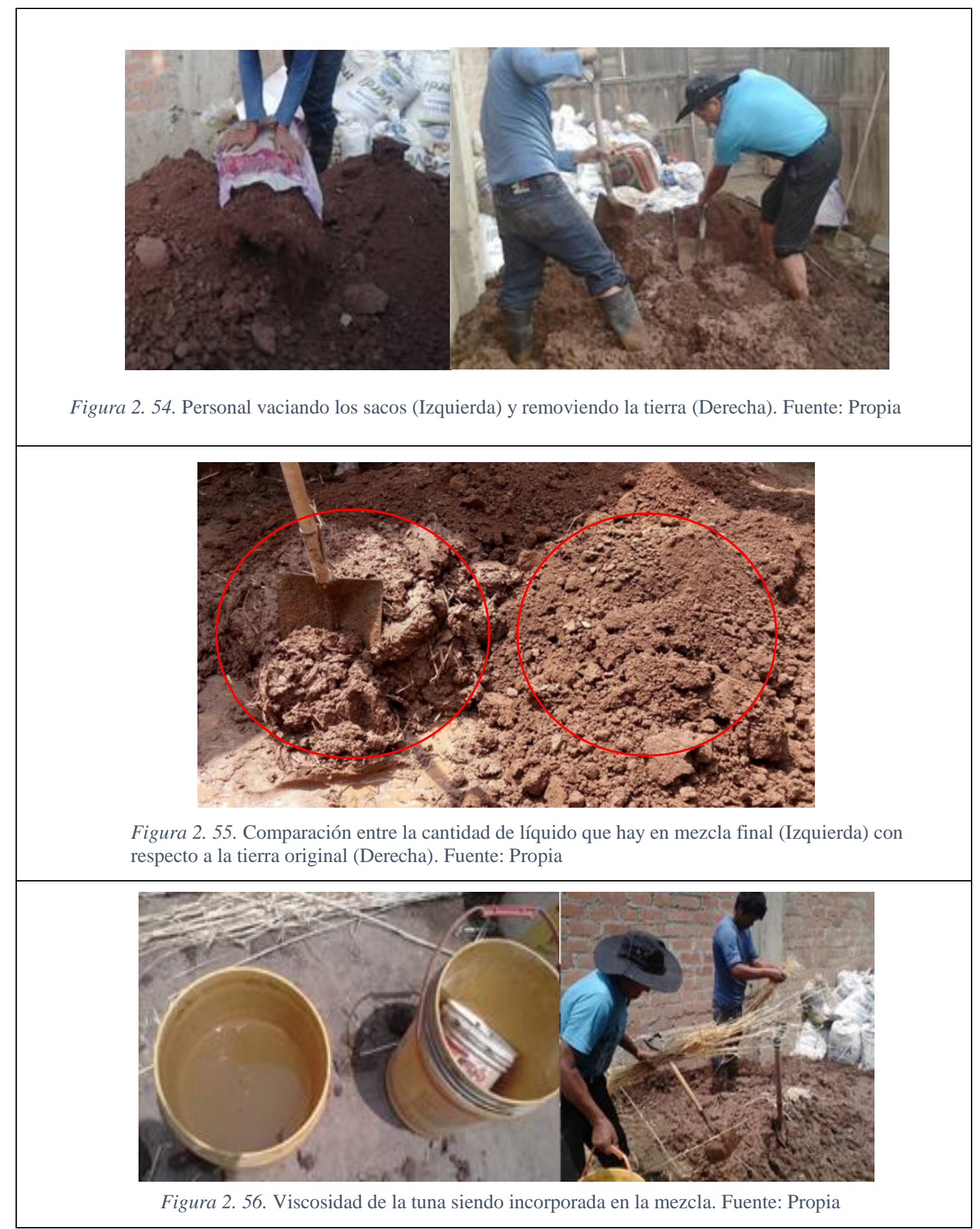




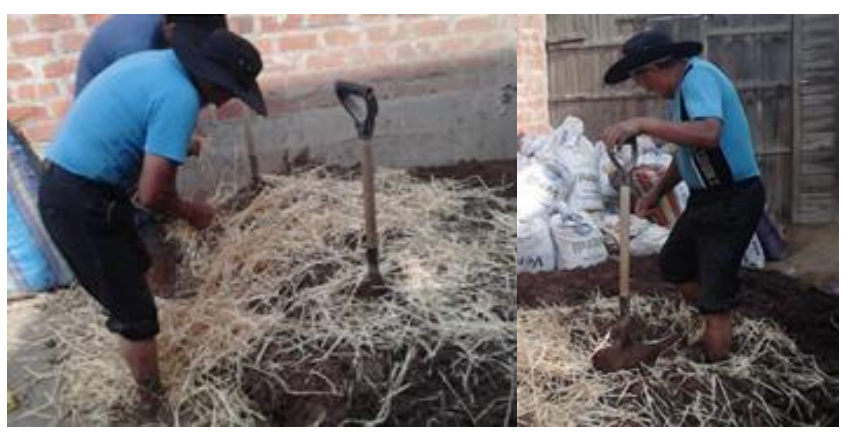

Figura 2. 57. Incorporación de la paja en la mezcla para elaboración del adobe .Fuente: Propia

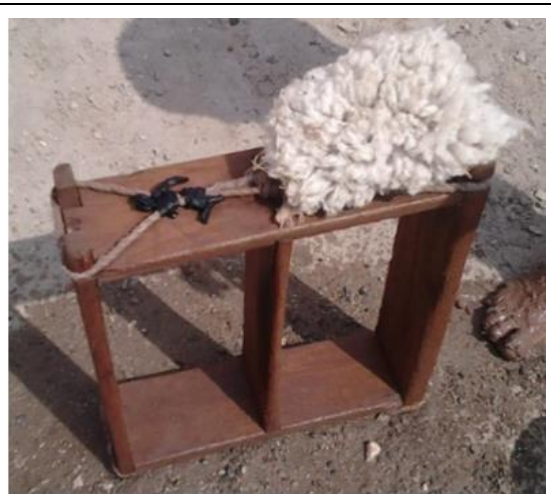

Figura 2. 58. Gabera con medidas de 40x20x13 $\mathrm{cm}$. Fuente: Propia

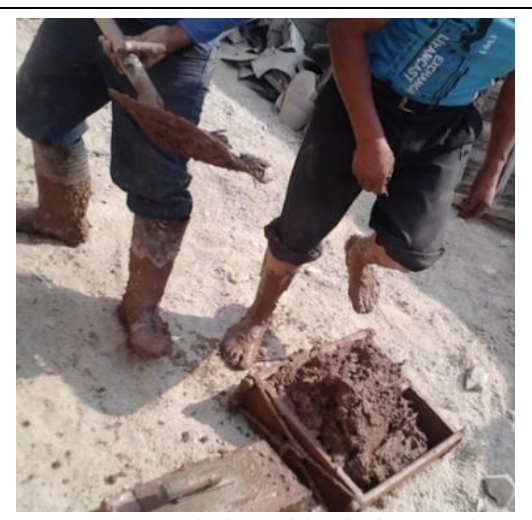

Figura 2. 59. Colocación de la mezcla en la gabera (Derecha). Fuente: Propia

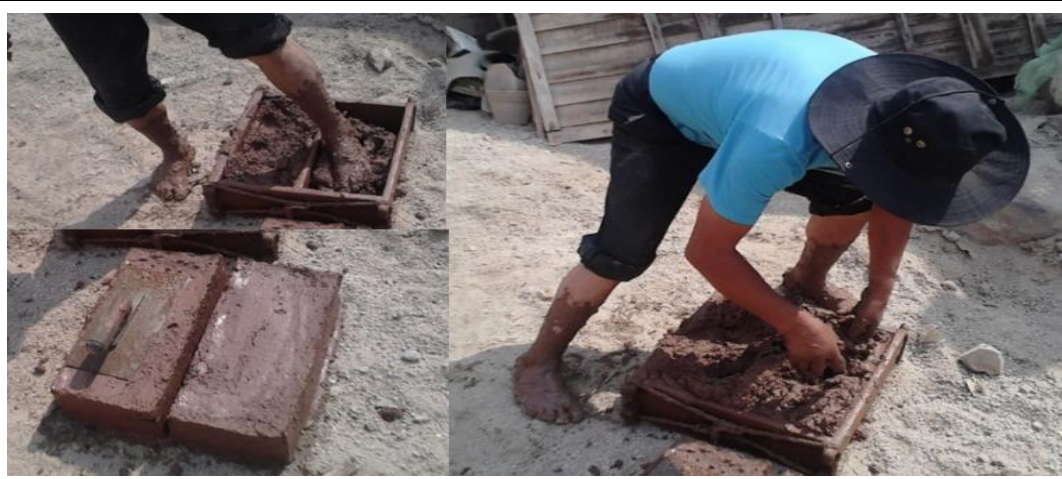

Figura 2. 60. Tierra aplastada con la mano y el pie para la elaboración del adobe. Fuente: Propia

Finalmente, los adobes deben de estar secando en un espacio que cuente con techo fijo o provisional con el fin de que este proteja de los rayos solares y prevenir la aparición de grandes fisuras. Los adobes deben de secar teniendo como base el lado con mayor área, luego de cinco días se colocó los adobes de costados para que cada lado pueda secarse de forma uniforme como se muestra en la figura $2.61 \mathrm{y}$ figura 2.62 (Este proceso se puede evidenciar en el manual adjunto en el Anexo K) 


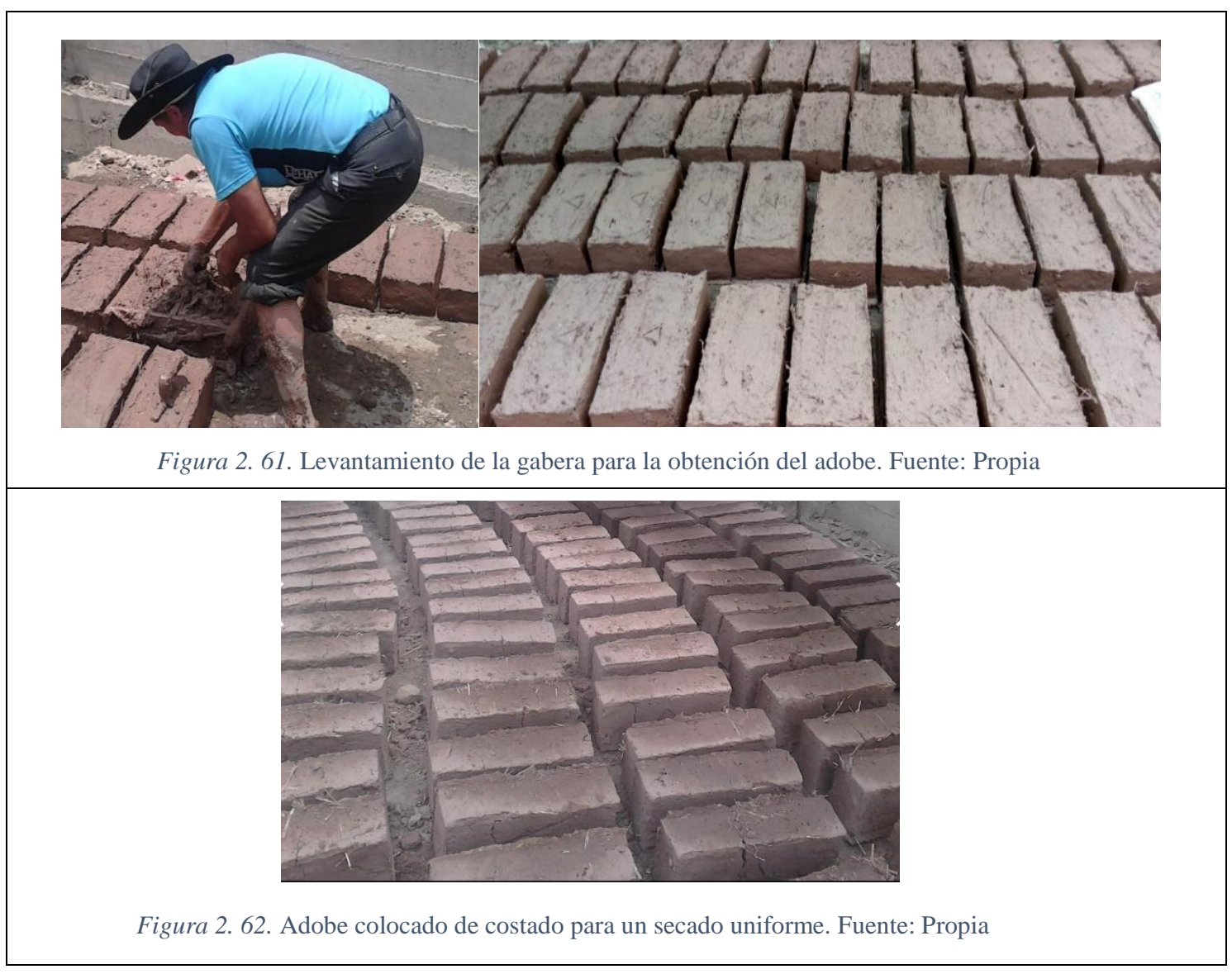

\section{Observaciones de procedimiento}

- Otra forma de calcular la cantidad de tuna necesaria para el procedimiento, es a través de un balde de 20lt de agua de capacidad, el cual puede contener aproximadamente $12.5 \mathrm{~kg}$ de tuna.

- Se debe tapar los recipientes con un material de plástico, con el fin de evitar que las moscas queden atrapadas en el líquido.

- La mezcla debe tener un olor fuerte a descomposición y un color verde oscuro, pues son estas características que indican que el líquido tiene buena viscosidad.

- La gabera debe ser sumergida en un balde de agua constantemente con el objetivo de prevenir que los adobes se peguen en ella.

- Los adobes deben ser colocados debajo de un techo con la finalidad de que este le proteja de los rayos solares y de esta manera evitar la aparición de fisuras.

\subsection{Ensayos por unidad de adobe}

Según la Norma E.080 (2017) titulada Diseño y Construcción con tierra reforzada, indica que se debe ensayar un mínimo de 6 unidades con el fin de elegir los mejores 3 resultados, para de esta manera obtener el máximo valor promedio (Los ensayos fueron realizados 
en la Universidad Peruana de Ciencias Aplicadas en la sede Villa). Asimismo, para realizar correctamente los ensayos se utilizó las normas American Society of Testing Materials (ASTM), La Norma Técnica Peruana (NTP) y La Norma E.080 diseño y construcción con tierra reforzada.

\subsection{1. Resistencia a la compresión}

Esta prueba muestra la capacidad de los adobes al ser sometidos a una carga axial, utilizando las especificaciones técnicas de la NTP 399.605: Unidades de Albañilería, el cual será explicado a continuación:

La norma indica que para este ensayo se puede utilizar cualquier máquina empleadas en el laboratorio para ensayos a compresión, en esta investigación se utilizará la Maquina Universal. En primer lugar, se toma 3 especímenes (20 cm x $20 \mathrm{~cm}$ x $13 \mathrm{~cm}$.) de cada concentración (muestra patrón, 8.5\%, 11.3\%, 13\%, 18\%, 20\%.) seco para ensayar y se le coloca individualmente sobre el apoyo de la máquina para después descender el cabezal como se observa en la figura 2.63, hasta lograr que la muestra falle. Asimismo, se debe de considerar 3 aspectos:

Primero, que el centro del apoyo debe de coincidir con la superficie del bloque que está en contacto con el espécimen. Segundo, que, si el área del apoyo es menor que el de la cara del espécimen, se debe de colocar una plancha de acero en la parte superior e inferior de este, el cual debe de tener una dureza Rockwell C 60 cuyo desnivel no sea mayor de $0.03 \mathrm{~mm}$ con respecto al plano horizontal. Tercero, si la superficie es irregular se recomienda rellenar con pasta de cemento portland por 24 horas antes de colocar el recubrimiento, con la finalidad de conseguir que los cabezales de la máquina de compresión tengan contacto uniforme con la superficie. Asimismo, se puede colocar un recubrimiento de yeso cocido o de una mezcla que contenga entre $40 \%$ y $60 \%$ de azufre.

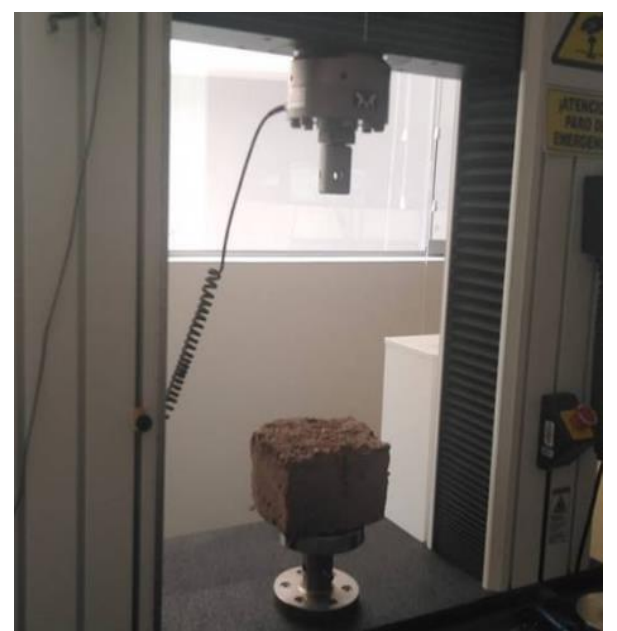


Luego, se calcula la resistencia a la compresión como lo describe a continuación:

La resistencia a la compresión ( $\left.\mathrm{f}^{\prime} \mathrm{b}\right)$ se determina dividiendo la carga de rotura $(\mathrm{Pu})$ entre el área bruta (A) de la unidad cuando esta es sólida o tubular y el área neta (A) cuando es hueca o perforada. Lo mencionado anteriormente fue expresado en la ecuación 2.1.

$$
f=\frac{P_{u}}{A}
$$

Donde:

$\mathrm{f}=$ Resistencia a la compresión $\left(\mathrm{kg} / \mathrm{cm}^{2}\right)$

$\mathrm{Pu}=$ Carga Aplicada hasta la rotura $(\mathrm{kg})$

$\mathrm{A}=$ Área bruta de aplicación de la carga $\left(\mathrm{cm}^{2}\right)$

\subsection{2. Resistencia a la flexión}

El propósito de esta prueba es determinar la capacidad de deformación del material y su capacidad de resistencia a la flexión a través del módulo de rotura (Mr) utilizando las especificaciones de la norma ASTM C78, el cual se explicará a continuación.

Primero, se selecciona 3 unidades de adobe de cada concentración (muestra patrón, 8.5\%, $11.3 \%, 13 \%, 18 \%, 20.5 \%$ ), las cuales tienen como medidas $20 \mathrm{~cm} \mathrm{x} 40 \mathrm{~cm} \mathrm{x} 13 \mathrm{~cm}$. Luego se coloca el adobe sobre dos rodillos de apoyo de la Máquina Universal, como se observa en la figura 2.64. Asimismo, un rodillo estará ubicado en la cara superior al centro de luz del adobe, el cual ejercerá una fuerza que irá incrementándose hasta producirse la falla la cual se expresa en MPa.

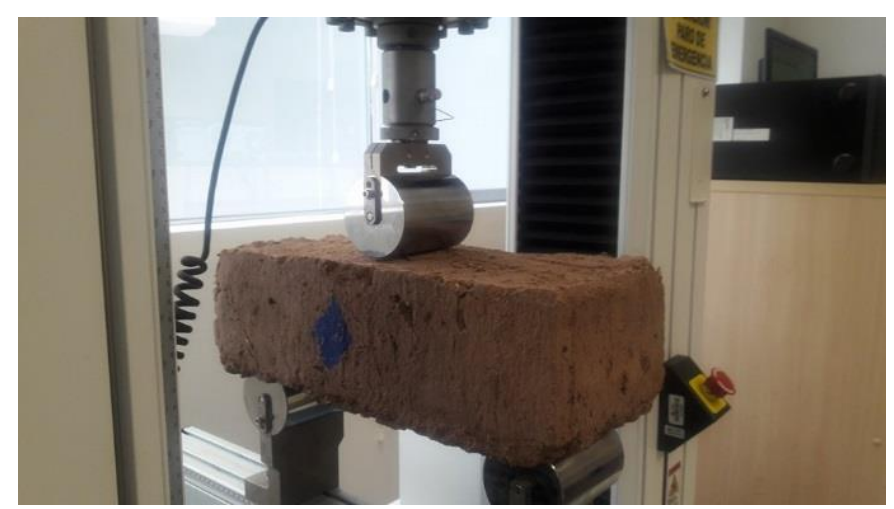

Figura 2. 64. Ensayo de resistencia la flexión en adobe. Fuente: Propia

Finalmente, el módulo de rotura (Mr) se determina dividiendo la carga de rotura $(\mathrm{P})$ y la distancia entre los soportes (L) entre el ancho promedio (b) y la altura promedia elevada al cuadrado (h2), como de expresa en la ecuación 2.2. 


$$
M_{r}=\frac{P \times L}{b \times h^{2}}
$$

Donde:

$\mathrm{Mr}=$ Módulo de rotura $\left(\mathrm{kg} / \mathrm{cm}^{2}\right)$

$\mathrm{P}=$ Carga Aplicada $(\mathrm{kg})$

$\mathrm{L}=$ Distancia entre apoyos $(\mathrm{cm})$

$\mathrm{b}=$ Ancho promedio $(\mathrm{cm})$

$\mathrm{h}=$ Altura promedio $(\mathrm{cm})$

\subsection{3. Ensayo de absorción}

Esta prueba se basó en la NTP 399.613: Unidades de Albañilería. Métodos de muestreo y ensayo de ladrillo de arcilla usados en albañilería, el cual tiene como objetivo conocer de absorción del espécimen, es decir encontrar un índice que refleje su capacidad de absorción al estar sumergidos en agua por 24 horas, el cual será expresada entre la diferencia del peso saturado con el peso seco, dividida entre el peso seco como se muestra en la ecuación 2.3.

Donde:

$$
\% A B S=\frac{P 2-P 1}{P 1} \times 100
$$

$\% \mathrm{ABS}=$ Porcentaje de absorción de agua (\%)

$\mathrm{P} 1=$ Peso de la unidad seca (gr)

$\mathrm{P} 2=$ Peso de la unidad saturada (gr)

El procedimiento que se siguió según la norma fue el siguiente:

Primero se secaron las unidades de adobe en el horno durante 24 horas a una temperatura de $110^{\circ} \mathrm{C}$ con la finalidad de eliminar la humedad natural en el elemento. A continuación, se pesan las muestras como se observa en la figura 2.65 para posteriormente ser sumergidas en el agua fría por alrededor de 24 horas, luego de transcurrido ese periodo de tiempo se retiran del agua para después ser secados superficialmente con un paño como se evidencia en la figura 2.66. A continuación, se pesaron y sus valores fueron anotados en una libreta de apuntes. Finalmente, se utilizó la ecuación 2.3 para calcular la absorción de cada elemento.

Se toma en cuenta que al momento de sumergirlos todas las caras deben de estar con un contacto directo con el agua, así como que las muestras una vez retiradas del agua deben ser pesadas dentro de los cinco minutos contacto con el agua. 


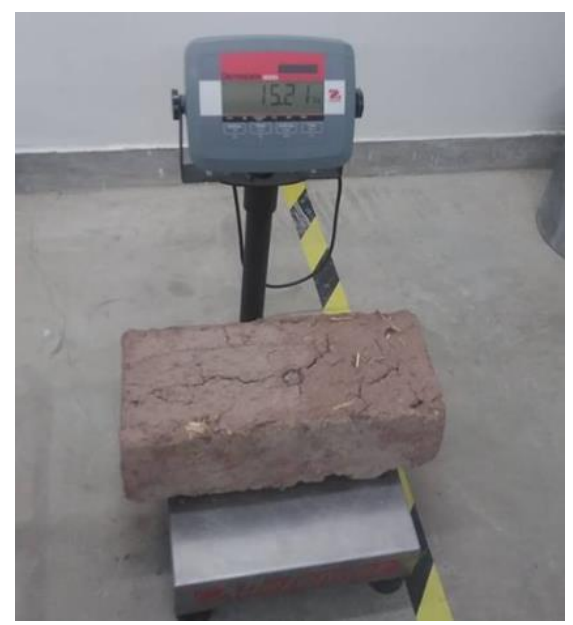

Figura 2. 65. Obtención del peso del adobe a través de una balanza. Fuente: Propia

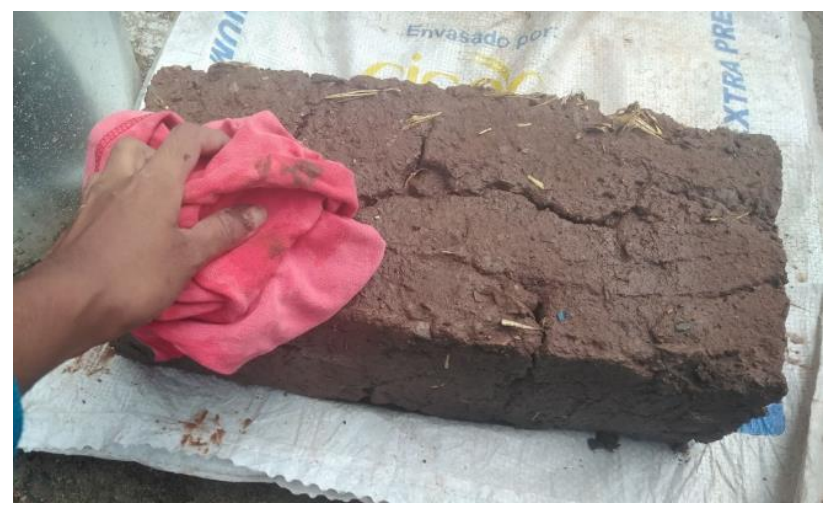

Figura 2. 66. Adobes secados superficialmente. Fuente: Propia

\subsection{4. Pruebas recomendadas por otros autores}

\section{- Prueba de inmersión}

El siguiente ensayo fue descrito por Micek et al (2006, citado por Benites, V., 2017) en su Manual de construcción en tierra: La tierra como material de construcción y sus aplicaciones en la arquitectura actual, el cual describe que para medir la durabilidad del adobe este debe ser expuesto a condiciones de inundación, que podrían ocurrir, después de fuertes lluvias. Este autor clasificó los adobes según el grado de desmoronamiento visible como se indica en la tabla 2. 15. 
Tabla 2. 15. Calificaciones de los resultados de la prueba de inmersión en los adobes Fuente: Benites, 2017

\begin{tabular}{|l|c|l|}
\hline \multicolumn{1}{|c|}{ CLASIFICACIÓN } & SÍMBOLO & \multicolumn{1}{c|}{ DESCRIPCIÓN } \\
\hline Despreciable & $\mathrm{N}$ & $\begin{array}{l}\text { La unidad no muestra ningún daño visible. No hay hendiduras producidas } \\
\text { por la presión de la inserción con un dedo. }\end{array}$ \\
\hline Ligero & $\mathrm{L}$ & $\begin{array}{l}\text { La unidad no muestra ningún daño visible, pero podría ocurrir con una } \\
\text { ligera presión. }\end{array}$ \\
\hline Moderado & $\mathrm{M}$ & $\begin{array}{l}\text { La unidad muestra daños estructurales visibles y hendiduras con una } \\
\text { ligera presión. El agua que queda en el tanque es de color marrón debido } \\
\text { a la descomposición de la unidad. }\end{array}$ \\
\hline Severo & $\mathrm{S}$ & $\begin{array}{l}\text { La unidad pierde la mayor parte de sus superficies o bordes. El agua que } \\
\text { queda en el tanque es de color marrón y fangoso por la erosión, y la unidad } \\
\text { no puede soportar ningún tipo de presión. }\end{array}$ \\
\hline
\end{tabular}

Para esta prueba los adobes fueron sumergidos en el pozo de curado y en algunas tinas con agua durante 24 horas como se observa en la figura 2.67, después de este periodo, se extrajeron del agua para después evaluar su deterioro o como este se comporta cuando se le ejerce una pequeña fuerza con los dedos, para posteriormente clasificarla según la tabla mencionada anteriormente como se muestra en la figura 2.68 .

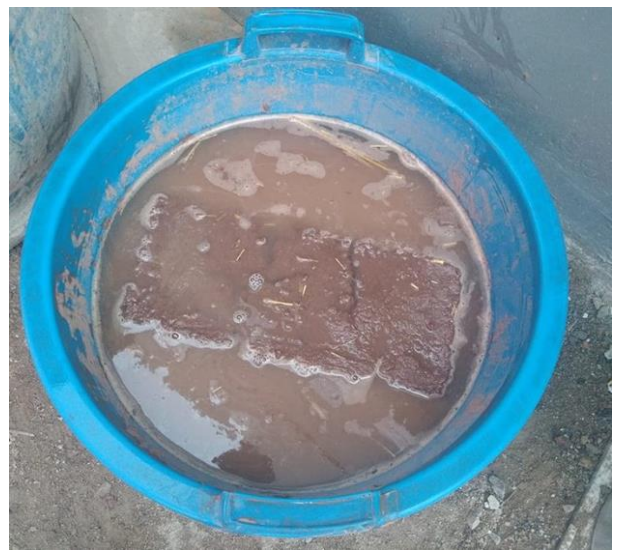

Figura 2. 67. Adobes sumergidos en tinas de agua por alrededor de 24 horas. Fuente: Propia

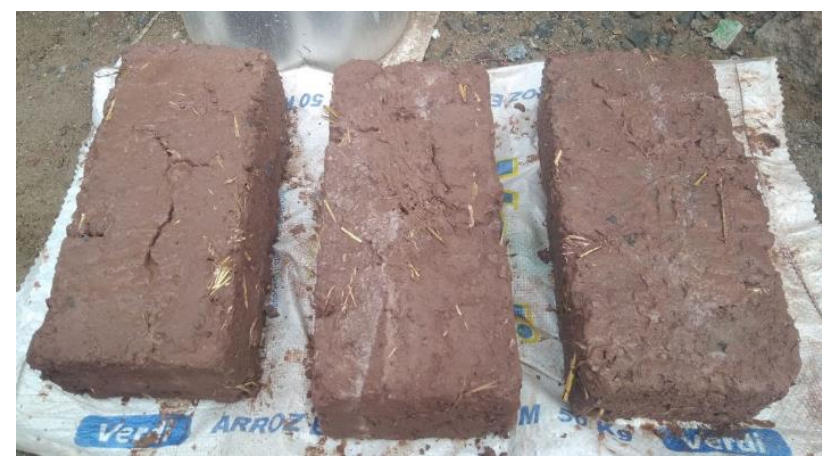

Figura 2. 68. Evaluación del deterioro de los adobes después de ser sumergido. Fuente: Propia 
Como se trata de una prueba basada en la observación se requerirá una valorización individual de al menos 2 personas para luego darle una clasificación.

\section{- Prueba de chorro de agua}

Esta prueba tiene como objetivo dar una idea de la durabilidad de los adobes cuando estas están sometidas a condiciones de lluvias intensas.

Consiste en aplicar un chorro de agua a una presión contante, distancia y tiempo de aplicación determinado como se muestra en la figura 2.69. Luego con ayuda de una vara y vernier se mide la profundidad de la marca dejada por el chorro sobre la superficie del adobe.

El método propuesto por Fox R., McDonald A. y Pritchard (2011) en su libro titulado Introducción a la Mecánica de Fluidos indica que la presión se calcula según la dinámica de fluidos, como se observa en la figura 2.70, la presión depende tanto de la velocidad como del área de la sección transversal por donde sale el fluido. A continuación, se utiliza la conservación del momento para calcular la fuerza del agua que sale de la boquilla (ecuación 2.4.a y 2.4.b). Finalmente, la presión del agua puede ser calculada utilizando la ecuación 2.5 .

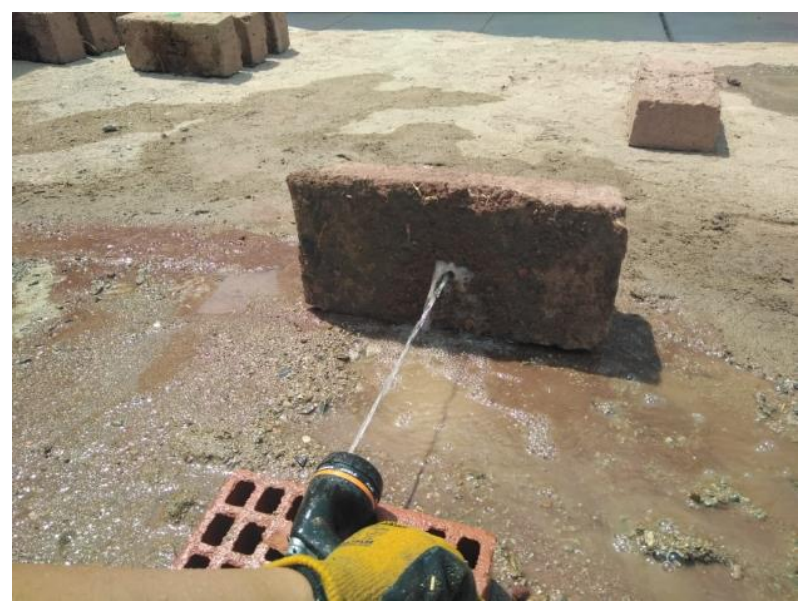

Figura 2. 69. Ensayo de chorro de agua en adobe. Fuente: Propia

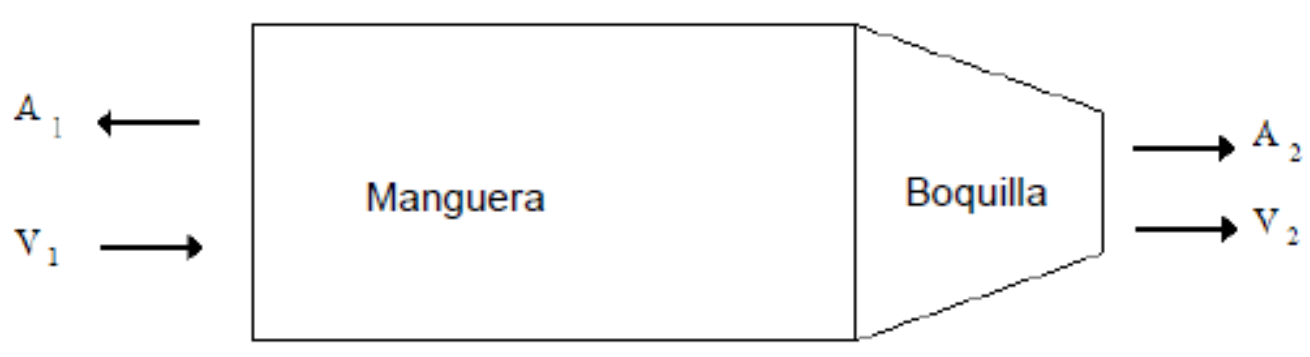

Figura 2. 70. Representación gráfica de las velocidades y áreas usadas para el cálculo del ensayo de chorro de agua. Fuente: Chen, 2009 


$$
\begin{gathered}
F=\int \rho V_{1}\left(V_{1} d A_{1}\right)+\int \rho V_{2}\left(V_{2} d A_{2}\right) \\
F=\rho\left(V_{2}^{2} A_{2}-V_{1}^{2} A_{1}\right)
\end{gathered}
$$

Donde:

$\mathrm{F}=$ fuerza $\left(\mathrm{kg} \cdot \mathrm{m} / \mathrm{s}^{2}\right.$ ó $\left.\mathrm{N}\right)$

$\mathrm{P}=$ densidad del agua $\left(1 \mathrm{~g} / \mathrm{cm}^{3}\right)$

$\mathrm{V} 1=$ velocidad del agua que entra a la boquilla $(\mathrm{m} / \mathrm{s})$

$\mathrm{V} 2=$ velocidad del agua que sale de la boquilla $(\mathrm{m} / \mathrm{s})$

$\mathrm{A} 1=$ área de la sección transversal de la manguera $\left(\mathrm{m}^{2}\right)$

A2= área de la sección transversal de la boquilla $\left(\mathrm{m}^{2}\right)$

$$
P=\frac{F}{A_{2}}
$$

Donde:

$\mathrm{P}=$ presión $\left(\mathrm{N} / . \mathrm{m}^{2}\right)$

$\mathrm{F}=$ fuerza $\left(\mathrm{kg} \cdot \mathrm{m} / \mathrm{s}^{2}\right.$ ó $\left.\mathrm{N}\right)$

A2= área de la sección transversal de la boquilla $\left(\mathrm{m}^{2}\right)$

Para determinar la presión en la boquilla primero se calcula la velocidad del agua en la boquilla con los siguientes pasos. Primero se determina el caudal que sale por el caño, como se muestra en la figura 2.71, se toma el tiempo que demora en llenar el recipiente hasta el nivel antes indicado. Una vez obtenido los datos de volumen y tiempo se calcula el caudal a través de la ecuación 2.6. Como el caudal es constante, utilizamos la ecuación 2.7 para determinar la velocidad del flujo para cualquier área transversal por donde viaja el flujo.

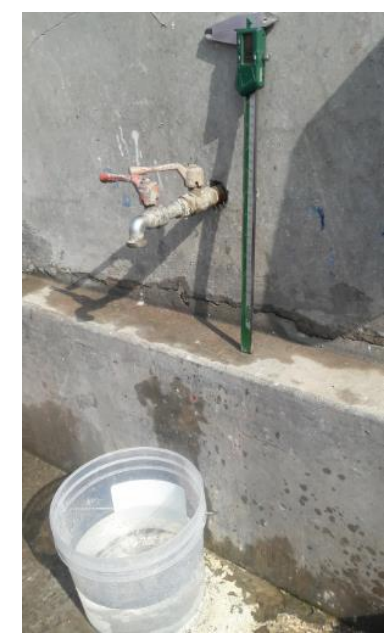

Figura 2. 71. Herramientas para calcular el caudal del agua que sale del caño. Fuente: Propia 


$$
Q=\frac{V}{t}
$$

Donde:

$\mathrm{Q}=$ caudal $\left(\mathrm{m}^{3} / \mathrm{s}\right)$

$\mathrm{V}=$ volumen $\left(\mathrm{m}^{3}\right)$

$\mathrm{T}=$ tiempo $(\mathrm{s})$

$$
V=\frac{Q}{A}
$$

Donde:

$\mathrm{V}=\operatorname{velocidad}(\mathrm{m} / \mathrm{s})$

$\mathrm{Q}=$ caudal $\left(\mathrm{m}^{3} / \mathrm{s}\right)$

$\mathrm{A}=$ área $\left(\mathrm{m}^{2}\right)$

OBJETIVO 3: Comparar los resultados de resistencia mecánica (compresión y flexión) y resistencia física (absorción) de las unidades y pilas de adobes convencionales de los adobes estabilizados.

\subsection{Pilas de adobe}

\subsection{Elaboración y secado de las pilas de adobe}

Las pilas de adobe son elaboradas con el fin de realizar el ensayo de compresión según el M.V.C.S E.0.80 “Adobe” (2017). Las pilas estarán compuestas por el número entero de adobes necesarios para obtener un coeficiente de esbeltez (altura/espesor) del orden de aproximadamente 3 como se indica en la ecuación 2.8 y 2.9 y en la figura 2.72 .

$$
\begin{aligned}
& \frac{h}{a} \cong 3 \\
& a<b
\end{aligned}
$$

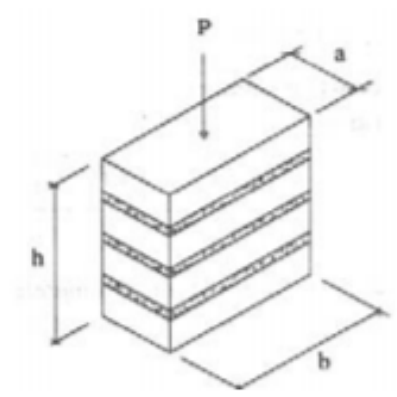

Figura 2. 72. Dimensiones de la pila de adobes. Fuente: M.V.C.S. Norma E.080, 2017 
Donde:

a: Ancho del área de la sección (cm)

b: Largo del área de la sección $(\mathrm{cm})$

h: Altura de la pila (cm)

P: esfuerzo producido sobre la pila $(\mathrm{kg})$

En este caso, se construyeron 3 pilas con unidades enteras de 3 hiladas cada una, con juntas de $2 \mathrm{~cm}$ aproximadamente como se observa en la figura 2.73. El mortero para la junta estuvo compuesto por tierra, agua y un poco de paja como se observa en la figura 2.74. El tiempo de secado del mortero de las pilas fue de 2 semanas.

Durante el proceso constructivo se verificó la verticalidad de las unidades conforme se van apilando. Las dimensiones de las pilas fueron de $53 \mathrm{~cm} \times 13 \mathrm{~cm} \times 20 \mathrm{~cm}$, siendo la esbeltez de la pila de 53/20 = 2.65 (dentro el rango indicado en la norma).

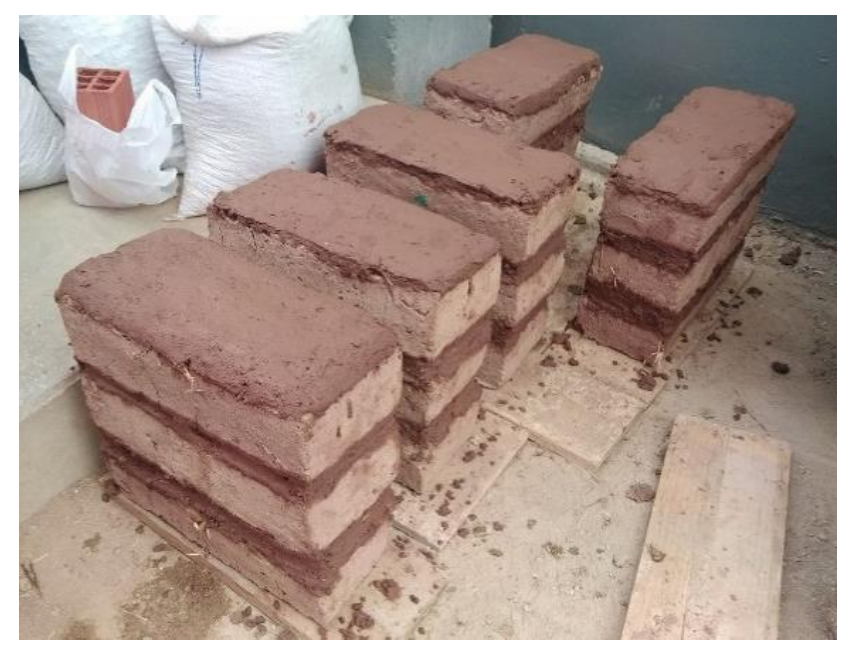

Figura 2. 73. Pilas de adobe, Fuente: Propia

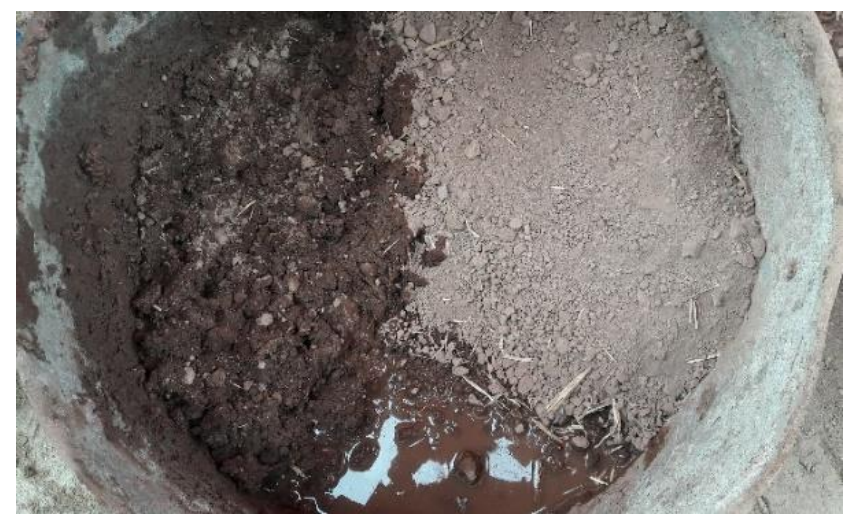

Figura 2. 74. Mortero para la pila de adobe, Fuente: Propia

\subsection{Ensayo de resistencia a la compresión en la pila de adobe}

Esta prueba muestra la capacidad de los adobes al ser sometidos a una carga axial (figura 2.75), utilizando las especificaciones técnicas de la NTP 399.605: Unidades de 
Albañilería, el cual fue explicado en el ítem 2.2.5.2.3.1

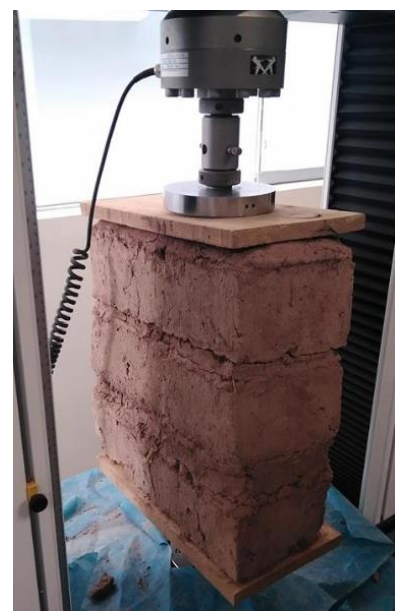

Figura 2. 75. Ensayo de compresión de la pila de adobe en la Maquina Universal. Fuente: Propia

Luego, se calcula la resistencia a la compresión como lo describe a continuación:

La resistencia a la compresión admisible de la pila (f'm) se determina dividiendo la carga de rotura $(\mathrm{Pu})$ entre el área bruta $(\mathrm{A})$ de la unidad. Lo mencionado anteriormente fue expresado en la ecuación 2.10

$$
f^{\prime} m=\frac{P_{u}}{A}
$$

Donde:

$f^{\prime} \mathrm{m}=$ Resistencia a la compresión admisible de la pila de adobe $\left(\mathrm{kg} / \mathrm{cm}^{2}\right)$

$\mathrm{Pu}=\mathrm{Carga}$ de rotura aplicada indicada por la maquina $(\mathrm{kg})$

$\mathrm{A}=$ Área bruta de la pila espécimen $\left(\mathrm{cm}^{2}\right)$

Se debe de tomar en cuenta que la resistencia a la compresión admisible de la pila debe ser mayor a $6.12 \mathrm{kgf} / \mathrm{cm}^{2}$ como indica la Norma E.080 (2017).

Asimismo, se calculó el esfuerzo de compresión último de la pila y el esfuerzo admisible de compresión por aplastamiento como lo indica la ecuación 2.11 y ecuación 2.12 respectivamente.

$$
f m=0.4 f^{\prime} m
$$

f $\mathrm{m}=$ Esfuerzo de compresión último de la pila

$$
f=1.25 f m
$$

$\mathrm{f}=$ Esfuerzo admisible de compresión por aplastamiento

Para realizar el ensayo se colocaron bases de madera para garantizar la uniformidad en la superficie durante el ensayo, las pilas fueron transportadas cuidadosamente hasta la Máquina Universal. 


\section{RESULTADOS}

A continuación, se mostrarán los resultados obtenidos en esta investigación, las cuales estarás ordenados según los objetivos específicos planteados anteriormente.

3.1. OBJETIVO 1: Analizar los materiales más adecuados para la elaboración de la mezcla a través de ensayos preliminares (prueba de color, prueba olfativa y prueba de brillo) y ensayos físicos (ensayo de cinta de barro, resistencia seca, granulometría, peso específico y límites de Atterberg) para el suelo y, ensayos de densidad y viscosidad para el mucílago de penca de tuna.

\subsubsection{Suelo}

Se ha realizado tres tipos de ensayos para cada muestra de este material $\left(1^{\circ}\right.$ muestra: suelo de Trabanda y $2^{\circ}$ muestra: suelo de Carachuco) con el fin de seleccionar el que tengas mejores características para ser utilizadas como parte de la mezcla en la elaboración del adobe.

\subsubsection{Ensayos preliminares}

Estos primeros ensayos fueron utilizados para descartar algún tipo de suelo que no cumplan con los indicadores básicos de color, olor y de brillo.

Tabla 3.1. Resultados de Pruebas Previas. Fuente: Propia

\begin{tabular}{|c|c|c|c|}
\hline \multirow{2}{*}{ PRUEBAS } & INDICADORES & $\begin{array}{c}\text { TRABANDA } \\
\left(\mathbf{1}^{\circ} \text { MUESTRA }\right)\end{array}$ & $\begin{array}{c}\text { CARACHUCO } \\
\left(\mathbf{2}^{\circ} \text { MUESTRA }\right)\end{array}$ \\
\hline \multirow{3}{*}{ Prueba de color } & Negro & $\mathrm{x}$ & $\mathrm{x}$ \\
\cline { 2 - 4 } & Claro y brillantes & Aprobado & Aprobado \\
\cline { 2 - 4 } & Gris claro & $\mathrm{x}$ & $\mathrm{x}$ \\
\hline \multirow{2}{*}{ Prueba olfativa } & Olor rancio & $\mathrm{x}$ & $\mathrm{x}$ \\
\hline \multirow{3}{*}{ Prueba de brillo } & Sin olor rancio & Aprobado & $\mathrm{x}$ \\
& Opacos & x & Aprobado \\
\cline { 2 - 4 } & Mates & Aprobado & $\mathrm{x}$ \\
\cline { 2 - 4 } & Brillantes & $\mathrm{x}$ & \\
\cline { 2 - 4 } & &
\end{tabular}

En la tabla 3.1 se observa los resultados de las muestras de las zonas de Trabanda y Carachuco, ambas presentan un color claro y brillante, un olor no rancio y brillo mates.

\subsubsection{Ensayos de campo}

En este ítem se colocará los resultados de dos ensayos: Cinta de barro y Presencia de Arcilla. 


\section{- Ensayo de cinta de barro}

En este ensayo se tomará en cuenta la longitud de la cinta de cada muestra, esto se puede evidenciar en las dos figuras a mostradas a continuación:

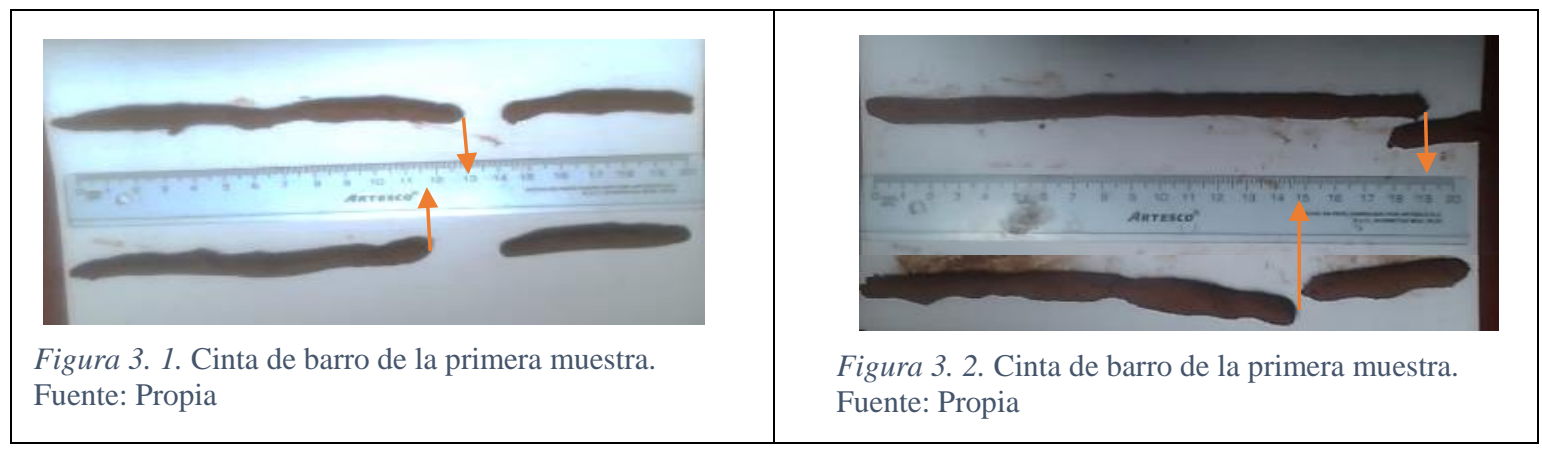

En la figura 3.1 se evidencia que las dos cintas de barro tuvieron una longitud de 11.5 $\mathrm{cm}$ y $13 \mathrm{~cm}$ mientras que en la figura 3.2 estas alcanzaron una longitud de $15 \mathrm{~cm}$ y 18 $\mathrm{cm}$.

\section{- Presencia de Arcilla o Resistencia Seca}

En esta prueba se mide la resistencia de la tierra a través de la presión con los dedos de la mano en esferas elaboradas con este material. A continuación, en la tabla 3.2 se evaluará si las esferas presentan o no fisuras.

Tabla 3.2. Presencia de fisuras en las dos muestras. Fuente: Propia

\begin{tabular}{|l|c|c|c|c|}
\hline \multicolumn{1}{|c|}{ MUESTRAS } & $\begin{array}{c}\text { ESFERA } \\
\mathbf{N}^{\circ} \mathbf{1}\end{array}$ & $\begin{array}{c}\text { ESFERA } \\
\mathbf{N}^{\circ} \mathbf{2}\end{array}$ & $\begin{array}{c}\text { ESFERA } \\
\mathbf{N}^{\circ} \mathbf{3}\end{array}$ & $\begin{array}{c}\text { ESFERA } \\
\mathbf{N}^{\circ} \mathbf{4}\end{array}$ \\
\hline $1^{\circ}$ Muestra & No & No & No & No \\
\hline $2^{\circ}$ Muestra & No & No & No & No \\
\hline
\end{tabular}

En la tabla mostrada anteriormente, indica que tanto para la primera y segunda muestra las 4 esferas de tierra no presentan fisuras, después de ejercerle la pequeña presión.

\subsubsection{Ensayos de laboratorio}

En este ítem se colocará y explicará los resultados de Granulometría de suelos por tamizado, peso específico, contenido de humedad, límites de Atterberg, clasificación de suelos SUCS.

\section{- Granulometría de suelos por tamizado}

En los resultados del anexo A se puede observar que la primera muestra presenta 27.2 $\%$ de finos arcillosos (limo y arcilla, material que pasa el tamiz $\mathrm{N}^{\circ} 200$ ) y un $72.8 \%$ de arena fina media mientras que en el anexo B la segunda muestra contiene $29 \%$ de 
finos arcillosos y un $71 \%$ de arena fina media.

\section{- Peso especifico}

A continuación, se mostrarán los Pesos Específicos de las dos muestras que se obtuvieron del distrito de Huarochirí. Asimismo, sus respectivos cálculos como se evidencia en la tabla 3.3 detallado en anexo C y tabla 3.4 detallado en anexo D para la primera y segunda muestra respectivamente.

Tabla 3.3. Resultado de peso específico relativo para la muestra 1. Fuente: Propia

\begin{tabular}{|c|c|c|c|}
\hline MUESTRA 1 & & UNIDAD & VALOR \\
\hline $\mathrm{k}\left(24,4^{\circ} \mathrm{C}\right)$ & & & 0,9997 \\
\hline Peso de la fiola & & gr & 0,1429 \\
\hline Peso muestra de suelo seco (sin corregir) & & gr & 0,1246 \\
\hline Peso muestra de suelo seco + peso de la fiola & & gr & 0,2657 \\
\hline Peso muestra de suelo seco (corregida) & W0 & $\mathrm{gr}$ & 0,1228 \\
\hline Peso muestra de suelo seco + peso de la fiola + peso agua & W1 & gr & 0,7622 \\
\hline Peso de la fiola + peso de agua & $\mathrm{W} 2$ & gr & 0,6844 \\
\hline Peso específico relativo de solidos & & $\mathrm{gr} / \mathrm{cm}^{3}$ & 2,7294 \\
\hline Peso específico relativo de solidos & & $\mathrm{kg} / \mathrm{m}^{3}$ & 2729,39 \\
\hline
\end{tabular}

Tabla 3.4. Resultado de peso específico para la muestra 2. Fuente: Propia

\begin{tabular}{|lcc|c|}
\hline \multicolumn{1}{|c|}{ MUESTRA 2 } & UNIDAD & VALOR \\
\hline $\mathrm{k}\left(24,3^{\circ} \mathrm{C}\right)$ & & 0,9990 \\
\hline Peso de la fiola & $\mathrm{gr}$ & 0,1912 \\
\hline Peso muestra de suelo seco (sin corregir) & $\mathrm{gr}$ & 0,1248 \\
\hline Peso muestra de suelo seco + peso de la fiola & $\mathrm{gr}$ & 0,3158 \\
\hline Peso muestra de suelo seco (corregida) & $\mathrm{gr}$ & 0,1246 \\
\hline Peso muestra de suelo seco + peso de la fiola+ peso agua & $\mathrm{W} 0$ & $\mathrm{gr}$ & 0,7100 \\
\hline Peso de la fiola + peso de agua & $\mathrm{W} 2$ & $\mathrm{gr}$ & 0,6312 \\
\hline Peso específico relativo de solidos & $\mathrm{gr} / \mathrm{cm}^{3}$ & 2,7197 \\
\hline Peso específico relativo de solidos & $\mathrm{kg} / \mathrm{m}^{3}$ & 2719,66 \\
\hline
\end{tabular}

En la tabla 3.3 la muestra №1 tiene un peso específico de $2729,39 \mathrm{~kg} / \mathrm{m}^{3}(2,73$ ton $/ \mathrm{m}^{3}$ ) mientras que en la tabla 3.4 la muestra $\mathrm{N}^{\circ} 2$ posee un peso específico de $2719,66 \mathrm{Kg} / \mathrm{m}^{3}\left(2,72 \mathrm{ton} / \mathrm{m}^{3}\right)$

\section{- Contenido de humedad}

En esta investigación, se determinó el contenido de humedad para ambas muestras de tierra como se observa en la tabla 3.5 y tabla 3.6 respectivamente. 
Tabla 3.5. Resultado del contenido de humedad de la muestra 1. Fuente: Propia

\begin{tabular}{|l|c|c|}
\hline \multicolumn{1}{|c|}{ DESCRIPCIÓN } & UNIDAD & CANTIDAD \\
\hline Peso de la muestra húmeda & gr & 680,00 \\
\hline Peso de la muestra seca & gr & 675,94 \\
\hline Contenido de agua & gr & 4,06 \\
\hline Contenido de humedad & $\%$ & 0,60 \\
\hline
\end{tabular}

Tabla 3.6. Resultado del contenido de humedad de la muestra 2. Fuente: Propia

\begin{tabular}{|l|c|c|}
\hline \multicolumn{1}{|c|}{ DESCRIPCIÓN } & UNIDAD & CANTIDAD \\
\hline Peso de la muestra húmeda & gr & 675,00 \\
\hline Peso de la muestra seca & gr & 672,00 \\
\hline Contenido de agua & gr & 3,00 \\
\hline Contenido de humedad & $\%$ & 0,45 \\
\hline
\end{tabular}

En la tabla 3.5 el contenido de humedad es de $0.60 \%$ mientras que en la tabla 3.6 la humedad correspondiente es de $0.45 \%$.

\section{- Límites de Atterberg (consistencia)}

A través de los ensayos realizados se ha podido obtener el Límite líquido (LL), el Límite plástico (LP) y el Índice plástico (IP) de cada muestra de tierra.

\section{Limite líquido}

Los resultados de este ensayo para la primera muestra (especificado en el anexo E) y segunda muestra (especificado en el anexo F) son $32.625 \%$ y $31.186 \%$ respectivamente.

\section{Limite plástico}

Los valores de límite plástico obtenidos para cada muestra son $19.77 \%$ y $24.26 \%$ respectivamente.

\section{- Clasificación de suelos SUCS}

Es una clasificación que permite describir la textura y tamaño de las partículas del suelo. A continuación, se indicarán los valores obtenidos:

\section{$\underline{\text { Primera muestra }}$}

○ Suelos de granos gruesos (72.8\% es retenido en el tamiz $\left.\mathrm{N}^{\circ} 200\right)$

○ Arenas (100\% de la fracción gruesa pasa por el tamiz $\mathrm{N}^{\circ} 4$ )

○ Arenas con finos, ya que su $\mathrm{Cu}=6.595$ y $\mathrm{Cc}=0.940$ no están dentro del rango establecido para considerarlo Arenas limpias $(\mathrm{Cu}>6$ y $1<\mathrm{Cc}<3)$.

Para determinar qué tipo de arena con finos predomina, se tomará en cuenta los resultados de Limites de Atterberg ( $\mathrm{LL}=32.6 \%, \mathrm{LP}=19.77 \%$ y $\mathrm{IP}=12.86 \%)$. En el 
anexo G, se observa que la intercepción proyectada de los valores de IP y LL está localizada por encima de la línea A y que el IP es mayor a 7. Entonces es Arcilla con grava o con arena (CL).

\section{$\underline{\text { Segunda muestra }}$}

○ Suelos de granos gruesos (71\% es retenido en el tamiz $\left.\mathrm{N}^{\circ} 200\right)$

- Arenas (100\% de la fracción gruesa pasa por el tamiz $\left.\mathrm{N}^{\circ} 4\right)$

- Arenas con finos, ya que $\mathrm{Cu}=4.10$ y $\mathrm{Cc}=0.929$ no están dentro del rango establecido para considerarlo Arenas limpias $(\mathrm{Cu}>6$ y $1<\mathrm{Cc}<3)$.

Para determinar qué tipo de arena con finos predomina, se tomará en cuenta los resultados de Límites de Atterberg (LL=31.19\%, LP=24.26\% y IP=6.93\%). En el anexo $\mathrm{H}$, se observa que la intercepción proyectada de los valores de IP y LL está localizada por debajo de granulola línea A y que el IP es menor a 4. Entonces es un Limo Orgánicos y arcilla limosa (OL) y Limos orgánicos (ML).

\subsubsection{Penca de Tuna}

\subsubsection{Extracción del mucílago de penca de Tuna}

Se observó que conforme el tiempo de remojo de la penca de tuna aumenta las características físicas varían. Durante los primeros días, el fluido presenta un color verde, una consistencia gomosa y sin ningún olor. El periodo de 7 a 20 días, el color cambia a marrón claro, adquiere una mayor viscosidad. Durante el último periodo a partir de los 21 días, la penca de tuna se disuelve completamente y solo queda la cascara, el flujo tiene un color oscuro y un olor a material orgánico descompuesto.

\subsubsection{Ensayos en el mucílago de penca de tuna}

\section{- Densidad}

A continuación, en la tabla 3.7 los resultados de la densidad, el cual posteriormente serán utilizados para hallar los valores de viscosidad.

Tabla 3.7. Densidad del mucílago de penca de tuna extraída a una temperatura de $24.2^{\circ}$ C. Fuente: Propia

\begin{tabular}{|l|c|c|c|c|c|c|}
\hline \multicolumn{1}{|c|}{ DATOS } & UNID & D: 20.5\% & D: 18\% & D: 13\% & D: 11.3\% & D: 8.5\% \\
\hline Masa del picnómetro vacío & $\mathrm{gr}$ & 36,08 & 36,08 & 36,08 & 36,08 & 36,08 \\
\hline $\begin{array}{l}\text { Masa del picnómetro enrasado } \\
\text { con agua }\end{array}$ & $\mathrm{gr}$ & 67,84 & 67,84 & 67,84 & 67,84 & 67,84 \\
\hline $\begin{array}{l}\text { Masa del picnómetro enrasado } \\
\text { con la solución }\end{array}$ & $\mathrm{gr}$ & 67,11 & 62,11 & 59,31 & 57,78 & 55,41 \\
\hline Densidad del agua & $\mathrm{gr} / \mathrm{ml}$ & 1,00 & 1,00 & 1,00 & 1,00 & 1,00 \\
\hline Densidad de la solución & $\mathrm{gr} / \mathrm{ml}$ & 0,98 & 0,82 & 0,73 & 0,68 & 0,61 \\
\hline Densidad de la solución & $\mathrm{kg} / \mathrm{m}^{3}$ & 977,01 & 819,54 & 731,36 & 683,18 & 608,54 \\
\hline
\end{tabular}


Se observa que las concentraciones D: $20.5 \%$, D: $18 \%$, D: $13 \%$, D: $11.3 \%$ y D: $8.5 \%$ presentaron densidades de $977.01 \mathrm{~kg} / \mathrm{m}^{3}, 819.54 \mathrm{~kg} / \mathrm{m}^{3}, 731.36 \mathrm{~kg} / \mathrm{m}^{3}, 683.18 \mathrm{~kg} / \mathrm{m}^{3}$ y $608.54 \mathrm{~kg} / \mathrm{m}^{3}$ respectivamente.

\section{- $\quad$ Viscosidad}

Para determinar la viscosidad de la solución se siguió la ley de Stoke. Los resultados, ordenados de mayor a menor dosificación se muestran en la tabla 3.8.

Tabla 3.8. Viscosidad del mucílago de penca de tuna. Fuente: Propia

\begin{tabular}{|l|c|c|c|c|c|c|}
\hline \multicolumn{1}{|c|}{ DATOS } & UNID & D: 20.5\% & D: 18\% & D: 13\% & D: 11.3\% & D: 8.5\% \\
\hline radio de la canica & $\mathrm{m}$ & 0,005 & 0,005 & 0,005 & 0,005 & 0,005 \\
\hline Densidad de la solución & $\mathrm{kg} / \mathrm{m}^{3}$ & 977,01 & 819,54 & 731,36 & 683,18 & 608,54 \\
\hline Densidad de la canica & $\mathrm{kg} / \mathrm{m}^{3}$ & 9549,30 & 9549,30 & 9549,30 & 9549,30 & 9549,30 \\
\hline Altura en el recipiente de solución & $\mathrm{m}$ & 0,09 & 0,09 & 0,09 & 0,09 & 0,09 \\
\hline $\begin{array}{l}\text { Tiempo que demora en descender la } \\
\text { canica en la solución }\end{array}$ & $\mathrm{s}$ & 43,0 & 43,3 & 43,7 & 44,2 & 44,5 \\
\hline Velocidad de la solución & $\mathrm{m} / \mathrm{s}$ & 0,0021 & 0,0021 & 0,0021 & 0,0020 & 0,0020 \\
\hline viscosidad de la solución & Poises & 20,09 & 20,60 & 21,00 & 21,36 & 21,68 \\
\hline
\end{tabular}

En la tabla 3.8 se puede observar que los valores de viscosidad para cada dosificación tienen una pequeña diferencia, pues para D: $20.5 \%$, D: $18 \%$, D: $13 \%$, D: $11.3 \%$ y D: $8.5 \%$ sus resultaron fueron $20.09 \mathrm{~kg} / \mathrm{m} . \mathrm{s}, 20.60 \mathrm{~kg} / \mathrm{m} . \mathrm{s}, 21.00 \mathrm{~kg} / \mathrm{m} . \mathrm{s}, 21.36 \mathrm{~kg} / \mathrm{m} . \mathrm{s}$ y $21.68 \mathrm{~kg} / \mathrm{m} . \mathrm{s}$, respectivamente.

3.2. OBJETIVO 2: Seleccionar la dosificación ideal de la mezcla para obtener los mejores resultados de resistencia a la compresión, flexión y absorción en la unidad de adobe estabilizado.

\subsubsection{Ensayo por unidad de adobe}

Para la muestra patrón y las 5 distintas dosificaciones se ensayaron tres unidades de adobes para los ensayos mecánicos (resistencia a la compresión, resistencia a la flexión) y 2 unidades para los ensayos físicos (absorción, prueba de inmersión y prueba de chorro de agua) como se muestra a continuación:

\subsubsection{Resistencia a la compresión}

Los resultados obtenidos en este ensayo fueron determinados según la explicación en el ítem 2.2.5.2.3.1. A continuación, en la tabla 3.9 se observa los valores del área promedio, carga de rotura y resistencia a la compresión de las tres unidades de adobe por cada muestra: el patrón y las 5 distintas concentraciones de baba de penca de tuna. 


\begin{tabular}{|l|c|c|c|}
\hline ESPÉCIMEN & $\begin{array}{c}\text { ÁREA } \\
\text { PROMEDIO } \\
\left(\mathbf{c m}^{2}\right)\end{array}$ & $\begin{array}{c}\text { CARGA DE } \\
\text { ROTURA } \\
(\mathbf{k g})\end{array}$ & $\begin{array}{c}\text { RESISTENCIA } \\
\left(\mathbf{k g} / \mathbf{c m}^{2}\right)\end{array}$ \\
\hline PATRON - & 400.00 & 7760.00 & 19.40 \\
\hline PATRON - 2 & 398.00 & 7442.60 & 18.70 \\
\hline PATRON - 3 & 397.98 & 7322.83 & 18.40 \\
\hline D: $8.5 \%-1$ & 399.99 & 7575.81 & 18.94 \\
\hline D: $8.5 \%-2$ & 400.00 & 7560.00 & 18.90 \\
\hline D: $8.5 \%-3$ & 394.00 & 7399.32 & 18.78 \\
\hline D: $11.3 \%-1$ & 401.98 & 8160.19 & 20.30 \\
\hline D: $11.3 \%-2$ & 397.98 & 7732.75 & 19.43 \\
\hline D: $11.3 \%-3$ & 400.00 & 8004.00 & 20.01 \\
\hline D: $13 \%-1$ & 401.98 & 8863.66 & 22.05 \\
\hline D: $13 \%-2$ & 394.00 & 8313.40 & 21.10 \\
\hline D: $13 \%-3$ & 392.04 & 8154.43 & 20.80 \\
\hline D: $18 \%-1$ & 398.00 & 10069.40 & 25.30 \\
\hline D: $18 \%-2$ & 399.99 & 9959.75 & 24.90 \\
\hline D: $18 \%-3$ & 400.00 & 10160.00 & 25.40 \\
\hline D: $20.5 \%-1$ & 399.00 & 9456.18 & 23.70 \\
\hline D: $20.5 \%-2$ & 400.00 & 9520.00 & 23.80 \\
\hline D: $20.5 \%-3$ & 410.00 & 9184.00 & 22.40 \\
\hline
\end{tabular}

Entre los valores obtenidos para cada dosificación, D: $8.5 \%\left(18.94,18.9\right.$ y $\left.18.78 \mathrm{~kg} / \mathrm{cm}^{2}\right)$ tuvo los valores más bajos a la resistencia a la compresión, mientras que las dosificaciones D: $13 \%\left(22.05,21.10\right.$ y $\left.20.8 \mathrm{~kg} / \mathrm{cm}^{2}\right)$, D: $11.3 \%\left(20.3,19.43\right.$ y $\left.20.01 \mathrm{~kg} / \mathrm{cm}^{2}\right)$ tuvieron un valor ligeramente cercano al de la D: 8.5\%. Por otro lado, D: 20.5\% (23.7, 23.8 y 22.4 $\left.\mathrm{kg} / \mathrm{cm}^{2}\right)$ y D: $18 \%\left(25.3,24.9\right.$ y $\left.25.4 \mathrm{~kg} / \mathrm{cm}^{2}\right)$, dosificaciones con mayor mucílago, tuvieron los mejores resultados entre todas las unidades ensayadas.

\subsubsection{Resistencia a la flexión}

En el ensayo de resistencia a la flexión el parámetro que se evalúa es el módulo de rotura. Los resultados obtenidos en este ensayo fueron determinados según la explicación en el ítem 2.2.5.2.3.2. A continuación, en la tabla 3.10 se observa la máxima carga aplicada en el ensayo a flexión y en la tabla 3.11 se muestra el módulo de rotura de cada muestra.

Tabla 3.10. Máxima carga aplicada en las 6 muestras distintas. Fuente: Propia

\begin{tabular}{|c|c|c|c|c|c|c|}
\hline $\mathbf{N}^{\mathbf{0}}$ & MUESTRA PATRON & D:8.5\% & D:11.3\% & D:13.0\% & D:18.0\% & D:20.5\% \\
\hline №1 (kgf) & 116,32 & 117,21 & 117,13 & 116,67 & 116,90 & 117,31 \\
\hline №2 (kgf) & 116,88 & 116,20 & 116,79 & 116,96 & 117,46 & 116,38 \\
\hline №3 (kgf) & 117,35 & 117,23 & 116,88 & 117,32 & 116,83 & 117,55 \\
\hline
\end{tabular}


Tabla 3.11. Módulo de rotura de las 6 muestras distintas. Fuente: Propia

\begin{tabular}{|c|c|c|c|c|c|c|}
\hline $\mathbf{N}^{\mathbf{0}}$ & $\begin{array}{c}\text { MUESTRA } \\
\text { PATRON }\end{array}$ & $\mathbf{D : 8 . 5 \%}$ & $\mathbf{D : 1 1 . 3 \%}$ & $\mathbf{D : 1 3 . 0 \%}$ & $\mathbf{D : 1 8 . 0 \%}$ & $\mathbf{D : 2 0 . 5 \%}$ \\
\hline Carga promedio & 116,85 & 116,88 & 116,93 & 116,98 & 117,06 & 117,08 \\
\hline Módulo de rotura & 17,58 & 17,59 & 17,59 & 17,60 & 17,61 & 17,62 \\
\hline
\end{tabular}

Para D: $8.5 \%$ y D: $11.3 \%$ tuvieron el mismo módulo de rotura promedio de $17.59 \mathrm{~kg} / \mathrm{cm}^{2}$, el cual resultó ser el valor más bajo entre todas las unidades estabilizadas ensayadas mientras que D: $13 \%$ presentó un valor de $17.60 \mathrm{~kg} / \mathrm{cm}^{2}$. Los resultados con mayor valor de resistencia a la flexión fueron D: $20.5 \%$ con 117.08 y D: $18 \%$ con $117.06 \mathrm{~kg} / \mathrm{cm}^{2}$ (dosificaciones con mayor cantidad de concentración de mucílago de pencas de tuna).

\subsubsection{Ensayo de absorción}

Los pesos secos de las unidades a ensayar varían entre los $14.74 \mathrm{~kg}$ y $15.76 \mathrm{~kg}$. En la tabla 3.12 se puede observar los valores de peso de la unidad seca (P1), peso de la unidad saturada (P2) y el porcentaje de absorción de agua (\% ABS) de las muestras sumergidas en agua por 24 horas.

Tabla 3.12. Ensayo de absorción de los adobes al ser sumergidos por 24 horas. Fuente: Propia

\begin{tabular}{|c|c|c|c|c|}
\hline MUESTRAS & P1 (kg) & P2 (kg) & $\% \mathrm{ABS}$ & PROMEDIO (\%) \\
\hline PATRON - 1 & 14.79 & - & - & \multirow{2}{*}{ - } \\
\hline PATRON - 2 & 14.85 & - & - & \\
\hline D: $8.5 \%-1$ & 14.74 & 16.5 & 11.94 & \multirow{2}{*}{12.64} \\
\hline D: $8.5 \%-2$ & 14.91 & 16.9 & 13.35 & \\
\hline D: $11.3 \%-1$ & 15.76 & 17.6 & 11.68 & \multirow{2}{*}{11.90} \\
\hline D: $11.3 \%-2$ & 15.1 & 16.93 & 12.12 & \\
\hline D: $13 \%-1$ & 15.37 & 16.98 & 10.47 & \multirow{2}{*}{11.04} \\
\hline D: $13 \%-2$ & 15.51 & 17.31 & 11.61 & \\
\hline D: $18 \%-1$ & 14.91 & 16.73 & 12.21 & \multirow{2}{*}{11.43} \\
\hline D: $18 \%-2$ & 15.21 & 16.83 & 10.65 & \\
\hline D: $20.5 \%-1$ & 14.72 & 16.18 & 9.92 & \multirow{2}{*}{10.99} \\
\hline D: $20.5 \%-2$ & 14.34 & 16.07 & 12.06 & \\
\hline
\end{tabular}

En la tabla anterior se puede observar que las unidades con menor porcentaje promedio de absorción son D: 25\% (10.99\%), D: 18 (11.43\%) y D: 13\% (11.04\%) mientras que D: $11.3 \%$ y D: $8.5 \%$ con $11.90 \%$ y $12.64 \%$ respectivamente contienen mayores valores de absorción. 


\subsubsection{Pruebas recomendadas por otros autores}

\section{- Ensayo de inmersión}

Los resultados de este ensayo experimental evidenciados en la tabla 3.13 fueron obtenidos a través de la valorización individual de 2 personas al observar las características de los adobes después de retirarlos del agua.

Tabla 3.13. Clasificación de los adobes después de la inmersión por dos días. Fuente: Propia

PERSONA $\mathbf{N}^{\circ} 1$

PERSONA $\mathbf{N}^{\circ} 2$

\begin{tabular}{|c|c|c|c|c|c|}
\hline MUESTRA & $\mathbf{N}^{\circ}$ & CLASIFICACIÓN & MUESTRA & $\mathbf{N}^{\circ}$ & CLASIFICACIÓN \\
\hline \multirow{2}{*}{ Muestra patrón } & 1 & $\mathrm{~S}$ & \multirow{2}{*}{ Muestra patrón } & 1 & $\mathrm{~S}$ \\
\hline & 2 & $\mathrm{~S}$ & & 2 & $\mathrm{~S}$ \\
\hline \multirow{2}{*}{ D: $8.5 \%$} & 1 & $\mathrm{M}$ & \multirow{2}{*}{ D: $8.5 \%$} & 1 & $\mathrm{M}$ \\
\hline & 2 & $\mathrm{M}$ & & 2 & $\mathrm{~S}$ \\
\hline \multirow{2}{*}{ D: $11.3 \%$} & 1 & $\mathrm{M}$ & \multirow{2}{*}{ D: $11.3 \%$} & 1 & $\mathrm{M}$ \\
\hline & 2 & M & & 2 & M \\
\hline \multirow{2}{*}{ D: $13.0 \%$} & 1 & $\mathrm{~L}$ & \multirow{2}{*}{ D: $13.0 \%$} & 1 & $\mathrm{~L}$ \\
\hline & 2 & $\mathrm{M}$ & & 2 & $\mathrm{M}$ \\
\hline \multirow{2}{*}{ D: $18.0 \%$} & 1 & $\mathrm{M}$ & \multirow{2}{*}{ D: $18.0 \%$} & 1 & $\mathrm{M}$ \\
\hline & 2 & $\mathrm{M}$ & & 2 & $\mathrm{~L}$ \\
\hline \multirow{2}{*}{ D: $20.5 \%$} & 1 & $\mathrm{~L}$ & \multirow{2}{*}{ D: $20.5 \%$} & 1 & M \\
\hline & 2 & $\mathrm{M}$ & & 2 & $\mathrm{~L}$ \\
\hline
\end{tabular}

La primera y segunda persona consideraron que la muestra patrón tuvo un daño severo, ya que estas se convirtieron en una masa pastosa mientras que las demás unidades con mucílago incorporado en su mezcla (D: $20.5 \%$, D: $18 \%$, D: $13 \%$, D: $11.3 \%$ y D: $8.5 \%$ ) presentaron una clasificación de moderado a leve, ya que algunos adobes se desmoronaban y otros al ejercerles una presión con los dedos en una zona determinada quedaban con una marca.

\section{- Prueba de chorro de agua}

Siguiendo lo indicado en el ítem 2.2.5.2.3.3 se aplicó una presión constante de 2,82 MPa al centro de cada adobe durante 60 segundos a distancia de $30 \mathrm{~cm}$. Posteriormente se obtuvo los siguientes resultados como se muestra en la tabla 3.14 , 
Tabla 3.14. Cálculo de presión para el ensayo de chorro de agua. Fuente: Propia.

\begin{tabular}{|l|c|c|}
\hline DESCRIPCIÓN & UNIDAD & VALOR \\
\hline Volumen del recipiente & $\mathrm{m}^{3}$ & 0,002 \\
\hline Tiempo & $\mathrm{S}$ & 8 \\
\hline Caudal del caño & $\mathrm{m}^{3} / \mathrm{s}$ & 0,00025 \\
\hline
\end{tabular}

\begin{tabular}{|l|c|c|}
\hline DESCRIPCIÓN & UNIDAD & VALOR \\
\hline Caudal & $\mathrm{m}^{3} / \mathrm{s}$ & 0,00025 \\
\hline Diámetro del caño & $\mathrm{Mm}$ & 15,60 \\
\hline Diámetro de la manguera & $\mathrm{Mm}$ & 14,00 \\
\hline Diámetro de la boquilla & $\mathrm{Mm}$ & 4,25 \\
\hline Área del caño & $\mathrm{m}^{2}$ & 0,00019 \\
\hline Área de la manguera & $\mathrm{m}^{2}$ & 0,00015 \\
\hline Área de la boquilla & $\mathrm{m}^{2}$ & 0,00001 \\
\hline Velocidad del caño & $\mathrm{m} / \mathrm{s}$ & 1,30798 \\
\hline Velocidad en la manguera & $\mathrm{m} / \mathrm{s}$ & 1,62403 \\
\hline Velocidad en la boquilla & $\mathrm{m} / \mathrm{s}$ & 17,62269 \\
\hline
\end{tabular}

\begin{tabular}{|l|c|c|}
\hline DESCRIPCIÓN & UNIDAD & VALOR \\
\hline Densidad del agua & $\mathrm{kg} / \mathrm{m}^{3}$ & 1000 \\
\hline Velocidad en la manguera & $\mathrm{m} / \mathrm{s}$ & 1,62403 \\
\hline Área de la manguera & $\mathrm{m}^{2}$ & 0,00015 \\
\hline Velocidad en la boquilla & $\mathrm{m} / \mathrm{s}$ & 17,62269 \\
\hline Área de la boquilla & $\mathrm{m}^{2}$ & 0,00001 \\
\hline Fuerza & $\mathrm{kg} / \mathrm{m} / \mathrm{s}^{2}$ & 3,9997 \\
\hline
\end{tabular}

\begin{tabular}{|l|c|c|}
\hline DESCRIPCIÓN & UNIDAD & VALOR \\
\hline Fuerza & $\mathrm{kg} * \mathrm{~m} / \mathrm{s}^{2}$ & 3,99967 \\
\hline Área de la boquilla & $\mathrm{m}^{2}$ & 0,00001 \\
\hline \multirow{2}{*}{ Presión } & $\mathrm{N} / \mathrm{m}^{2}$ & 281939,5 \\
\cline { 2 - 3 } & $\mathrm{MPa}$ & 2,81939 \\
\hline
\end{tabular}


En la tabla 3.15 se muestra la longitud y el porcentaje de penetración respecto al espesor total de las tres unidades de adobe por cada muestra: el patrón y las 5 distintas concentraciones de mucílago de penca de tuna.

Tabla 3.15. Longitud de penetración de las 6 muestras distintas. Fuente: Propia

\begin{tabular}{|l|c|c|c|c|c|c|}
\hline \multicolumn{1}{|c|}{$\mathbf{N}^{\mathbf{0}}$} & $\begin{array}{c}\text { MUESTRA } \\
\text { PATRON }\end{array}$ & $\mathbf{D : 8 . 5 \%}$ & $\mathbf{D : 1 1 . 3 \%}$ & $\mathbf{D : 1 3 . 0 \%}$ & D:18.0\% & D:20.5\% \\
\hline Penetración $\mathbf{N}^{\mathbf{0}}$ (mm) & 6,36 & 7,01 & 7,01 & 5,80 & 5,08 & 4,33 \\
\hline Penetración No2 (mm) & 6,87 & 7,62 & 5,62 & 4,57 & 5,71 & 5,63 \\
\hline Penetración No3 (mm) & 8,74 & 7,30 & 6,53 & 5,98 & 5,15 & 4,72 \\
\hline Penetración Prom $(\mathrm{mm})$ & 7,32 & 7,31 & 6,39 & 5,45 & 5,31 & 4,89 \\
\hline
\end{tabular}

Entre los valores obtenidos, la muestra patrón $(6.36,6.87,8.74 \mathrm{~mm})$ tuvo mayor medida de penetración en milímetros que las unidades estabilizadas mientras que D: $11.3 \%$ (7.01, 7.62 y $7.30 \mathrm{~mm})$ y D: $8.5 \%(7.01,7.62$, y $7.30 \mathrm{~mm})$ presentaron valores muy cercanos a la muestra patrón. Las unidades con D: 13\% (5.80, 4.57, $5.98 \mathrm{~mm})$ mostraron un resultado intermedio con respecto a los demás valores. Por otro lado, las dosificaciones D: $20.5 \%$ (4.33, 5.63, y $4.72 \mathrm{~mm})$ y D: $18 \%(5.08,5.71$ y $5.15 \mathrm{~mm})$, que contenían mayor solución de mucílago de penca, presentaron menor penetración en $\mathrm{mm}$ frente al chorro de agua.

3.3. OBJETIVO 3: Comparar los resultados de resistencia mecánica (compresión y flexión) y resistencia física (absorción) de las unidades y pilas de adobes convencionales de los adobes estabilizados.

\subsubsection{Ensayo por unidad de adobe}

Para realizar la comparación entre los valores obtenidos en los ensayos, se tomará en cuenta el valor promedio de la muestra patrón y de las dos mejores dosificaciones.

\subsubsection{Resistencia a la compresión}

En la gráfica 3.1 se evidencia los valores promedio de los esfuerzos máximos a compresión obtenidos al reemplazar la carga de rotura y el área promedio en la ecuación 2.1, explicada con anterioridad. 
Gráfica 3. 1. Promedio de los 3 valores de esfuerzo máximo de compresión por cada muestra. Fuente: Propia

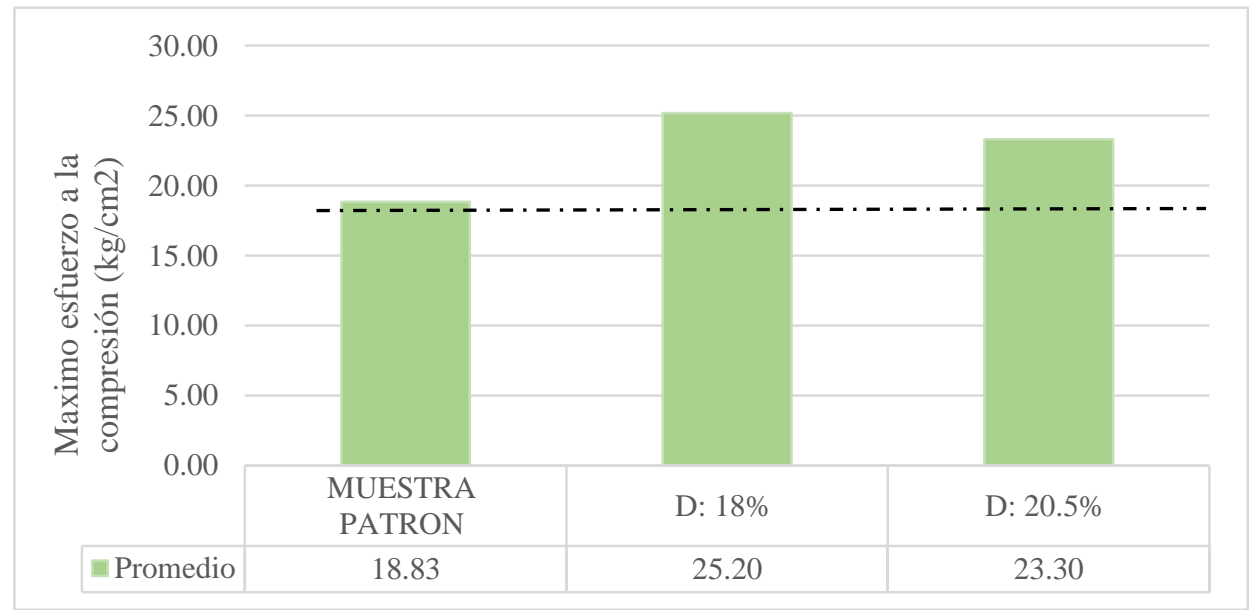

En la gráfica 3.1, se puede observar 3 valores promedios de resistencia a la compresión de cada grupo a analizar. El primer promedio, correspondiente a la muestra patrón, posee un valor de resistencia a la compresión de $18.83 \mathrm{~kg} / \mathrm{cm}^{2}$, el cual es el valor más bajo en comparación con los promedios de D: $20.5 \%$ con $23.30 \mathrm{~kg} / \mathrm{cm}^{2}$ y D: $18 \%$ con $25.20 \mathrm{~kg} / \mathrm{cm}^{2}$. Asimismo, se puede interpretar que D: $20.5 \%$ y D: $18 \%$, tienen una resistencia de $23.72 \%$ y $33.81 \%$ mayor que el de la muestra patrón.

\subsubsection{Resistencia a la flexión}

En la gráfica 3.2 se visualiza el módulo de rotura obtenida de la carga promedio para la muestra patrón y las dos mejores dosis de adobes estabilizados.

Gráfica 3. 2. Módulo de Rotura para cada muestra. Fuente: Propia

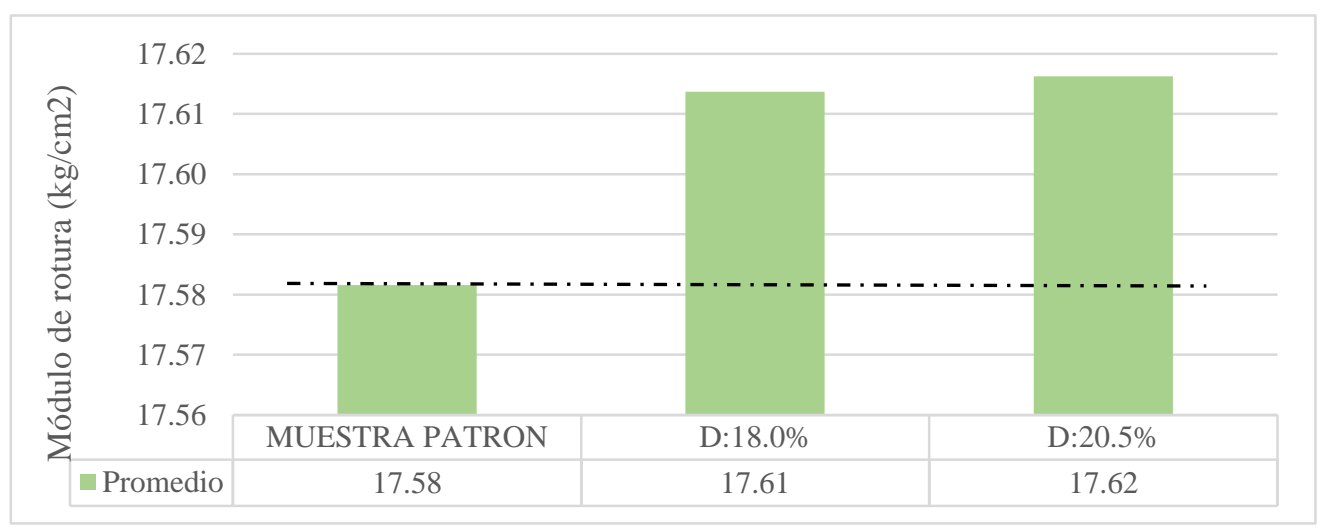

En la gráfica, se puede observar 3 valores promedios de módulo de rotura de cada grupo a 
analizar. El primer promedio, correspondiente al adobe sin estabilizar (muestra patrón), posee un valor de resistencia a la flexión $17.58 \mathrm{~kg} / \mathrm{cm}^{2}$, el cual es el valor más bajo en comparación con los promedios de D: $20.5 \%$ con $17.62 \mathrm{~kg} / \mathrm{cm}^{2}$ y D: $18 \%$ con $17.61 \mathrm{~kg} / \mathrm{cm}^{2}$. Asimismo, se puede interpretar que D: $20.5 \%$ y D: $18 \%$, tienen una resistencia de $0.23 \%$ y $0.17 \%$ mayor que el de la muestra patrón.

\subsubsection{Ensayo de absorción}

En la gráfica 3.3 se evidencia el valor promedio de absorción de los dos especímenes ensayados para la muestra patrón y los adobes estabilizados.

Gráfica 3. 3. Promedio de los 2 valores de absorción por cada muestra. Fuente: Propia

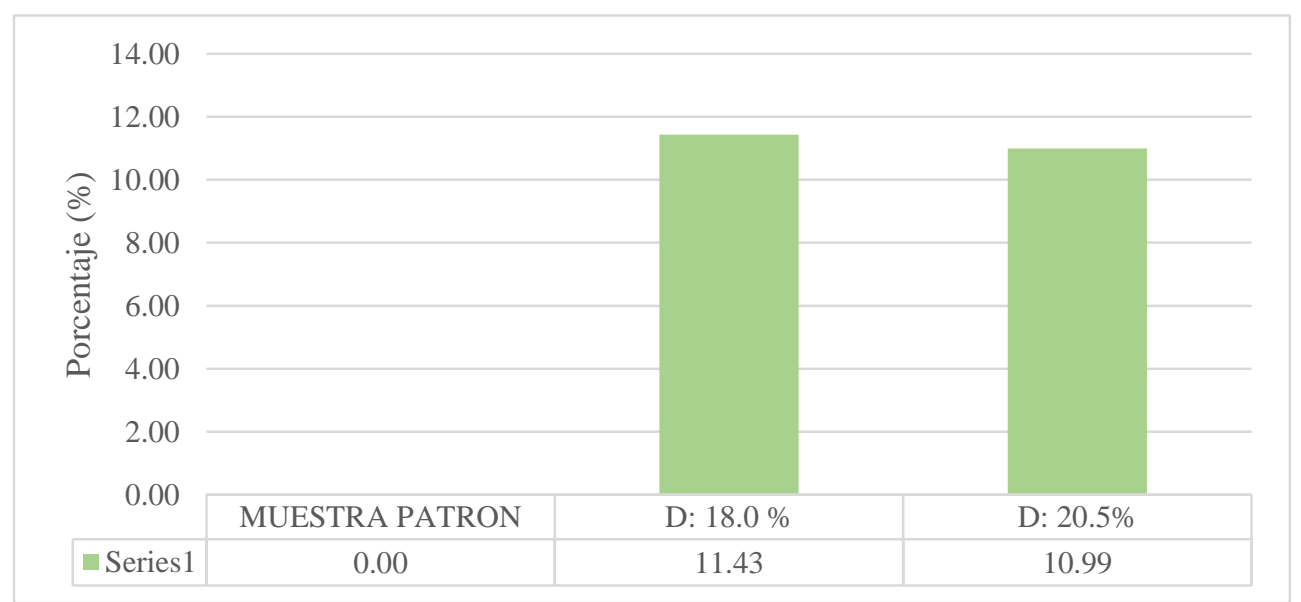

La absorción de la muestra patrón no se pudo determinar, debido a que los adobes al ser retirados del agua se desmoronaban rápidamente; por lo tanto, no se pudo realizar la prueba de forma correcta mientras que los adobes con mayor mucílago de penca de tuna tuvieron mejores resultados (D: $20.5 \%$ con $10.99 \%$ y D: $18 \%$ con $11.43 \%$ ).

\subsubsection{Pruebas recomendadas por otros autores}

\section{- Prueba de inmersión}

En la gráfica 3.4 se observa la clasificación de inmersión de la unidad con respecto con un determinado puntaje, el cual representa la clasificación descrito por Micek et al (2006, citado por Benites, V., 2017). Donde severo representa 3 puntos, moderado 2 puntos, leve 1 punto y despreciable 0 puntos. 
Gráfica 3. 4. Clasificación final de las dosificaciones según su deterioro. Fuente: Propia

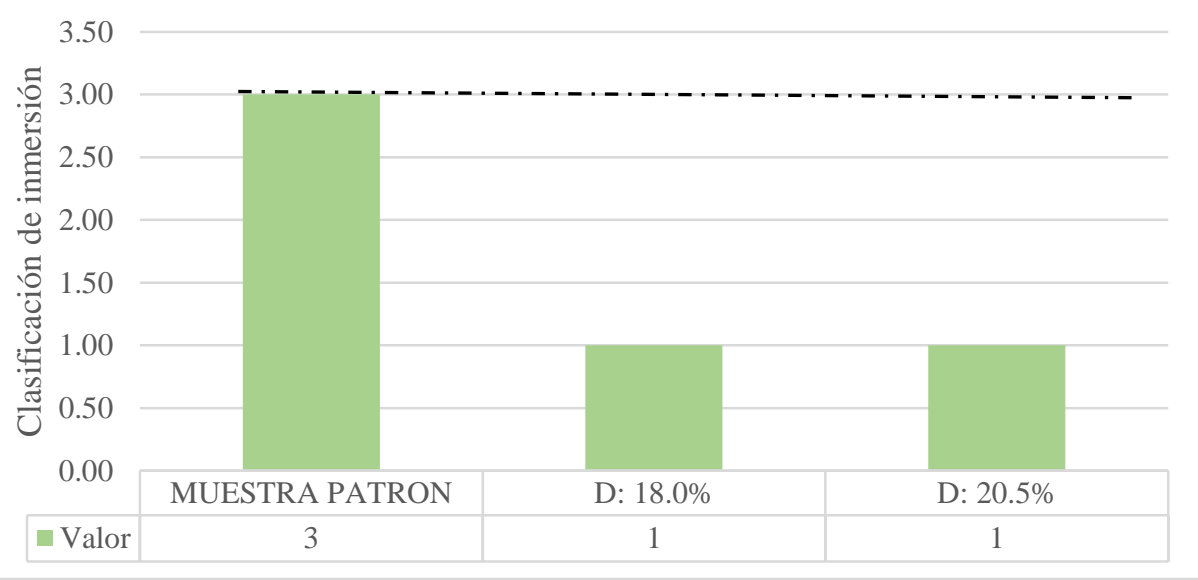

Según los resultados generales, la muestra patrón tiene un puntaje de 3 que representa daños severos, pues los adobes no soportaban ningún tipo de presión y tenían una consistencia pastosa, mientras que los mejores puntajes fueron de D: $20.5 \%$ y D: $18.0 \%$ (unidades con mayor dosificación de mucílago), pues no mostraban daños estructurales visibles.

\section{- Prueba de chorro de agua}

En la gráfica 3.5 se evidencia el porcentaje de penetración con respecto a su valor de profundidad en mm obtenida en la prueba de chorro de agua para la muestra patrón y las dos mejores dosis de adobes estabilizados.

Gráfica 3. 5. Profundidad de penetración de las dosificaciones. Fuente: Propia

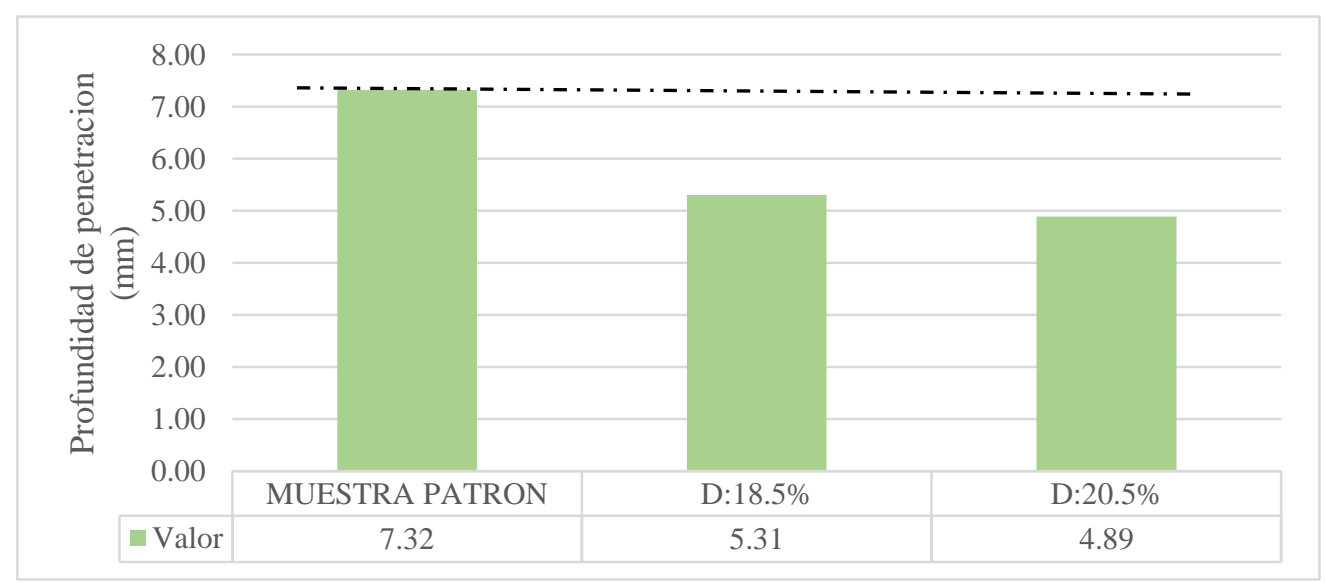


En esta prueba la muestra patrón, D: $20.5 \%$ y D: $18 \%$ tuvieron resultados de penetración promedio de 7.32, 4.89 y $5.31 \mathrm{~mm}$ respectivamente. Esto resultados son debidos a los valores de resistencia a la compresión de cada dosificación mencionado anteriormente, pues a mayor resistencia menor será la penetración del líquido en la unidad.

\subsubsection{Ensayos por pila de adobe}

En esta comparación se tomará en cuenta los valores de la pila de la muestra patrón y las pilas de las dos mejores dosificaciones.

\subsubsection{Resistencia a la compresión}

Los resultados obtenidos en este ensayo fueron determinados según la explicación en el ítem 2.2.5.2.3.1. A continuación, en la tabla 3.16 se observa el ancho (a) y largo (b) de la sección, carga de rotura, resistencia y resistencia última a la compresión en las dos pilas de adobes.

Tabla 3.16. Ensayos a compresión en pilas de adobes de $20 \mathrm{~cm}$ x $40 \mathrm{~cm}$ x $42 \mathrm{~cm}$. Fuente: Propia

\begin{tabular}{|c|c|c|c|}
\hline ESPÉCIMEN & $\begin{array}{c}\text { ÁREA PROMEDIO } \\
\left(\mathrm{cm}^{2}\right)\end{array}$ & $\begin{array}{c}\text { CARGA DE ROTURA } \\
(\mathrm{kg})\end{array}$ & 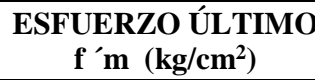 \\
\hline PATRON - 1 & 788.04 & 9727.74 & 12.34 \\
\hline PATRON - 2 & 794.01 & 9899.44 & 12.47 \\
\hline D: $18 \%-1$ & 795.40 & 13346.30 & 16.78 \\
\hline D: $18 \%-2$ & 796.00 & 13298.35 & 16.71 \\
\hline D: $20.5 \%-1$ & 792.00 & 11498.15 & 14.52 \\
\hline D: $20.5 \%-2$ & 798.00 & 11993.89 & 15.03 \\
\hline
\end{tabular}

En la gráfica 3.6 se evidencia los valores promedio de los esfuerzos máximos últimos a compresión obtenidos al reemplazar la carga de rotura, el ancho y largo de la sección en la ecuación 2.10 y 2.11, explicada con anterioridad. 
Gráfica 3. 6. Ensayos a compresión en pilas de adobes de $20 \mathrm{~cm}$ x $40 \mathrm{~cm}$ x $42 \mathrm{~cm}$. Fuente: Propia

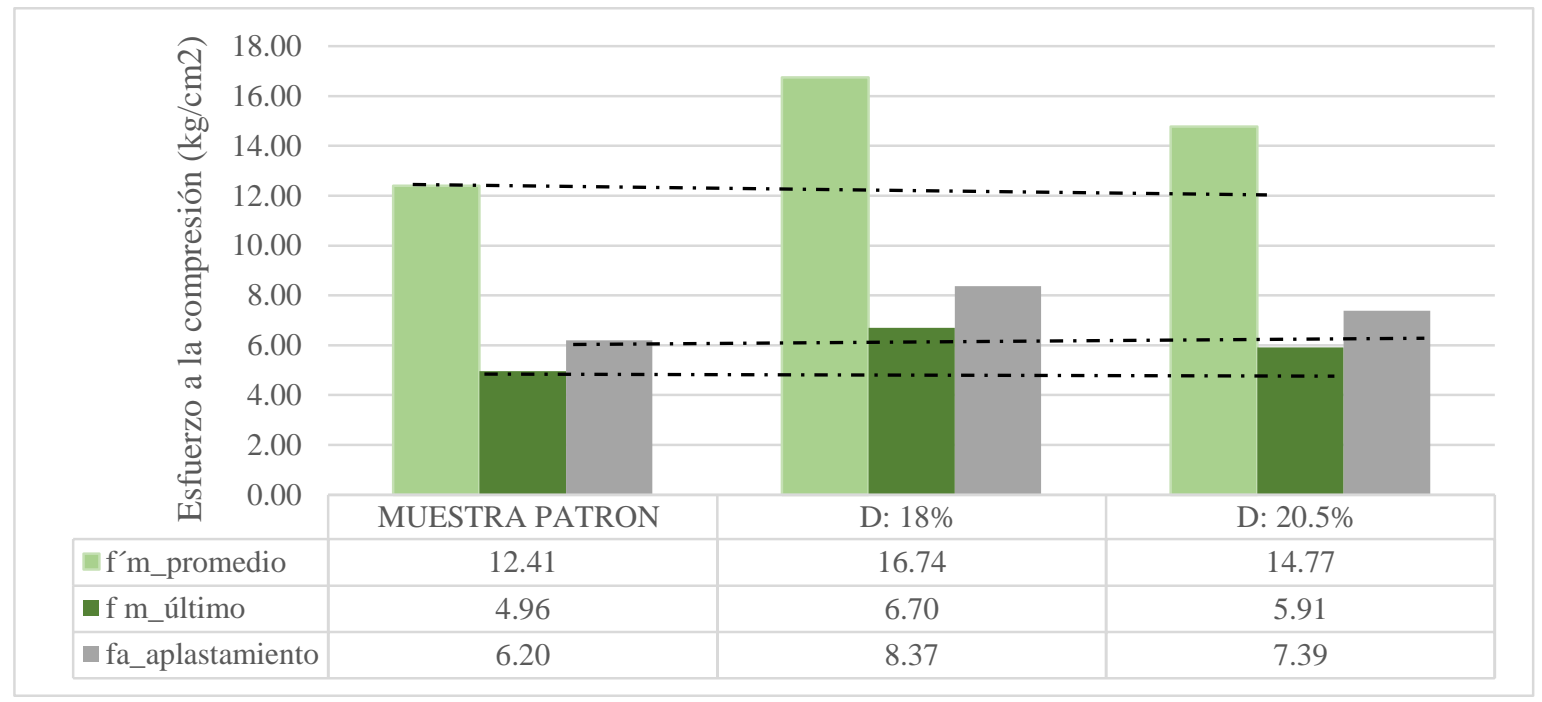

Se tomará en cuenta la recomendación de la Norma E 080 (2017) para validar los resultados promedios en esta comparación. En la norma establece que la resistencia de las pilas de adobes debe ser al menos $6.12 \mathrm{kgf} / \mathrm{cm}^{2}$ en cada espécimen ensayado. En esta investigación, todos los resultados promedios del esfuerzo a la compresión están por encima de este límite como se muestra a continuación: el valor promedio del esfuerzo a la compresión (f'm) por pila de adobes para la muestra patrón es de $12.41 \mathrm{~kg} / \mathrm{cm}^{2}$, el cual es el resultado con menor valor pues D: $20.5 \%$ y D: $18 \%$ tienen valores de $16.74 \mathrm{~kg} / \mathrm{cm}^{2}$ y $14.77 \mathrm{~kg} / \mathrm{cm}^{2}$ respectivamente. Esta inferioridad también se evidencia en el esfuerzo de compresión último (f m) en donde los mejores valores le corresponden a D: $18 \%$ con $6.70 \mathrm{~kg} / \mathrm{cm}^{2}$ y D: $20.5 \%$ con $5.91 \mathrm{~kg} / \mathrm{cm}^{2}$. Asimismo, esto se repite para el esfuerzo a la compresión por aplastamiento (fa), los cuales son el resultado de multiplicar a f'm por 1.25. Es decir, la concentración D: $20.5 \%$ y D: $18 \%$ presentan $34.96 \%$ y $19.09 \%$ mayor resistencia a la compresión que la muestra sin estabilización. 


\section{DISCUSIÓN DE RESULTADOS}

El capítulo comprende la discusión de hallazgos con respecto a los resultados de la investigación del presente trabajo al destallar la variación de resistencia a la compresión, flexión y absorción en la unidad de adobe estabilizado con mucílago de penca de tuna.

\subsection{Verificación y discusión}

La verificación y discusión de resultados permite analizar los resultados encontrados en la investigación, enfatizando en aquellos aspectos importantes o novedosos y comparar los resultados de la investigación con resultados de otros estudios realizados en diferentes partes del mundo.

\subsubsection{OBJETIVO 1: Analizar los materiales más adecuados para la elaboración de la mezcla a través de ensayos preliminares (prueba de color, prueba olfativa y prueba de brillo) y ensayos físicos (ensayo de cinta de barro, resistencia seca, granulometría, peso específico y límites de Atterberg) para el suelo y, ensayos de densidad y viscosidad para el mucílago de penca de tuna.}

\subsubsection{Suelo}

Se ha realizado tres tipos de ensayos para cada muestra de este material $\left(1^{\circ}\right.$ muestra: suelo de Trabanda y $2^{\circ}$ muestra: suelo de Carachuco) con el fin de seleccionar el que tengas mejores características para ser utilizadas como parte de la mezcla en la elaboración del adobe.

\subsection{Ensayos preliminares}

Para garantizar si las muestras de suelo analizadas a simple vista son consideras aceptables para ser utilizadas como un material para la elaboración del adobe, se decidió tomar en cuenta las recomendaciones de Tejada S. (2001) en su libro "Buena Tierra- Apuntes para el diseño y construcción con Adobe", en este libro se evidencia los tipos de prueba, los principales indicadores que se puede observar en una tierra y cuáles son los resultados aceptados, entre las pruebas se tiene a las pruebas de color, olfativa y de brillo, las cuales deben de priorizar un color claro y brillante, un olor no rancio y brillo mates respectivamente. Según los resultados que mostraron la primera y segunda muestra de tierra estas dos cumplen con lo 
mencionado anteriormente, pues presentan las características aprobadas (color claro y brillante, un olor no rancio y brillo mates)

\subsection{Ensayos de campo}

En este ítem se explicará la verificación de resultados de Granulometría de suelos por tamizado, peso específico, contenido de humedad, límites de Atterberg, clasificación de suelos SUCS.

\section{- Ensayo de cinta de barro}

En este ensayo se tomó en cuenta las indicaciones y recomendaciones de la Norma E 080 (2017), el cual indica que, para considerar un suelo apto, las longitudes de las cintas de barro deben estar entre el rango de 11 a $19 \mathrm{~cm}$ (recomendado $15 \mathrm{~cm}$ ), pues si sus dimensiones están dentro de 20 a $25 \mathrm{~cm}$ se considera un suelo arcilloso mientras que si su longitud es menor a $10 \mathrm{~cm}$ este se le considera un suelo arenoso. Por lo tanto, la primera y segunda muestras son consideradas aceptables, pues tienen longitudes promedios de 12.3 y $16.5 \mathrm{~cm}$ respectivamente.

\section{- Presencia de Arcilla o Resistencia Seca}

En esta prueba para considerar si los resultados de este ensayo son aceptables se tomó en cuenta los requisitos presentados en ICG (2014). En esta nos indican que se deben de elaborar bolitas de tierra, secarlas por dos días para posteriormente ejercerle una presión con los dedos de las manos y que estos no presenten fisuras ni mucho menos ruptura para considerar a la tierra apta. Con lo mencionado anteriormente se puede evidenciar que la primera y segunda muestras son aceptables, pues las 4 bolitas de cada una de ellas no presentaron ninguna ruptura ni fisura.

\subsection{Ensayos de laboratorio}

\section{- Granulometría de suelos por tamizado}

Se tomará en cuenta las indicaciones de la Norma E.080 (2000) "Adobe” y de acuerdo al Sistema Unificado de Clasificación de Suelos-SUCS para determinar si los porcentajes de arcillas y limos (finos arcillosos) con respecto a las arenas de los resultados de los ensayos están cercanos al rango establecido. En la Norma establece que la gradación del suelo debe contener aproximadamente arcilla $10-20 \%$, limo $15-25 \%$ y arena $55-70 \%$ (estos 
valores pueden cambiar si se elaboran adobes estabilizados) mientras que en SUCS, pueden considerarse aceptables los suelos cuyo porcentaje de arenas varíe de 55 a 75\% (retenidos en la malla $\mathrm{N}^{\mathrm{o}}$ 200) y el porcentaje de finos entre de 25 a $45 \%$ (limos, arcillas, etc. que pasan la malla $\mathrm{N}^{\mathrm{o}} 200$ ). Por lo tanto, según lo descrito anteriormente la primera muestra es considerada aceptable, pues presenta $27.2 \%$ de finos arcillosos y un $72.8 \%$ de arena fina, el cual tiene una composición de arena y arcilla aceptable, ya que contiene menos arcilla que arena. La segunda muestra, no está totalmente dentro de los rangos establecidos pues se puede evidenciar que tiene $29 \%$ de finos arcillosos y un $71 \%$ de arena fina media, eso quiere decir que se recomienda realizar más ensayos para ser aceptada.

\section{- Peso especifico}

Siguiendo con el análisis de suelo, se tomará en cuenta para la verificación de los resultados a la tabla 4.1, el cual indica los pesos específicos promedio para cada tipo de suelo extraídos según Gutierrez, J. (2013) del manual de laboratorio de UPC. En este se evidencia que ambas muestras son aceptables, pues La muestra No1 tiene un peso específico de $2729,39 \mathrm{~kg} / \mathrm{m}^{3}\left(2,73 \mathrm{ton} / \mathrm{m}^{3}\right)$ y la muestra $\mathrm{N}^{\circ} 2$ posee un peso específico de $2719,66 \mathrm{Kg} / \mathrm{cm}^{3}$ (2,72 ton $/ \mathrm{m}^{3}$ ), estos resultados los ubican dentro del rango $2.70 \mathrm{ton} / \mathrm{m}^{3}$ 2.80 ton $/ \mathrm{m}^{3}$, los cuales son considerados suelo de arcilla inorgánica; es decir, que pueden ser utilizados como material de construcción, pues no reducirán la resistencia a la compresión y la humedad como lo hacen los suelos orgánicos.

Tabla 4.1. Tabla de Pesos Específicos promedio (ton/m³), Fuente: Gutierrez, 2013.

\begin{tabular}{|l|c|}
\hline \multicolumn{1}{|c|}{ TIPOS DE SUELO } & Gs $\left(\mathbf{t o n} / \mathbf{m}^{\mathbf{3}}\right)$ \\
\hline Arena & $2.65-2.67$ \\
\hline Arena limosa & $2.67-2.70$ \\
\hline Arcilla inorgánica & $2.70-2.80$ \\
\hline Suelos con micas o hierro & $2.75-3.00$ \\
\hline Suelos orgánicos & Variable, puede ser inferior a 2.00 \\
\hline
\end{tabular}

\section{- Límites de Atterberg (consistencia)}

Los resultados serán validados según la recomendación de los autores Lopez, J. y Bernilla, P. en su tesis titulada: "EVALUACIÓN FUNCIONAL Y CONSTRUCTIVA DE VIVIENDAS CON ADOBE ESTABILIZADO EN CAYALTI. PROGRAMA COBE -1976”. En este indica que el limite líquido (LL) debe variar entre $20 \%$ y $40 \%$, pues debajo de $20 \%$ se trata de 
suelos no cohesivos y por encima de los $40 \%$ el suelo no tiene suficiente humedad. Asimismo, el índice plástico (IP) debe ser menor que 20\%. Entonces analizando los resultados se podrá decir que la primera muestra $(\mathrm{LL}=32.626 \%$ y $\mathrm{IP}=12.86 \%)$ y segunda muestra ( $\mathrm{LL}=31.186 \%$ y $\mathrm{IP}=6.93 \%$ ) están dentro de los rangos; por lo tanto, son aceptables. Asimismo, estos valores se asemejan a los resultados obtenidos por Benites V. (2017) las cuales presentan un $\mathrm{LL}=27 \%$ y un $\mathrm{IP}=12 \%$

\section{- Clasificación de suelos SUCS}

Con los resultados de los ensayos de granulometría y límites de Atterberg se realizó la clasificación de suelos según SUCS.

- Para la primera muestra (Suelo de Trabanda) los resultados mostraron que es un suelo de grano grueso en la sub categoría de arenas con finos; por lo tanto, se tomará en cuenta los valores LL y LP obtenidos anteriormente, estos datos ubicados en la en el anexo G (IP\% vs LL\%) están posicionados en la parte superior de la línea A, entonces el suelo es denominado una arcilla con grava o con arena (CL). Es aceptable, pues no contiene presencia de restos orgánicos.

- Para la segunda muestra (Suelo de Carachuco) los resultados mostraron que es un suelo de grano grueso en la sub categoría de arenas con finos; por lo tanto, se tomará en cuenta los valores LL y LP obtenidos anteriormente, estos datos ubicados en el anexo H (IP\% vs LL\%) están por debajo de la línea A, entonces, el suelo es denominado un Limo Orgánico y arcilla limosa (OL) y Limo orgánicos (ML). Este suelo no es considerado apto, pues es según su simbología este contiene restos orgánicos.

\subsubsection{Penca de Tuna}

Para esta investigación las pencas de tuna son el material esencial, puesto que la solución requerida para ser utilizada en la mezcla, dependerá de sus características.

\subsection{Extracción del mucílago de penca de tuna}

Para esta investigación se optó por el método de remojar los trozos de penca de tuna en agua para la obtención del mucílago, el cual fue recomendado por Vargas J., Heredia E., Bariola 
J. \& Povindar K. (1986) y León R. (2012), pues es considerado como el método más económico y de fácil de realizar. Asimismo, según el autor el mucílago tendría que tener un color verde oscuro con un fuerte olor a materia orgánica descompuesta, estas características al ser comparadas con las de nuestros resultados concuerdan exitosamente.

\subsection{Ensayos en el mucílago de penca de tuna}

Como se demostró, para un mismo periodo de remojo, las dosificaciones $(20.5 \%, 18 \%, 13 \%$, $11.3 \%$ y $8.5 \%)$ presentar distintas características de densidad y viscosidad. En cuanto a la densidad, la mayor dosis $\left(977.01 \mathrm{~kg} / \mathrm{m}^{3}\right)$ es la que se aproxima más a la densidad del agua $\left(1000 \mathrm{~kg} / \mathrm{m}^{3}\right)$ facilitado la combinación de los fluidos y obteniendo una solución homogénea, mientras que para la menor dosis $\left(608.54 \mathrm{~kg} / \mathrm{m}^{3}\right)$, la diferencia de densidades, dificulta la combinación y la solución resulta no ser muy homogénea, produciendo que en ciertas partes de la mezcla se concentre menor cantidad de mucílago de penca de tuna. En cuanto a la viscosidad, una sustancia más viscosa es más difícil de trabajar, la mayor dosis presenta menor viscosidad siendo esta una ventaja.

\subsubsection{OBJETIVO 2: Seleccionar la dosificación ideal de la mezcla para obtener los mejores resultados de resistencia a la compresión, flexión y absorción en la unidad de adobe estabilizado.}

\subsubsection{Ensayo por unidad de adobe}

Se ensayaron 3 unidades de adobes por cada distinta dosificación para los ensayos mecánicos (resistencia a la compresión, resistencia a la flexión) y 2 unidades para los ensayos físicos (Absorción, prueba de inmersión y prueba de chorro de agua) como se muestra a continuación:

\subsection{Resistencia a la compresión}

Se puede observar en el primer promedio, correspondiente a la muestra patrón, posee un valor de resistencia a la compresión de $18.83 \mathrm{~kg} / \mathrm{cm}^{2}$, el cual es el valor más bajo en comparación con los promedios de D: $20.5 \%$ con $25.20 \mathrm{~kg} / \mathrm{cm}^{2}$ y D: $18 \%$ con $23.3 \mathrm{~kg} / \mathrm{cm}^{2}$. Asimismo, se puede interpretar que D: $20.5 \%$ y D: $18 \%$, tienen una resistencia de $33.81 \%$ y $23.72 \%$ mayor 
que el de la muestra de menor. Estos resultados se pueden validar tomando en cuenta que autores como Suarez E. y Aranda Y. (2013) y Galan et al. (2010) obtuvieron un incremento de resistencia con respectos a su la menor y mayor unidad estabilizado en $26.25 \%$ y $20.4 \%$ al estabilizarlos con mucílago de nopal y lana de oveja respectivamente. Asimismo, podemos corroborar que nuestros resultados cumplen las indicaciones de la Norma E 080 (2017), en el cual menciona que la resistencia última debe ser al menos $10.2 \mathrm{kgf} / \mathrm{cm}^{2}$ por cada espécimen ensayado.

\subsection{Resistencia a la flexión}

Para verificar si los resultados obtenidos son correctos, se tomará en cuenta la variación de las máximas fuerzas aplicadas en las unidades de adobes según la dosificación, como se evidencia en la siguiente tabla 4.2 .

Tabla 4.2. Porcentaje de variación de las máximas fuerzas aplicadas según dosificación. Fuente: Propia

\begin{tabular}{|c|c|c|c|c|c|c|}
\hline $\mathbf{N}^{\circ}$ & $\begin{array}{c}\text { MUESTRA } \\
\text { PATRON }\end{array}$ & D:8.5\% & D:11.3\% & D:13.0\% & D:18.0\% & D:20.5\% \\
\hline $\mathrm{N}^{\circ} 1$ (kgf) & 116.32 & 117.21 & 117.13 & 116.67 & 116.9 & 117.31 \\
\hline $\mathrm{N}^{\circ} 2(\mathrm{kgf})$ & 116.88 & 116.2 & 116.79 & 116.96 & 117.46 & 116.38 \\
\hline $\mathrm{N}^{\circ} 3(\mathrm{kgf})$ & 117.35 & 117.23 & 116.88 & 117.32 & 116.83 & 117.55 \\
\hline
\end{tabular}

\begin{tabular}{|l|l|l|l|l|l|l|}
\hline Min (kgf) & 116.32 & 116.20 & 116.79 & 116.67 & 116.83 & 116.38 \\
\hline
\end{tabular}

\begin{tabular}{|c|c|c|c|c|c|c|}
\hline $\mathrm{N}^{\circ} 1$ & - & $0.87 \%$ & $0.29 \%$ & - & $0.06 \%$ & $0.80 \%$ \\
\hline $\mathrm{N}^{\circ} 2$ & $0.48 \%$ & - & - & $0.25 \%$ & $0.54 \%$ & - \\
\hline $\mathrm{N}^{\circ} 3$ & $0.89 \%$ & $0.89 \%$ & $0.08 \%$ & $0.56 \%$ & - & $1.01 \%$ \\
\hline
\end{tabular}

La tabla 4.2 muestra la variación de porcentaje que hay entre el mínimo valor de cada grupo con respecto a los valores restantes. Entonces para D: $8.5 \%$ la variación de porcentaje es de $0.87 \%$ y $0.89 \%$ mientras que para D: $11.3 \%$ son $0.29 \%$ y $0.08 \%$. Asimismo, para D: $13 \%$ tienen una variación de $0.25 \%$ y $0.56 \%$, y para D: $18.0 \%$ están con $0.06 \%$ y $0.54 \%$. Finalmente, D: $20.5 \%$ le corresponde una variación de $0.8 \%$ y $1.01 \%$. Por lo tanto, con lo mostrado anteriormente se puede interpretar que los valores obtenidos muestran una ligera mejora de la resistencia a la flexión en los adobes estabilizados, lo cual significa que la estabilización no aporta significativamente a la resistencia a la flexión. 


\subsection{Ensayo de absorción}

Para validar que los resultados de este ensayo sean los correctos, primero se corroboró que el horno eléctrico tenga la temperatura adecuada $\left(12^{\circ} \mathrm{C}\right)$ para secar los diferentes adobes. Segundo, se comprobó la sensibilidad de la balanza digital a utilizar (+-0.1g), ya que los resultados en este ensayo dependen principalmente de lo mencionado anteriormente. Entre los resultados en este ensayo se pudo calcular que el porcentaje de absorción de las 5 dosificaciones $(20.5 \%, 18 \%, 13 \%, 11.3 \%$ y $8.5 \%)$ varían entre un rango de $9.92 \%$ a $13.35 \%$.

\subsection{Pruebas recomendadas por otros autores}

\section{- Ensayo de inmersión}

No se tiene valores estandarizados con que limitar los resultados del ensayo a inmersión, pues es un ensayo experimental realizado por el autor Micek et al (2006, citado por Benites, 2017) en su Manual de construcción en tierra: La tierra como material de construcción y sus aplicaciones en la arquitectura actual, en esta se realiza una clasificación según los daños que muestra las unidades, después de extraerlas del agua. En este ensayo se obtuvieron resultados para las diferentes dosificaciones como se presenta a continuación: Para D: 13\%, D: $11.3 \%$ y D: $8.5 \%$ tuvieron un daño moderado, pues algunos adobes se desmoronaron y tenían fisuras notables mientras que las dosificaciones D: $20.5 \%$ y D: $18 \%$ fueron considerados con daños leves-moderados, pues al ejercerles presión con los dedos, quedaban algunas marcas. Estos resultados son muy similares a Benites V. que utiliza para estabilizar su unidad de adobe con cabuya (polímero natural), el cual nos expone que sus resultados frente a este ensayo están entre daños levesmoderados.

\section{- Prueba de chorro de agua}

No se tiene valores estandarizados con que validar los resultados de prueba de chorro de agua, pues es un método experimental propuesto por Fox R., McDonald A y Pritchard (2011) en su libro titulado Introducción a la Mecánica de Fluidos, el cual tiene como objetivo medir la profundidad de la marca provocada por un chorro constante de agua. En esta investigación las diferentes dosificaciones, presentaron los siguientes resultados: $\mathrm{La}$ dosificación D: $20.5 \%$ (4.33, 5.63, y $4.72 \mathrm{~mm})$, D: $18 \%$ (5.08, 5.71 y $5.15 \mathrm{~mm})$, D: $13 \%$ $(5.80,4.57,5.98 \mathrm{~mm}), \mathrm{D}: 11.3 \%(7.01,7.62$ y $7.30 \mathrm{~mm})$ y D: $8.5 \%(7.01,7.62$, y 7.30 
$\mathrm{mm}$ ). Entre el mayor y menor resultado presentan $43.2 \%$ de diferencia, porcentaje superior a lo que presenta el autor Benites V. pues este se evidencia un incremento menor al $1 \%$, esta diferencia se debe posiblemente a que en esta investigación se utiliza un el mucílago de penca de tuna mientras que Benites V. incorpora en su mezcla cascara de arroz y extracto de cabuya, los cuales son polímeros muy diferentes.

\subsubsection{OBJETIVO 3: Comparar los resultados de resistencia mecánica (compresión y flexión) y resistencia física (absorción) de las unidades y pilas de adobes convencionales de los adobes estabilizados.}

\subsubsection{Ensayo por unidad de adobe}

En la comparación de los ensayos se tomará en cuenta el promedio de los valores de cada unidad y pila ensayada por cada dosificación.

\subsection{Resistencia a la compresión}

Se tomará en cuenta las indicaciones la Norma E.080 (2017) para validar los resultados de este ensayo. En la norma establece que la resistencia última debe ser al menos $10.2 \mathrm{kgf} / \mathrm{cm}^{2}$ en cada espécimen ensayado. En esta investigación, todos los resultados promedios de resistencia a la compresión están por encima de este límite como se muestra a continuación: muestra patrón, D: $20.5 \%$ y D: $18 \%$ fueron de $18.83 \mathrm{~kg} / \mathrm{cm}^{2}, 23.30 \mathrm{~kg} / \mathrm{cm}^{2}$ y $25.20 \mathrm{~kg} / \mathrm{cm}^{2}$ respectivamente. Asimismo, las unidades estabilizadas tuvieron un incremento de $23.72 \%$ y $33.81 \%$ para D: $20.5 \%$ y D: $18 \%$ con respecto a la muestra patrón mientras que en las investigaciones de Suarez E. y Aranda Y. (2013) y Galan et al. (2010) obtuvieron una variación de resistencia de $28.58 \%$ y $39.8 \%$ al estabilizarlos con mucílago de nopal y lana de oveja respectivamente

\subsection{Resistencia a la flexión}

Los resultados muestran una ligera mejora de la resistencia a la flexión en los adobes estabilizados en comparación a los adobes convencionales, pues un incremento de $0.23 \%$ representa que la estabilización no aporta significativamente a la resistencia a la flexión.

En la investigación de Benites V. (2017) los resultados muestran un incremento en la resistencia a la flexión en $57.91 \%$., un incremento mayor de porcentaje con respecto a la de 
nuestra investigación. La diferencia de resultados se debe al tipo de estabilizador empleado y el objetivo del estudio, ya que nuestra investigación busca determinar el porcentaje óptimo de mucílago de penca de tuna para un tiempo de remojo de 15 días mientras que Benites busca se analizar el efecto de estabilizar adobes con extracto de cabuya a 5, 10 y 20 días.

\subsection{Ensayo de absorción}

De acuerdo a los resultados del ensayo, el adobe convencional se desintegra en su totalidad y los adobes con porcentaje de mucílago de penca de tuna resisten al ensayo. Asimismo, la dosis de $20.5 \%$ absorbe $3.85 \%$ menos de agua que la dosificación de $18 \%$.

En la investigación de Benites V. (2017) se puede apreciar que luego de realizar el ensayo de absorción, los adobes convencionales se desintegran en su totalidad, en cambio los adobes estabilizados no se desintegran y absorben $16 \%$ de agua.

En ambas investigaciones los adobes convencionales no resisten el ensayo de absorción y se demuestra que los estabilizantes naturales proporcionan cierto porcentaje de permeabilidad a la unidad.

\subsection{Pruebas recomendadas por otros autores}

\section{- Ensayo de inmersión}

El adobe convencional y el de menor concentración de mucílago de penca de tuna $(8.5 \%)$ presentan daños severos, mientras se incrementa la concentración de mucílago de penca de tuna los daños disminuyendo hasta ser leve - moderado.

En la investigación de Benites V. (2017) se puede apreciar que luego de realizar el ensayo de inmersión, el adobe convencional presenta daño severo, los adobes estabilizados con cabuya macerada 5 días y 10 días presentan daños moderados y el adobe estabilizado con cabuya macerada 20 días presenta daño leve. Los resultados muestran que las estabilizaciones con polímeros son efectivas para reducir la destrucción de las unidades cuando son sometidos al agua por inundación.

\section{- Prueba de chorro de agua}

Los valores de comparación de este ítem son considerados aceptables, pues son el promedio de los valores justificados en el objetivo 2 en el ítem 4.1.2.1.4. En esta investigación la muestra patrón y las dos mejores dosificaciones, presentaron los siguientes resultados promedios: la muestra patrón con $7.31 \mathrm{~mm}$, D: $20.5 \%$ con $4.89 \mathrm{~mm}$ y D: $18 \%$ 
con $5.31 \mathrm{~mm}$ de profundidad de penetración. En otras palabras, el porcentaje de penetración disminuye hasta $33.5 \%$ conforme incrementa la dosis de solución de mucílago de penca de tuna.

Benites V. (2017) luego de realizar el ensayo en su investigación, obtiene que los chorros de agua en los adobes convencionales penetran $6.74 \%$ y los adobes estabilizados penetran $0.33 \%$. Los resultados, muestra que los adobes estabilizados ofrecen una superficie resistente al golpe de agua por ende soportara más las lluvias intensas.

\subsubsection{Ensayos por pila de adobe}

\subsection{Resistencia a la compresión}

Se tomará en cuenta la recomendación de la Norma E.080 (2017) titulada Diseño y Construcción con tierra reforzada para validar los resultados promedios en esta comparación. En la norma establece que las resistencias últimas de las pilas de adobes deben ser al menos $6.12 \mathrm{kgf} / \mathrm{cm}^{2}$ en cada espécimen ensayado. En esta investigación, todos los resultados promedios del esfuerzo a la compresión están por encima de este límite como se muestra a continuación: El valor promedio del esfuerzo a la compresión (f'm) por pila de adobes para la muestra patrón, D: $20.5 \%$ y D: $18 \%$ es de $12.41 \mathrm{~kg} / \mathrm{cm}^{2}, 14.77 \mathrm{~kg} / \mathrm{cm}^{2}$ y $16.74 \mathrm{~kg} / \mathrm{cm}^{2}$ respectivamente. 


\section{CONCLUSIONES}

Sobre la base de los resultados obtenidos en la presente investigación y detallados en el capítulo anterior, se ha podido llegar a las siguientes conclusiones expuestas a continuación:

\section{Sobre la selección de los materiales:}

- El suelo adecuado para la elaboración de adobes es un suelo: Arcilla con grava o con arena (CL) que no contenga material orgánico y que la cantidad de arcilla sea menos que la cantidad de arena para cumplir las recomendaciones de la N.T.E E.0.80 “Adobe” y las especificaciones SUCS. El suelo utilizado para la elaboración de los adobes fue la primera muestra, pues presenta las siguientes características: $27.2 \%$ de arcilla, $17 \%$ de arena, peso específico de $2729,39 \mathrm{~kg} / \mathrm{cm}^{3}$, limite liquido de $32.626 \%$, un índice plástico de 12.86 \% y sin presencia de restos orgánicos, la cual cumple con las especificaciones de la norma.

- El método más económico y factible para extraer el mucílago de penca de tuna es del remojo por 15 días. Se analizaron 5 dosis distintas, de las cuales la dosis de $18 \%(7.2$ $\mathrm{kg}$ de trozos de penca de tuna y 40 litros de agua) y $20.5 \%$ (8.2 $\mathrm{kg}$ de trozos de penca de tuna y 40 litros de agua) presentan mejores resultados de densidad $\left(819.54 \mathrm{~kg} / \mathrm{m}^{3}\right.$, $\left.977.01 \mathrm{~kg} / \mathrm{m}^{3}\right)$ y viscosidad $(20.60 \mathrm{~kg} / \mathrm{m} . \mathrm{s}, 20.09 \mathrm{~kg} / \mathrm{m} . \mathrm{s})$, los resultados de viscosidad y densidad dependerán de la cantidad de trozos de penca de tuna y el periodo que estos trozos estarán sumergidos en agua.

- De acuerdo a los datos obtenidos se puede concluir que la viscosidad y densidad del mucílago de penca de tuna tienen una relación inversamente proporcional, ya que cuanto mayor es la viscosidad menor es su densidad.

\section{Sobre los ensayos mecánicos y físicos de las unidades estabilizadas:}

- El incremento de la resistencia a la compresión (R.C) entre los adobes estabilizados de dosis de $18 \%$ (máxima R.C) y $8.5 \%$ (mínima R.C) de mucílago de penca de tuna es de $20.99 \%$. En las dosis de $18 \%$ y $20.5 \%$ de mucílago de penca de tuna, se obtuvo mayor resistencia a la compresión, $25.20 \mathrm{~kg} / \mathrm{cm}^{2}$ y $23.30 \mathrm{~kg} / \mathrm{cm}^{2}$ respectivamente. En la dosis de $11.3 \%$ de mucílago de penca de tuna se obtuvo $19.91 \mathrm{~kg} / \mathrm{cm}^{2}$. Caso 
contrario sucede con la resistencia la flexión, pues los adobes estabilizados incrementan el módulo de rotura en $0.17 \%$, la máxima dosis de $20.50 \%$ de mucílago de penca de tuna tuvo un valor de $17.62 \mathrm{~kg} / \mathrm{cm}^{2}$, la dosis de $18 \%$ de mucílago de penca de tuna tuvo un valor de $17.61 \mathrm{Kg} / \mathrm{cm}^{2}$ y la menor dosis de $8.5 \%$ de mucílago de penca de tuna tuvo un valor de $17.59 \mathrm{~kg} / \mathrm{cm}^{2}$. Para el ensayo de absorción, el adobe que contiene mayor dosis de mucílago de penca de tuna posee mayor permeabilidad en comparación a los adobes que contienen menor dosis de mucílago de penca de tuna, la dosis de $20.5 \%$ de mucílago de penca de tuna absorbió $10.99 \%$ de agua, la dosis de $18 \%$ de mucílago de penca de tuna absorbió $11.43 \%$ y la menor dosis de $8.5 \%$ de mucílago de penca de tuna absorbió $12.64 \%$.

- Según los ensayos recomendados por otros autores se puede concluir que la prueba de inmersión, la cual muestra la resistencia de los adobes sometidos a inundaciones prolongadas y la prueba de chorro de agua, la cual muestra la resistencia del adobe frente a lluvias intensas, los adobes estabilizados con mayor dosis de mucílago de penca de tuna muestran mejores resultados. Para la primera prueba, la dosis $8.5 \%$ de mucílago de penca de tuna presenta daño severo, las dosis de $11.3 \%$ y $13 \%$ de mucílago de penca de tuna presentan daños moderados y las dosis $18 \%$ y $20.5 \%$ de mucílago de penca de tuna presentan daños leves - moderados. Para la segunda prueba, la dosis $20.5 \%$ de mucílago de penca de tuna penetra $4.89 \mathrm{~mm}$, la menor dosis $8.5 \%$ penetra $7.31 \mathrm{~mm}$, la dosis $11.3 \%$ y $13 \%$ se encuentran entre el promedio con $6.39 \mathrm{~mm}$ y $5.45 \mathrm{~mm}$ de penetración respectivamente.

- Según los resultados de los diversos ensayos, la dosis de $18 \%$ y $20.5 \%$ de mucílago de penca de tuna incrementan la resistencia mecánica y física del adobe.

\section{Sobre la comparación de las resistencias del adobe convencional y los adobes estabilizados:}

- Se puede concluir, que la diferencia entre los resultados de compresión es mínima, ya que la dosis de $18 \%$ de mucílago de penca de tuna incrementa la resistencia a la compresión en $33.81 \%$ y la dosis de $20.5 \%$ de mucílago de penca de tuna incrementa la compresión en $23.72 \%$ con respecto al adobe convencional. 
- En los ensayos de compresión tanto en la unidad como la pila, la dosis de $18 \%$ de mucílago de penca de tuna obtiene mejores resultados, la resistencia de compresión en la unidad de adobe es $25.20 \mathrm{~kg} / \mathrm{cm}^{2}$ y la resistencia de compresión en la pila de adobe es $16.74 \mathrm{~kg} / \mathrm{cm}^{2}$. Mientras que, en la dosis de $20.5 \%$ de mucílago de penca de tuna, la resistencia de compresión en la unidad de adobe es $23.30 \mathrm{~kg} / \mathrm{cm}^{2}$ y la resistencia de compresión en la pila de adobe es $14.77 \mathrm{~kg} / \mathrm{cm}^{2}$.

- En el ensayo de flexión, el incremento de las resistencias en comparación al adobe convencional es mínimo, la dosis de $18 \%$ de mucílago de penca de tuna incrementa la resistencia en $0.17 \%$ y la dosis de $20.5 \%$ de mucílago de penca de tuna incrementa la resistencia en $0.23 \%$.

- Luego de realizar el ensayo de absorción, los adobes convencionales se desmoronan por completo y no resisten a estar sumergidos en agua por 24 horas. En cambio, los adobes estabilizados con $18 \%$ de mucílago de penca de tuna de mucílago de penca de tuna absorben $11.43 \%$ de agua y los adobes estabilizados con $20.5 \%$ de mucílago de penca de tuna de mucílago de penca de tuna absorben $10.99 \%$ de agua.

- Según las pruebas recomendadas por otros autores, ambas dosis resistirán a las grandes inundaciones y fuertes lluvias, la diferencia entre los resultados es mínima. En el ensayo de inmersión ambas dosis presentan daños leves - moderados. En el ensayo de chorro de agua la dosis de $18 \%$ de mucílago de penca de tuna penetra $27.36 \%$ y la dosis de $20.5 \%$ de mucílago de penca de tuna penetra $33.5 \%$ menos que el adobe convencional. 


\section{RECOMENDACIONES}

En el siguiente capítulo se mencionará sugerencias y recomendaciones para futuras investigaciones en la misma línea temática propuesta por la tesis.

\section{Sobre la selección de los materiales:}

- Se sugiere recolectar pencas de tuna de mediano espesor (8 $\mathrm{mm}$ a $12 \mathrm{~mm}$ ), pues las delgadas contienen poca viscosidad y las gruesas son muy difíciles de cortar debido a que al poseer mayor etapa de vida estas se comienzan a endurecer.

- Se recomienda realizar la elaboración de los adobes hasta 5 días después de retirar las cáscaras de pencas de tuna de la solución, con la finalidad de que la consistencia del líquido tenga una mínima variación al ser incorporadas en la mezcla, pues con ese lapso de tiempo el líquido aún tiene un color verdoso oscuro y un olor fuerte a material descompuesto como lo recomienda Vargas J., Heredia E., Bariola J. \& Povindar K. (1986) y León R. (2012).

- Se recomienda que el agua que se utiliza para la elaboración de los adobes estén libres de residuos orgánicos, sales, solidos o posibles sustancias dañinas, para no afectar las propiedades físicas y mecánicas del elemento, y de esta manera cumplir con lo estipulado en el Art. 5 de la norma E.080 Diseño y Construcción con Tierra Reforzada.

\section{Sobre los ensayos mecánicos y físicos de las unidades estabilizadas:}

- Se sugiere que, para próximas investigaciones, se opte por realizar adobes incorporados con mucílago de penca de tuna extraída de manera distinta a lo mencionado en esta investigación, para posteriormente realizar ensayos a la unidad y pilas de adobes y finalmente comparar resultados. Entre los métodos de extracción diferente de mucílago de nopal se tiene la extracción con solventes, la extracción por ultrafiltración, extracción acuosa, extracción por calentamiento, entre otras.

- Se recomienda agregar a la unidad de adobe estabilizado con mucílago de penca de tuna un estabilizante de fibra vegetal (fibra de cabuya, corteza de árbol, etc.), con el objetivo de estudiar el efecto que tiene combinar distintos métodos de estabilización 
en un mismo elemento.

- Se recomienda realizar un estudio comparativo entre las tres categorías de estabilización que existen (consolidantes, fibras o impermealizantes). Observar el efecto que tiene cada método de estabilización para mejorar la resistencia mecánica y física de la unidad de adobe.

\section{Sobre la comparación de las resistencias del adobe convencional y los adobes estabilizados:}

- Evaluar el comportamiento sísmico de los adobes estabilizados y convencionales en muros portantes en escala real, considerando la información de la Norma Sismorresistente E.030.

- Se sugiere emplear en el proceso constructivo un sistema de Aparejo Americano para construir viviendas de adobes; asimismo, reforzar los muros con cañas horizontales cada tres hiladas en el tercio central y cada dos hiladas en el tercer superior como lo indica la norma E.080 (2017), con la finalidad de conseguir viviendas más seguras y resistentes.

- Se recomienda emplear adobes estabilizados con mucílago de penca de tuna para la construcción de viviendas rurales en la Sierra del Perú, pues a pesar de que habría un aumento en los gastos a corto plazo, ya que el costo por unidad de adobe se incrementaría en 1.38 soles (costo por extracción del mucílago) como se muestra en el anexo I, este gasto se recuperaría a largo plazo, pues los muros con unidades estabilizadas tendrán una menor cantidad de reparaciones en comparación con los muros de adobes convencionales en un determinado periodo de tiempo (sus costos de reparación entre ellos serán menores, pues dependen del deterioro que estos presentan.), el cual se puede evidenciar en los anexo I y anexo J .

- Se recomienda utilizar en la mezcla para la elaboración de la junta un porcentaje de mucílago de penca de tuna de la dosificación utilizada en los adobes estabilizados, con la finalidad de que al entrar al contacto con el agua tenga una mayor resistencia y durabilidad. 


\section{REFERENCIAS BIBLIOGRÁFICAS}

En el siguiente capítulo se mostrarán los diferentes tipos de publicaciones y referencias utilizadas para la presente investigación.

- Arteaga K., Humberto O., \& Gutiérrez O. (2011) Facultad de Ingeniería: Bloque de tierra comprimida como material constructivo, 20 (31), 55-68. Recuperado de http://www.redalyc.org/pdf/4139/413940770005.pdf (Consulta 17 julio 2019)

- ASTM C78 (2002), Método de Ensayo Normalizado para la Determinación de la Resistencia a la Flexión del Concreto. Recuperado de https://es.scribd.com/doc/187747328/ASTM-C78 (Consulta 20 marzo 2019)

- ASTM D-2216 (2010), Contenido de humedad. Recuperado de https://es.scribd.com/document/246727682/Astm-d2216 (Consulta 15 de junio 2019)

- ASTM D-854 (2014), Gravedad Específica de Partículas Sólidas. Recuperado de https://infostore.saiglobal.com/en-us/Standards/ASTM-D854-14151515_SAIG_ASTM_ASTM_357207/ (Consulta 11 de febrero 2019)

- Barrantes W. (2013). Efecto de la concentración de sólidos solubles de aguamiel de Cabuya (Furcraea Andina) en las características sensoriales de una bebida destilada tipo tequila blanco. Cientifi-k, 1(1), 47-61. Recuperado de. https://issuu.com/congresouniversidadcesarvallejo/docs/revistacientifi-k $\quad$ Consulta 10 febrero 2019)

- Bañon L. (2010) Durabilidad (Tema 08). Recuperada de https://rua.ua.es/dspace/bitstream/10045/25641/8/Tema\%2008\%20\%20Durabilidad.pdf (Consulta: 15 febrero 2019).

- Benites V. (2017) Adobe estabilizado con extracto de cabuya (Furcraea andina). Tesis de pregrado. Universidad de Piura. Perú. Recuperado de https://pirhua.udep.edu.pe/bitstream/handle/11042/2993/ICI_237.pdf?sequence=1 (Consulta 29 de abril 2019)

- Cervantes L. \& Cuya S. (2015). Elaboración de miel de Cabuya y estudio de prefactibilidad de una planta en el distrito de Huanca Huanca, Provincia de Angaraes, Departamento de Huancavelica. Universidad Nacional Mayor de San Marcos. Perú: 
Lima.

Recuperado

de

https://alicia.concytec.gob.pe/vufind/Record/UNMS_83729764f2b8d9f69632059b57ae

$\underline{\text { 533f/Details }}$ (Consulta 20 de febrero 2019)

- Compendio Estadístico Perú (2014). Territorio. Recuperado de https://www.inei.gob.pe/media/MenuRecursivo/publicaciones_digitales/Est/Lib1173/ca p01/cap01.pdf (Consulta 27 de Noviembre 2019)

- De Olarte J., Linares Z., Rodríguez J. \& Jiménez F. (2003). Base de Datos de Sistemas constructivos para Edificación que se utilizan en el Perú. Recuperado de https://books.google.com.pe/books/about/BASCE_Per\%C3\%BA.html?hl=es\&id=19G5 ZwEACAAJ\&redir_esc=y (Consulta 15 de enero 2019)

- Fox R. \& McDonald A. (2011). Introducción a la Mecánica de Fluidos, México. ISBN: 9789701006696. Recuperado de http://librosysolucionariosdeingenieria.blogspot.com/2015/11/mecanica-de-fluidos-fox-

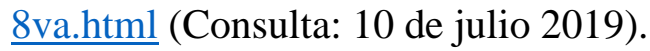

- Gallegos H. \& Casabonne, C (2005) Albañilería Estructural. 3ra Edición. Recuperado de https://aportealaingcivil.blogspot.pe/2016/05/albanileria-estructural-gallegos.html (Consulta: 17 de abril 2019)

- Gendrop P. (2001). Diccionario de arquitectura mesoamericana (pp. 238). México: Trillas. Recuperado de https://es.scribd.com/doc/316897368/Diccionario-de-

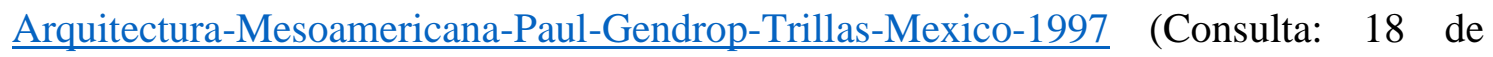
marzo 2019)

- Gerencia Regional Agraria (2009) Cultivo de tuna. Recuperado de http://www.agrolalibertad.gob.pe/sites/default/files/MANUAL\%20TECNICO\%20DE\% 20TUNA.pdf (Consulta: 3 de enero 2019)

- Gutierrez J. (2013). Manual de Laboratorio de Mecánica de Suelos. Lima: Editorial UPC Recuperado de https://es.scribd.com/document/241548412/Guia-de-Laboratorios-MSUPC (Consulta: 13 de enero 2019)

- Instituto de la Construcción y Gerencia -ICG (2010). Materiales de construcción. (Consulta: 19 de febrero 2019)

- Instituto Nacional de Defensa Civil - INDECI (2011). Compendio estadístico de INDECI en la atención de emergencias y desastres 2011, Perú. Recuperado 
https://www.indeci.gob.pe/compend_estad/2011/comp_2011.pdf (Consulta: 19 de julio 2019)

- Instituto Nacional De Estadística e informática (INEI). Censos Nacionales 2007: IX de Población y VI de viviendas. Sociodemográfico del Perú. Perfil. Recuperado de http://censos.inei.gob.pe/cpv2007/tabulados/\# (Consulta: 20 de enero 2019)

- Instituto Nacional de Estadística e Informática (INEI) (07/08/18). En el país existen más de diez millones de viviendas particulares censadas. El Perú Primero. Recuperado de https://www.inei.gob.pe/estadisticas/indice-tematico/housing/ (Consulta: 08 de Junio 2019)

- Klees D. \& Natalini M. (2014). Fabricación de Componentes Modulares para la Construcción de Viviendas de Bajo Costo Utilizando Suelo-Cemento. Recuperado de https://studylib.es/doc/8705903/fabricaci\%C3\%B3n-de-componentes-modulares-parala-construcci\%C3\%B3n-de (Consulta 29 de abril 2019)

- León, R. (2012) Evaluación de nopal como red de retracción en concreto autoconsolidable (Tesis de Maestría. Universidad Nacional de Ingeniería. Perú). Recuperado de

https://cd.dgb.uanl.mx/handle/201504211/1311/browse?value=Le\%C3\%B3n+Castillo \%2C+Ricardo+de\&type $=$ author $($ Consulta: 18 de julio 2019)

- Lopez, J. \& Bernilla P. (2012). Evaluación funcional y constructiva de las viviendas con adobe estabilizado en Cayalti: Programa cobe-1976. (Tesis de Maestría. Universidad Nacional de Ingeniería. Perú). Recuperado de http://cybertesis.uni.edu.pe/bitstream/uni/1130/1/lopez_gj.pdf (Consulta: el 26 de mayo 2019)

- Lupicinio I (2008) Métodos Cualitativos de Investigación en Ciencias. Recuperado de http://docplayer.es/29599835-Metodos-cualitativos-de-investigacion-en-cienciassociales-profesor-lupicinio-iniguez.html (Consulta: 10 de marzo 2019)

- Minke G. (2008). Manual de Construcción en Tierra. La tierra como material de Construcción y sus aplicaciones en la arquitectura actual. Uruguay: Fin de siglo. Recuperado de https://www.muscaria.com/manual-construccion-tierra.htm (Consulta 30 de marzo 2019) 
- Ministerio de Vivienda, Construcción y Saneamiento - Dirección Nacional de Construcción (2010) Manual de construcción: Edificaciones antisísmicas de adobe. Recuperado de https://es.scribd.com/doc/69354080/Edificaciones-Antisismicas-deAdobe (Consulta: 30 de marzo 2019)

- Mispireta C. (2012) Correlacion de la viscosidad con la energía potencial Ion-Dipolo en soluciones acuosas y acetónicas de hexafluorofosfato y tetrafluoroborato de 1-n-butil-3metilimidazolio. (Tesis de pregrado, Pontificia Universidad Catolica del Perú, Facultadad de Ciencias e Ingenieria, Perú). Recuperado de http://tesis.pucp.edu.pe/repositorio/handle/20.500.12404/4772 (Consulta: 14 de enero 2019)

- Norma Técnica Peruana (NTP) 399.127. Contenido de humedad de un suelo. Recuperado de https://es.scribd.com/doc/213648347/NTP-339-127-Contenido-de-Humedad (Consulta: 15 de enero 2019)

- Norma Técnica Peruana (NTP) 399.605. Unidades de Albañilería. Método de ensayo para la determinación de resistencia en compresión de prismas de albañilería. Recuperado de https://es.scribd.com/document/351903031/Norma-Tecnica-Peruana-Ntp-399-605-2002 (Consulta: 28 de marzo 2019)

- Norma Técnica Peruana (NTP) 399.613. Unidades de Albañilería. Métodos de muestreo y ensayo de ladrillo de arcilla usados en albañilería. 2da Edición. Recuperdo de https://es.scribd.com/document/287179871/NTP-399-613-pdf (Consulta: 28 de abril 2019)

- Norma E.080 (2000). Adobe (Ministerio de vivienda, construcción y saneamiento) Recuperado de https://centrocidart.files.wordpress.com/2013/10/norma-peruana-deadobe.pdf (Consulta: 10 de enero 2019)

- Norma E.080 (2017). Diseño y construcción con tierra reforzada (Ministerio de vivienda, construcción y saneamiento). Recuperado de http://procurementnotices.undp.org/view_file.cfm?doc_id=109376 (Consulta: 10 de enero 2019)

- Perez J. (2016). Efecto de la sustitución de la baba de penca de tuna en la resistencia a la compresión y el tiempo de fraguado de un concreto de $\mathrm{f}^{\prime} \mathrm{c}=210 \mathrm{~kg} / \mathrm{cm}^{2}$. (Tesis de pregrado. Universidad San Pedro. Facultad de Ingeniería Civil. Huaraz: Perú). 
Recuperado de https://es.scribd.com/document/329985844/Plan-de-Tesis-FORMATO2016-II (Consulta: 25 de abril 2019)

- Ramírez M. (2011). Deterioro y estabilización del adobe. (Tesis de Maestría. Instituto Politécnico Nacional, Facultad de Ingeniería y Arquitectura. México). Recuperado de http://tesis.ipn.mx/bitstream/handle/123456789/21734/Tesis\%20\%20Miguel\%20\%C3\%81ngel\%20Ram\%C3\%ADrez\%20Pacheco.pdf?sequence=1\&is Allowed=y (Consulta: 26 de julio 2019)

- Ríos E. (2010). Efecto de la adición de látex natural y jabón en la resistencia mecánica y absorción del adobe compactado. (Tesis de Maestría. Instituto Politécnico Nacional. Oaxaca: México). Recuperado de http://tesis.ipn.mx/bitstream/handle/123456789/10621/199.pdf?sequence=1 (Consulta: 20 de enero 2019)

- Rodríguez J. (2016) Resistencia a compresión, flexión y absorción del adobe compactado con adición de goma de tuna. (Tesis de pregrado. Universidad Privada del norte. Facultad de Ingeniería. Cajamarca: Perú). Recuperado de http://repositorio.upn.edu.pe/bitstream/handle/11537/10482/Bola\%C3\%B1os\%20Rodr \%C3\%ADguez\%20Juan.pdf?sequence=1\&isAllowed=y (Consulta: 15 de marzo 2019)

- Romero I. \& Pereyra J. (2012). Mejoramiento de las construcciones de adobe ante una exposición prolongada de agua por efecto de inundaciones- Parte2. (Tesis de pregrado. Pontificia Universidad Católica del Perú. Facultad de Ciencias e Ingeniería. Lima: Perú. Recuperado de https://es.scribd.com/document/293885721/adobe-estabilizado (Consulta: 30 de abril 2019)

- Sabino C. (14 de diciembre del 2015). Elaboración del Ante-Proyecto 2 (4to y 5to) [Entrada blog] a Recuperado de https://proyectoseducativoscr.wordpress.com/elaboracion-del-ante-proyecto/capituloiii-marco-metodologico-de-la-investigacion/3-5-tecnica-e-instrumento-de-recoleccionde-datos/ (Consulta: 10 de marzo 2019)

- Sánchez K. (2010). Propuesta de aditivos naturales y microfibras de papel para reparar fisuras en muros de monumento históricos de tierra. (Tesis de pregrado. Pontificia Universidad Católica del Perú. Facultad de Ciencias e Ingeniería. Lima: Perú. Recuperado de http://tesis.pucp.edu.pe/repositorio/handle/123456789/506 (Consulta: 20 
de enero 2019)

- Saroza B., Rodríguez M., Menéndez J. \& Barroso I. (2008). Estudio de la resistencia a compresión simple del adobe elaborado con suelos procedentes de Crescencio Valdés, Villa Clara, Cuba. Revista de Informes de la Construcción (60),41-47, ISSN:0020- 0883 e I $\quad$ SSN: 1988-3234. Recuperado de http://informesdelaconstruccion.revistas.csic.es/index.php/informesdelaconstruccion/art icle/viewFile/745/830 (Consulta: 8 de junio 2019)

- SENAMHI (2017) Mapa Climático Nacional, Lima (Mapa) Recuperado de https://www.senamhi.gob.pe/?\&p=mapa-climatico-del-peru (Consulta: 30 de abril 2019)

- Servicio Nacional de Meteorología e hidrología del Perú (Senamhi). Boletín Hidroclimático de la Dirección Zonal 4: Enero 2015 - Diciembre 2015. Recuperado de http://www.senamhi.gob.pe/load/file/03801SENA-21.pdf http://www.senamhi.gob.pe/load/file/03801SENA-28.pdf (Consulta: 17 de junio 2019)

- Servicio Nacional de Meteorología e hidrología del Perú (Senamhi). Boletín Hidroclimático de la Dirección Zonal 4: Enero 2016- Diciembre 2016. Recuperado de http://www.senamhi.gob.pe/load/file/03801SENA-29.pdf al http://www.senamhi.gob.pe/load/file/03801SENA-40.pdf (Consulta: 17 de junio 2019)

- Servicio Nacional de Meteorología e hidrología del Perú (Senamhi). Boletín Hidroclimático de la Dirección Zonal 4: Enero 2017- Setiembre 2017. Recuperado de http://www.senamhi.gob.pe/load/file/03801SENA-41.pdf al http://www.senamhi.gob.pe/load/file/03801SENA-49.pdf (Consulta: 17 de junio 2019)

- Servicio Nacional de Meteorología e hidrología del Perú (Senamhi). Boletín Semana de lluvias: Regiones Andina y Amazónica. Informe de la semana 12 al 18 de Setiembre del 2016 - Informe de la semana 26 de diciembre del 2016 al 01 de Enero del 2017. Recuperado de http://www.senamhi.gob.pe/load/file/02233SENA-62.pdf al http://www.senamhi.gob.pe/load/file/02233SENA-78.pdf (Consulta: 10 de Octubre 2017). (Consulta: 17 de junio 2019)

- Sistema Nacional de Información Ambiental (Sinia) (2006) Indice de Desarrollo Humano Departamental, Peru 2005. Recuperado de https://sinia.minam.gob.pe/mapas/indicedesarrollo-humano-departamental-peru-2005 (Consulta 7 de Octubre 2019) 
- Sistema Nacional de Información Ambiental (Sinia) (2006) Mapa de Perfil Ambiental del Peru. Recuperado de https://sinia.minam.gob.pe/mapas/mapa-perfil-ambiental-peru (Consulta 7 de Octubre 2019)

- Suárez E. y Aranda Y. (2013) Efecto de la impermeabilidad del Mucílago de Nopal en bloques de tierra comprimidos (Revista, Nova Scientia en la Universidad de la Salle Bajío. México). Recuperado de http://www.imbiomed.com.mx/1/1/articulos.php?method=showDetail\&id_articulo=984 67\&id_seccion=4877\&id_ejemplar=9610\&id_revista=321 (Consulta: 10 de enero 2019)

- Tejada U. (2001) Buena Tierra- Apuntes para el diseño y construcción con Adobe, Lima, Perú. Centro de Investigación, Documentación y Asesoría Poblacional (169), ISBN: 9728550103 e ISBN: 9789728550103. Recuperada de http://biblio.uarm.edu.pe/cgibin/koha/opac-detail.pl?biblionumber=43716 (Consulta: 10 de julio 2019).

- Torres R. (2016) Las fibras naturales como refuerzo sísmico en la edificación de viviendas de adobe en la costa del departamento de Ica. (Tesis de pregrado. Universidad Nacional Agraria. Facultad de Ingeniería Agrícola. La Molina: Perú). Recuperado de http://repositorio.lamolina.edu.pe/bitstream/handle/UNALM/2486/N10-T6 T.pdf? sequence $=1$ (Recuperado: 29 de abril 2019)

- Vargas J., Heredia E., Bariola J. \& Povindar K. (1986) Preservación de las construcciones de adobe en áreas lluviosas (Tesis de pregrado. Pontificia Universidad católica del Perú. Facultad de Ingeniería. Lima: Perú). Recuperado de http://www.urbislibnet.org/vufind/Record/ICCROM.ICCROM44464 (Consulta: 18 de abril 2019)

- Vargas J., Torrealva D. \& Blondet M. (2015). CASAS SISMORRESISTENTES Y SALUDABLES DE ADOBE REFORZADO CON CUERDAS. Recuperado de http://files.pucp.edu.pe/posgrado/wp-content/uploads/2015/09/24233900/ManualConstrucci\%C3\%B3n-Adobe-reforzado-con-mallas-de-Driza_final.compressed.pdf (Consulta: 14 de junio 2019)

- Vargas I. (2004). Determinación de la Variación de Algunas Propiedades Físicas en Leche Cruda de las Regiones Octava, Novena y Décima (Tesis de grado. Universidad Austral De Chile. Facultad de INGENIERIA EN ALIMENTOS: Chile). Recuperado de http://cybertesis.uach.cl/tesis/uach/2004/fav297d/doc/fav297d.pdf (Consulta: 20 de setiembre 2019) 
- Vélez G. (2010). Arquitectura de barro. Revista digital apuntes de arquitectura. Venezuela. Recuperado de

http://apuntesdearquitecturadigital.blogspot.com/2010/08/arquitectura-con-barro-arqgonzalo.html (Consulta: 29 de mayo 2019) 


\section{ANEXOS}

A continuación, se presentarán los anexos del caso práctico y anexos de normativas.

Anexo A: Granulometría de la primera muestra

G R A N U L O M E T Rí A

POR TAMIZADO NORMA ASTM D 422

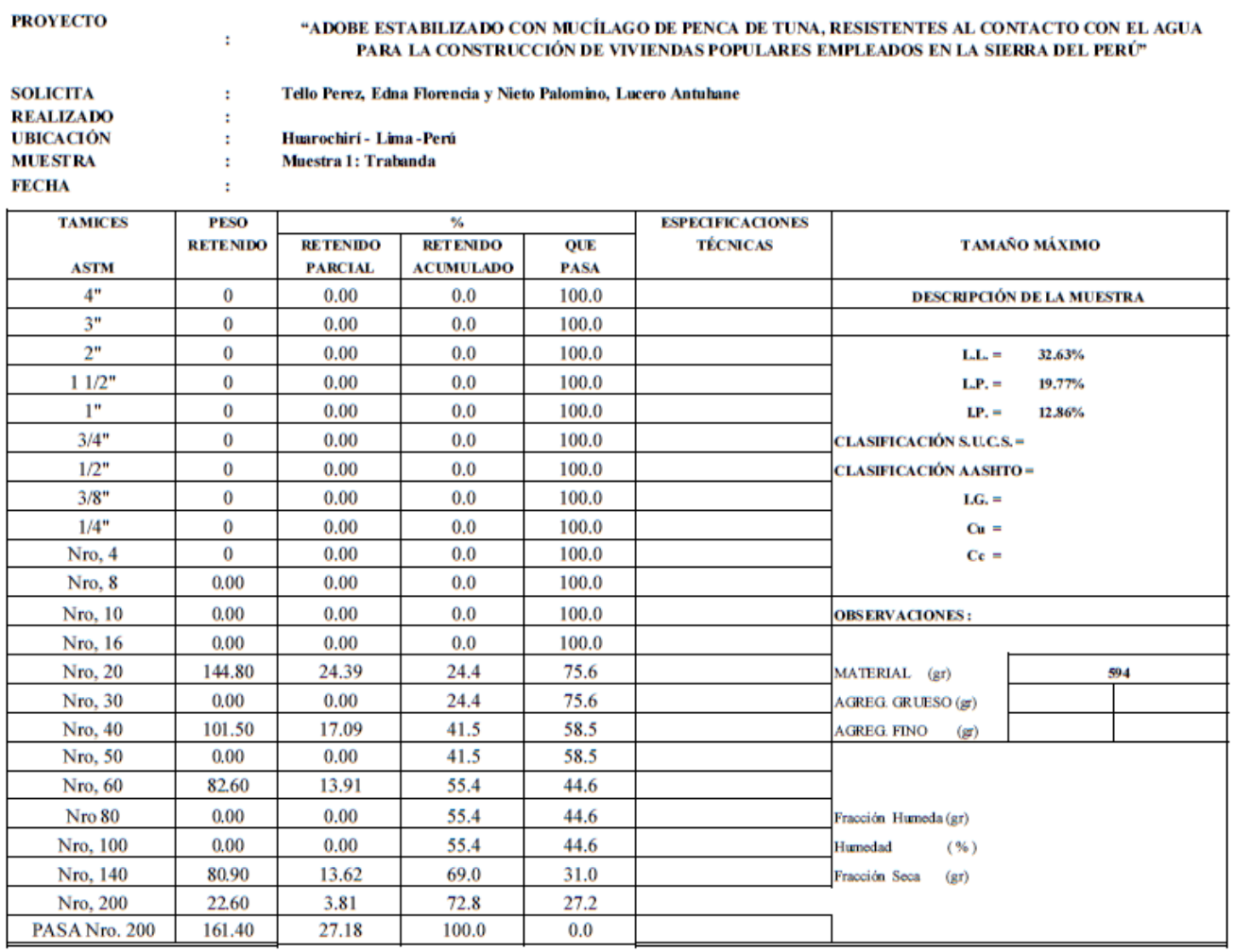

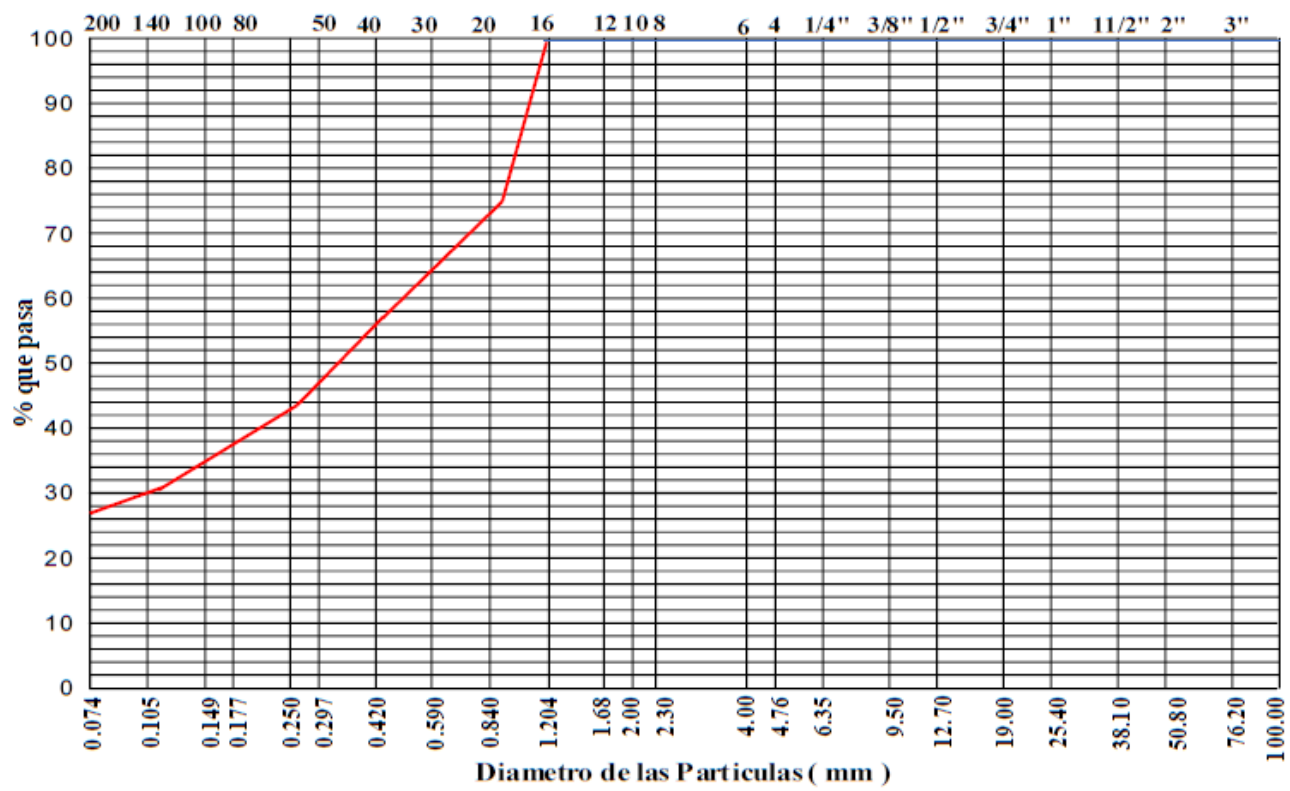


Anexo B: Granulometría de la segunda muestra

\section{G R A N UL O M E T RÍ A POR TAMIZADO NORMA ASTM D 422}

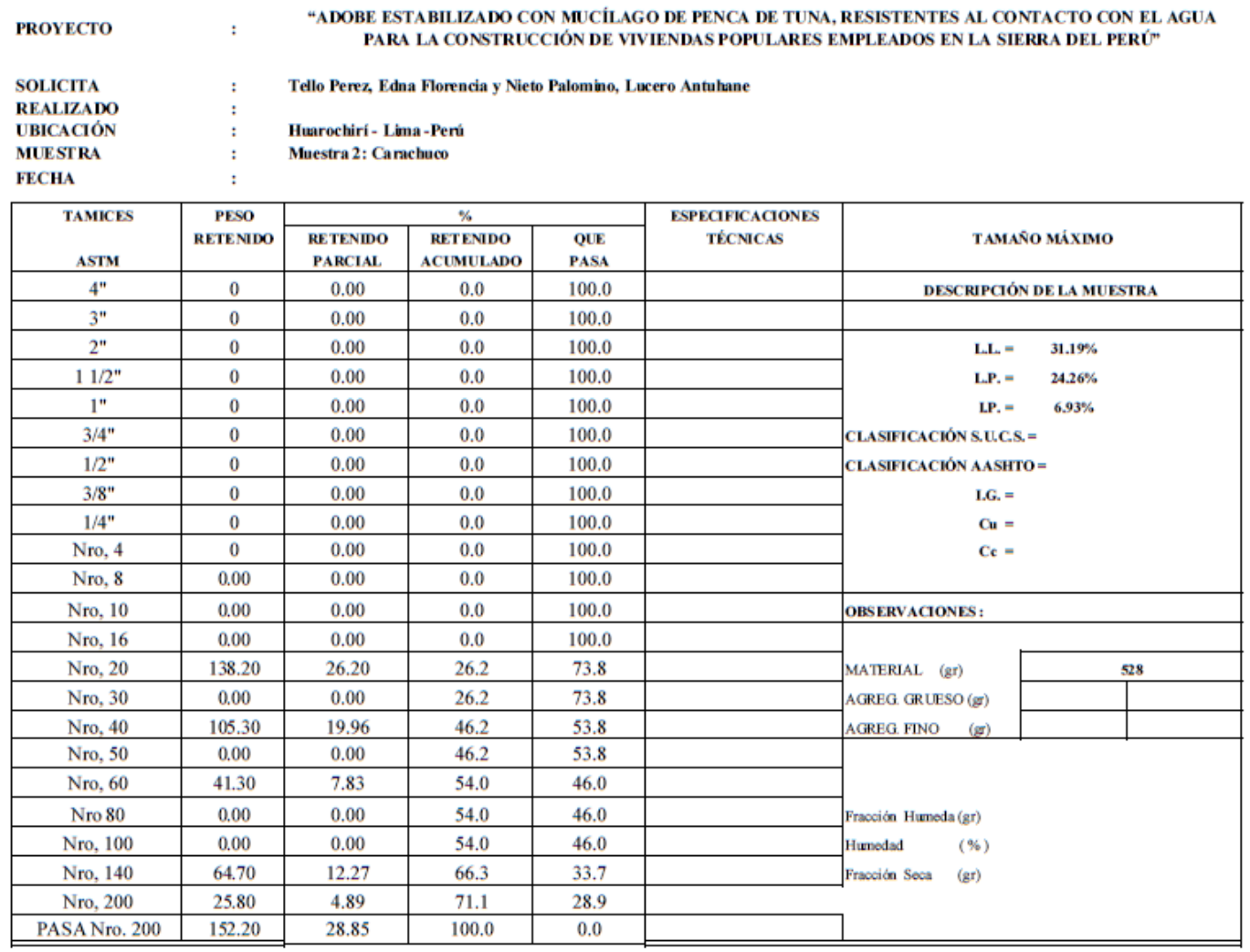

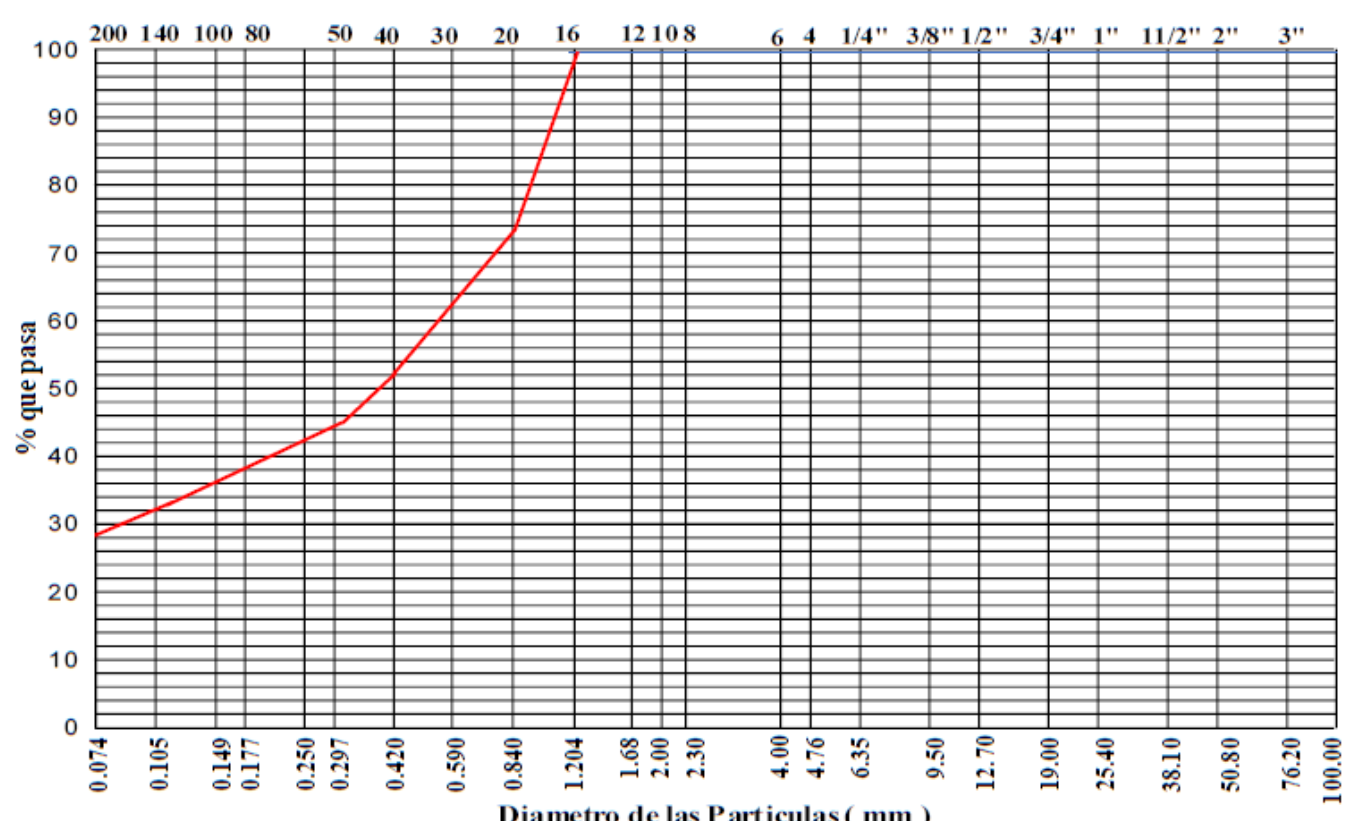




\section{GRAVEDAD ESPECÍFICA DE LOS SUELOS (PICNÓMETRO) NORMA ASTM D-854}

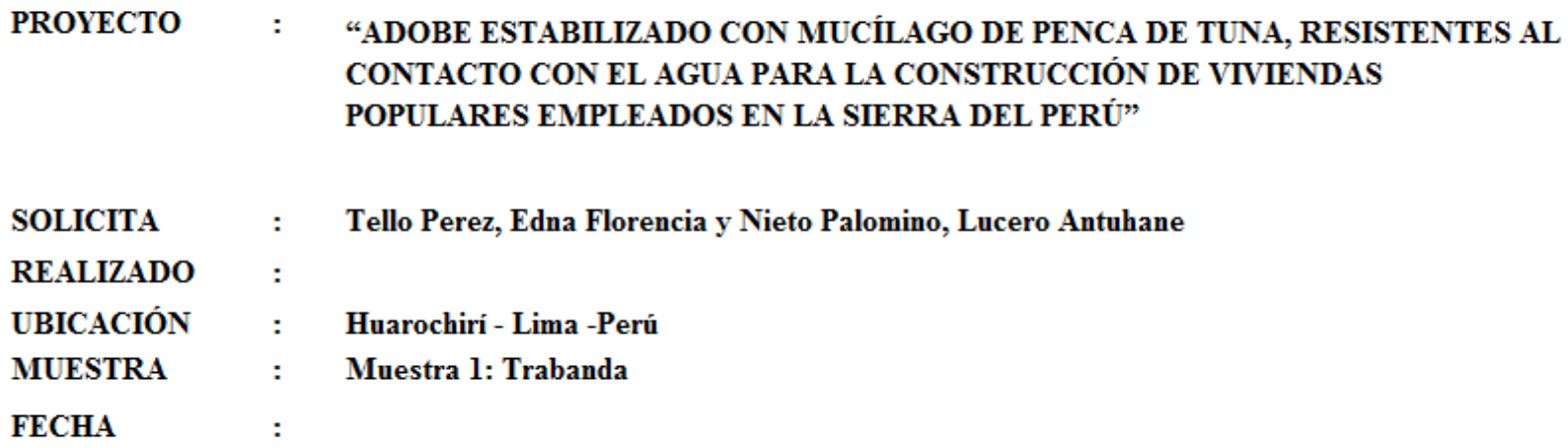

\begin{tabular}{|c|c|c|}
\hline DESCRIPCION & UNIDAD & VALOR \\
\hline \% pasante del tamiz N ${ }^{\circ} 4$ & $\mathrm{G}$ & 0.9997 \\
\hline Temperatura & ${ }^{\circ} \mathrm{C}$ & 24.4 \\
\hline
\end{tabular}

\begin{tabular}{|l|c|c|}
\hline \multicolumn{1}{|c|}{ DESCRIPCION } & UNIDAD & VALOR \\
\hline Peso de la fiola & gr & 0.1429 \\
\hline Peso muestra de suelo seco (sin corregir) & gr & 0.1246 \\
\hline Peso muestra de suelo seco + peso de la fiola & $\mathrm{gr}$ & 0.2657 \\
\hline Peso muestra de suelo seco (corregida) & $\mathrm{gr}$ & 0.1228 \\
\hline Peso muestra de suelo seco + peso de la fiola+ peso agua & $\mathrm{gr}$ & 0.7622 \\
\hline Peso de la fiola + peso de agua & $\mathrm{gr}$ & 0.6844 \\
\hline Peso especifico relativo de solidos & $\mathrm{gr} / \mathrm{cm}^{3}$ & 2.7294 \\
\hline Peso especifico relativo de solidos & $\mathrm{kg} / \mathrm{m}^{3}$ & 2729.3852 \\
\hline
\end{tabular}


Anexo D: Gravedad específica de los suelos (Picnómetro) para la segunda muestra

\section{GRAVEDAD ESPECÍFICA DE LOS SUELOS (PICNÓMETRO) NORMA ASTM D-854}

\section{PROYECTO : “ADOBE ESTABILIZADO CON MUCÍLAGO DE PENCA DE TUNA, RESISTENTES AL CONTACTO CON EL AGUA PARA LA CONSTRUCCIÓN DE VIVIENDAS POPULARES EMPLEADOS EN LA SIERRA DEL PERÚ"}

$\begin{array}{lll}\text { SOLICITA } & : & \text { Tello Perez, Edna Florencia y Nieto Palomino, Lucero Antuhane } \\ \text { REALIZADO } & : & \\ \text { UBICACIÓN } & : & \text { Huarochirí - Lima -Perú } \\ \text { MUESTRA } & : & \text { Muestra 2: Carachuco } \\ \text { FECHA } & : & \end{array}$

\begin{tabular}{|c|c|c|}
\hline DESCRIPCION & UNIDAD & VALOR \\
\hline \% pasante del tamiz $\mathrm{N}^{\circ} 4$ & $\mathrm{G}$ & 0.999 \\
\hline Temperatura & ${ }^{\circ} \mathrm{C}$ & 24.3 \\
\hline
\end{tabular}

\begin{tabular}{|l|c|c|}
\hline \multicolumn{1}{|c|}{ DESCRIPCION } & UNIDAD & VALOR \\
\hline Peso de la fiola & gr & 0.1912 \\
\hline Peso muestra de suelo seco (sin corregir) & gr & 0.1248 \\
\hline Peso muestra de suelo seco + peso de la fiola & gr & 0.3158 \\
\hline Peso muestra de suelo seco (corregida) & gr & 0.1246 \\
\hline Peso muestra de suelo seco + peso de la fiola+ peso agua & gr & 0.71 \\
\hline Peso de la fiola + peso de agua & gr & 0.6312 \\
\hline Peso especifico relativo de solidos & $\mathrm{gr} / \mathrm{cm}^{3}$ & 2.7197 \\
\hline Peso especifico relativo de solidos & $\mathrm{kg} / \mathrm{m}^{3}$ & 2719.6557 \\
\hline
\end{tabular}


Anexo E: Formato de límite de consistencia de la primera muestra

\section{LIMITE DE CONSISTENCIA NORMA ASTM D 422}

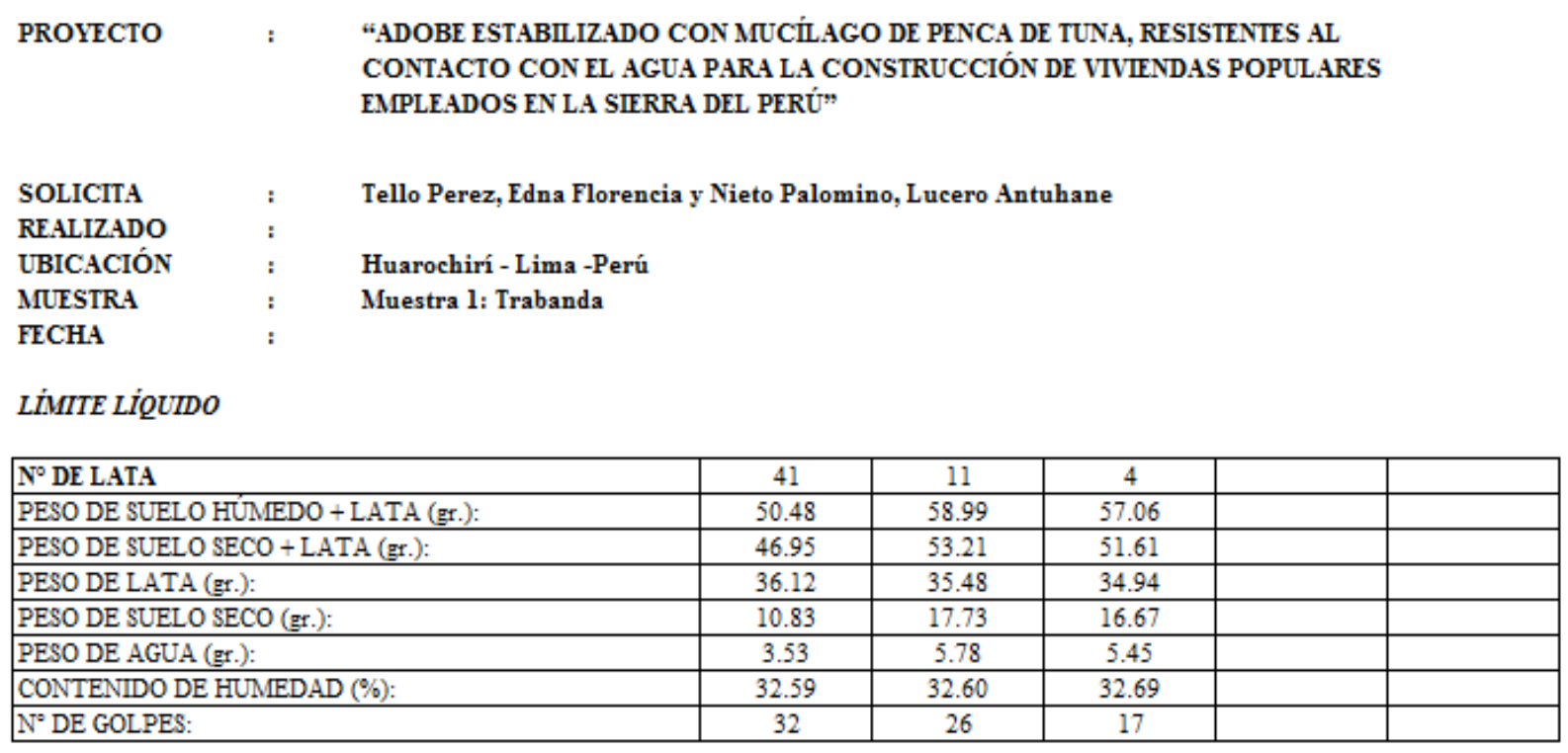

\section{LIMMTE PLÁSTICO}

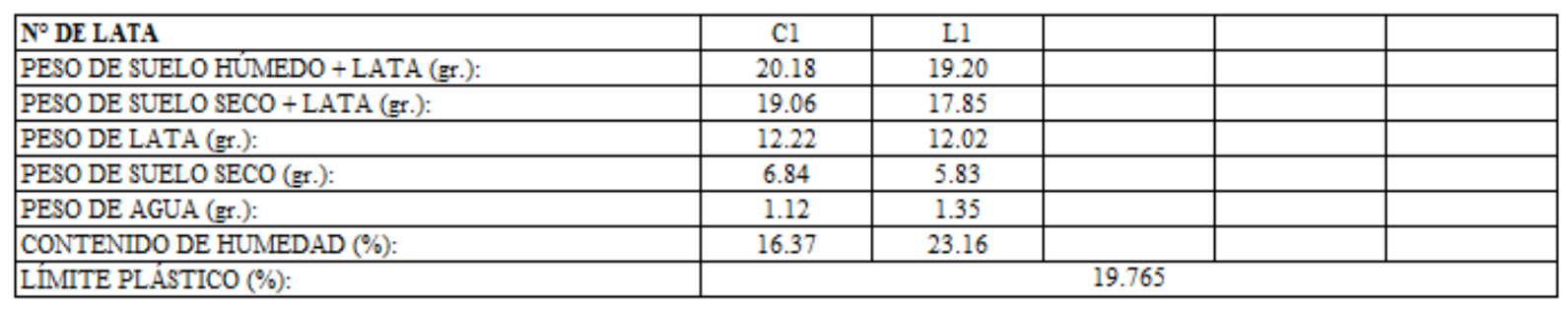
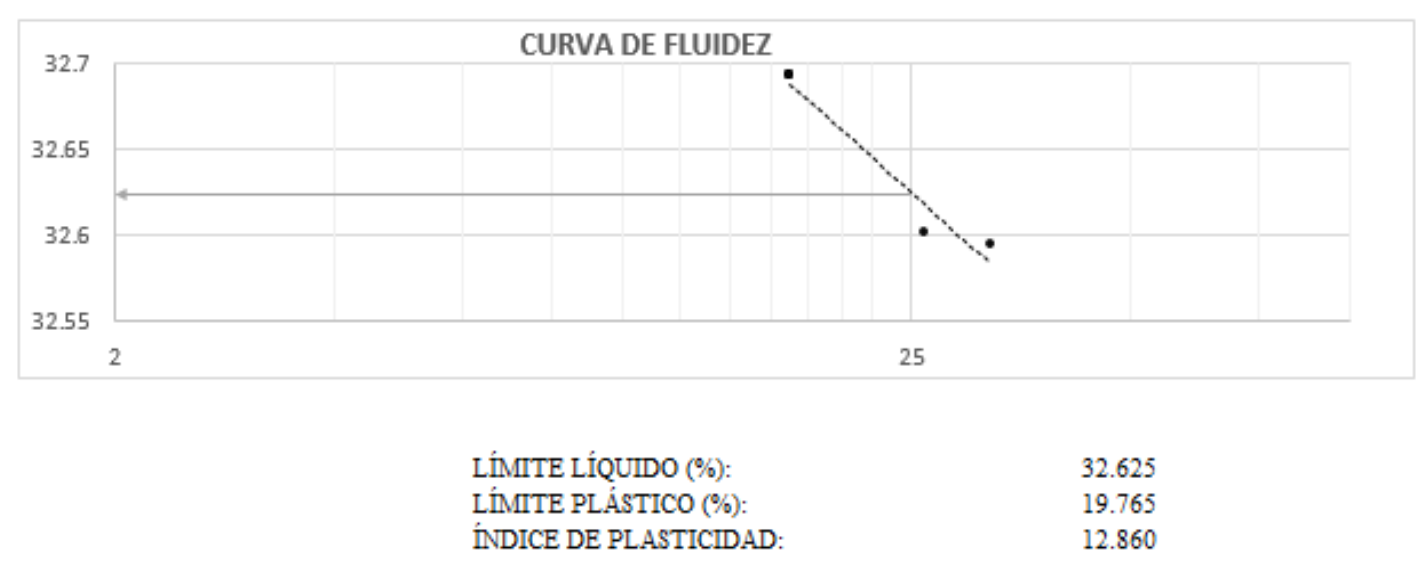
Anexo F: Formato de Límite de consistencia de la segunda muestra

\section{LIMITE DE CONSISTENCIA NORMA ASTM D-4318}

$\begin{array}{lll}\text { PROYECTO } & : & \begin{array}{l}\text { "ADOBE ESTABILIZADO CON MUCILAGO DE PENCA DE TUNA, RESISTENTES AL } \\ \text { CONTACTO CON EL AGUA PARA LA CONSTRUCCIÓN DE VIVIENDAS POPULARES } \\ \text { EMPLEADOS EN LA SIERRA DEL PERÚ" }\end{array} \\ \text { SOLICITA } & : & \text { Tello Perez, Edna Florencia y Nieto Palomino, Lucero Antuhane } \\ \text { REALIZADO } & : & \\ \text { UBICACIÓN } & : & \text { Huarochirí - Lima -Perú } \\ \text { MUESTRA } & : & \text { Muestra 2: Carachuco } \\ \text { FECHA } & : & \end{array}$

\section{LIMMTE LIQQUIDO}

\begin{tabular}{|l|c|c|c|c|c|}
\hline$N^{\circ}$ DE LATA & 15 & 20 & 16 & & \\
\hline PESO DE SUELO HÚMEDO + LATA (gr.): & 58.50 & 53.84 & 57.17 & & \\
\hline PESO DE SUELO SECO + LATA (gr.): & 53.05 & 49.48 & 52.04 & & \\
\hline PESO DE LATA (gr.): & 34.94 & 35.45 & 36.06 & & \\
\hline PESO DE SUELO SECO (gr.): & 18.11 & 14.03 & 15.98 & & \\
\hline PESO DE AGUA (gr.): & 5.45 & 4.36 & 5.13 & & \\
\hline CONTENIDO DE HUMEDAD (\%): & 30.09 & 31.08 & 32.10 & & \\
\hline$N^{*}$ DE GOLPES: & 33 & 27 & 19 & & \\
\hline
\end{tabular}

\section{LĹMTE PLÁSTICO}

\begin{tabular}{|c|c|c|c|c|c|}
\hline $\mathrm{N}^{\circ} \mathrm{DE}$ LATA & $\mathrm{s}$ & $\mathrm{L}$ & & & \\
\hline PESO DE SUELO HUMMEDO + LATA (gr.): & 19.66 & 18.62 & & & \\
\hline PESO DE SUELO SECO + LATA (gr.): & 18.11 & 17.40 & & & \\
\hline PESO DE LATA (gr.): & 12.03 & 12.10 & & & \\
\hline PESO DE SUELO SECO (gr.): & 6.08 & 5.30 & & & \\
\hline PESO DE AGUA (gr.): & 1.55 & 1.22 & & & \\
\hline CONTENIDO DE HUMEDAD (\%): & 25.49 & 23.02 & & & \\
\hline LÍMITE PLÁSTICO (\%): & & & 24.256 & & \\
\hline
\end{tabular}

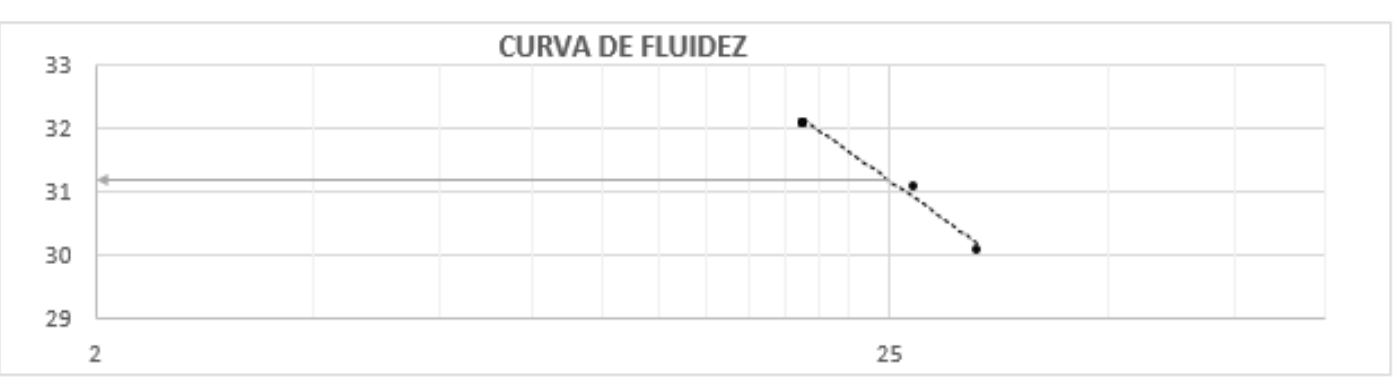

LÍMTTE LÍQUIDO (\%):

LÍMITE PLÁSTICO (\%):

ÍNDICE DE PLASTICIDAD:
31.186

24.256

6.930 
Anexo G: Sistema de clasificación de suelos unificados (SUCS) para la tierra de la primera muestra

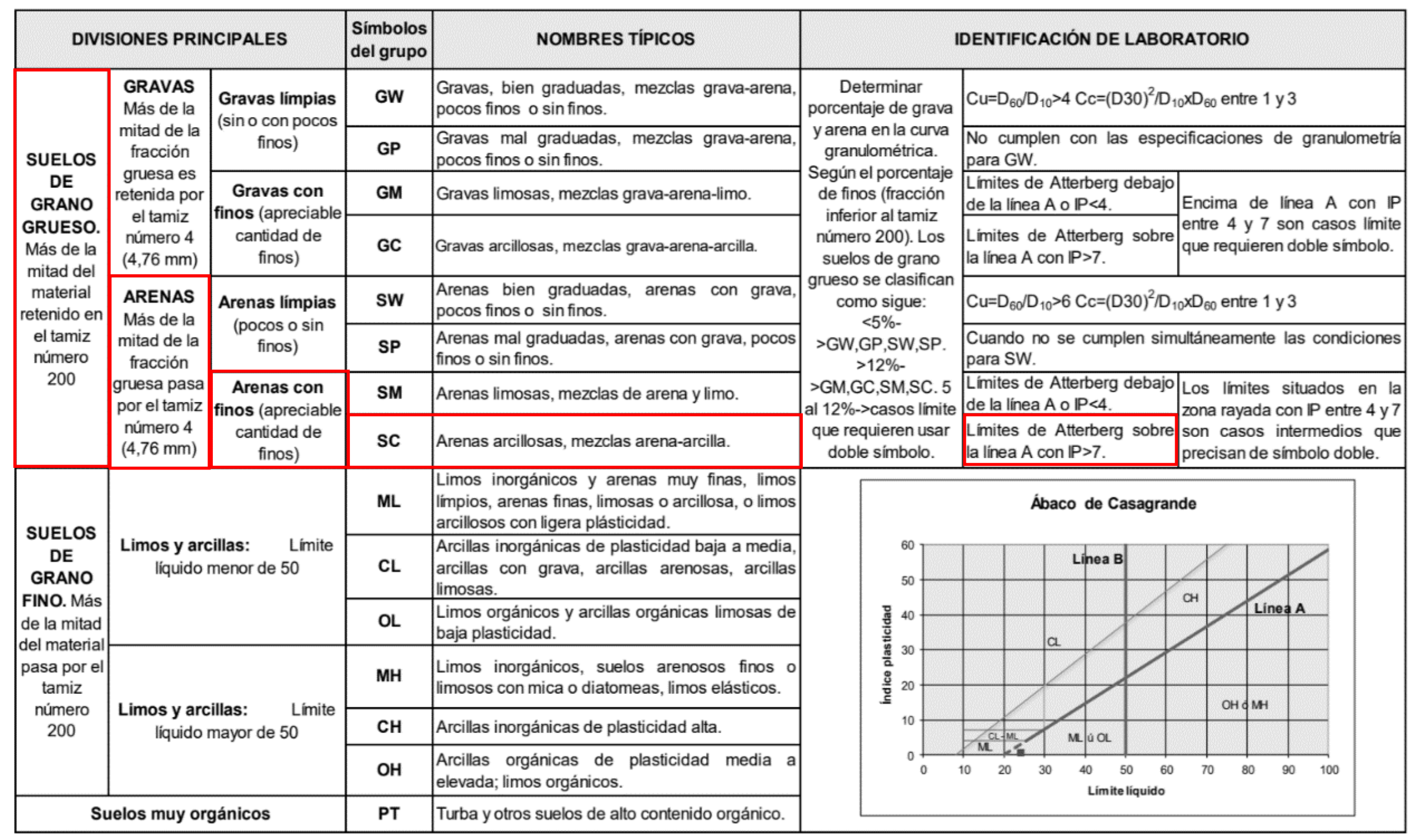


Anexo H: Sistema de clasificación de suelos unificados (SUCS) para la tierra de la segunda muestra

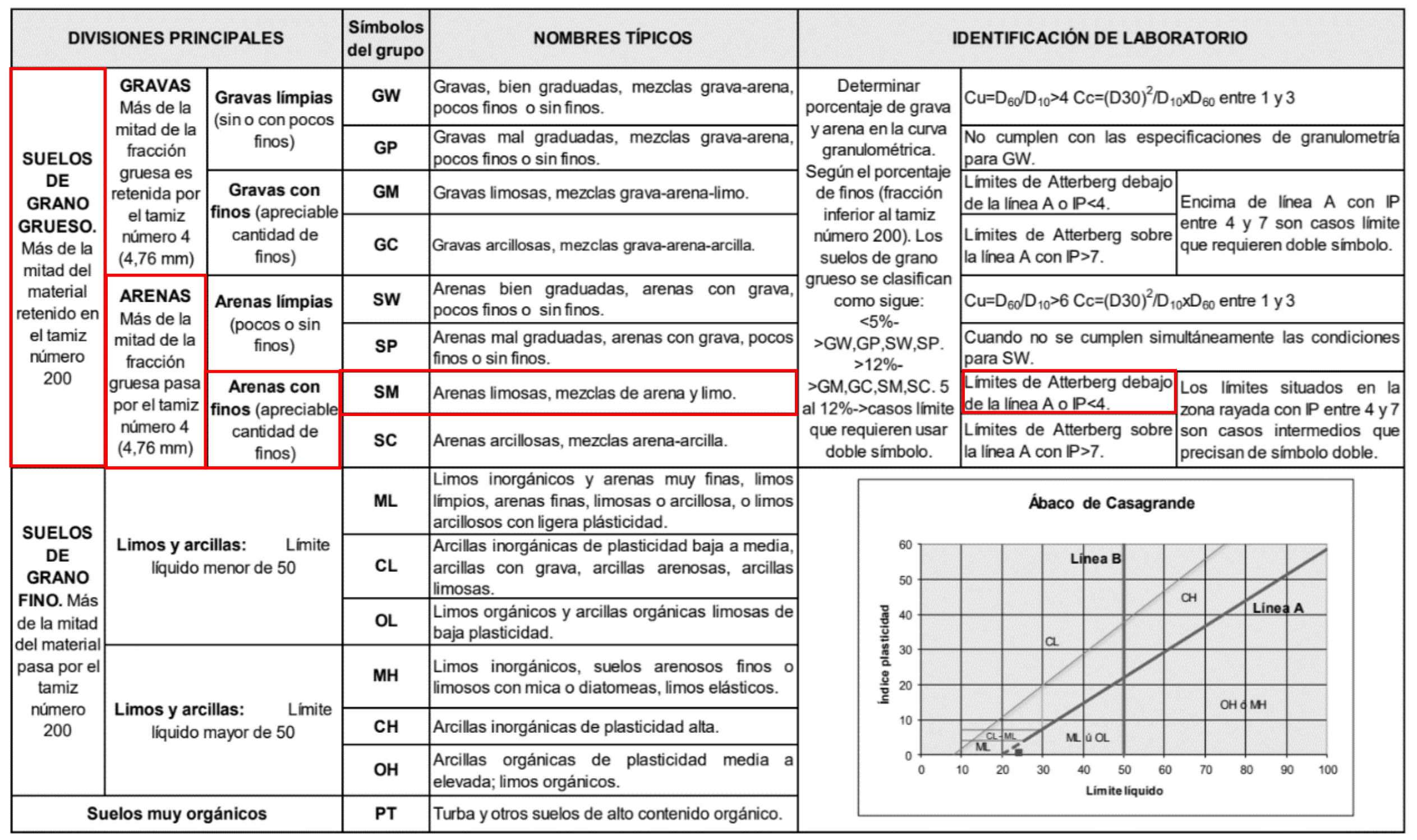


Anexo I: Costo unitario de elaboración de adobes, muros y reparación de muros estabilizados con mucílago de penca de tuna

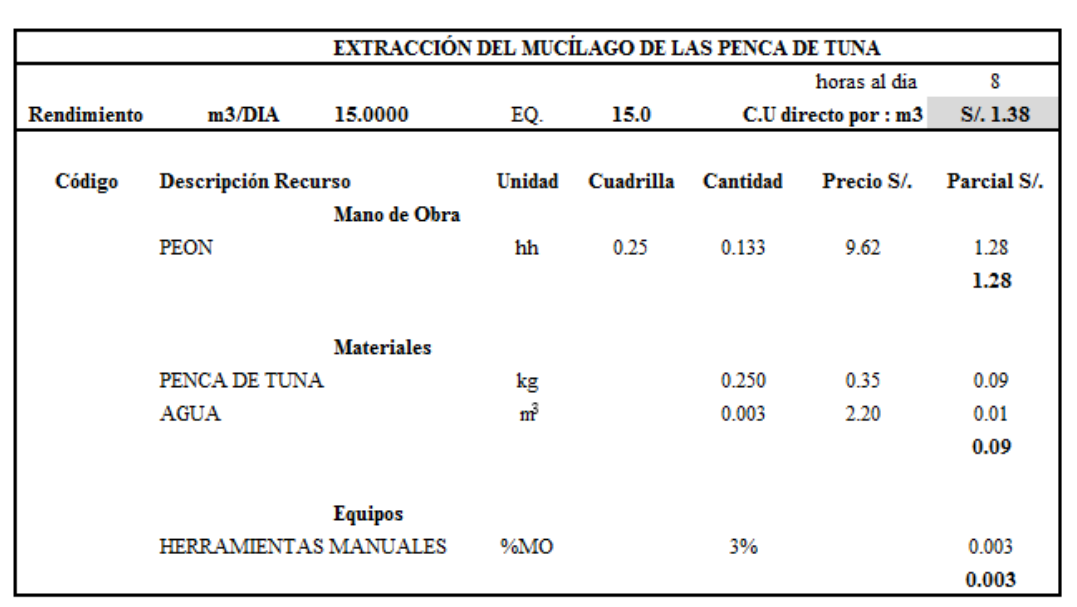

\begin{tabular}{|c|c|c|c|c|c|c|c|}
\hline \multicolumn{8}{|c|}{ MUROS DE ADOBES ESTABLIZADOS EN APAREJO DE CABEZA } \\
\hline \multirow[b]{2}{*}{ Rendimiento } & \multirow[b]{2}{*}{$\mathrm{m} 2 / \mathrm{DLA}$} & \multirow[b]{2}{*}{5.0000} & \multirow[b]{2}{*}{$\mathrm{EQ}$. } & \multirow[b]{2}{*}{5.0} & \multirow{2}{*}{\multicolumn{2}{|c|}{$\begin{array}{c}\text { horas al dia } \\
\text { C.U directo por : } \mathbf{m} 2\end{array}$}} & 8 \\
\hline & & & & & & & S/.73.85 \\
\hline \multirow[t]{13}{*}{ Código } & Descripción & Recurso & Unidad & Cuadrilla & Cantidad & Precio S/. & Parcial S/. \\
\hline & & Mano de Obra & & & & & \\
\hline & OFICLAL & & hh & 1.0 & 1.600 & 10.74 & 17.18 \\
\hline & PEON & & hh & 1.0 & 1.600 & 9.62 & 15.39 \\
\hline & & & & & & & 32.58 \\
\hline & & Materiales & & & & & \\
\hline & TIERRA DE & HACRA & $\mathrm{kg}$ & & 80.000 & 0.04 & 3.33 \\
\hline & ADOBE EST & ABILIZADO & unidad & & 28.674 & 1.28 & 36.69 \\
\hline & AGUA & & $\mathrm{m}^{3}$ & & 0.020 & 2.20 & 0.04 \\
\hline & & & & & & & 40.07 \\
\hline & & Equipos & & & & & \\
\hline & HERRAMIE & TAS MANUAI & $\% \mathrm{MO}$ & & $3 \%$ & & 1.20 \\
\hline & & & & & & & 1.20 \\
\hline
\end{tabular}

\begin{tabular}{|c|c|c|c|c|c|c|c|}
\hline \multicolumn{8}{|c|}{ UNIDADES DE ADOBE ESTABLIZADO $(40 \mathrm{~cm} \times 20 \mathrm{~cm} \times 13 \mathrm{~cm})$} \\
\hline \multirow[b]{2}{*}{ Rendimiento } & \multirow[b]{2}{*}{ unidades/DIA } & \multirow[b]{2}{*}{200.0000} & \multirow[b]{2}{*}{ EQ. } & \multirow[b]{2}{*}{144.0} & \multirow{2}{*}{\multicolumn{2}{|c|}{$\begin{array}{c}\text { horas al dia } \\
\text { C.U por unidad }\end{array}$}} & 8 \\
\hline & & & & & & & S/. 1.28 \\
\hline \multirow[t]{14}{*}{ Código } & Descripción Recu & & Unidad & Cuadrilla & Cantidad & Precio S/. & Parcial S/. \\
\hline & & Mano de Obra & & & & & \\
\hline & OFICLAL & & hh & 1.0 & 0.040 & 10.74 & 0.43 \\
\hline & PEON & & hh & 0.5 & 0.020 & 9.62 & 0.19 \\
\hline & & & & & & & 0.62 \\
\hline & & Materiales & & & & & \\
\hline & TIERRA DE CHA & & $\mathrm{kg}$ & & 10.300 & 0.04 & 0.46 \\
\hline & PAJA & & $\mathrm{kg}$ & & 0.019 & 2.00 & 0.04 \\
\hline & AGUA & & $\mathrm{m}^{3}$ & & 0.006 & 2.20 & 0.01 \\
\hline & MUCLLAGO DE P & NCA DE TUNA & $\mathrm{m}^{3}$ & & 0.090 & 1.38 & 0.12 \\
\hline & & & & & & & 0.64 \\
\hline & & Equipos & & & & & \\
\hline & HERRAMIENTAS & MANUALES & $\% \mathrm{MO}$ & & $3 \%$ & & 0.02 \\
\hline & & & & & & & 0.02 \\
\hline
\end{tabular}

\begin{tabular}{|c|c|c|c|c|c|c|c|}
\hline \multicolumn{8}{|c|}{$\begin{array}{l}\text { REPARACIÓN DE MUROS DE ADOBES ESTABILIZADOS EN APAREJO DE CABEZA CON INYECCIÓN DE } \\
\text { BARRO LIQQUIDO }\end{array}$} \\
\hline \multirow[b]{2}{*}{ Rendimiento } & & & & & & horas al dia & 8 \\
\hline & $\mathrm{m} 2 / \mathrm{DLA}$ & 3.0000 & $\mathrm{EQ}$. & 3.0 & \multicolumn{2}{|c|}{ C.U directo por : $\mathrm{m} 2$} & S/.43.08 \\
\hline \multirow[t]{13}{*}{ Código } & Descripción & Recurso & Unidad & Cuadrilla & Cantidad & Precio S/. & Parcial S/. \\
\hline & & Mano de Obra & & & & & \\
\hline & OFICLAL & & hh & 1.0 & 2.667 & 10.74 & 28.64 \\
\hline & PEON & & hh & 0.5 & 1.333 & 9.62 & 12.83 \\
\hline & & & & & & & 41.47 \\
\hline & & Materiales & & & & & \\
\hline & TIERRA DE & HACRA & $\mathrm{kg}$ & & 36.000 & 0.04 & 1.50 \\
\hline & PAJA & & $\mathrm{kg}$ & & 0.018 & 2.00 & 0.04 \\
\hline & AGUA & & $\mathrm{m}^{3}$ & & 0.013 & 2.20 & 0.03 \\
\hline & & & & & & & 1.56 \\
\hline & & Equipos & & & & & \\
\hline & HERRAMIE & TAS MANUAI & $\% \mathrm{MO}$ & & $3 \%$ & & 0.05 \\
\hline & & & & & & & 0.05 \\
\hline
\end{tabular}


Anexo J: Costo unitario de elaboración de adobes, muros y reparación de muros convencionales

\begin{tabular}{|c|c|c|c|c|c|c|c|}
\hline \multicolumn{8}{|c|}{ UNIDADES DE ADOBE CONVENCIONAL $(40 \mathrm{~cm} \times 20 \mathrm{~cm} \times 13$} \\
\hline \multirow[b]{2}{*}{ Rendimiento } & \multirow[b]{2}{*}{ unidades/DIA } & \multirow[b]{2}{*}{200.0000} & \multirow[b]{2}{*}{ EQ. } & \multirow[b]{2}{*}{200.0} & \multicolumn{2}{|r|}{ horas al dia } & \multirow{2}{*}{$\begin{array}{c}8 \\
\text { S/. } 1.24 \\
\end{array}$} \\
\hline & & & & & & C.U por unidad & \\
\hline \multirow[t]{13}{*}{ Código } & Descripción Re & urso & Unidad & Cuadrilla & Cantidad & Precio S/. & Parcial S/. \\
\hline & & Mano de Obra & & & & & \\
\hline & OFICLAL & & hh & 1.0 & 0.040 & 10.74 & 0.43 \\
\hline & PEON & & hh & 0.5 & 0.020 & 9.62 & 0.19 \\
\hline & & & & & & & 0.62 \\
\hline & & Materiales & & & & & \\
\hline & TIERRA DE CH & CRA & $\mathrm{kg}$ & & 10.300 & 0.04 & 0.43 \\
\hline & PAJA & & $\mathrm{kg}$ & & 0.019 & 2.00 & 0.04 \\
\hline & AGUA & & $\mathrm{m}^{3}$ & & 0.060 & 2.20 & 0.13 \\
\hline & & & & & & & 0.60 \\
\hline & & Equipos & & & & & \\
\hline & HERRAMIENT & S MANUALES & $\% \mathrm{MO}$ & & $3 \%$ & & 0.02 \\
\hline & & & & & & & 0.02 \\
\hline
\end{tabular}

\begin{tabular}{|c|c|c|c|c|c|c|c|}
\hline \multicolumn{8}{|c|}{$\begin{array}{l}\text { REPARACIÓN DE MUROS DE ADOBES CONVENCIONALES EN APAREJO DE CABEZA CON INYECCIÓN DE } \\
\text { BARRO LIQUIDO }\end{array}$} \\
\hline Rendimiento & $\mathrm{m} 2 / \mathrm{DIA}$ & 3.0000 & $\mathrm{EQ}$. & 3.0 & \multicolumn{2}{|c|}{ C.U directo por : $\mathrm{m} 2$} & $\begin{array}{c}8 \\
S / .43 .08\end{array}$ \\
\hline \multirow[t]{10}{*}{ Código } & Descripció & Recurso & Unidad & Cuadrilla & Cantidad & Precio S/. & Parcial S/. \\
\hline & OFICLAL & & hh & 1.0 & 2.667 & 10.74 & 28.64 \\
\hline & PEON & & hh & 0.5 & 1.333 & 9.62 & $\begin{array}{r}12.83 \\
41.47\end{array}$ \\
\hline & & Materiales & & & & & \\
\hline & TIERRA DI & CHACRA & $\mathrm{kg}$ & & 36.000 & 0.04 & 1.50 \\
\hline & PAJA & & $\mathrm{kg}$ & & 0.018 & 2.00 & 0.04 \\
\hline & AGUA & & $\mathrm{m}^{3}$ & & 0.013 & 2.20 & 0.03 \\
\hline & & & & & & & 1.56 \\
\hline & & Equipos & & & & & \\
\hline & HERRAMI & TAS MANUALES & $\% \mathrm{MO}$ & & $3 \%$ & & 0.05 \\
\hline
\end{tabular}

\begin{tabular}{|c|c|c|c|c|c|c|c|}
\hline \multirow[b]{2}{*}{ Rendimiento } & \multirow[b]{2}{*}{$\mathrm{m} 2 / \mathrm{DLA}$} & \multirow[b]{2}{*}{5.0000} & \multirow[b]{2}{*}{$\mathrm{EQ}$. } & \multirow[b]{2}{*}{5.0} & \multicolumn{2}{|r|}{ horas al dia } & \multirow{2}{*}{$\begin{array}{c}8 \\
\text { S/.72.71 } \\
\end{array}$} \\
\hline & & & & & C.U dir & cto por : $\mathrm{m} 2$ & \\
\hline \multirow[t]{13}{*}{ Código } & Descripción $R$ & urso & Unidad & Cuadrilla & Cantidad & Precio S/. & Parcial S/. \\
\hline & & Mano de Obra & & & & & \\
\hline & OFICLAL & & hh & 1.0 & 1.600 & 10.74 & 17.18 \\
\hline & PEON & & hh & 1.0 & 1.600 & 9.62 & 15.39 \\
\hline & & & & & & & 32.58 \\
\hline & & Materiales & & & & & \\
\hline & TIERRA DE CF & CRA & $\mathrm{kg}$ & & 80.000 & 0.04 & 3.33 \\
\hline & ADOBE CONV & VCIONAL. $40 \times .20$ : & unidad & & 28.674 & 1.24 & 35.59 \\
\hline & AGUA & & $\mathrm{m}^{3}$ & & 0.020 & 2.20 & 0.04 \\
\hline & & & & & & & 38.96 \\
\hline & & Equipos & & & & & \\
\hline & HERRAMIENT & S MANUALES & $\% \mathrm{MO}$ & & $3 \%$ & & 1.17 \\
\hline & & & & & & & 1.17 \\
\hline
\end{tabular}


Anexo $K$ : Manual de elaboración de adobe resistente al agua

\section{E L A B O RACI Ò D E A D O E RESISTENTE A L A G A}

\section{Preparación previa}

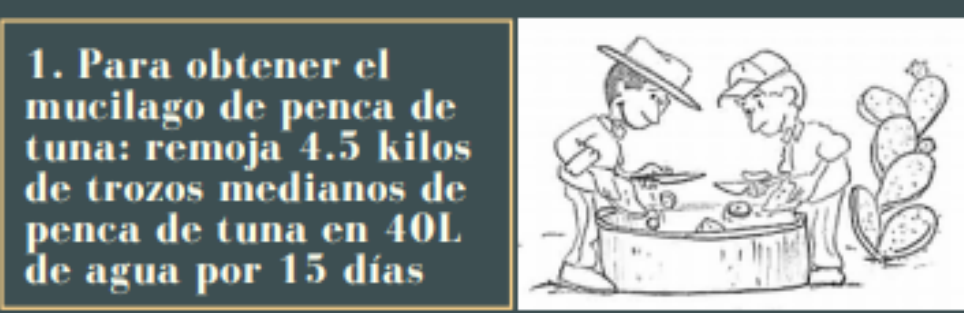

Al finalizar el periodo retira las cascaras de la solución viscosa y reserva en un recipiente limpio.

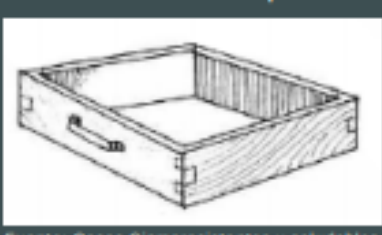

2. Elabora los gaberos de $25 \mathrm{~cm} \times 40 \mathrm{~cm} \times 13 \mathrm{~cm}$ que servirán como moldes para el adobe.

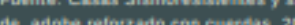

\section{Preparación del barro para los} adobes

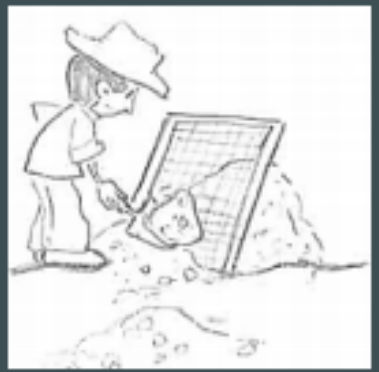

1. Tamiza 2000kg de tierra por una zaranda con el fin de separar las piedras de mayor

diámetro $(1 \mathrm{~cm}$ o $1.5 \mathrm{~cm})$, cantidad necesaria para fabricar 200 unidades de adobes.

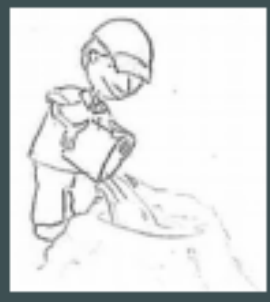

\section{Acomoda la tierra en} rumos, échale agua hasta que se forme barro y déjalo reposar por 1 día.

\section{Preparación de la mezcla}

1. Prepara la mezcla según las indicaciones del cuadro
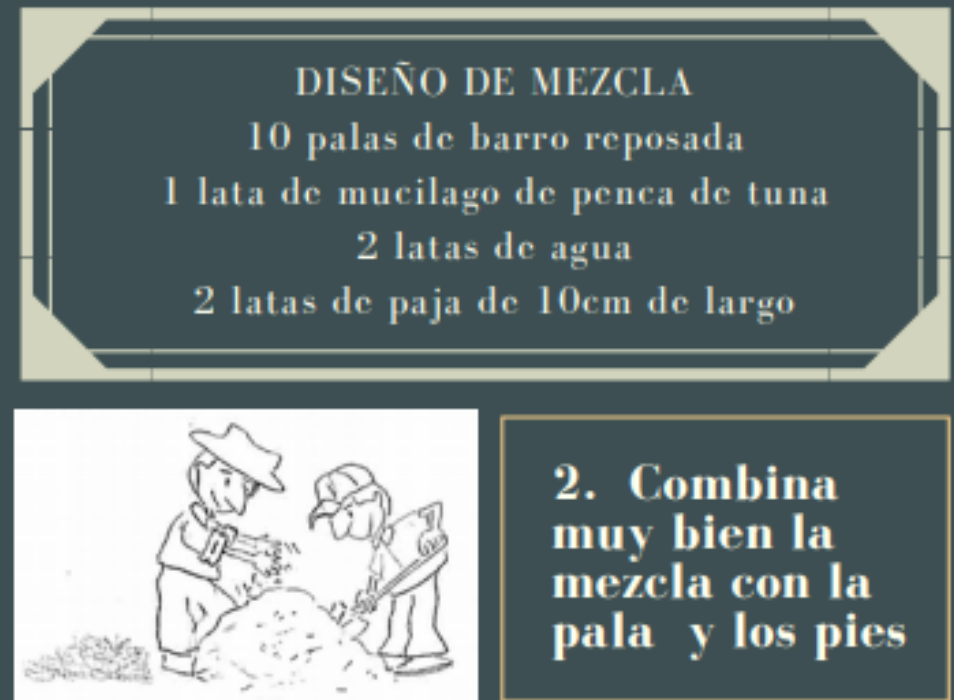

2. Combina muy bien la mezcla con la pala y los pies 


\section{E L A B O RACI Ò N D A D O B E R E I S T E N T E A L A G U A}

Los adobes deben de ser preparados en una superficie nivelada previamente habilitada, si es posible cubrir la

zona con un plástico para evitar que los rayos del sol rajen los adobes.
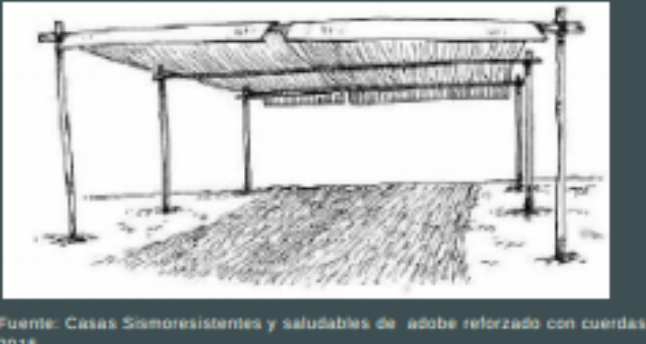

\section{Preparación de los adobes}

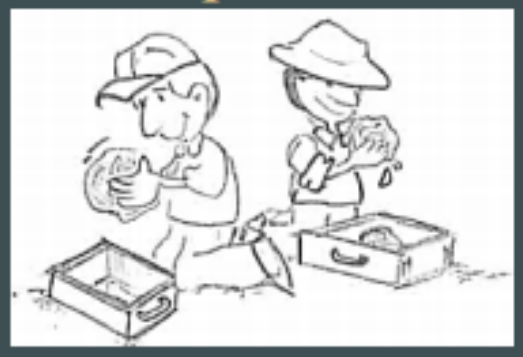

1. Con ayuda de la pala colocar la mezcla en el

gabero la cual debe de estar previamente húmeda.

2. Compacta la mezcla con las manos y los pies por la esquina $y$ el centro del molde

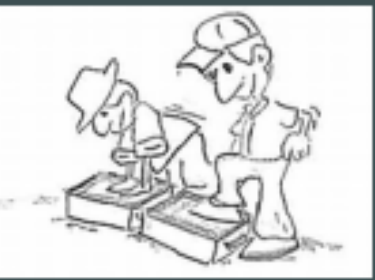

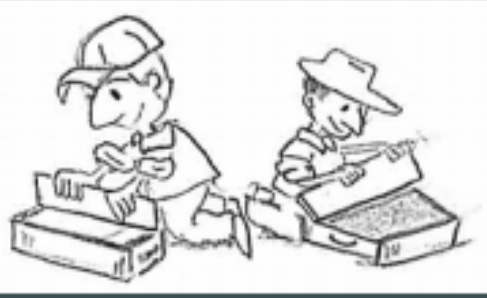

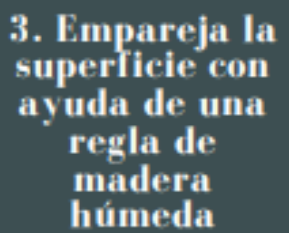

3. Empareja la superficie con

ayuda de una regla de madera húmeda

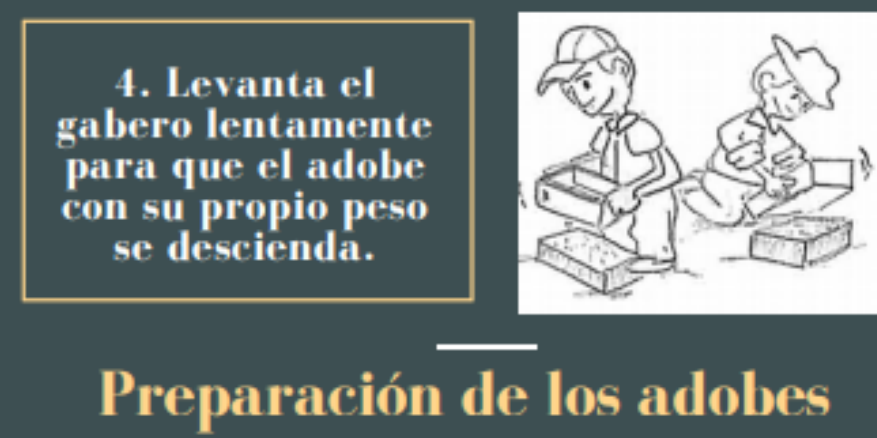

Los adobes deben ser secados por 3 semanas teniendo como base el área de mayor área, luego cada 5 se va dando vuelta los adobes de modo que todos los lados sequen de manera uniforme.
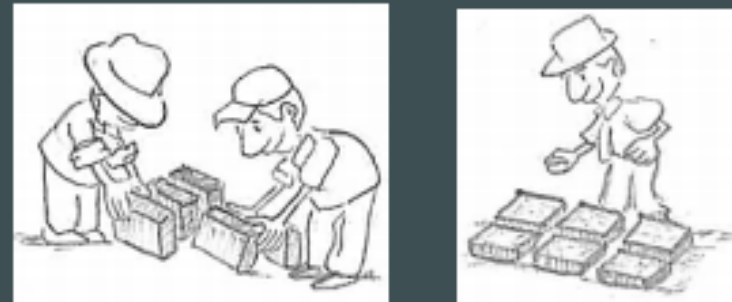